\title{
On the formation and reactivity of multinuclear silsesquioxane metal complexes
}

\author{
PROEFSCHRIFT
}

ter verkrijging van de graad van doctor aan de Technische Universiteit Eindhoven, op gezag van de Rector Magnificus, prof.dr. R.A. van Santen, voor een commissie aangewezen door het College voor

Promoties in het openbaar te verdedigen op maandag 26 mei 2003 om 16.00 uur

door

Robbie Willem Johan Maria Hanssen

geboren te Meijel 
Dit proefschrift is goedgekeurd door de promotoren:

prof.dr. R.A. van Santen

en

prof.dr. D. Vogt

Copromotor:

dr. H.C.L. Abbenhuis

Copyright (C) 2003 by Rob Hanssen.

The cover shows a graphical representation of the crystal structure of a tetranuclear silsesquioxane complex, that is found throughout this thesis. The four metal atoms are replaced by images of the four elements (air, fire, water and earth). The frontcover image was generated with PovChem (http://www.chemicalgraphics.com/PovChem) and POV-Ray (http://www.povray.org).

Printed at Universiteitsdrukkerij, Eindhoven University of Technology

\section{CIP-DATA LIBRARY TECHNISCHE UNIVERSITEIT EINDHOVEN}

Hanssen, Robbie W.J.M.

On the formation and reactivity of multinuclear silsesquioxane metal complexes / by Robbie W.J.M. Hanssen. - Eindhoven : Technische Universiteit Eindhoven, 2003.

Proefschrift. - ISBN 90-386-2924-9

NUR 913

Trefwoorden: anorganische chemie / coördinatiechemie / silsesquioxanen / overgangsmetaalcomplexen / dichtheidsfunctionaaltheorie ; DFT

Subject headings: inorganic chemistry / coordination chemistry / silsesquioxanes / transition metal complexes / density functional theory ; DFT 
"The chemists are a strange class of mortals, impelled by an almost maniacal impulse to seek their pleasures amongst smoke and vapour, soot and flames, poisons and poverty, yet amongst all these evils I seem to live so sweetly that I would rather die than change places with the King of Persia." - Johann Joachim Becher Mendeleyev's Dream; Physica Subterranea (1667) 


\section{Table of Contents}

\section{Introduction}

Silsesquioxanes: introduction and history $\quad 2$

Metal silsesquioxanes $\quad 5$

Outlook of silsesquioxane metal chemistry $\quad 15$

Scope of this thesis 16

2. Synthesis and reactivity of magnesium silsesquioxane complexes Introduction $\quad 22$

$\begin{array}{ll}\text { Synthesis and characterization } & 23\end{array}$

$\begin{array}{ll}\text { Reactivity and catalytic behavior } & 27\end{array}$

Density Functional Computations $\quad 30$

Reactivity of other silsesquioxane trisilanol compounds with 31

Grignard reagents

Concluding remarks. 35

3. Synthesis and reactivity of zinc silsesquioxane complexes

Introduction

Synthesis of alkyl zinc silsesquioxane complexes $\quad 45$

$\begin{array}{ll}\text { Crystal structures } & 47\end{array}$

Synthesis of a silsesquioxane zinc chloride complex $\quad 50$

Reactivity of the outer zinc atoms

Polymerization of lactide $\quad 56$

$\begin{array}{ll}\text { Concluding remarks } & 57\end{array}$

4. The formation of heterobimetallic silsesquioxane clusters

Introduction

Heterometallic main group metal complexes $\quad 67$

Heterobimetallic transition metal complexes $\quad 74$

$\begin{array}{ll}\text { Concluding remarks } & 77\end{array}$

5. Vanadium(III) and Titanium(III) silsesquioxanes in alkene polymerization catalysis

Introduction $\quad 84$

Synthesis and reactivity of vanadium (III) silsesquioxane complexes $\quad 86$

Synthesis and reactivity of titanium (III) silsesquioxane complexes $\quad 89$

Catalytic polymerization of ethene $\quad 89$

Ethene polymerization studied by Density Functional computations 91

Self-immobilizing polymerization catalysts? 92

$\begin{array}{ll}\text { Concluding remarks } & 94\end{array}$ 
Summary and Conclusions

Samenvatting en Conclusies

Graphical Abstract

Dankwoord

111

Curriculum Vitae 



\section{Introduction}

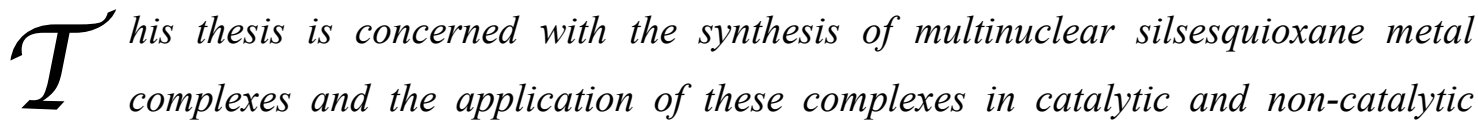
reactivity studies. The introductory section gives a short overview of the synthesis of silsesquioxanes and their metal complexes, and the application of these complexes in catalytic and stoichiometric processes. Furthermore, the scope of this thesis is explained. 


\section{Silsesquioxanes: introduction and history}

Silasesquioxane or silsesquioxane is the general IUPAC name for a family of polycyclic compounds consisting of silicon and oxygen (See Figure 1). The name sil(a)sesquioxane is derived from sil-oxane (compounds of silicon and oxygen) and sesqui (Latin, meaning one and a half), and the general name reflects the ratio of silicon and oxygen in the completely condensed silsesquioxanes (vide infra), $\left[\mathrm{RSiO}_{1 \frac{1}{2}}\right]_{2 \mathrm{n}}$.
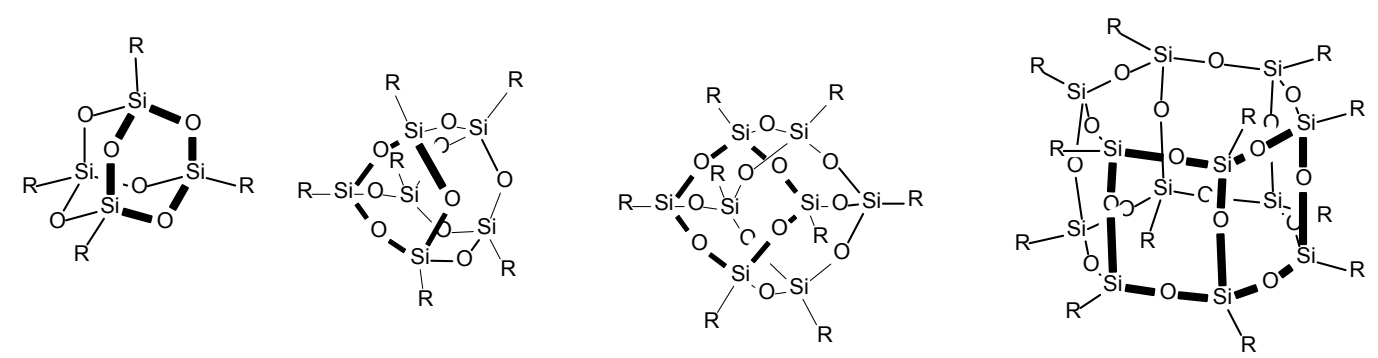
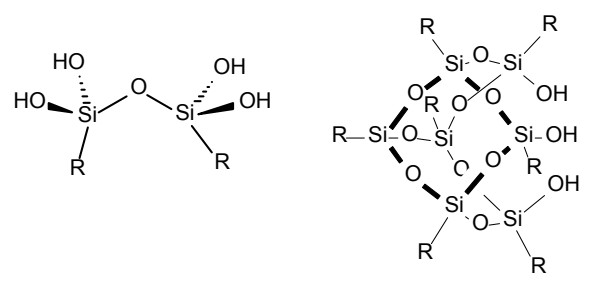

$$
\text { possible } \mathbf{R}
$$

$$
\begin{aligned}
& \text { isobutyl } \\
& \text { cyclopentyl } \\
& \text { cyclohexyl }
\end{aligned}
$$
cycloheptyl

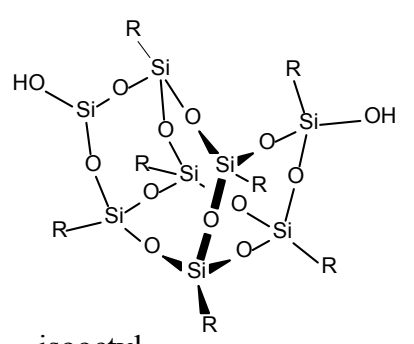

isooctyl

norbornyl

Figure 1. Overview of incompletely and completely condensed silsesquioxanes in literature

Silsesquioxanes are part of a larger family of silicon-oxygen compounds, called spherosilicates. The main distinction of silsesquioxanes is the presence of one non-silicate, organic group on the silicon atoms. The initial discovery of silsesquioxanes dates back to 1946, when $\operatorname{Scott}^{1}$ described completely condensed methyl-substituted silsesquioxanes. Although he was not able to assign the exact structure, he was able to determine that the general formula was $\left(\left(\mathrm{CH}_{3}\right) \mathrm{SiO}_{3 / 2}\right)_{2 \mathrm{n}}$, in which $n$ was integer. Nine years later, the molecular structure of a series of organosilsesquioxanes was determined via single crystal X-ray diffraction by Barry et al. ${ }^{2}$ They first showed the cubic or hexagonal prismatic shape of the completely condensed molecules.

A major contribution in the synthesis of silsesquioxanes (completely and incompletely condensed) was published by Brown and Vogt in 1965. ${ }^{3}$ They described the polycondensation of cyclohexyltrichlorosilane in an acetone/water mixture. The main 
products that were formed at the beginning of the reaction were incompletely condensed dimers $\left(\mathrm{RSi}(\mathrm{OH})_{2} \mathrm{ORSi}(\mathrm{OH})_{2}, \mathrm{R}=\right.$ cyclohexyl) and higher oligomers, that still contained silanol groups. After some time, days to months, the cubic incompletely condensed silsesquioxane trisilanol $\left(\mathrm{R}_{7} \mathrm{Si}_{7} \mathrm{O}_{9}\right)(\mathrm{OH})_{3}$ was formed to a greater extend together with the completely condensed $\mathrm{R}_{6} \mathrm{Si}_{6} \mathrm{O}_{9}$ with no residual silanol groups. In the 1990's, Feher described the same procedure for cyclopentyl- and cycloheptyltrichlorosilane. ${ }^{4}$ In this case no completely condensed products were isolated. The hydrolytic polycondensation of cyclopentyltrichlorosilane led exclusively to the formation of the trisilanol (c$\left.\mathrm{C}_{5} \mathrm{H}_{9}\right)_{7} \mathrm{Si}_{7} \mathrm{O}_{9}(\mathrm{OH})_{3}$, while polycondensation of cycloheptyltrichlorosilane led to a mixture of trisilanol $\left(c-\mathrm{C}_{7} \mathrm{H}_{13}\right)_{7} \mathrm{Si}_{7} \mathrm{O}_{9}(\mathrm{OH})_{3}$ and tetrasilanol $\left(c-\mathrm{C}_{7} \mathrm{H}_{13}\right)_{6} \mathrm{Si}_{6} \mathrm{O}_{7}(\mathrm{OH})_{4}$. The application of norbornyl as organic sidegroup was explored by Hambley et al. A mixture of trisilanol and tetrasilanol was formed. ${ }^{5}$

The process of formation of the silsesquioxane compounds is described as a multi-step hydrolysis-condensation reaction (see Scheme 1). The first step is the hydrolysis of a alkylsilane-precursor with water, forming organopolysilanol compounds (step $i$ ). In the right environment, depending on the concentration of water, solvent and $\mathrm{pH}$, these precursors can condense with each other, leading to the formation of oligosiloxanes (step ii). Thermodynamics, ${ }^{6-8}$ kinetics and solubility of the products will determine the resulting product mixture, ranging from lower oligosiloxane dimers or tetramers, to polyhedral oligomeric silsesquioxanes like the tri- and tetrasilanol silsesquioxanes.

For a long time the major hurdle in the use of silsesquioxanes was the long preparation time (ranging from a few weeks to 36 months) and the limitation of the organic side groups on the silicon atoms. New developments and ideas have shortened the preparation times considerably. The use of high-throughput experimentation techniques and automated synthesis robots may accelerate the optimization of synthesis conditions. Till now this often yields a complicated mixture of products. ${ }^{9}$ The base-catalyzed polycondensation reactions have proven to be the excellent way to prepare large quantities of silsesquioxanes (up to $1 \mathrm{~kg}$ ) per day. Lichtenhan and Abbenhuis applied for patents on the preparation of completely condensed and incompletely condensed silsesquioxanes with isobutyl and isooctyl side groups that could be prepared on large scales in a short time. 


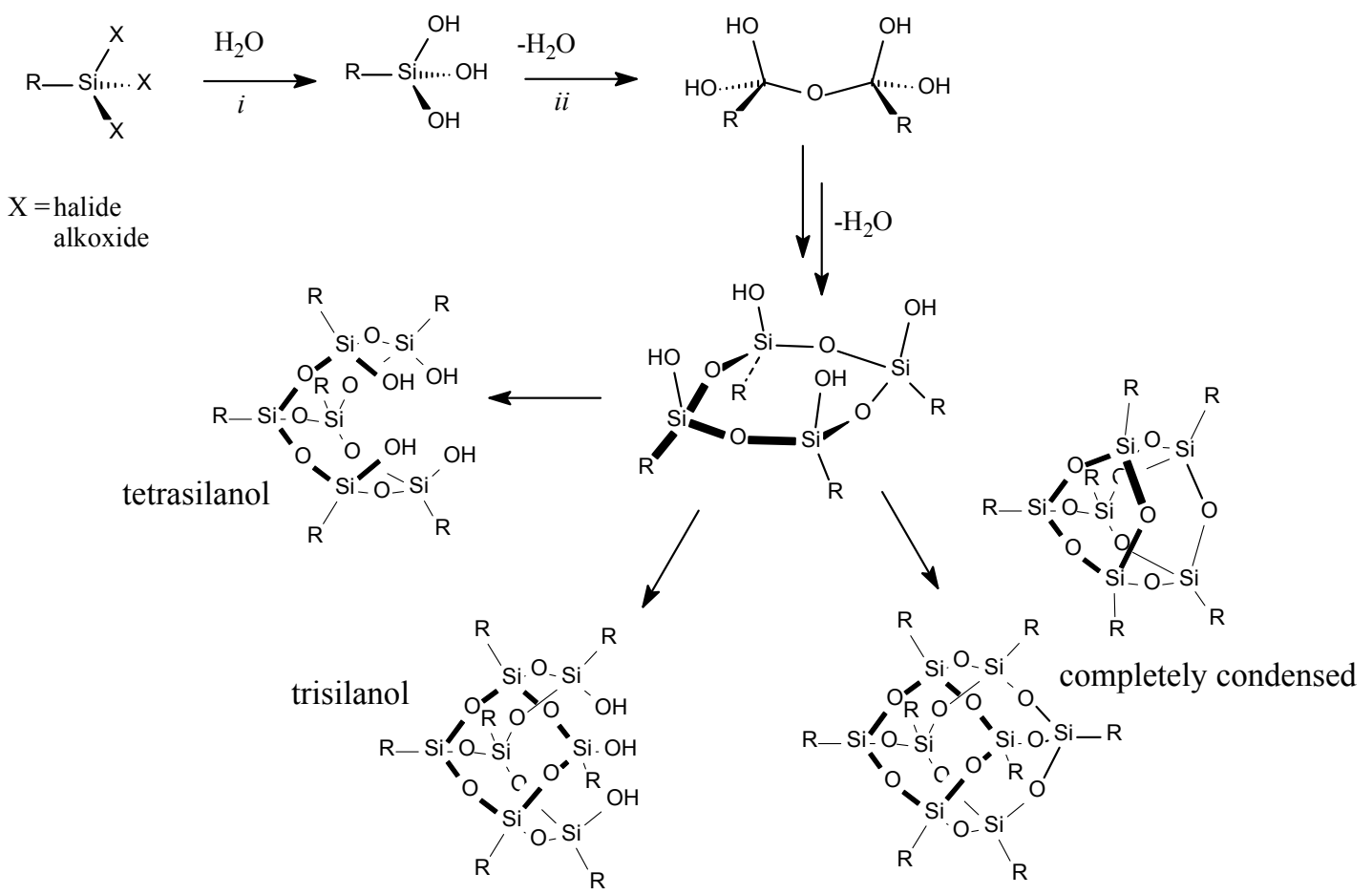

Scheme 1. Generalized formation scheme for siloxanes and silsesquioxane-type compounds

Until recently, functionalization of the silsesquioxane ligand core has been limited to either corner-capping of the trisilanol with a tri-halide organosilane moiety, leaving no further reactive silanol group $(a)$, or reaction of the trisilanol with mono- or dihalide organosilane reactants, leaving two or one silanol groups, respectively $(b)$. In the first case $(a)$, a large number of possible side groups can be introduced, ranging from simple alkyl groups to reactive alcohols, amines and vinyl groups. These groups allow the silsesquioxane cores to be included in polymeric materials. Furthermore, there is a substantial interest in octafunctional silsesquioxanes where all the side groups on the silicon atoms are identical and reactive. In these cases the functionality ranges from alkyls, alcohols, amides and carboxylates to halides, nitrates and phosphines. ${ }^{10-25}$ These can even be used as building blocks for dendrimers, as shown by Cole-Hamilton et al. for use in catalytic hydroformylation reactions (vide infra). ${ }^{26-}$ 29 In the second case $(b)$, the introduction of reactive functional groups besides the silsesquioxane's silanols proved to be more complex. To date, the groups in the added functionality are limited to trialkyl- and triarylsilicon and -tin groups, and these groups are rather used for protection of one or more of the silanol groups than for functionalization. Selectivity in these reactions either arises from different acidities of the silanols of the starting material or from steric hindrance of the silylating agent. 


\section{Metal silsesquioxanes}

The group of Feher initiated the research towards the use of silsesquioxane molecules as ligands for main group and transition metals at the end of the $1980 \mathrm{~s}^{30}$ considering silsesquioxanes as models for industrially used silica supports. The resemblance of silsesquioxanes to silica supports is not only apparent from the molecular structure, but the electronic properties of silsesquioxane silanol groups mimic the behavior of silica as well.
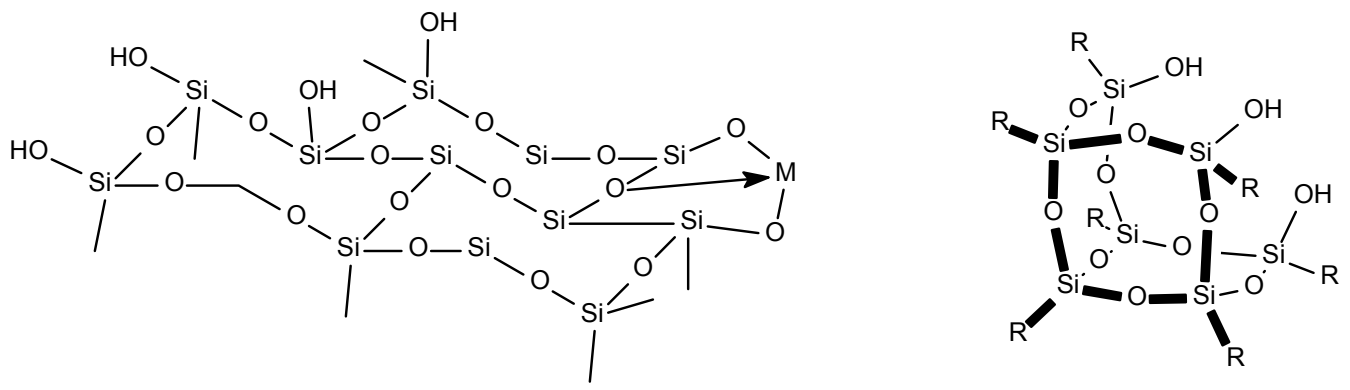

Figure 2. Schematic overview of a silica-based catalyst support, indicating important surface properties

In Figure 2, a few important structural similarities between silsesquioxanes and silica surfaces are depicted. First of all, the defined orientation of the silanol groups, which is also present in silsesquioxanes, may ensure a strong multi-dentate bonding to metals. Furthermore, silsesquioxanes have enough residual siloxane bridges to resemble the silica surface and these residual siloxane bridges can have an interaction with the metal. Finally, the crystal structure of the silsesquioxane trisilanol bears a striking resemblance to the simulated structure of $\beta$-crystoballite, as shown in Figure 3.

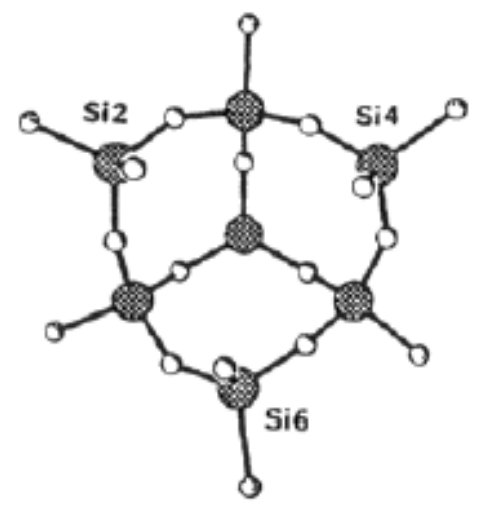

(a)

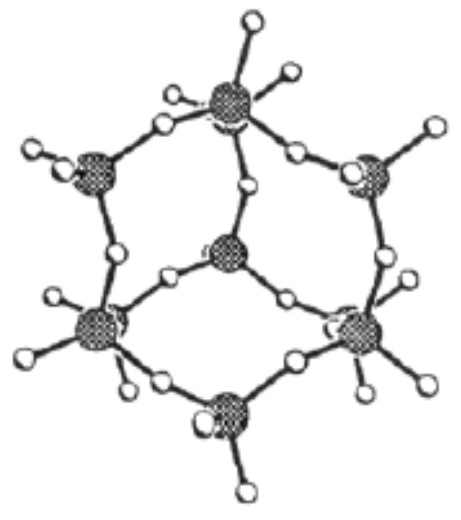

(b)

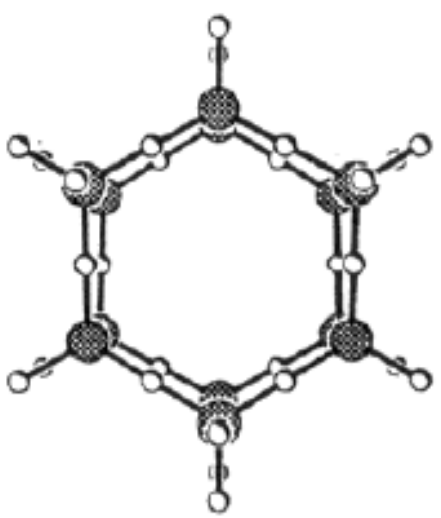

(c)

Figure 3. (a) ORTEP plot of $\mathrm{R}_{7} \mathrm{Si}_{7} \mathrm{O}_{9}(\mathrm{OH})_{3}$ viewed over the pseudo three-fold axis. (b) ORTEP plot of an idealized (111) face of $\beta$-crystoballite. (c) ORTEP plot of idealized (001) rhombohedral face of $\beta$ tridymite. 
Furthermore, silsesquioxanes can be modified via silylation to resemble the different silanol sites that can be present on a silica surface. Dijkstra et al. performed an in-depth study on the synthesis and characterization of silsesquioxane models for silica silanol sites (see Figure 4). ${ }^{31}$ By comparison of the relative ion pair acidities in THF for the different silanol sites, they found that the geminal silanols are among the least acidic, hence least reactive silanol groups, closely followed by isolated silanol groups. Due to their ability for extensive hydrogen bonding, the Brønsted acidity of vicinal disilanol and trisilanol groups is orders of magnitude larger. These findings provide insight into the relative reactivity of species on a silica surface.

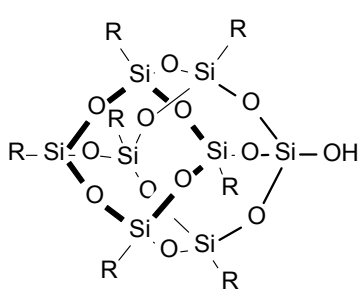

1

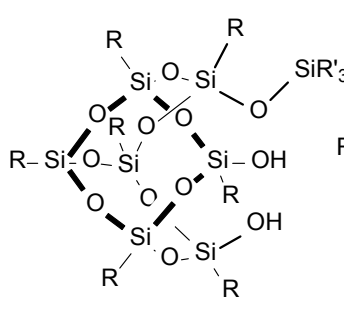

2

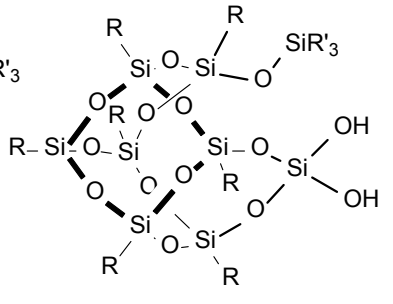

3

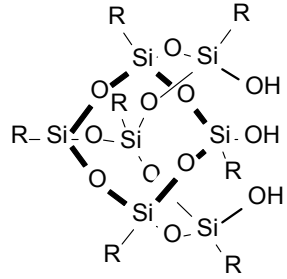

4

Figure 4. Silsesquioxane representations of silanol sites on silica surfaces: 1 isolated silanol; 2 vicinal disilanol; 3 geminal disilanol; 4 vicinal trisilanol

Since the discovery of silsesquioxanes, a rich coordination chemistry has been developed with elements throughout the periodic table (Figure 5).

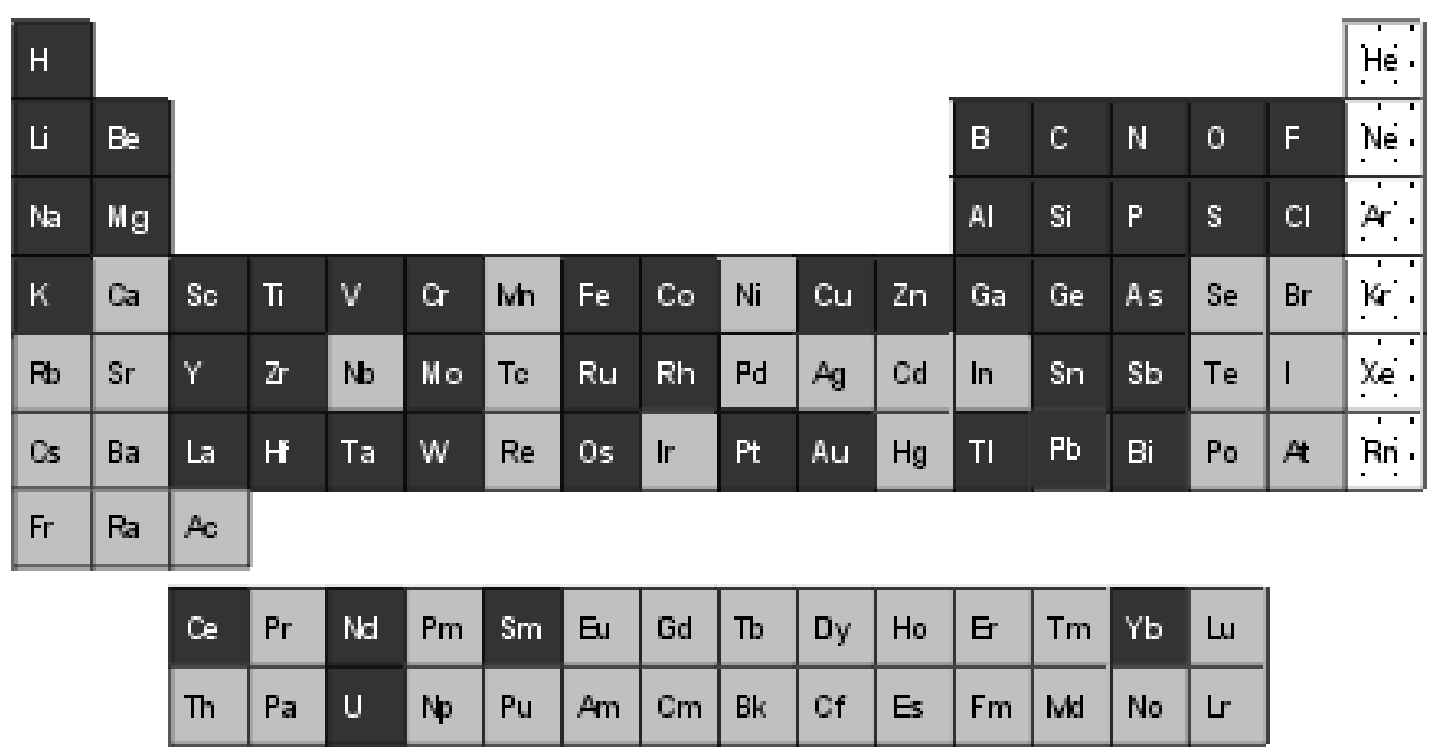

Figure 5. Overview of the elements that have been incorporated in silsesquioxane complexes in literature (figure by R. Duchateau reproduced from Chemical Reviews). 
Group $1(\mathrm{Li}, \mathrm{Na}, \mathrm{K})$

Feher et al. have mentioned sodium complexes as intermediates in the synthesis of transition metal complexes. ${ }^{32}$ These intermediates were either not isolated or found to be unstable out of solution. The groups of Aspinall, Edelmann and Abbenhuis have used lithium silsesquioxanes extensively as a transmetallation agent to prepare transition metal complexes. ${ }^{33-35}$ In some cases the lithium ions remain present in the transition or main group metal complex. ${ }^{33 ; 35-37}$ Duchateau et al. reported a mixed boron-lithium silsesquioxane. ${ }^{38}$ The group of Edelmann also reported on a potassium silsesquioxane complex and showed a crystal structure, although no experimental details were provided in the review article. ${ }^{35}$

\section{Group 2 (Be, $M g)$}

The chemistry of Group 2 elements has not been explored much in the past. Edelmann et al. published a crystal structure of a mixed beryllium-lithium silsesquioxane. ${ }^{36}$ Smet et al. reported the use of a magnesium substituted silsesquioxane as an intermediate in the reaction with epoxides. ${ }^{39}$ Lichtenhan reported a polymeric material based on silsesquioxane disilanol 3 (Figure 1) and dialkyl magnesium. ${ }^{40}$ Liu and Feher reported the application of magnesium substituted silsesquioxanes as model supports for titanium based alkene polymerization catalysts. $^{41 ; 42}$ Chapter 2 and 4 of this thesis explore the chemistry of magnesium silsesquioxanes. ${ }^{43 ; 44}$

\section{Group 3 (Sc, Y, La, lanthanides and actinides)}

Hermann et al. first mentioned the synthesis and crystal structures of $\mathrm{Nd}$ and $\mathrm{Y}$ silsesquioxane complexes. ${ }^{45}$ Due to the high solubility of Group 3 silsesquioxanes, they were not able to isolate a 'naked' $\mathrm{Y}$ silsesquioxane, but addition of coordinating triphenylphosphineoxide yielded crystals suitable for X-ray crystal structure analysis. The large ion size and high electrophilicity of the ion induced a high degree of coordination of siloxide and siloxane groups from the ligand to the metal showing, for the first time, an interaction of a siloxane-bridge with a metal ion. Aspinall et al. isolated a PMDTA adduct of an yttrium silsesquioxane. ${ }^{46}$ By applying the method of lithium transmetallation they synthesized a mixed lithium-ytterbium complex. ${ }^{33}$ Edelmann et al. displayed a large interest in the synthesis of Group 3 and lanthanide complexes. They reported samarium and scandium complexes of the isolated silanol silsesquioxane $\mathbf{1}$ (Figure 4 ), ${ }^{37}$ a seven-coordinated cerium(IV) silsesquioxane (starting from a Ce(III) precursor), ${ }^{47}$ and various mixed-metal 
lithium-lanthanide complexes. ${ }^{35}$ They also mentioned the synthesis of the first known actinide silsesquioxane complex: a six-coordinate uranium (VI) complex that was formed regardless of the uranium precursor, indicating that oxidation reactions occur when using this ligand class. ${ }^{35}$ Although most of the papers deal with models for catalysts on silica surfaces, no catalytic experiments were performed.

Group 4 (Ti, Zr, Hf)

Much work has been done on Group 4 silsesquioxane complexes and the application of these complexes in catalytic processes such as ethene polymerization, ${ }^{41 ; 42 ; 48-55}$ alkene epoxidation ${ }^{9 ; 39 ; 56-69}$ and Oppenauer oxidations. ${ }^{70}$ Most of the work in this area has been the topic of several excellent review articles. ${ }^{35 ; 53 ; 66}$ A specific interest in the group of Abbenhuis is the heterogenization of active and selective epoxidation catalysts. Krijnen et al. reported the heterogenization of titanium silsesquioxane complexes in mesoporous MCM-41 type materials. ${ }^{61 ; 63 ; 65 ; 71}$ No leaching was observed for all-silica MCM-41 materials, while aluminum-containing MCM-41 had to be silylated after impregnation of the titanium silsesquioxane complex.
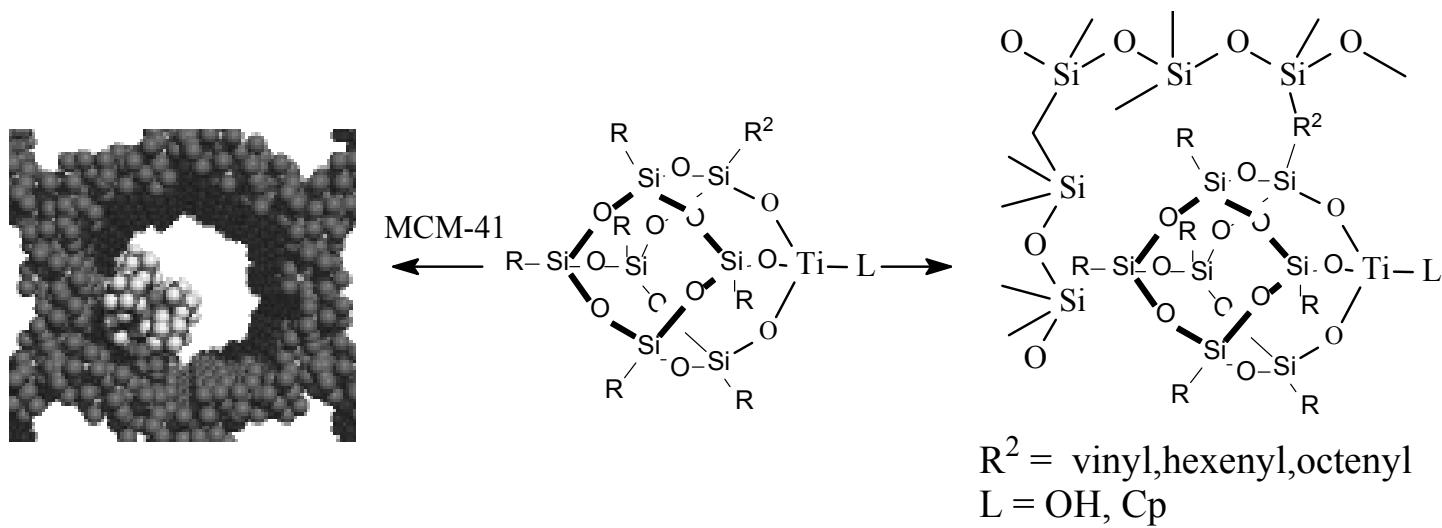

Figure 6. Immobilization of a titanium silsesquioxane complex by physisorption in a mesoporous MCM41 host (left) or tethering to a 3D-netted siloxane polymer (right)

Skowronska-Ptasinski et al. described the copolymerization and cross-linking of vinylsubstituted silsesquioxane titanium complexes with siloxane oligomers. ${ }^{59}$ The resulting materials proved to be active and selective catalysts for the epoxidation of alkenes with the cheap oxidant hydrogen peroxide. A material obtained by physical encapsulation of a nonvinyl functionalized titanium silsesquioxane complex also was active as a catalyst, while the titanium complex in solution could not activate hydrogen peroxide. This is stressing the 
importance of the physical surrounding of the catalytic center in epoxidation reactions, where one should avoid high concentrations of water and peroxide near the active metal center. More about Group 4 silsesquioxane complexes can be found in literature. ${ }^{30 ; 32 ; 40 ; 72-77}$ Chapter 5 of this thesis reports on the use of Ti(III) silsesquioxane complexes in ethene polymerization catalysis.

\section{Group $5(V, T a)$}

Feher et al. explored the use of Group 5 metals ligated by silsesquioxanes by reacting vanadium(III) and vanadium(V) precursors with silsesquioxane trisilanol compounds. ${ }^{77-80}$ The magnetic properties of the paramagnetic vanadium (III) silsesquioxanes were studied. The application of the diamagnetic vanadium (V) silsesquioxane complexes as precursors for ethene polymerization was studied in-depth. Based on in-situ NMR studies, Feher et al. were able to propose a catalytic model for the interaction of the vanadium systems with aluminium activators. One of the most important steps for the activation of the system was the breaking of metal-siloxy bonds in order for the metal to gain its catalytic activity, as shown in Scheme 2. Chapter 5 of this thesis describes the use of vanadium (III) silsesquioxanes as precursors for ethene polymerization catalysts. Wada et al. used the vanadium (V) complexes to prepare microporous vanadium silicates by controlled calcination of the complex in air at $723 \mathrm{~K}$. The materials proved to be efficient catalysts for the photo-catalytic oxidation of methane, ${ }^{82}$ benzene and cyclohexane. ${ }^{83}$

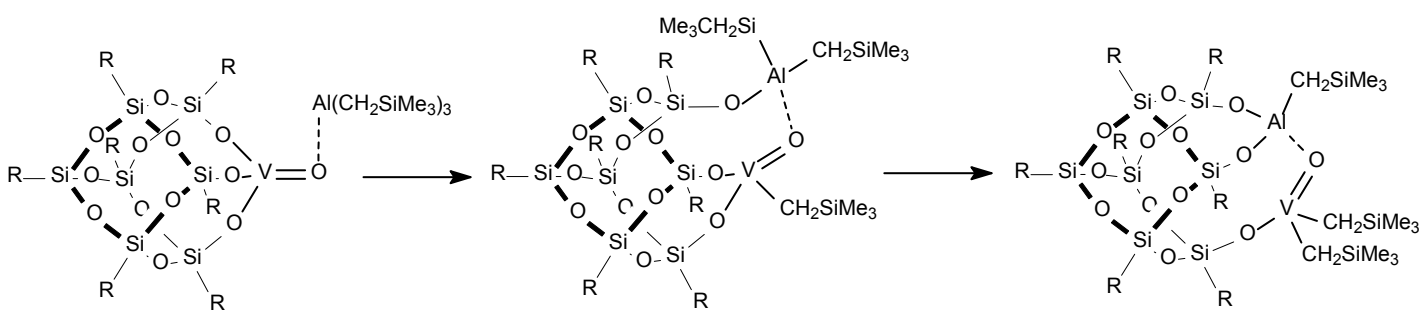

Scheme 2. Activation of a vanadium(V) silsesquioxane complex with an aluminum alkyl compound ${ }^{81}$

The other metal in Group 5 that is investigated was tantalum. Basset et al. used a tantalum silsesquioxane complex as a model compound for metathesis catalysts to explain the formation of tantalum alkylidene species on a silica surface. ${ }^{84}$ The group of Edelmann reported the synthesis of amido and carborane tantalum silsesquioxane complexes. ${ }^{85}$ 
Group $6(\mathrm{Cr}, \mathrm{Mo}, \mathrm{W})$

Reaction of chromium oxide with a mono-protected trisilanol led to the formation of a bisoxo chromium silsesquioxide ester (see Figure 7). Feher et al. tested this compound in the polymerization of ethene as a surface model for the chromium based Phillips catalyst. ${ }^{81 ; 86}$ It produced medium molecular weight polyethene with a high polydispersity indicating multiple active sites. Vorstenbosch et al. employed this type of chromium silsesquioxane ester for the catalytic epoxidation of alkenes with tert-butylhydroperoxide. Although the respective epoxide was formed in high yield, it was found that the active species in the reaction was a non-silsesquioxane chromium species, an indication for metal leaching. ${ }^{60}$ Maxim et al. used the chromium silsesquioxane for the synthesis of microporous silica supported chromium that was found to be active in the low-temperature catalytic oxidation of ammonia. ${ }^{87 ; 88}$ Feher et al. also synthesized the corresponding dioxo-molybdenum silsesquioxide ester via the thallium transmetallation route (vide infra). ${ }^{89} \mathrm{~A}$ variant to the well-known molybdenumbased Schrock-carbene showed high activity in olefin metathesis reactions (see Figure 7). ${ }^{32}$ The high activity was attributed to the highly electron-withdrawing character of the silsesquioxane framework.

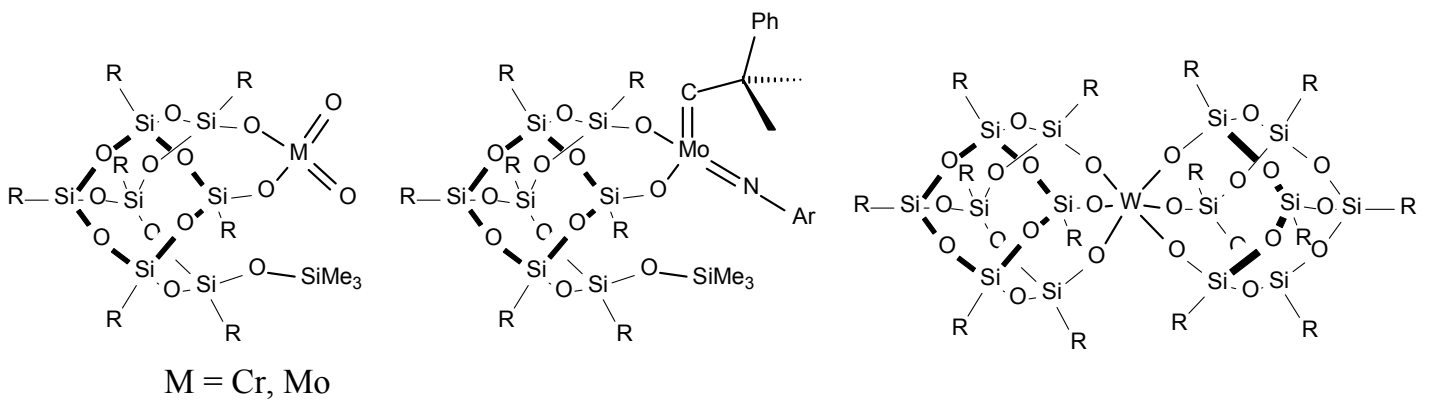

Figure 7. Examples of silsesquioxane Group 6 complexes

Cross-metathesis of vinyl-substituted silsesquioxanes with the Schrock-carbene $\left(\mathrm{Mo}\left(\mathrm{CHCMe}_{2} \mathrm{Ph}\right)(\mathrm{NAr})\left\{\mathrm{OCMe}\left(\mathrm{CF}_{3}\right)_{2}\right\}_{2}\right)$ yielded a silsesquioxane with an alkylidene metal fragment attached to the former vinyl side group. ${ }^{90}$ In an attempt to synthesize a model for silica supported tungsten catalysts, Smet et al. synthesized the bis-silsesquioxane tungsten complex (Figure 7), for which the synthesis is atypical as no base is required to trap the $\mathrm{HCl}$ formed. ${ }^{91}$ More work on Group 6 metal silsesquioxanes can be found in the references. ${ }^{10 ; 30 ; 89 ; 92-94}$ 
Group 7 (Mn)

To date, no one has reported the synthesis of Group 7 metal silsesquioxanes where the metal is directly linked to the silanolate groups. Attempts to synthesize rhenium silsesquioxane complexes resulted in either dehydratation reactions of the silsesquioxane, or yielded complicated product mixtures. ${ }^{95}$ Lücke et al. reported the synthesis of an octafunctionalized phosphorus silsesquioxane, that was used as a ligand for $\mathrm{CpMn}(\mathrm{CO})_{2}{ }^{10}$

Group 8 (Fe, Ru, Os)

Although the introduction of iron in the form of ferrocene as side group on the silicon has been reported in $1993,{ }^{96-98}$ Ott et al. ${ }^{99}$ and Edelmann et al. ${ }^{100}$ have only recently reported the synthesis and application of iron silsesquioxanes, where the iron atom is attached to the silanolate groups.
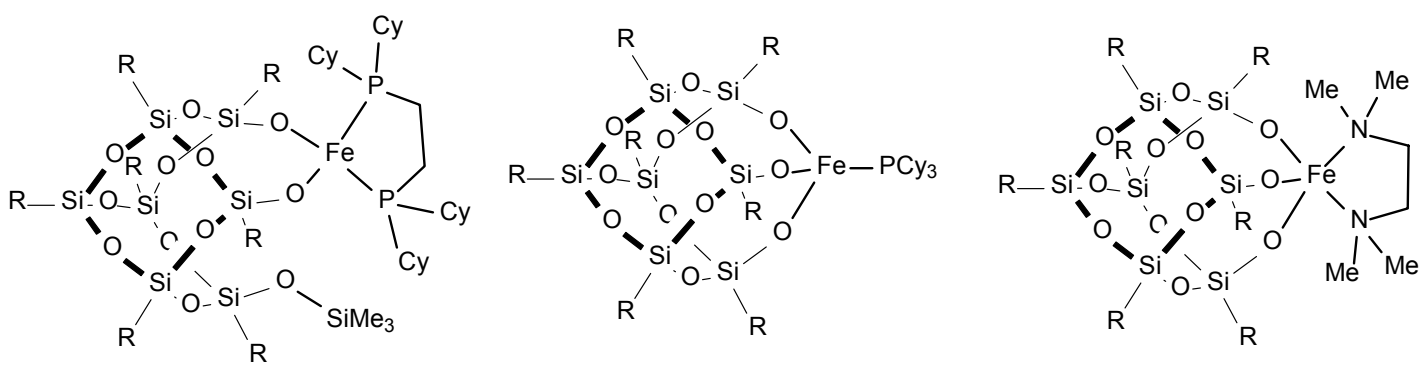

Figure 8. Iron silsesquioxanes reported by Ott et al. and Edelmann et al.

Ott et al. used monophosphines and diphosphines as stabilizing agents for the unfilled coordination sphere on the metal. Addition of small amounts of water to these compounds led to the loss of the phosphine ligand and the formation of anionic oxygen-bridged bis (ironsilsesquioxane) species. Because of structural similarities to the active center of iron found in zeolites, they applied the iron silsesquioxane complexes in the catalytic oxidation of benzene with $\mathrm{N}_{2} \mathrm{O}$ to phenol. No conversion to phenol was observed, possibly due to the low temperature. Edelmann et al. used TMEDA instead of diphosphines. The complex of Edelmann was used by Maxim et al. to prepare iron on microporous silica by controlled calcination of the complex. ${ }^{34}$ The iron was well dispersed in the material and was present as nano-sized metal oxide particles of about $2-8 \mathrm{~nm}$ in size. The addition of extra silsesquioxane trisilanol to the mixture before calcination enabled them to vary the iron content in the material, while keeping the material properties unchanged. Mixing a third component into the pre-calcination mixture, viz. the chromium silsesquioxide ester (vide supra), allowed Maxim 
to synthesize mixed-metal oxide-on-silica materials. ${ }^{101}$ These materials were tested in catalytic decomposition of $\mathrm{N}_{2} \mathrm{O}$ to $\mathrm{N}_{2}$ and $\mathrm{O}_{2}$, and were found to be more active than the irononly systems, and more selective than the chromium-only systems. A mixed metal-oxide phase (Fe-Cr-Si-O) was identified by Raman-spectroscopy.

Four examples of ruthenium attached to a silsesquioxane core have been reported up till now. Feher et al. synthesized one, via the cross-metathesis method as described for molybdenum. ${ }^{90}$ Wada et al. used a phosphorus-functionalized silsesquioxane as a ligand for ruthenium. ${ }^{102}$ Marsmann et al. used thiol-functionalized silsesquioxanes to bind to ruthenium and osmium carbonyl clusters. ${ }^{103}$ Hong et al. published about Ru(terpy) ${ }_{3}$-complexes covalently linked to silsesquioxane dendrimers. ${ }^{104}$ Liu et al. reported the crystal structure of a silsesquioxane substituted osmium cluster in $1990 .{ }^{105}$
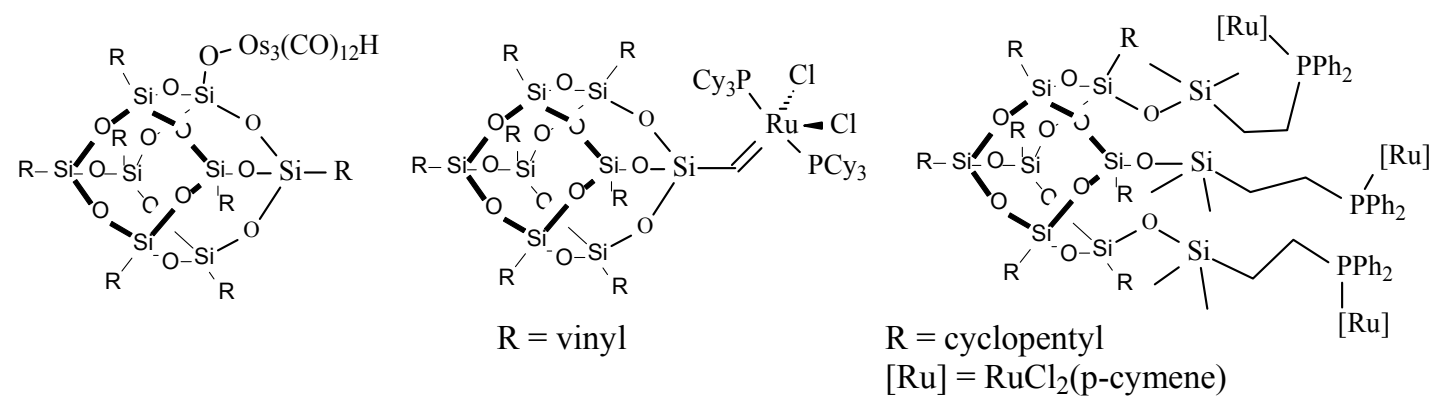

Figure 9. Examples of silsesquioxane complexes of osmium and ruthenium

\section{Group 9-10 (Co, Rh, Pt)}

The direct coupling of metals in this group to the silanol functionality of silsesquioxanes has been limited to platinum (see Figure 10). Abbenhuis et al. described the reaction of $\mathrm{Pt}\left(\mathrm{CO}_{3}\right)(\mathrm{dppe})$ with trisilanol and mono-silylated disilanol silsesquioxane ligands. ${ }^{106}$ Johnson et $a l .,{ }^{107}$ and Feher et $a l .{ }^{32}$ used mono-silylated thallium silsesquioxide complexes as transmetallating agent to make silsesquioxane platinum compounds, although in some cases the use of thallium silsesquioxide complexes frustrated the synthesis of the complex due to residual thallium ions in the isolated materials. ${ }^{107}$ 

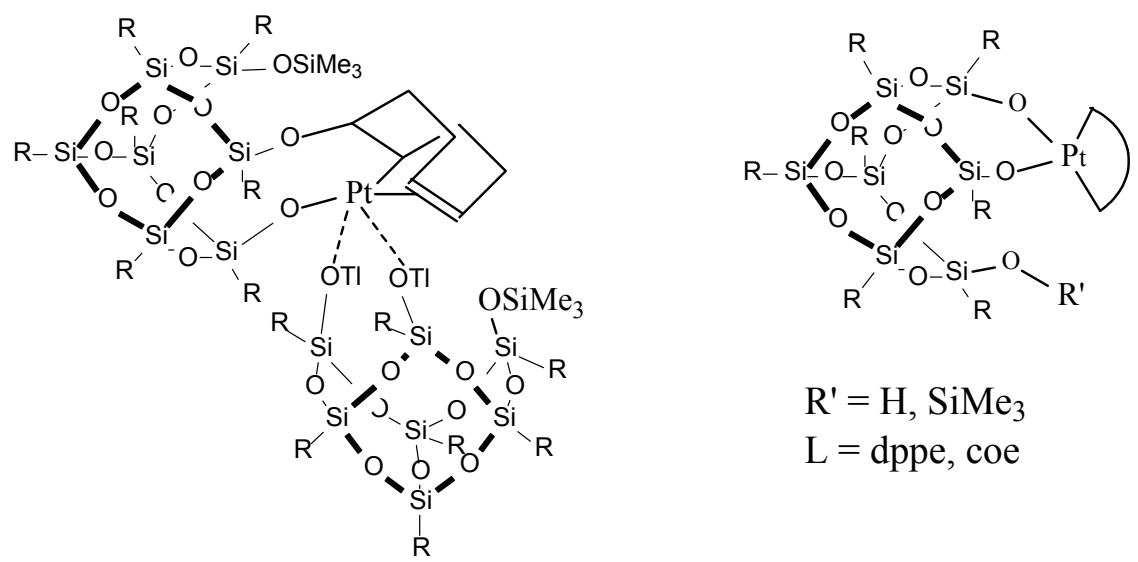

$$
\begin{aligned}
& \mathrm{R}^{\prime}=\mathrm{H}, \mathrm{SiMe}_{3} \\
& \mathrm{~L}=\text { dppe, coe }
\end{aligned}
$$

Figure 10. Pt silsesquioxane complexes by Johnson, Feher and Abbenhuis

Other reported methods of attaching Group 9-10 metals to silsesquioxanes are coordination of a donor group to the metal $\left(\mathrm{S},{ }^{103 ; 108} \mathrm{P}^{10 ; 26 ; 29 ; 102 ; 108-110}\right)$ and oxidative addition of a metal to $\mathrm{Si}$ $\mathrm{H}\left(\mathrm{Co},{ }^{97 ; 111} \mathrm{Rh}^{112}\right)$. Cole-Hamilton et al. used phosphorus-functionalized silsesquioxanebased dendrimers as ligands for rhodium to perform hydroformylation reactions. ${ }^{26 ; 29}$ They found a positive dendritic effect towards the linear product. Nowotny et al. used a phosphorus-functionalized silsesquioxane to chelate a Rh-cluster which functions as a model for a P-functionalized silica surface. ${ }^{109}$ No catalytic tests were reported for the silsesquioxane compound.

Group 11-12 (Cu, $\mathrm{Au}, \mathrm{Zn})$

The silsesquioxane metal chemistry has not been developed to a large extend for metals in these groups. Chapter 3 and 4 of this thesis provide the first insights into zinc silsesquioxane chemistry. Edelmann et al. reacted $\left(\mathrm{CuO}^{t} \mathrm{Bu}\right)_{4}$ with monosilylated disilanol and obtained a crystal structure in which the tetrameric core of the copper alkoxide is maintained (see Figure 11). ${ }^{113}$ Pugin et al. used sulfur-functionalized silsesquioxanes as ligands for $\mathrm{Au}_{55}$ clusters and were able to correlate the increased Coulomb gap to the increased size of the cluster going from $\mathrm{PPh}_{3}$ to the silsesquioxane-based ligand. ${ }^{114}$ Abis et al. prepared bis- and tris-substituted gold silsesquioxanes as a model for the interaction of gold carbamate precursors with silica surfaces (see Figure 11). ${ }^{115}$ 


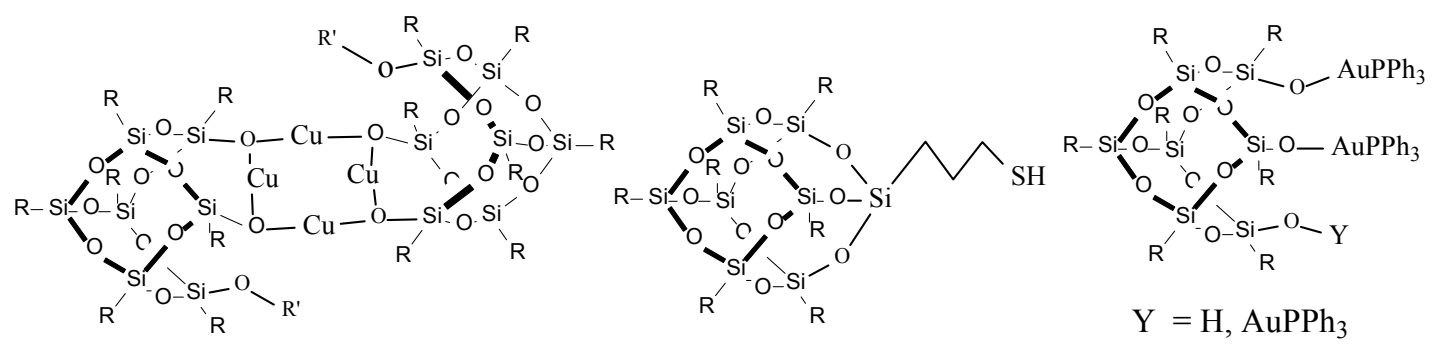

Figure 11. Examples of complexes of copper and gold and a thiol-functionalized ligand for gold clusters

Group 13 (B, Al, Ga, Tl)

Due to the high reactivity of particularly the metal alkyl precursors from this group with silanol groups, the silanolate coordination chemistry is well developed. Duchateau et al., ${ }^{116-}$ ${ }^{118}$ Edelmann et al., ${ }^{119}$ and Feher et al. ${ }^{120-122}$ prepared aluminum silsesquioxane complexes as models for aluminum sites in zeolites and on silica, and as models for methyl alumoxane compounds. Abbenhuis et al. applied aluminum containing silsesquioxane polymers as heterogeneous catalysts for the acceleration of Diels-Alders reactions of enones. ${ }^{123}$ Maxim et al. used aluminum silsesquioxanes as precursors for microporous aluminosilicates via the method of controlled calcination. ${ }^{44}$

Feher et al., ${ }^{124}$ and Duchateau et al. ${ }^{38}$ investigated the interaction of gallium precursors $\left(\mathrm{GaMe}_{3}\right.$ and $\left.\mathrm{GaCl}_{3}\right)$ with silsesquioxane ligands. ${ }^{125}$ Wada et al. used gallium silsesquioxane precursors to synthesize microporous gallium silicate materials with acidic sites by controlled calcination of the complexes in air. ${ }^{126}$

The interaction of boron with silsesquioxanes was the topic of research of Feher, Collins and Duchateau. Feher et al., ${ }^{127}$ and Duchateau et al. ${ }^{38}$ investigated the possible geometries that can be adopted by boron in a strained silsesquioxane environment. They found that boron could adopt both trigonal planar and tetrahedral geometries. Collins ${ }^{128}$ and Duchateau ${ }^{51}$ synthesized silsesquioxane organoboranes and organoborates that could be used as models for silica-supported borane activators for Group 4 olefin polymerization catalysts. Reaction with bisalkyl zirconocene complexes showed that both boranes and borates were susceptible to borane-zirconium exchange reactions, rendering the catalyst inactive (Figure 12). They concluded that the grafting of boranes on silica is not a useful method for subsequent immobilization of polymerization catalysts. 


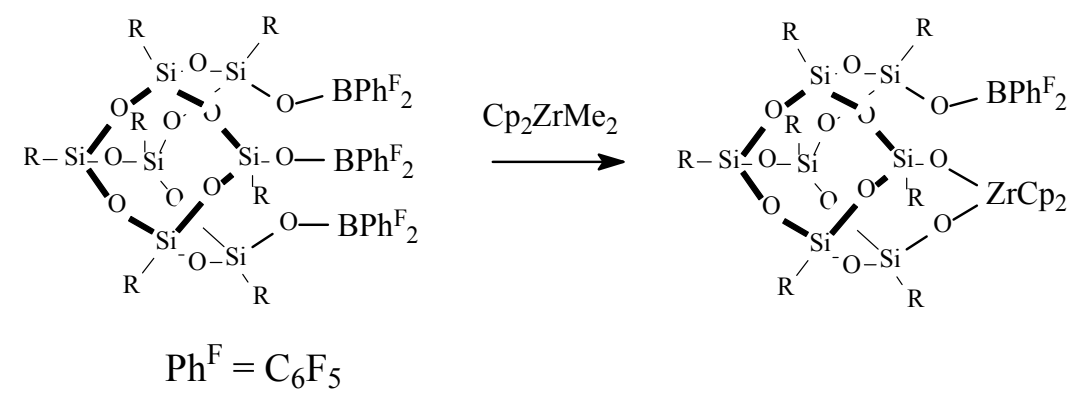

Figure 12. Interaction of dimethylzirconocene with a tris(organobora)silsesquioxane leading to boranezirconocene exchange (Collins et al.)

Thallium silsesquioxane complexes have been mainly applied for transmetallation reactions where the thallium is replaced by high valent transition metals. ${ }^{32 ; 89}$ Their ability to withstand dehydration reactions of the silsesquioxane framework, a common occurrence when using high valent transition metals in combination with amine bases, make these complexes suitable for the synthesis of middle and late transition metal complexes, although the high toxicity of thallium is a serious disadvantage.

\section{Outlook on silsesquioxane metal chemistry}

Besides extending the range of metals that can be incorporated in silsesquioxane ligands, there are many challenges for the future of silsesquioxane chemistry. The introduction of functional groups besides the silanol groups can give new insights in the coordination chemistry of silsesquioxanes, and the introduction of coordinating groups like amines, thiols and phosphines can have interesting effects on the catalytic performance of metal complexes. The introduction of silsesquioxane ligands and complexes in an approach as proposed by Skowronska-Ptasinski can revolutionize the way supported catalysts are made, due to the precise environment in which the metal center is incorporated. Controlled calcination of mixtures of silsesquioxane ligands and metal complexes yields highly dispersed and small metal oxide particles or even molecularly dispersed metal ions on a silica surface, with controllable multi-metallic content. Finally, the knowledge gained from the silsesquioxane model work should be transferred more to actual silica-supported systems or the ideas should be used to synthesize active and selective homogeneous catalysts, appropriate for industrial use. 


\section{Scope of this thesis}

Over the last decade silsesquioxanes have proven to be reliable models for the surface of silica materials and good ligands for a variety of transition and main group metals. Complexes of metals with silsesquioxane silanolate ligands have been applied in a wide variety of essentially Lewis acid mediated catalytic processes. A detailed knowledge of the synthetic part towards catalytically active complexes is needed in order to make the appropriate complexes. In this thesis the reactivity of silsesquioxane ligands with metals precursors is investigated in detail.

Chapter 2 deals with the synthesis of magnesium silsesquioxane complexes. Reaction of Grignard reagents with silsesquioxane trisilanol ligands leads to the formation of an unprecedented type of tetranuclear magnesium complexes. A formation mechanism is proposed and confirmed by synthesis of some of the intermediates. Crystal structures, reactivity studies and DFT computation lead to the conclusion that the metal centers in the complex are highly electron-deficient, mainly due to the electron-withdrawing character of the silsesquioxane ligand, and possibly due to the influence of the metallaligand environment.

In Chapter 3 the reaction of the silsesquioxane trisilanols with zinc reagents is investigated. Again the tetranuclear motif as described in Chapter 2 is found for a variety of ligands and zinc precursors, and a formation mechanism conform the previous Chapter is found. Reaction of dialkyl zinc materials with silsesquioxane trisilanols in the absence of coordinating moieties leads to the synthesis of three-coordinate zinc silsesquioxane complexes. These are reactive towards coordinating substances as pyridine or THF, and react with alcohols to form the corresponding zinc alkoxides.

Chapter 4 describes the use of the metallaligands found in Chapters 2 and 3, as ligands for magnesium, zinc, aluminium and vanadium, leading to heterobimetallic complexes. The formation mechanism as described in Chapters 2 and 3 is confirmed. The obtained vanadium complexes are used as ethene polymerization catalysts and are found to have a high activity and produce high-molecular weight PE.

Finally, Chapter 5 deals with the application of substituted silsesquioxane disilanols as ligands for vanadium(III) and titanium(III) for application in ethene polymerization. Although the stability of the complexes towards conventional activators such as MAO is 
doubted, diethyl aluminum chloride activates the precursors to high-activity polymerization catalysts. An attempt to form self-immobilizing catalysts by incorporation of alkene groups in the ligands is proposed. A possible catalytic cycle is described by DFT computations. 


\section{Bibliography}

[1] Scott,D.W. J.Am.Chem.Soc. 1946, 68, 356-358.

[2] Barry,A.J.; Daudt,W.H.; Domicone,J.J.; Gilkey,J.W. J.Am.Chem.Soc. 1955, 77, 4248-4252.

[3] Brown,J.F., Jr.; Vogt,L.H., Jr. J.Am.Chem.Soc. 1965, 87, 4313-4317.

[4] Feher,F.J.; Budzichowski,T.A.; Blanski,R.L.; Weller,K.J.; Ziller,J.W. Organometallics 1991, 10, 25262528.

[5] Hambley,T.W.; Maschmeyer,T.; Masters,A.F. Appl.Organomet.Chem. 1992, 6, 253-260.

[6] Kudo,T.; Gordon,M.S. J.Am.Chem.Soc. 1998, 120, 11432-11438.

[7] Kudo,T.; Gordon,M.S. J.Phys.Chem.A 2000, 104, 4058-4063.

[8] Jug,K.; Wichmann,D. J.Comp.Chem. 2000, 21, 1549-1553.

[9] Pescarmona,P.P.; Van der Waal,J.C.; Maxwell,I.E.; Maschmeyer,T. Angew.Chem.Int.Ed. 2001, 40, 740-743.

[10] Lücke,S.; Stoppek-Langner,K.; Kuchinke,J.; Krebs,B. J.Organomet.Chem. 1999, 584, 11-15.

[11] Feher,F.J.; Schwab,J.J.; Tellers,D.M.; Burstein,A. Main Group Chemistry 1998, 2, 169-181.

[12] Müller,E.; Edelmann,F.T. Main group metal chemistry 2000, 485

[13] Zhang,X.; Haxton,K.J.; Ropartz,L.; Cole-Hamilton,D.J.; Morris,R.E. J.Chem.Soc.Dalton Trans. 2001, 3261-3268.

[14] Fasce,D.P.; Williams,R.J.J.; Erra-Balsells,R.; Ishikawa,Y.; Nonami,H. Macromol. 2001 , 34, 35343539.

[15] Choi,J.; Harcup,J.; Yee,A.F.; Zhu,Q.; Laine,R.M. J.Am.Chem.Soc. 2001, 123, 11420-11430.

[16] Dittmar,U.; Hendan,B.J.; Marsmann,H.C. J.Organomet.Chem. 1995, 489, 185-194.

[17] Hong,B.; Thoms,T.P.; Murfee,H.J.; Lebrun,M.J. Inorg.Chem. 1997, 36, 6146-6147.

[18] Feher,F.J.; Wyndham,K.D.; Knauer,D.J. Chem.Commun. 1998, 2393-2394.

[19] Feher,F.J.; Wyndham,K.D.; Scialdone,M.A.; Hamuro,Y. Chem.Commun. 1998, 1469-1470.

[20] Feher,F.J.; Wyndham,K.D. Chem.Commun. 1998, 323-324.

[21] Manson,B.W.; Morrison,J.J.; Coupar,P.I.; Jaffrés,P.A.; Morris,R.E. J.Chem.Soc.Dalton Trans. 2001, 1123-1127.

[22] Coupar,P.I.; Jaffrés,P.A.; Morris,R.E. J.Chem.Soc.Dalton Trans. 1999, 2183-2187.

[23] Hendan,B.J.; Marsmann,H.C. J.Organomet.Chem. 1994, 483, 33-38.

[24] Rikowski,E.; Marsmann,H.C. Polyhedron 1997, Vol 16, 3357-3361.

[25] Gravel,M.C.; Zhang,C.; Dindermann,M.; Laine,R.M. Appl.Organomet.Chem. 1999, 13, 329-336.

[26] Ropartz,L.; Morris,R.E.; Schwarz,G.P.; Foster,D.F.; Cole-Hamilton,D.J. Inorg.Chem.Comm. 2000, 3, 714-717.

[27] Ropartz,L.; Morris,R.E.; Foster,D.F.; Cole-Hamilton,D.J. Chem.Commun. 2001, 361-362.

[28] Ropartz,L.; Haxton,K.J.; Foster,D.F.; Morris,R.E.; Slawin,A.M.Z.; Cole-Hamilton,D.J. J.Chem.Soc.Dalton Trans. 2002, 4323-4334.

[29] Ropartz,L.; Morris,R.E.; Foster,D.F.; Cole-Hamilton,D.J. J.Mol.Catal.A 2002, 182-183, 99-105.

[30] Feher,F.J. J.Am.Chem.Soc. 1986, 108, 3850-3852.

[31] Dijkstra,T.W.; Duchateau,R.; Van Santen,R.A.; Meetsma,A.; Yap,G.P.A. J.Am.Chem.Soc. 2002, 124, 9856-9864.

[32] Feher,F.J.; Budzichowski,T.A. Polyhedron 1995, 14, 3239-3253.

[33] Annand,J.; Aspinall,H.C.; Steiner,A. Inorg.Chem. 1999, 38, 3941-3943.

[34] Maxim,N.; Overweg,A.; Kooyman,P.J.; Van Wolput,J.H.M.C.; Hanssen,R.W.J.M.; Van Santen,R.A.; Abbenhuis,H.C.L. J.Phys.Chem.B 2002, 106, 2203

[35] Lorenz,V.; Fisher,A.; Giessman,S.; Gilje,J.W.; Gunko,Y.K.; Jacob,K.; Edelmann,F.T. Coor.Chem.Rev. 2000, 206-207, 321-368.

[36] Lorenz,V.; Fischer,A.; Edelmann,F.T. Inorg.Chem.Comm. 2000, 3, 292-295.

[37] Lorenz,V.; Fischer,A.; Edelmann,F.T. J.Organomet.Chem. 2002, 647, 245-249.

[38] Duchateau,R.; Gerritsen,G.; Van Santen,R.A.; Yap,G.P. Organometallics 2003, 22, 100-110.

[39] Smet,P.; Riondato,J.; Pauwels,T.; Moens,L.; Verdonck,L. Inorg.Chem.Comm. 2000, 3, 557-562.

[40] Haddad,T.S.; Lichtenhan,J.D. J.Inorg.Organomet.polymers 1995, 5, 237-246.

[41] Liu,J.C. Chem.Commun. 1996, 1109-1110.

[42] Liu,J.C. Appl.Organomet.Chem. 1999, 13, 295-302.

[43] Hanssen,R.W.J.M.; Meetsma,A.; Van Santen,R.A.; Abbenhuis,H.C.L. Inorg.Chem. 2000, 40, 40494052.

[44] Maxim,N.; Magusin,P.C.M.M.; Kooyman,P.J.; Van Wolput,J.H.M.C.; Van Santen,R.A.; Abbenhuis,H.C.L. Chem.Mater. 2001, 13, 2958-2964.

[45] Hermann,W.A.; Anwander,R.; Dufaud,V.; Scherer,W. Angew.Chem. 1994, 106, 1338-1340.

[46] Aspinall,H.C.; Annand,J. J.Chem.Soc.Dalton Trans. 2000, 1867-1871. 
[47] Gunko,Y.K.; Reilly,R.; Edelmann,F.T.; Schmidt,H.G. Angew.Chem.Int.Ed. 2001, 40, 1279-1281.

[48] Duchateau,R.; Abbenhuis,H.C.L.; Van Santen,R.A.; Meetsma,A.; Thiele,S.K.; Van Tol,M.F. Organometallics 1998, 17, 5663-5673.

[49] Duchateau,R.; Abbenhuis,H.C.L.; Van Santen,R.A.; Thiele,S.K.; Van Tol,M.F. Organometallics 1998, $17,5222-5224$.

[50] Duchateau,R.; Cremer,U.; Harmsen,R.J.; Mohamud,S.I.; Abbenhuis,H.C.L.; Van Santen,R.A.; Meetsma,A.; Thiele,S.K.; Van Tol,M.F.; Kranenburg,M. Organometallics 1999, 18, 5447-5459.

[51] Duchateau,R.; Van Santen,R.A.; Yap,G.P. Organometallics 2000, 19, 809-816.

[52] Severn,J.R.; Duchateau,R.; Van Santen,R.A.; Ellis,D.D.; Spek,A.L. Organometallics 2002, 21, 4-6.

[53] Duchateau,R. Chem.Rev. 2002, 102, 3525-3542.

[54] Edelmann,F.T.; Giessman,S.; Fischer,A. Chem.Commun. 2000, 2153-2154.

[55] Abbenhuis,H.C.L. Angew.Chem. 1999, 111, 1125-1127.

[56] Abbenhuis,H.C.L.; Krijnen; Van Santen,R.A. Chem.Commun. 1997, 331-332.

[57] Maschmeyer,T.; Klunduk,M.C.; Martin,C.M.; Shephard,D.S.; Thomas,J.M.; Johnson,B.F. Chem.Commun. 1997, 1847-1848.

[58] Klunduk,M.C.; Maschmeyer,T.; Thomas,J.M.; Johnson,B.F. Chem.Eur.J. 1999, 5, 1481-1485.

[59] Skowronska-Ptaskinski,M.D.; Vorstenbosch,M.L.; Van Santen,R.A.; Abbenhuis,H.C.L. Angew.Chem.Int.Ed. 2002, 41, 637-639.

[60] Vorstenbosch, M. L. W. Alkene epoxidation with silsesquioxane based chromium and titanium complexes. 2002. Schuit Institute of Catalysis.

[61] Krijnen,S.; Abbenhuis,H.C.L.; Hanssen,R.W.; Van Hooff,J.H.; Van Santen,R.A. Angew.Chem.Int.Ed. 1998, 37, 356-358.

[62] Van Santen, R. A., Abbenhuis, H. C. L., and Vorstenbosch, M. L. Method for producing silsasesquioxane metal complexes, novel silsesquioxane metal complexes and the use thereof. PCT/EP98/01932(WO 98/46352)

[63] Krijnen,S.; Mojet,B.L.; Abbenhuis,H.C.L.; Van Hooff,J.H.; Van Santen,R.A. Phys.Chem.Chem.Phys. 1999, 1, 361-365.

[64] Krijnen,S.; Harmsen,R.J.; Abbenhuis,H.C.L.; Van Hooff,J.H.; Van Santen,R.A. Chem.Commun. 1999, 501-502.

[65] Krijnen,S.; Abbenhuis,H.C.L.; Hanssen,R.W.; Van Hooff,J.H.; Van Santen,R.A. Mater.Res.Soc. 1999, 645-650.

[66] Abbenhuis,H.C.L. Chem.Eur.J. 2000, 6, 25-32.

[67] Crocker,M.; Herold,R.H.; Orpen,A.G. Chem.Commun. 1997, 2411-2412.

[68] Crocker,M.; Herold,R.H.; Orpen,A.G.; Overgaag,M. J.Chem.Soc.Dalton Trans. 1999, 3791-3804.

[69] Crocker, M. and Herold, R. H. Preparation of oxirane compounds with titanasilsesquioxane catalysts. PCT/EP96/05873(WO 97/24344). 1999

[70] Meijer, R. H. The winding road from oppenhauer to sustainable catalytic oxidations of alcohols. 2002

[71] Van Santen, R. A., Krijnen, S., and Hanssen, R. W. Method for producing a supported catalyst. WO 99/03581(PCT/EP98/040598).

[72] Edelmann,F.T.; Giessman,S.; Fisher,A. J.Organomet.Chem. 2001, 620, 80-89.

[73] Wada,K.; Nakashita,M.; Bundo,M.; Ito,K.; Kondo,T.; Mitsudo,T. Chem.Lett. 1998, 1998, 659-660.

[74] Wada,K.; Bundo,M.; Nakabayashi,D.; Itayama,N.; Mitsudo,T. Chem.Lett. 2000, 628-629.

[75] Gunko,Y.K.; Nagy,L.; Bruser,W.; Lorenz,V.; Fischer,A.; Giessmann,S.; Edelmann,F.T.; Jacob,K.; Vertes,A. Monatshefte für Chemie 1999, Vol 130, 45-54.

[76] Feher,F.J.; Gonzales,S.L.; Ziller,J.W. Inorg.Chem. 1988, 27, 3440-3442.

[77] Feher,F.J.; Walzer,J.F. Inorg.Chem. 1990, 29, 1604-1611.

[78] Feher,F.J.; Walzer,J.F. Inorg.Chem. 1991, 30, 1689-1694.

[79] Feher,F.J.; Walzer,J.F.; Blanski,R.L. J.Am.Chem.Soc. 1991, 113, 3618-3619.

[80] Feher,F.J.; Blanski,R.L.J.Am.Chem.Soc. 1992, 114, 5886-5887.

[81] Feher,F.J.; Blanski,R.L. Makromolekulare Chemie-Macromolecular Symposia 1993, 66, 95-107.

[82] Wada,K.; Nakashita,M.; Yamamoto,A.; Mitsudo,T. Chem.Commun. 1998, 133-134.

[83] Wada,K.; Nakashita,M.; Yamamoto,A.; Wada,H.; Mitsudo,T. Chem.Lett. 1997, 12, 1209-1210.

[84] Chabanas,M.; Quadrelli,E.A.; Fenet,B.; Coperet,C.; Thivolle-Cazat,J.; Basset,J.M.; Lesage,A.; Emsley,L. Angew.Chem.Int.Ed. 2001, 40, 4493

[85] Fei,Z.; Schmutzler,R.; Edelmann,F.T. Z.Anorg.Allg.Chem. 2003, 629, 353-356.

[86] Feher,F.J.; Blanski,R.L. J.Chem.Soc.Chem.Commun. 1990, 1614-1616.

[87] Maxim,N.; Abbenhuis,H.C.L.; Stobbelaar,P.J.; Mojet,B.L.; Van Santen,R.A. Phys.Chem.Chem.Phys. 1999, 1, 4473-4477.

[88] Maxim, N. Metal Silsesquioxanes as Precursors to Microporous Metallosilicates. 2002.

[89] Feher,F.J.; Rahimian,K.; Budzichowski,T.A. Organometallics 1995, 14, 3920-3926. 
[90] Feher,F.J.; Soulivong,D.; Eklund,A.G.; Wyndham,K.D. Chem.Commun. 1997, 1185-1186.

[91] Smet,P.; Devreese,B.; Verpoort,F.; Pauwels,T.; Svoboda,I.; Foro,S.; Van Beeumen,J.; Verdonck,L. Inorg. Chem. 1998, 37, 6583-6586.

[92] Budzichowski,T.A.; Chacon,S.T.; Chisholm,M.H.; Feher,F.J.; Steib,W. J.Am.Chem.Soc. 1991, 113, 689-691.

[93] Feher,F.J.; Budzichowski,T.A.; Rahimian; Ziller,J.W. J.Am.Chem.Soc. 1992, 114, 3859-3866.

[94] Chisholm,M.H.; Budzichowski,T.A.; Feher,F.J.; Ziller,J.W. Polyhedron 1992, 11, 1575-1579.

[95] Abbenhuis,H.C.L. personal communication

[96] Morán,M.; Casado,C.M.; Cuadrado,I. Organometallics 1993, 12, 4327-4333.

[97] Marcolli,C.; Calzaferri,G. Appl.Organomet.Chem. 1999, 13, 213-226.

[98] Casado,C.M.; Cuadrado,I.; Morádo,M.; Alonso,B.; Barranco,M.; Losada,J. Appl.Organomet.Chem. 1999, 13, 245-249.

[99] Baker,R.T.; Ott,K.C.; Tumas,W.; Liu,F.; John,K.D.; Scott,B.L. Angew.Chem.Int.Ed. 2000, 39, 31273130.

[100] Edelmann,T.; Lorenz,V.; Fischer,A. Z.Anorg.Allg.Chem. 2000, 626, 1728-1730.

[101] Maxim,N.; Overweg,A.; Kooyman,P.J.; Van Santen,R.A.; Abbenhuis,H.C.L. J.Mater.Chem. 2002, 3792-3798.

[102] Wada,K.; Izuhara,D.; Shiotsuki,M.; Kondo,T.; Mitsudo,T. Chem.Lett. 2001, 734

[103] Braunstein,P.; Galsworthy,J.R.; Hendan,B.J.; Marsmann,H.C. J.Organomet.Chem. 1998, 551, $125-131$.

[104] Murfee,H.J.; Thoms,T.P.; Greaves,J.; Hong,B. Inorg.Chem. 2000, 39, 5209-5217.

[105] Liu,J.C.; Wilson,S.R.; Shapley,J.R.; Feher,F.J. Inorg.Chem. 1990, 29, 5138-5139.

[106] Abbenhuis,H.C.L.; Burrows,A.D.; Kooijman,H.; Lutz,M.; Palmer,M.T.; Van Santen,R.A.; Spek,A.L. Chem.Commun. 1998, 2627-2628.

[107] Johnson,B.F.; Quadrelli,E.A.; Davies,J.E.; Feeder,N. Chem.Commun. 2000, 1031-1032.

[108] Hendan,B.J.; Marsmann,H.C. Appl.Organomet.Chem. 1999, 13, 287-294.

[109] Nowotny,M.; Maschmeyer,T.; Johnson,B.F.; Lahuerta,P.; Thomas,J.M.; Davies,J.E. Angew.Chem.Int.Ed. 2001, 40, 955-958.

[110] Bahtiar,R.; Feher,F.J. Rapid.Comm.Mass.Spectr. 1999, 13, 687-694.

[111] Rattay,M.; Fenske,D.; Jutzi,P. Organometallics 1998, 17, 2930-2932.

[112] Harrison,P.G.; Hall,C.H. J.Sol-gel.Sci.Tech. 1998, 13, 391-396.

[113] Edelmann,F.T.; Giessmann,S.; Fischer,A. Inorg.Chem.Commun. 2000, 3, 658-661.

[114] Schmid,G.; Pugin,R.; Malm,J.O.; Bovin,J.O. Eur.J.Inorg.Chem. 1998, 813-817.

[115] Abis,L.; Armelao,L.; Belli Dell'Amico,D.; Calderazzo,F.; Garbassi,F.; Merigo,A.; Quadrelli,E.A. J.Chem.Soc.Dalton Trans. 2001, 2709

[116] Duchateau,R.; Harmsen,R.J.; Abbenhuis,H.C.L.; Van Santen,R.A.; Meetsma,A.; Thiele,S.K.; Kranenburg,M. Chem.Eur.J. 1999, 5, 3130-3135.

[117] Skowronska-Ptaskinska,M.D.; Duchateau,R.; Van Santen,R.A.; Yap,G.P.A. Organometallics 2001, 20, 3519-3530.

[118] Skowronska-Ptaskinska,M.D.; Duchateau,R.; Van Santen,R.A.; Yap,G.P. Eur.J.Inorg.Chem. 2001, 133-137.

[119] Edelmann,F.T.; Gun; Giessman,S.; Olbrich,F. Inorg.Chem. 1999, 38, 210-211.

[120] Feher,F.J.; Budzichowski,T.A.; Weller,K. J.Am.Chem.Soc. 1989, 111, 153-163.

[121] Feher,F.J.; Weller,K. Organometallics 1990, 9, 2638-2640.

[122] Feher,F.J.; Weller,K.; Ziller,J.W. J.Am.Chem.Soc. 1992, 114, 9686-9688.

[123] Abbenhuis,H.C.L.; Van Herwijnen,H.W.; Van Santen,R.A. Chem.Commun. 1996, 1941-1942.

[124] Feher,F.J.; Budzichowski,T.A.; Ziller,J.W. Inorg.Chem. 1997, Vol 36, 4082-4086.

[125] Maxim,N.; Abbenhuis,H.C.L.; Magusin,P.C.M.M.; Van Santen,R.A. Chinese Journal of Chemistry 2001, 19,

[126] Wada,K.; Yamada,K.; Kondo,T.; Mitsudo,T. Chem.Lett. 2001, 12-13.

[127] Feher,F.J.; Budzichowski,T.A.; Ziller,J.W. Inorg.Chem. 1992, 31, 5100-5105.

[128] Metcalfe,R.A.; Kreller,D.I.; Tian,J.; Kim,H.; Taylor,N.J.; Corrigan,J.F.; Collins,S. Organometallics 2002, 21, 1719-1726. 


\section{Synthesis and reactivity of magnesium silsesquioxane complexes}

he reaction of silsesquioxane trisilanols $\left(\mathrm{C}_{5} \mathrm{H}_{9}\right)_{7} \mathrm{Si}_{7} \mathrm{O}_{9}(\mathrm{OH})_{3}$ and $\left(\mathrm{C}_{7} \mathrm{H}_{13}\right)_{7} \mathrm{Si}_{7} \mathrm{O}_{9}(\mathrm{OH})_{3}$
with methyl magnesium chloride led to unprecedented tetranuclear magnesium silsesquioxane complexes in high yield. The complexes were structurally and spectroscopically analyzed. The crystal structures showed an unusually short $\mathrm{Mg}-\mathrm{Cl}$ bond, indicative of an electron-deficient magnesium atom. This has been confirmed by density functional computations. Collaborated by an alternative synthesis method, a mechanism of formation could be proposed. The cyclopentyl substituted complex has been tested as a catalyst in the Diels-Alder reaction of enones and the ring-opening polymerization of raclactide. It was found to be inactive in both reactions. For the former reaction this was possibly due to the strong interaction between the complex and the ketone. For the latter the inability to activate the $\mathrm{Mg}-\mathrm{Cl}$ bond was responsible for the inactivity. The complex was used as transmetallation agent for the synthesis of metal silsesquioxane complexes. The transmetallation activity was low, but in one case it led to a reaction that could easily be followed by multinuclear NMR. 


\section{Introduction}

Over the past several years, silsesquioxane complexes ${ }^{1}$ have been used to mimic silica surfaces $^{2-5}$ silica supported metal catalysts ${ }^{6-8}$ and to synthesize new porous materials. ${ }^{9} \mathrm{~A}$ relatively new approach is the use of silsesquioxane derivatives as catalysts for a variety of processes involving Diels-Alder reactions, ${ }^{10}$ polymerization, ${ }^{11-16}$ metathesis ${ }^{17}$ and epoxidation of alkenes. ${ }^{18-21}$ The electron-withdrawing properties of their $\mathrm{Si} / \mathrm{O}$ skeletons make silsesquioxane complexes highly suitable for accelerating Lewis acid catalyzed reactions, in which electron deficient metal centers are required. The key to success in all of the areas aforementioned is the development of efficient methodologies to synthesize silsesquioxane ligands and complexes. Although the chemistry of silsesquioxane ligands and their metal complexes has seen a great evolution over the last years, some problems still occur in complex formation. Especially the cyclodehydration of the silanol groups upon reaction with high valent metal complexes when assisted by amines remains a problem to be solved. Feher et al. found new ways to overcome such problems, viz. the transmetallation of high valent metal chlorides with main group metal substituted silsesquioxanes, but this approach involved the use of the synthetically not readily available pentamethyl antimony ${ }^{22}$ or highly toxic thallium compounds. ${ }^{23,24}$ Aspinall et al. explored the use of silsesquioxane lithium complexes as transmetalating agents. ${ }^{25}$ The use of magnesium compounds as transmetalating agents has, however, not yet been explored in silsesquioxane chemistry, although they are being widely used in many areas of inorganic and organometallic chemistry. ${ }^{26}$

In this chapter we report the synthesis, structural characterization, transmetallation activity as well as density functional theory (DFT) computations of new tetranuclear magnesium silsesquioxane complexes that can easily be synthesized by the protolysis reaction of methyl magnesium chloride and the incompletely condensed silsesquioxane trisilanol (c$\left.\mathrm{C}_{5} \mathrm{H}_{9}\right)_{7} \mathrm{Si}_{7} \mathrm{O}_{9}(\mathrm{OH})_{3}$ or $\left(c-\mathrm{C}_{7} \mathrm{H}_{13}\right)_{7} \mathrm{Si}_{7} \mathrm{O}_{9}(\mathrm{OH})_{3}$. A possible mechanism of formation of the resulting polyoxometalate is discussed. The reactivity of the cyclopentyl substituted magnesium cluster is discussed in detail with regard to catalysis $(\mathrm{Mg}-\mathrm{Cl}$ activation) and to synthesis of other metal silsesquioxane complexes by transmetallation ( $\mathrm{Mg}-\mathrm{O}$ activation). 


\section{Synthesis and characterization}

The reaction of the silsesquioxane trisilanol $\left(c-\mathrm{C}_{5} \mathrm{H}_{9}\right)_{7} \mathrm{Si}_{7} \mathrm{O}_{9}(\mathrm{OH})_{3}$ with three equivalents of methylmagnesium chloride in THF proceeds rapidly, with the vigorous release of methane gas, even when performed at $-40^{\circ} \mathrm{C}$ (Scheme 1, step $i$ ). Concentration of the solution and crystallization by subsequent heating and slow cooling yields large colorless cube-like crystals of 1a, as a moderately air and moisture stable compound.

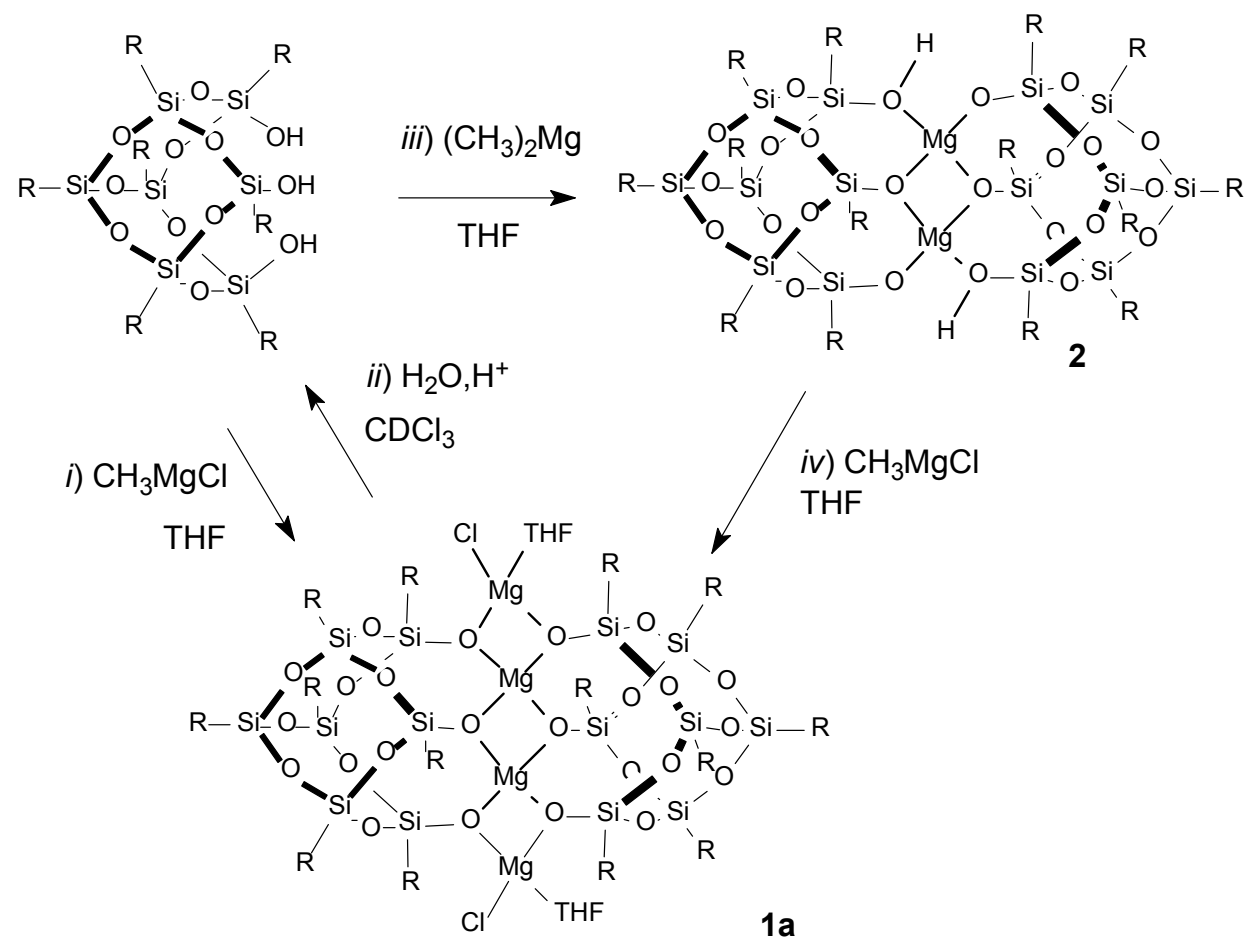

Scheme 1. Synthesis of the tetranuclear silsesquioxane magnesium complex 1a via two different routes

Reaction of 1a with diluted hydrochloric acid in an NMR tube yields the starting silsesquioxane trisilanol in quantitative yield, together with a white powder that was insoluble in the NMR solvent (Scheme 1, step $i i$ ). Dissolving 1a in $\mathrm{CDCl}_{3} /$ pyridine- $d_{5}$ mixture results in THF-pyridine exchange, as indicated by the presence of free THF observed in the ${ }^{1} \mathrm{H}$ NMR, while the symmetry of the ligand system remains the same. Complex 1a is very soluble in chloroform and dichloromethane while it is moderately soluble in THF, benzene and toluene. Attempts to prepare complexes with other than two magnesium atoms per silsesquioxane ligand by Grignard addition all yield complex 1a. An alternative way to synthesize complex 1a involves the reaction of the silsesquioxane trisilanol (c$\left.\mathrm{C}_{5} \mathrm{H}_{9}\right)_{7} \mathrm{Si}_{7} \mathrm{O}_{9}(\mathrm{OH})_{3}$ with one equivalent of a dialkyl magnesium reagent $\mathrm{R}_{2} \mathrm{Mg}(\mathrm{R}=\mathrm{Me}$, $\mathrm{CH}_{2} \mathrm{Ph}$ ). In contrast to the findings of Liu et al. for the related trisilanol (c- 
$\left.\mathrm{C}_{6} \mathrm{H}_{11}\right)_{7} \mathrm{Si}_{7} \mathrm{O}_{9}(\mathrm{OH})_{3},{ }^{13 ; 27}$ in THF this reaction yields a single product 2 , that can be converted into 1a (vide infra). Upon reaction of the cyclohexyl substituted silsesquioxane with butylethyl magnesium in boiling heptane, Liu et al. identified at least three different silsesquioxane magnesium complexes, that were not structurally analyzed. ${ }^{28}$ NMR data of 2 are consistent with a silsesquioxane complex in which two of the three silanol groups have reacted with the dialkyl magnesium and the third silanol is left unreacted, as shown in Scheme 1 (step iii). The reaction of 2 with two equivalents of methyl magnesium chloride yields the tetranuclear complex 1a (Scheme 1, step $i v$ ). This alternative route has led us to propose a formation mechanism as depicted in Scheme 2.

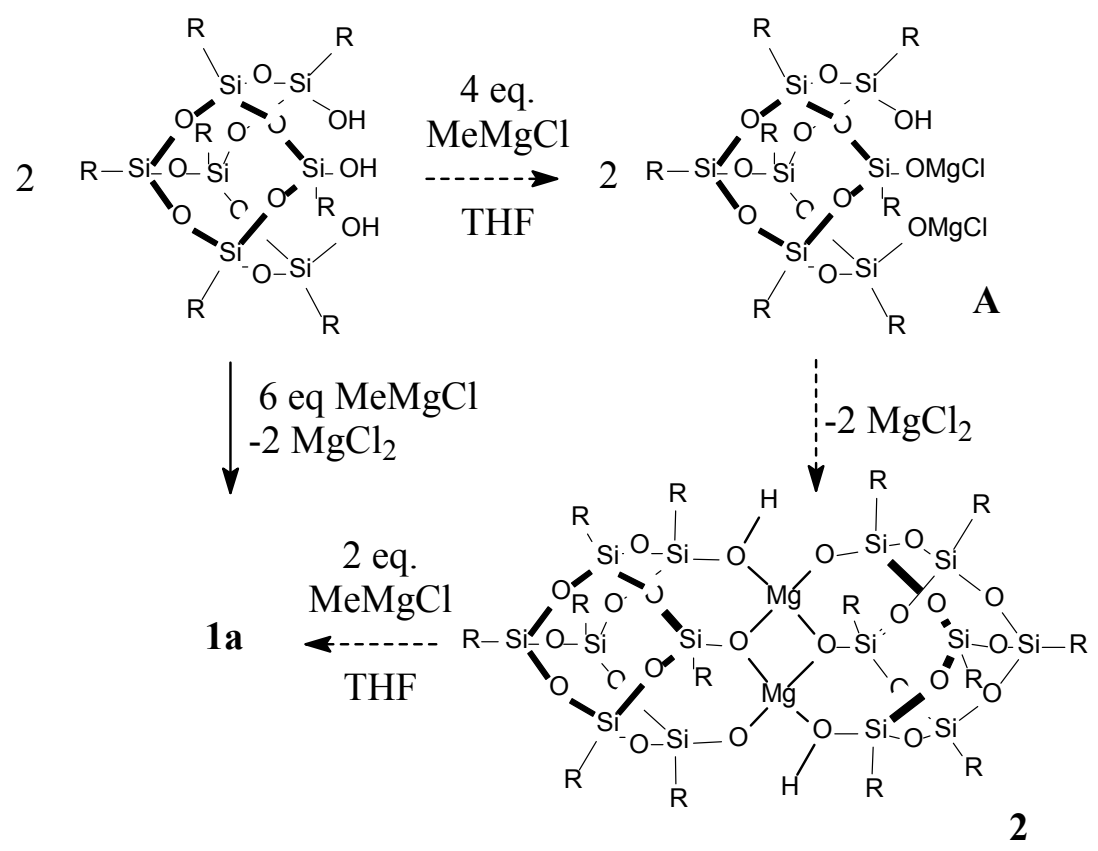

Scheme 2. Proposed mechanism of the formation of complex 1a. Dashed arrows indicate proposed reaction steps

The first step is believed to be the protolysis of methylmagnesium chloride with two of the silsesquioxane silanols forming intermediate A. The second, more intriguing step is the elimination of $\mathrm{MgCl}_{2}$ from $\mathbf{A}$ leading to 2. This step is also involved in the well-known Schlenk equilibrium. However, for alkoxy magnesium halides, such as the proposed structure, this is less common. Possibly there is an equilibrium between $\mathbf{A}$ and $\mathbf{2}$, which is shifted towards 1a via 2 due to the slow reaction of $\mathbf{2}$ with a third equivalent of methyl magnesium chloride to form the thermodynamically most stable and less THF-soluble complex 1a. 
Since an unambiguous assignment of the structure of the magnesium complex could not be established on the basis of the spectroscopic data alone, a single-crystal X-ray diffraction study was performed on 1a. Crystals suitable for an X-ray single-crystal study were obtained by slow cooling of a warm saturated solution of $\mathbf{1 a}$ in THF to room temperature. An ORTEP drawing of 1a is shown in Figure 1. Selected bond lengths and angles are given in Table 1.

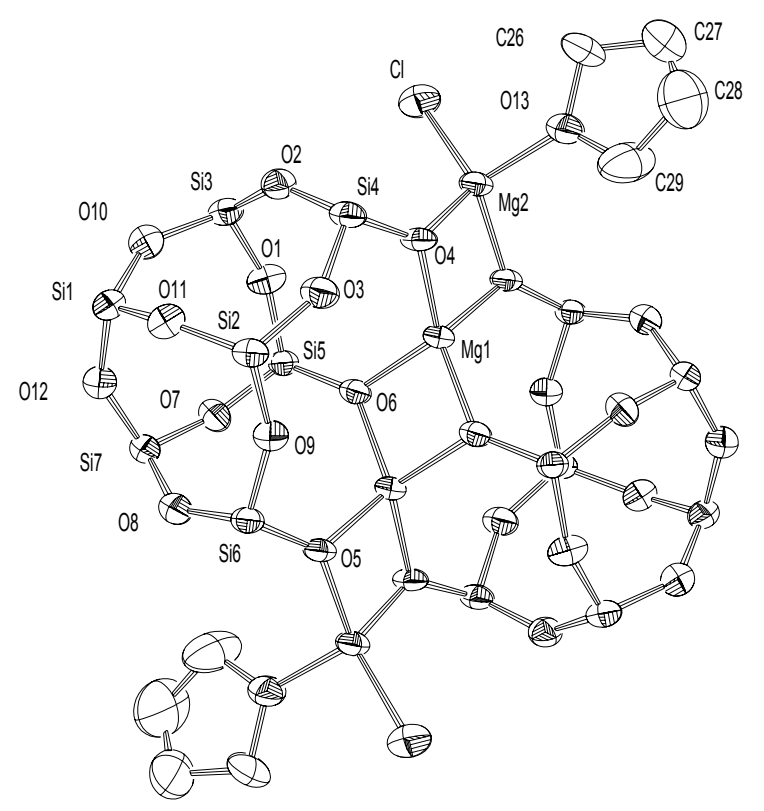

Figure 1. Structure of $\left[\left(\mathrm{C}_{5} \mathrm{H}_{9}\right)_{7} \mathrm{Si}_{7} \mathrm{O}_{12}\right]_{2} \mathrm{Mg}_{4} \mathrm{Cl}_{2}(\mathrm{THF})_{2}$ (1a) in the crystal (ORTEP drawing with $50 \%$ propability elipsoids). The cyclopentyl groups have been omitted for clarity.

The monoclinic unit cell contains two units of the title compound and twelve THF solvent molecules separated by normal van der Waals distances. Each asymmetric unit contains half a molecule of 1a, and three lattice THF solvent molecules, of which one is highly disordered. The structure determination shows 1a to be an inversion symmetric, tetranuclear, tetracoordinated magnesium species, with two sets of chemically differently magnesium atoms. One magnesium atom (denoted as $\mathrm{Mg} 1$ ) is connected to two silsesquioxane ligands via three crystallographically different oxygen atoms, of which one oxygen atom (O6) is $\mu_{3^{-}}$ bonded to the magnesium atom and two oxygen atoms $(\mathrm{O} 4, \mathrm{O} 5)$ are $\mu_{3}$-bonded to both magnesium atoms. The magnesium atom $(\mathrm{Mg} 2)$ is connected to one chloride and to two silsesquioxane ligands via two oxygen atoms. To complete the tetrahedral coordination sphere of $\mathrm{Mg} 2$, this $\mathrm{Mg}$ atom also has one coordinated THF molecule. 
The four magnesium atoms are incorporated in an interlayer between the two trianionic silsesquioxide ligands. This interlayer consists of three almost planar four-membered metallaoxocycles, alternatingly perpendicular to each other, in which the four magnesium atoms are in a linear structure (the dihedral angle of $\mathrm{Mg} 2 \mathrm{a}-\mathrm{Mg} 1 \mathrm{a}-\mathrm{Mg} 1-\mathrm{Mg} 2$ is $180^{\circ}$ ). The two outer metallaoxocycles are virtually planar (the sum of all angles is $359^{\circ}$ ) and the oxygen atoms are bent slightly out of plane toward the coordinated THF molecule. The inner metallaoxocycle is perfectly planar (sum of all angles is $360.0^{\circ}$ )

Table 1. Selected bond lengths $(\AA)$ and angles $\left(^{\circ}\right)$ for $1 \mathrm{a}$.

\begin{tabular}{llcl}
\hline & \multicolumn{3}{c}{ Bond lengths } \\
\hline $\mathrm{Mg} 2-\mathrm{Cl}$ & $\mathrm{Mg} 1-\mathrm{O} 5 \mathrm{a}$ & $1.968(3)$ \\
$\mathrm{Mg} 2-\mathrm{O} 13$ & $1.989(4)$ & $\mathrm{Mg} 1-\mathrm{O} 6$ & $1.964(3)$ \\
$\mathrm{Mg} 2-\mathrm{O} 4$ & $1.962(3)$ & $\mathrm{Si} 4-\mathrm{O} 4$ & $1.614(3)$ \\
$\mathrm{Mg} 2-\mathrm{O} 5 \mathrm{a}$ & $1.945(3)$ & $\mathrm{Si}-\mathrm{O} 6$ & $1.600(3)$ \\
$\mathrm{Mg} 1-\mathrm{O} 4$ & $1.969(3)$ & $\mathrm{Si}-\mathrm{O} 5$ & $1.605(3)$ \\
& & Bond angles & \\
$\mathrm{Cl}-\mathrm{Mg} 2-\mathrm{O} 13$ & $104.00(12)$ & $\mathrm{Si} 4-\mathrm{O} 4-\mathrm{Mg} 2$ & $132.01(19)$ \\
$\mathrm{Cl}-\mathrm{Mg} 2-\mathrm{O} 4$ & $120.28(12)$ & $\mathrm{Si} 4-\mathrm{O} 4-\mathrm{Mg} 1$ & $128.92(19)$ \\
$\mathrm{Mg} 2-\mathrm{O} 4-\mathrm{Mg} 1$ & $93.37(13)$ & $\mathrm{Si} 5-\mathrm{O} 6-\mathrm{Mg} 1$ & $130.76(19)$ \\
$\mathrm{Mg} 2-\mathrm{O} 5 \mathrm{a}-\mathrm{Mg} 1$ & $93.96(13)$ & $\mathrm{Si} 5-\mathrm{O} 6-\mathrm{Mg} 1 \mathrm{a}$ & $135.65(19)$ \\
$\mathrm{Mg} 1-\mathrm{O} 6-\mathrm{Mg} 1 \mathrm{a}$ & $92.95(13)$ & $\mathrm{Si}-\mathrm{O}-\mathrm{O} 5-\mathrm{Mg} 2 \mathrm{a}$ & $137.66(19)$ \\
$\mathrm{O} 4-\mathrm{Mg} 2-\mathrm{O} 5 \mathrm{a}$ & $86.16(13)$ & $\mathrm{O} 4-\mathrm{Mg} 1-\mathrm{O} 6$ & $118.84(14)$ \\
$\mathrm{O} 4-\mathrm{Mg} 1-\mathrm{O} 5 \mathrm{a}$ & $85.37(13)$ & $\mathrm{O} 5 \mathrm{a}-\mathrm{Mg} 1-\mathrm{O} 6 \mathrm{a}$ & $117.26(13)$ \\
$\mathrm{O} 6-\mathrm{Mg} 1-\mathrm{O} 6 \mathrm{a}$ & $87.05(13)$ & $126.71(18)$ \\
\hline
\end{tabular}

Standard deviations in the last decimal place are given in parentheses.

The tetrahedral coordination of the magnesium atoms is highly distorted with an average $\mathrm{O}-\mathrm{Mg}-\mathrm{O}$ angle of 86.2 degrees. This was also found for other $\operatorname{Mg}\left(\mu_{3}-\mathrm{O}\right)_{2} \mathrm{Mg}$ complexes with angles ranging from 79.1 degrees in $\left\{\left(4{ }^{\mathrm{i}} \mathrm{PrPh}-\mathrm{O}\right)(\mathrm{Br})\left(\mathrm{Et}_{2} \mathrm{O}\right) \mathrm{Mg}\left(\mu_{3}-\mathrm{O}-\mathrm{Ph}\right)\right\}_{2}{ }^{29}$ to 95.1 degrees in $\left\{(\mathrm{Br})\left(\mathrm{Et}_{2} \mathrm{O}\right) \mathrm{Mg}\left(\mu_{3}-\mathrm{O}-(2,2-\text { dimethylpent-3-en-3-olato })\right)\right\}_{2}{ }^{30}$ The $\mathrm{Mg}-\mathrm{O}$ bond lengths (average $1.96 \AA$ ) are consistent to those compiled by Holloway and Melnik for tetracoordinated magnesium compounds $(1.819$ - $2.219 \AA) .{ }^{31}$ However, the magnesiumchloride bond is exceptionally short $(2.255 \AA)$ in comparison to other similar magnesium complexes, suggesting a highly electron deficient magnesium atom. The shortest $\mathrm{Mg}-\mathrm{Cl}$ 
bond found in the Cambridge Crystallographic Database was $2.310 \AA$ for chloro\{bis(cyclohexyl-( $\mu_{2}-3,5$-dimethylpyrazolyl-N-N')-(THF)-gallium\}-magnesium. ${ }^{32}$ The $\mathrm{Mg} 2-$ O13(THF) distance is in the normal range (1.989 $\AA$ ), but reasonably short, which could also be explained by a relatively high electron deficiency on the magnesium atom.

\section{Reactivity and catalytic behaviour}

Complex 1a was tested as a catalyst in the Diels-Alder reaction of 2,4-dimethyl-1,3-butadiene with 2-methyl-1,3-propenone in $\mathrm{CDCl}_{3}$ at room temperature, a relatively simple reaction that already found precedent in silsesquioxane based catalysis. ${ }^{10} \mathrm{~A}$ high reaction rate is expected for a Lewis acidic metal complex, since the reactivity of the alkene bond in enones increases upon bonding of the carbonyl group to an electron withdrawing metal center. A measure for the Lewis acidity is the electron deficiency of the metal center, in this case the magnesium atom. No catalytic acceleration of the reaction could be observed. Probably the Lewis-acidic functionality of the magnesium atom is unavailable due to a strongly coordinating ketone molecule, which does not dissociate any more from the complex under reaction conditions (room temperature to $50^{\circ}$ ). This was shown by an in-situ NMR study: upon addition of aceton- $d_{6}$, the proton resonances of the coordinated THF molecule were shifted upfield and the initially broad resonances showed a sharp coupling pattern, indicating the dissociation of the THF molecule from the magnesium atom.
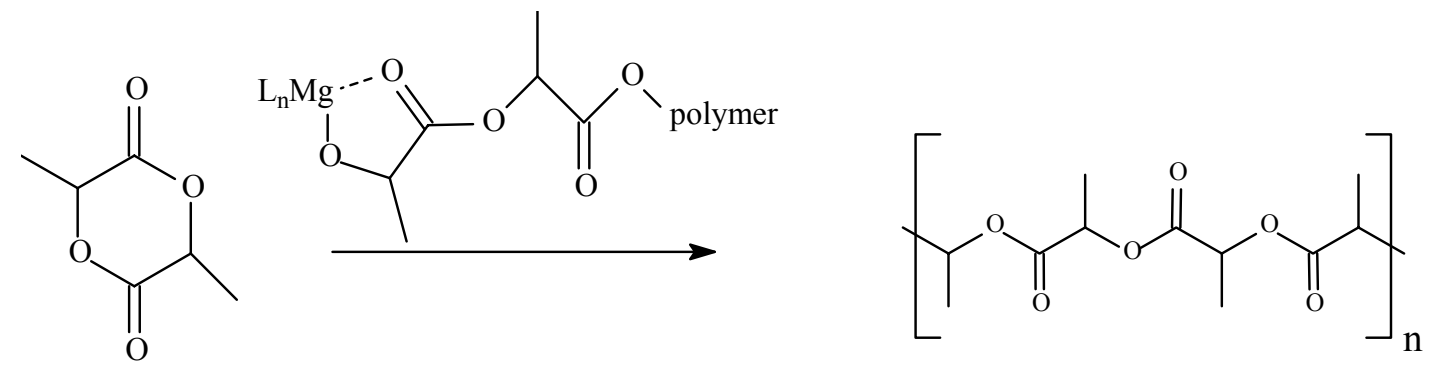

\section{Scheme 3. Ring opening polymerization of lactide}

Similar behavior is shown for the reaction of complex 1a with rac-lactide. In an attempt to use 1a as a ring-opening polymerization catalyst for lactide polymerization, ${ }^{33 ; 34}$ a solution of 1a and rac-lactide in dry $\mathrm{CHCl}_{3}$ was treated with methanol, to induce chloride-alkoxide exchange, an important activation step in lactide polymerization. Scheme 3 shows the ring opening polymerization of lactide and the proposed magnesium alkoxide intermediate. After 
16 hours no polymer could be detected. An in-situ NMR study indicated THF-ketone exchange, but no activation of the $\mathrm{Mg}-\mathrm{Cl}$ bond. Various attempts of activation of the metalchloride bonds with alcohols, lithium alkoxides, amines and lithium amides proved to be unsuccessful. This again is an indication of the high bond strength between $\mathrm{Mg}$ and $\mathrm{Cl}$ caused by the marked electron deficiency of the magnesium atoms. Attempt to react 1a, in analogy to the work by Smet et al., with epoxides in order to synthesize silicon alkoxides were also unsuccessful, although Smet et al. reported this. ${ }^{35}$ Only after treatment with silver triflate in THF or $\mathrm{Et}_{2} \mathrm{O}$, precipitation of silver chloride could be observed. The product however could not be identified as the expected magnesium di-cation complex, since ${ }^{19} \mathrm{~F}$ NMR showed no signals of the triflate counter anion. NMR of the other nuclei $\left({ }^{13} \mathrm{C}\right.$ and $\left.{ }^{1} \mathrm{H}\right)$ indicated the formation of a mixture of numerous compounds, which could not be identified. Presumably the abstraction of the chloride anion leads to significant degradation of the complex framework.
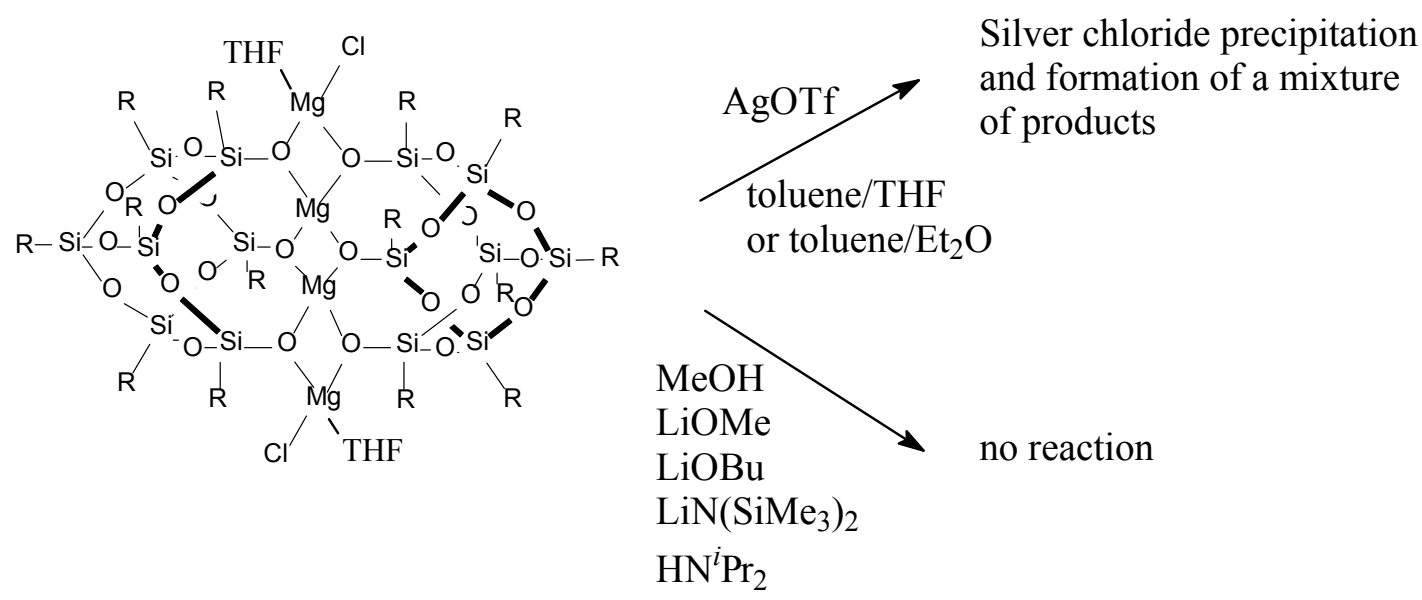

Scheme 4. Overview of the reactivity of the magnesium cluster 1a towards amines, amides, alcohols and alkoxides.

The silsesquioxane magnesium complex 1a was tested in transmetallation reactions, potentially leading to various known silsesquioxane complexes. In $48 \mathrm{~h}$ the reaction of $1 \mathrm{a}$ with $\left(\eta^{5}-\mathrm{C}_{5} \mathrm{H}_{5}\right) \mathrm{TiCl}_{3}$ in $\mathrm{CDCl}_{3}$ leads to the corner-capped cyclopentadienyl titanium silsesquioxane complex together with precipitation of $\mathrm{MgCl}_{2}$ (Scheme 5, step $i$ ). ${ }^{8 ; 22}$ However, this reaction proceeds slowly compared to the conventional reaction conditions, viz. amine hydrochloride elimination. ${ }^{5}$ Yet the low rate of the reaction offers the opportunity to follow it by NMR. Immediately after addition of $\left(\eta^{5}-\mathrm{C}_{5} \mathrm{H}_{5}\right) \mathrm{TiCl}_{3}$, signals in the low field resonances for $\mathrm{Cp}$ in the ${ }^{1} \mathrm{H}-\mathrm{NMR}$ are observed ( $\delta 7.05$ to $\left.\delta 6.44 \mathrm{ppm}\right)$. In time, other resonances appear while the original peaks decrease and eventually disappear. After 48 hours, only resonances 
of the cyclopentadienyl titanium silsesquioxane are observed (i.e. a single $\mathrm{Cp}$ resonance at $6.48 \mathrm{ppm})$. This indicates that the transmetallation reaction proceeds via numerous intermediates, possibly being one-, two- and three-bonded silsesquioxane titanium complexes and their $\mathrm{MgCl}_{2}$-adducts. The reaction of $\mathbf{1 a}$ with $\mathrm{SiCl}_{4}$ in $\mathrm{CDCl}_{3}$ (Scheme 5, reaction $\mathrm{ii}$ ) also proceeded slowly, but led to the expected product ${ }^{15 ; 36}$ overnight. The absence of a characteristic ${ }^{1} \mathrm{H}-\mathrm{NMR}$ resonance in the reacting moieties frustrates the observation of intermediate products and prohibits a clear assignment of the resonances, but it is likely that reaction ii proceeds via numerous intermediates as in the previous reaction.

$$
\mathrm{R}=\text { cyclopentyl }
$$
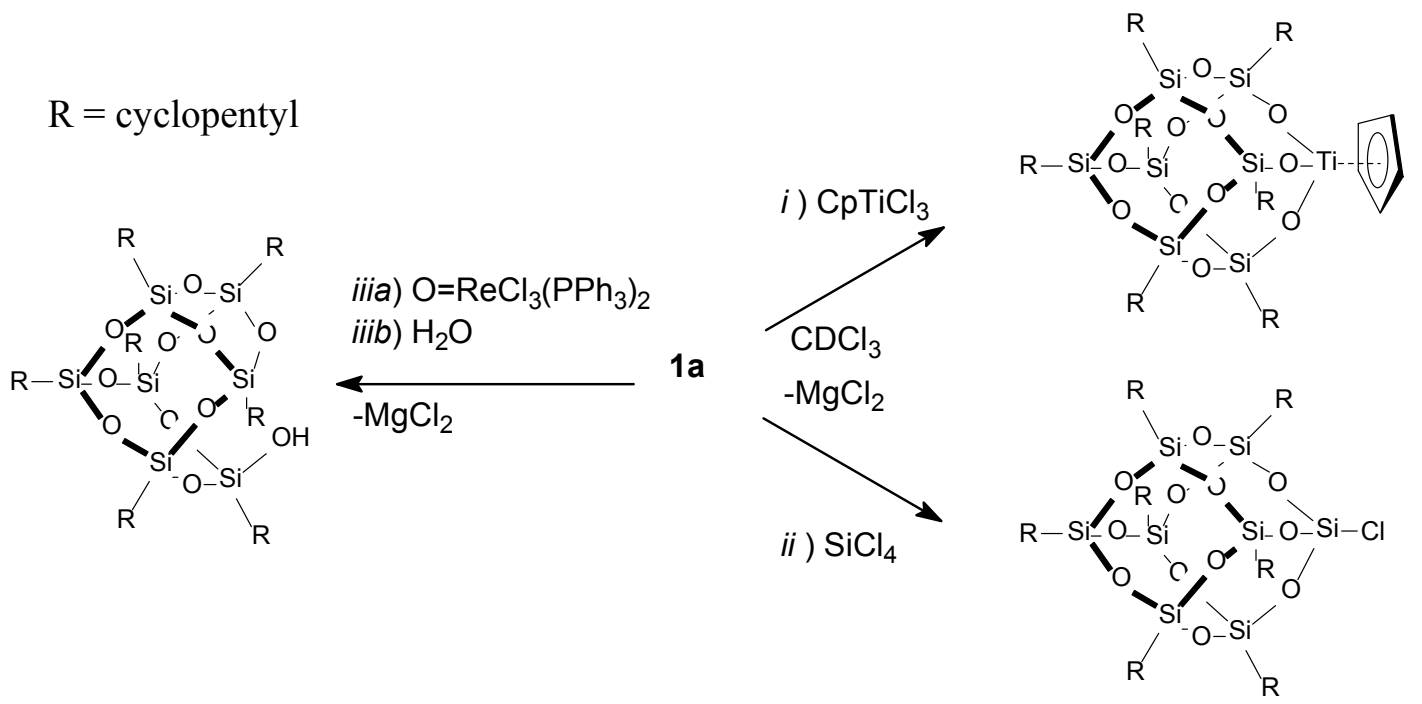

Scheme 5. Transmetallation reactions of 1a with metal chloride species leading to the expected products

However, the reaction of 1a with $\mathrm{O}=\mathrm{ReCl}_{3}\left(\mathrm{PPh}_{3}\right)_{2}$ in $\mathrm{CDCl}_{3}$ was less successful (Scheme 5, step iiia). In one day of reaction a single product was observed by NMR. After careful hydrolysis (Scheme 5, step iiib), the cyclodehydration product ${ }^{21}$ was identified. This behavior

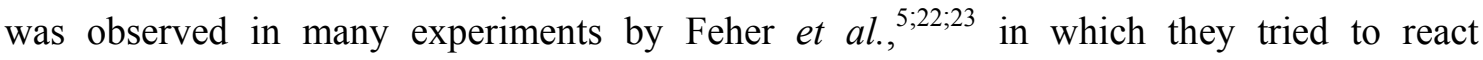
silsesquioxane trisilanols and silsesquioxide tetramethyl antimony complexes with high valent metal halides such as $\mathrm{MoO}_{2} \mathrm{Cl}_{2}$ or $\mathrm{WO}_{2} \mathrm{Cl}_{2}$, and $\mathrm{POCl}_{3}$. This indicates that $1 \mathrm{a}$ has a transmetallation behavior similar to the tetramethyl antimony substituted silsesquioxane complexes, and is therefore limited to applications not involving high valent metal species. In contrast to the tetramethylantimony substituted silsesquioxane complexes however, magnesium complex 1a is easily available. It also has some advantage over the tetramethyl antimony silsesquioxide complexes, i.e. the transmetallation byproduct $\mathrm{MgCl}_{2}$ is almost completely insoluble in non-coordinating solvents, while $\mathrm{Me}_{4} \mathrm{SbCl}$ is soluble in a variety of solvents, which could lead to equilibrium mixtures of transmetalated and non-transmetalated 
products. The absence of metal-carbon bonds in 1a, as opposed to tetramethyl antimony silsesquioxide complexes also eliminates the chance of alkyl transfer, which could happen with late transition metals.

\section{Density Functional Computations}

In order to illustrate the electron deficiency of the magnesium atom further, DFT computations were performed on 1a and other magnesium complexes to investigate the charges on the magnesium atoms and the bond lengths between magnesium and attached chloride atoms and THF molecules. Simple magnesium complexes were used as representatives of complexes with $\mathrm{Mg}-\mathrm{Cl}$ and $\mathrm{Mg}-\mathrm{O}$ (THF) bonds found in literature and which are small enough to calculate with DFT. $\mathrm{MgCl}_{2}(\mathrm{THF})_{4}(\mathbf{5 a})$ is the smallest possible complex with $\mathrm{Mg}-\mathrm{Cl}$ and $\mathrm{Mg}-\mathrm{O}$ (THF) bonds, found in literature. ${ }^{37}$ The octahedral nature of this complex makes it a less appropriate comparison to 1a, which has tetrahedrally coordinated $\mathrm{Mg}$ atoms. To make the comparison more suitable, the non-existent tetrahedral $\mathrm{MgCl}_{2}(\mathrm{THF})_{2}(\mathbf{5 b})$ was also computed. Scheme 6 shows complexes $\mathbf{5 a}$ and $\mathbf{5 b}$. Results of the DFT computations are listed in Table 2. Charges were calculated according to the Voronoi Deformation Density and Mulliken Population Analysis. In general, bond angles found in the DFT computations are consistent with the crystal structure, but bond lengths are known to increase during the structure optimization. This is consistent with the results presented here.

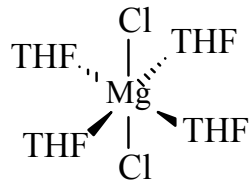

$5 \mathbf{a}$

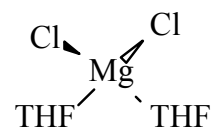

$\mathbf{5 b}$

Scheme 6. Complexes $5 \mathrm{a}$ and $5 \mathrm{~b}$ that are used in the Density Functional computations

The charges on the magnesium atoms show a clear trend. The lowest charge is found on the magnesium atom of complex 5a. A direct comparison of this complex with 1a is not possible as the magnesium atom is octahedrally surrounded instead of tetrahedrally. To show the effect of coordination number, the same complex with two THF molecules less was computed to emulate the tetrahedral coordination geometry. It is clear from Table 3 , that the high charge on complex 1a is more then a difference in coordination number, because the charge on the magnesium atom in complex $\mathbf{5 b}$ is still significantly lower then the charge on $\mathrm{Mg} 2$ of complex 1a. The high electron withdrawing properties of the silsesquioxane ligands can explain this difference in charge. This is made even clearer by the difference in charge 
between $\mathrm{Mg} 1$ and $\mathrm{Mg}$ 2, as the higher charge is on the magnesium atom bound to four siloxy groups from the silsesquioxane ligand.

Table 2. Results of the DFT Calculations on Complex 1a, $\mathrm{MgCl}_{2}(\mathrm{THF})_{4}(5 \mathrm{a}), \mathrm{MgCl}_{2}(\mathrm{THF})_{2}(5 \mathrm{~b})$.

\begin{tabular}{|c|c|c|c|c|}
\hline & Charge Mg1 & Charge Mg2 & $\begin{array}{l}\mathrm{Mg}-\mathrm{Cl} \text { bond } \\
\text { Length }\end{array}$ & $\begin{array}{l}\mathrm{Mg}-\mathrm{O}(\mathrm{THF}) \\
\text { bond length }\end{array}$ \\
\hline $1 \mathrm{a}$ & $\begin{array}{l}0.551 \\
{[1.1027]}\end{array}$ & $\begin{array}{l}0.497 \\
{[1.027]}\end{array}$ & 2.290 & 2.095 \\
\hline $5 a$ & $\begin{array}{l}0.415 \\
{[0.927]}\end{array}$ & n.a. & 2.440 & 2.251 \\
\hline $5 b$ & $\begin{array}{l}0.465 \\
{[0.9379]}\end{array}$ & n.a. & 2.309 & 2.167 \\
\hline
\end{tabular}

Charges on selected atoms, according to the Voronoi Deformation Density analysis and Mulliken Population analysis (in brackets) and selected bond lengths (in $\AA$ ).

The same trend can be seen from the bond lengths of the magnesium with the chloride and THF molecule. Going from the octahedral to the tetrahedral coordination of the magnesium atom in complex $\mathbf{5 a}$ and $\mathbf{5 b}$, a decrease in bond length is observed, for both the $\mathrm{Mg}-\mathrm{Cl}$ and the $\mathrm{Mg}-\mathrm{O}$ (THF) bonds. The $\mathrm{Mg}-\mathrm{Cl}$ and the $\mathrm{Mg}-\mathrm{O}$ (THF) bonds of complex $1 \mathrm{a}$ are even shorter, showing the higher electron deficiency of $\mathrm{Mg}$ 2, compared to the magnesium dichloride complexes $\mathbf{5 a}$ and $\mathbf{5 b}$.

\section{Reactivity of other silsesquioxane trisilanol compounds with Grignard reagents}

To investigate the steric effects of the cycloalkyl side groups on the silsesquioxane ligand, we used the trisilanol silsesquioxanes $\left(\mathrm{C}_{6} \mathrm{H}_{11}\right)_{7} \mathrm{Si}_{7} \mathrm{O}_{9}(\mathrm{OH})_{3}$ and $\left(\mathrm{C}_{7} \mathrm{H}_{13}\right)_{7} \mathrm{Si}_{7} \mathrm{O}_{9}(\mathrm{OH})_{3}$ as precursors for magnesium complexes. Immediately upon addition of the methyl magnesium chloride to a solution of the cyclohexyl substituted silsesquioxane a precipitate was formed, that proved to be insoluble in a variety of solvents (THF, ether, toluene, chloroform, dichloromethane) with which it did not react. This is an indication of the formation of a polymeric material. The opposite difference in reactivity between the comparable trisilanols was noted in aluminum silsesquioxane complexes, where the cyclohexyl substituted silsesquioxane complexes were molecularly defined while the use of cyclopentyl substituted ligands led to polymeric materials. ${ }^{38}$ Solid state NMR on the material showed that the solid material formed by precipitation during the reaction consists of a mixture of products that show wide bands in the 
solid state ${ }^{1} \mathrm{H}-\mathrm{NMR}$ and ${ }^{13} \mathrm{C}\left\{{ }^{1} \mathrm{H}\right\}$-NMR. These resonances are too wide to be assignable to any product, but broad resonances at $3.48 \mathrm{ppm}\left({ }^{1} \mathrm{H}\right)$ and 68.4 and $24.6 \mathrm{ppm}\left({ }^{13} \mathrm{C}\right)$ seem to indicate that the products still contains some THF even after extensive drying. This could either be solvent that is caught in the polymeric matrix or coordinated THF to the magnesium atoms. Due to the width of the peaks a differentiation between these species cannot be made. ${ }^{29} \mathrm{Si}$ NMR (see Figure 2) shows many resonances in the so-called T-region $\left(\mathrm{CSiO}_{3}\right)$. Four of these peaks are in the region normally assigned to silanol containing Si-groups ( $>-60 \mathrm{ppm})$, indicating that the reaction did not lead to completely substituted silanol groups. The total number of peaks in the Si-NMR spectrum again indicates a large number of products or a large number of different kinds of interconnections in the polymeric material.

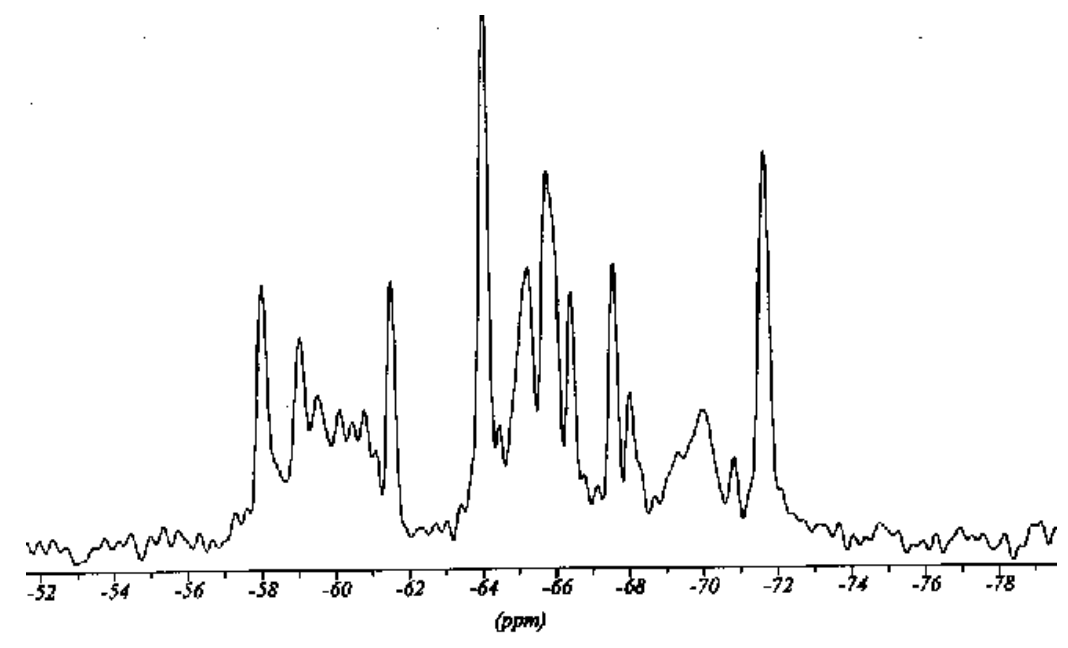

Figure 2. Solid-state ${ }^{29} \mathrm{Si}-\mathrm{NMR}$ of the insoluble material from the reaction of cyclohexyl substituted trisilanol silsesquioxane with methyl magnesium chloride

The cycloheptyl substituted silsesquioxane trisilanol showed similar behavior as the cyclopentyl silsesquioxane. A short time after the addition of the Grignard reagent, a white material that was identified as spectroscopically pure 1c, precipitated from solution in the form of microcrystals. The complex is sparsely soluble in THF, and moderately soluble in chloroform, toluene and dichloromethane. Layering THF on a chloroform solution of 1c grew crystals suitable for crystal structure determination. An ORTEP drawing of 1c is shown in Figure 3. Selected bond distances and bond angles are given in Table 3. The unit cell contains four units of the complex 1c and contains no further THF molecules in contrast to the unit cell of 1a. The reason for this is the much denser packing of the molecules in the cell (four instead of two), which leaves no space for solvent molecules. 


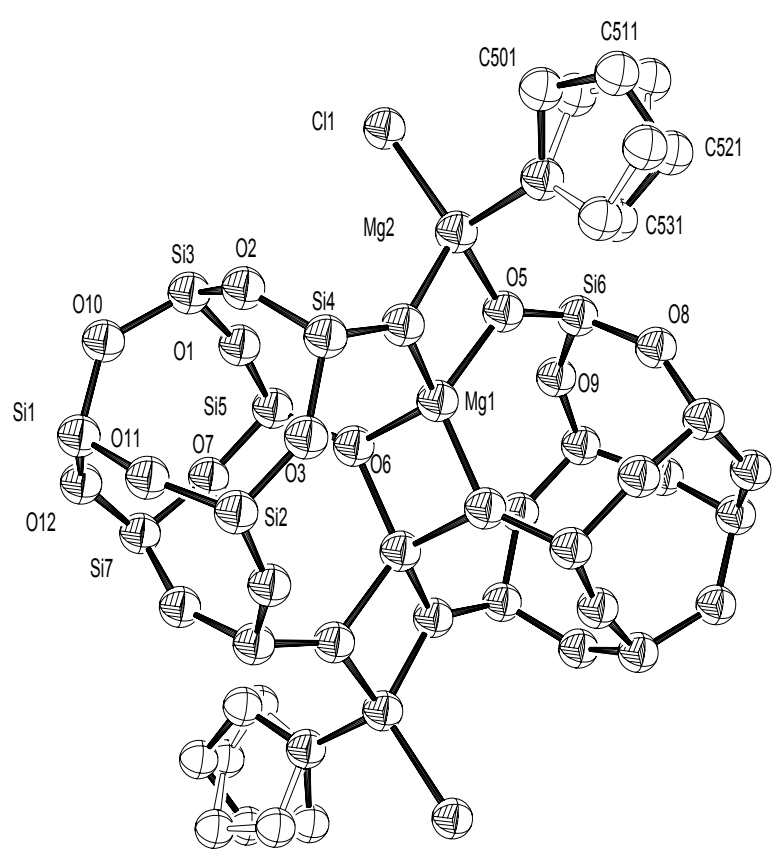

Figure 3. Structure of $\left[\left(\mathrm{C}_{7} \mathrm{H}_{13}\right)_{7} \mathrm{Si}_{7} \mathrm{O}_{12}\right]_{2} \mathrm{Mg}_{4} \mathrm{Cl}_{2}(\mathrm{THF})_{2}$ (1c) in the crystal (ORTEP drawing). The cycloheptyl groups have been omitted for clarity.

The crystal structure of 1c shows the same structural elements as its cyclopentyl-substituted congener 1a. It is also an inversion symmetric tetranuclear tetracoordinated magnesium complex with two chemically different magnesium atoms. The bonding of the magnesium atoms to the silsesquioxane ligand and peripheral ligands (chloride and THF) is identical as in 1a (vide supra). The bond lengths and bond angles are marginally different than in complex 1a and these data show that bond lengths and angles do not depend very much on the cycloalkyl side groups. Complex 1c has a very short $\mathrm{Mg} 2-\mathrm{Cl}$ bond $(2.251 \AA)$ and the bond between $\mathrm{Mg} 2$ and $\mathrm{O} 13$ (O-THF) is in the normal range, but also reasonably short. Both indicate that also in this complex the magnesium atoms are highly electropositive, just as found for the cyclopentyl substituted variant.

The cycloalkyl side groups in 1c show some differences compared to 1a. The cycloheptyl groups on silicon atoms $\mathrm{Si} 2, \mathrm{Si} 3, \mathrm{Si} 4, \mathrm{Si} 6$ and $\mathrm{Si} 7$ each show a distribution of two conformations in space. Each of these conformations has a spatial occupation of $50 \%$. The coordinated THF groups also appear in two conformations, one rotated with respect to the other about the Mg2-O131 axis. 
Table 3. Selected bond lengths $(\AA)$ and angles $\left(^{\circ}\right)$ for $1 \mathrm{c}$.

\begin{tabular}{llcl}
\hline \multicolumn{5}{c}{ Bond lengths } \\
\hline $\mathrm{Mg} 2-\mathrm{Cl}$ & $\mathrm{Mg} 1-\mathrm{O} 5 \mathrm{a}$ & $1.972(4)$ \\
$\mathrm{Mg} 2-\mathrm{O} 13$ & $1.984(4)$ & $\mathrm{Mg} 1-\mathrm{O} 6$ & $1.981(3)$ \\
$\mathrm{Mg} 2-\mathrm{O} 4$ & $1.959(4)$ & $\mathrm{Si} 4-\mathrm{O} 4$ & $1.617(3)$ \\
$\mathrm{Mg} 2-\mathrm{O} 5 \mathrm{a}$ & $1.943(4)$ & $\mathrm{Si} 5-\mathrm{O} 6$ & $1.619(3)$ \\
$\mathrm{Mg} 1-\mathrm{O} 4$ & $1.969(3)$ & $\mathrm{Si}-\mathrm{O} 5$ & $1.619(4)$ \\
& & $\mathrm{Si} 4-\mathrm{O} 4-\mathrm{Mg} 2$ & $135.3(2)$ \\
$\mathrm{Cl}-\mathrm{Mg} 2-\mathrm{O} 13$ & $105.95(12)$ & $\mathrm{Si} 5-\mathrm{O} 6-\mathrm{Mg} 1$ & $130.02(19)$ \\
$\mathrm{Cl}-\mathrm{Mg} 2-\mathrm{O} 4$ & $121.47(14)$ & $\mathrm{Si} 5-\mathrm{O} 6-\mathrm{Mg} 1 \mathrm{a}$ & $136.4(2)$ \\
$\mathrm{Mg} 2-\mathrm{O} 4-\mathrm{Mg} 1$ & $93.05(15)$ & $\mathrm{Si} 6-\mathrm{O} 5-\mathrm{Mg} 1 \mathrm{a}$ & $127.12(18)$ \\
$\mathrm{Mg} 2-\mathrm{O} 5 \mathrm{a}-\mathrm{Mg} 1$ & $93.46(15)$ & $\mathrm{Si} 6-\mathrm{O} 5-\mathrm{Mg} 2$ & $136.9(2)$ \\
$\mathrm{Mg} 1-\mathrm{O} 6-\mathrm{Mg} 1 \mathrm{a}$ & $92.50(14)$ & $\mathrm{O} 4-\mathrm{Mg} 1-\mathrm{O} 6$ & $117.42(15)$ \\
$\mathrm{O} 4-\mathrm{Mg} 2-\mathrm{O} 5 \mathrm{a}$ & $86.56(15)$ & $\mathrm{O} 5 \mathrm{a}-\mathrm{Mg} 1-\mathrm{O} 6 \mathrm{a}$ & $120.54(16)$ \\
$\mathrm{O} 4-\mathrm{Mg} 1-\mathrm{O} 5 \mathrm{a}$ & $85.50(15)$ & $87.50(14)$ & $\mathrm{O} 27.12(18)$ \\
$\mathrm{O} 6-\mathrm{Mg} 1-\mathrm{O} 6 \mathrm{a}$ & &
\end{tabular}

Standard deviations in the last decimal place are given in parentheses.

The results show that small differences in the steric ligand structure of the silsesquioxane ligand can have a tremendous impact on the structure of silsesquioxane magnesium complexes. However, the origin of these small differences between the silsesquioxane trisilanol ligands is as yet unknown. The most probable explanation is the difference in sterics of the various trisilanols in the THF solution. The cyclopentyl substituted trisilanol will have a more open structure in coordinating solvent such as THF, while the cycloheptyl substituted trisilanol has a more protected silanol environment. The open structure favors the reaction with the Grignard reagent and the subsequent fast dimerization, while the closed structure inhibits both the reaction of the alkyl magnesium chloride and the dimerization, keeping intermediate structures in solution for a longer time. In time these intermediates will also form the thermodynamically stable dimer 1c. In contrast, the cyclohexyl-substituted trisilanol will have a structure that is from a steric point of view in between the cyclopentyl and cycloheptyl substituted silsesquioxanes. This will slow down the reaction of the Grignard with the silanol units, but the steric protection is not sufficient to prevent the formation of 
higher oligomers of the magnesium complexes, nor does it allow for a fast formation of the dimer.

\section{Concluding remarks}

Reaction of silsesquioxane trisilanols with Grignard reagents leads to molecularly defined tetranuclear magnesium complexes in the case of cyclopentyl and cycloheptyl substituted silsesquioxanes. Use of the cyclohexyl substituted silsesquioxane trisilanol ligand leads to the formation of a polymer. A theory on the formation of the tetranuclear frameworks was proposed and individual steps were investigated. The first step seems to be the protolysis of the Grignard reagent with the trisilanol, followed by the second step, the rearrangement of the metal-ligand bonds and loss of $\mathrm{MgCl}_{2}$. Reaction of the last silanol groups with the Grignard reagent concludes the reaction path. Investigation of the crystal structure of the tetranuclear complexes showed that the $\mathrm{Mg}-\mathrm{Cl}$ bonds in the complexes are extremely short, an indication of a very electropositive metal center and a very strong bond. This was investigated by testing the reactivity of the complex with various reagents. Only silver triflate was able to activate the $\mathrm{Mg}-\mathrm{Cl}$ bond, but this led to degradation of the complex. Activation of the $\mathrm{Mg}-\mathrm{O}$ bonds seemed to be less difficult since complex 1a could be successfully used as a transmetallation agent to synthesize known silsesquioxane transition metal complexes. However, reactions were very slow. Density Functional computations were used to compare the magnesium silsesquioxanes with other magnesium reference compounds to get insight in the charge distribution of the magnesium atoms. Also these computations indicated a significantly higher charge on the magnesium atoms in 1a and 1c, in comparison to known magnesium compounds. 


\section{Experimental Section}

\section{General remarks.}

All operations involving air and moisture sensitive materials were performed in an inert atmosphere using standard Schlenk techniques and an argon filled glovebox. Solvents were dried over $\mathrm{Na} / \mathrm{K}$ alloy (THF, toluene) or $4 \AA$ molecular sieves $\left(\mathrm{CDCl}_{3}\right)$ and were degassed before use. Methyl magnesium chloride $(3.0 \mathrm{M}$ solution in THF, Merck), $\mathrm{SiCl}_{4}\left(99.8+\%\right.$, Acros) and $\mathrm{Cr}(\mathrm{acac})_{3}$ (97\%, Jansen-Chimica) were used as purchased. The THF adduct of dimethyl magnesium was prepared by 1,4-dioxane precipitation of magnesium dichloride from methyl magnesium chloride ${ }^{39}$ in THF and subsequent evaporation of the solvent. A benzyl magnesium chloride solution was prepared by reaction of benzylchloride (99\%, Merck) with excess magnesium turnings in diethyl ether. The concentration of the Grignard reagent was determined by quenching in excess hydrochloric acid followed by backtitration with $1.0 \mathrm{M}$ sodium hydroxide, after removal of excess magnesium turnings. The silsesquioxane ligands ${ }^{40 ; 41}\left(\eta^{5}-\mathrm{C}_{5} \mathrm{H}_{5}\right) \mathrm{TiCl}_{3}{ }^{42}$ and $\mathrm{O}=\mathrm{ReCl}_{3}\left(\mathrm{PPh}_{3}\right)_{2}{ }^{43}$ were prepared according to literature procedures. NMR spectra were recorded on VARIAN Mercury 400 and VARIAN Inova 500 spectrometers and referred to residual solvent resonances $\left({ }^{1} \mathrm{H},{ }^{13} \mathrm{C}\right)$ or $\mathrm{SiMe}_{4}\left({ }^{29} \mathrm{Si}\right)$. Transmission IR spectra were measured on a Nicolet AVATAR 360 FT-IR. The Organic Chemistry Department of the Eindhoven University of Technology (The Netherlands) carried out the elemental analyses. Crystal structures were determined at the Crystal Structure Center (University of Groningen, 1a) and The Laboratory of Crystal and Structural Chemistry (University of Utrecht, 1c)

\section{Synthesis of $\left\{\left[\left(c-\mathrm{C}_{5} \mathrm{H}_{9}\right)_{7} \mathrm{Si}_{7} \mathrm{O}_{12}\right]_{2} \mathrm{Mg}_{4} \mathrm{Cl}_{2}(\mathrm{THF})_{2}\right\} \cdot 4 \mathrm{THF}(1 \mathrm{a})$}

Method 1: $\mathrm{CH}_{3} \mathrm{MgCl}(2.4 \mathrm{~mL}, 7.20 \mathrm{mmol}$ of a $3.0 \mathrm{M}$ solution in THF) was added to a solution of the trisilanol silsesquioxane $\left(c-\mathrm{C}_{5} \mathrm{H}_{9}\right)_{7} \mathrm{Si}_{7} \mathrm{O}_{9}(\mathrm{OH})_{3}(2.10 \mathrm{~g}, 2.40 \mathrm{mmol})$ in THF $(15 \mathrm{~mL})$. Immediately after addition of the Grignard reagent, a vigorous evolution of gas took place. The resulting clear solution was stirred for 5 minutes and was subsequently left standing. After two hours spectroscopically pure 1a (2.18 g, $1.05 \mathrm{mmol}, 87 \%)$ had crystallized from the solution. Colorless block-shaped crystals suitable for crystal structure determination were obtained by recrystallization from THF. The crystals were picked from the mother liquor and were covered with paraffin oil to avoid deterioration due to loss of solvent from the crystal lattice. NMR data: ${ }^{1} \mathrm{H}(400 \mathrm{MHz}$, $\left.\mathrm{CDCl}_{3}, \delta\right): 4.05\left(\mathrm{~m}, \mathrm{THF}-\alpha-\mathrm{CH}_{2}, 8 \mathrm{H}\right), 1.95$ (m, THF- $\left.\beta-\mathrm{CH}_{2}, 8 \mathrm{H}\right), 1.9-1.3\left(\mathrm{~m}, \mathrm{CH}_{2}-\mathrm{C}_{5} \mathrm{H}_{9}, 112 \mathrm{H}\right), 1.1-0.7(\mathrm{CH}$, $\left.\mathrm{C}_{5} \mathrm{H}_{9}, 14 \mathrm{H}\right) ;{ }^{13} \mathrm{C}\left\{{ }^{1} \mathrm{H}\right\}\left(100 \mathrm{MHz}, \mathrm{CDCl}_{3}, \delta\right): 69.07$ (s, THF- $\left.\alpha-\mathrm{CH}_{2}\right)$ 28.04, 27.97, 27.78, 27.62, 27.56, 27.12, 27.03, 26.96, 26.89 (s, $\left.\mathrm{CH}_{2}-\mathrm{C}_{5} \mathrm{H}_{9}\right), 25.42$ (s, THF- $\left.\beta-\mathrm{CH}_{2}\right), 24.49,24.13,23.79,22.53,22.07$ (s, $C \mathrm{H}-\mathrm{C}_{5} \mathrm{H}_{9}$, ratio $1: 2: 1: 2: 1) ;{ }^{29} \mathrm{Si}\left\{{ }^{1} \mathrm{H}\right\} \quad\left(99.3 \mathrm{MHz}, \mathrm{CDCl}_{3}, 0.02 \mathrm{M} \mathrm{Cr}(\mathrm{acac})_{3}, \delta\right):-63.83,-68.59,-70.01,-70.65,-75.52$ (s, $\mathrm{C}_{5} \mathrm{H}_{9} \mathrm{SiO}_{3}$, ratio 2:1:1:2:1). Anal. Calcd. for $\mathrm{C}_{78} \mathrm{H}_{142} \mathrm{Cl}_{2} \mathrm{Mg}_{4} \mathrm{O}_{26} \mathrm{Si}_{14} \cdot 2\left(\mathrm{C}_{4} \mathrm{H}_{8} \mathrm{O}\right): \mathrm{C} 45.54 \%$, H 6.96\%. Found C 42. $90 \%$, H $6.37 \%$ (Possibly due to formation of silicon carbides, no satisfying elemental analyses could be obtained)

Method 2: $\mathrm{CH}_{3} \mathrm{MgCl}(0.40 \mathrm{~mL}, 1.14 \mathrm{mmol}$ of a $3.0 \mathrm{M}$ solution in THF) was added to 2 (1.12 g, $1.20 \mathrm{mmol})$, dissolved in THF $(20 \mathrm{~mL})$. Immediately after the addition of the $\mathrm{CH}_{3} \mathrm{MgCl}$, vigorous evolution of gas was observed and the solution was stirred for 30 minutes. After concentration of the solution in vacuo and 
subsequent heating and slow cooling, large block-shaped colorless crystals of spectroscopically pure 1a $(0.87 \mathrm{~g}$, $0.43 \mathrm{mmol}, 71 \%$ ) were formed.

Method 3: Benzyl magnesium chloride $\left(2.1 \mathrm{~mL}, 3.42 \mathrm{mmol}\right.$ of $1.65 \mathrm{M}$ solution in $\left.\mathrm{Et}_{2} \mathrm{O}\right)$ was added to a solution of the trisilanol silsesquioxane $\left(c-\mathrm{C}_{5} \mathrm{H}_{9}\right)_{7} \mathrm{Si}_{7} \mathrm{O}_{9}(\mathrm{OH})_{3}(1.00 \mathrm{~g}, 1.14 \mathrm{mmol})$ in THF $(15 \mathrm{~mL})$ and the solution was stirred for a few minutes. Over the course of hours, spectroscopically pure 1a crystallized from solution.

\section{Reaction of $\left(c-\mathrm{C}_{6} \mathrm{H}_{11}\right)_{7} \mathrm{Si}_{7} \mathrm{O}_{9}(\mathrm{OH})_{3}$ with methylmagnesium chloride (1b)}

$\mathrm{CH}_{3} \mathrm{MgCl}(1.9 \mathrm{~mL}$ of a $2.6 \mathrm{M}$ solution in THF, $5.0 \mathrm{mmol})$ was added to a solution of the trisilanol silsesquioxane $\left(\mathrm{c}-\mathrm{C}_{6} \mathrm{H}_{11}\right)_{7} \mathrm{Si}_{7} \mathrm{O}_{9}(\mathrm{OH})_{3}(1.45 \mathrm{~g}, 1.48 \mathrm{mmol})$ in THF $(20 \mathrm{~mL})$. Immediately after the addition of the Grignard reagent, a vigorous gas evolution took place and the solution became cloudy. This suspension was stirred for 30 minutes and then left standing till all powder had settled. The solvent was then separated by filtration and the remaining white power was dried in vacuo. Yield $1.0 \mathrm{~g}$. Solid state NMR data: ${ }^{1} \mathrm{H}(500 \mathrm{MHz}$,

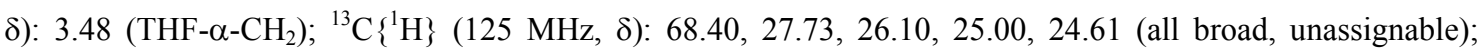

${ }^{29} \mathrm{Si}\left\{{ }^{1} \mathrm{H}\right\}(99.3 \mathrm{MHz}, \delta):-58.27,-59.15,-56.56,-60.03,-63.84,-64.92,-65.17,-65.75,-66.41,-67.53,-68.04,-$ $70.14,-70.78,-71.54$ (no clear intensities, unassignable)

\section{Synthesis of $\left\{\left[\left(c-\mathrm{C}_{7} \mathrm{H}_{13}\right)_{7} \mathrm{Si}_{7} \mathrm{O}_{12}\right]_{2} \mathrm{Mg}_{4} \mathrm{Cl}_{2}(\mathrm{THF})_{2}\right\} \cdot 4$ THF (1c)}

$\mathrm{CH}_{3} \mathrm{MgCl}(1.90 \mathrm{~mL}$ of a $2.6 \mathrm{M}$ solution in THF, $4.94 \mathrm{mmol})$ was added to a suspension of the trisilanol silsesquioxane $\left(c-\mathrm{C}_{7} \mathrm{H}_{13}\right)_{7} \mathrm{Si}_{7} \mathrm{O}_{9}(\mathrm{OH})_{3}(1.75 \mathrm{~g}, 1.63 \mathrm{mmol})$ in THF $(30 \mathrm{~mL})$. Immediately after the addition of the Grignard reagent, a vigorous gas evolution took place and the silsesquioxane trisilanol dissolved. The clear solution was stirred for 5 minutes, and was left standing for 3 hours. The white microcrystalline material that had crystallized from this solution was filtered off and dried in vacuo. Total yield $0.95 \mathrm{~g}(0.38 \mathrm{mmol}, 48 \%)$. Layering of THF on top of a chloroform solution yielded colorless block-shaped crystals suitable for crystal structure determination. The crystals were picked from the mother liquor and were covered with paraffin oil to avoid deterioration due to loss of solvent from the crystal lattice. NMR data: ${ }^{1} \mathrm{H}\left(400 \mathrm{MHz}, \mathrm{CDCl}_{3}, \delta\right): 3.82(\mathrm{~m}$, THF- $\left.\alpha-\mathrm{CH}_{2}, 8 \mathrm{H}\right), 1.92$ (m, THF- $\left.\beta-\mathrm{CH}_{2}, 8 \mathrm{H}\right), 1.9-1.1\left(\mathrm{~m}, \mathrm{CH}_{2}-\mathrm{C}_{7} \mathrm{H}_{13}, 182 \mathrm{H}\right), 1.1-0.4\left(\mathrm{CH}, \mathrm{C}_{7} \mathrm{H}_{13}, 14 \mathrm{H}\right)$; ${ }^{13} \mathrm{C}\left\{{ }^{1} \mathrm{H}\right\}\left(100 \mathrm{MHz}, \mathrm{CDCl}_{3}, \delta\right): 68.50\left(\mathrm{~s}, \mathrm{THF}-\alpha-\mathrm{CH}_{2}\right)$ 30.38, 30.25, 31.00, 30.04, 29.39, 28.96, 28.64, 28.52, 28.49, 27.99, 27.95, 27.90, 27.78 (s, $\left.\mathrm{CH}_{2}-\mathrm{C}_{7} \mathrm{H}_{13}\right), 25.52$ (s, THF- $\left.\beta-C \mathrm{H}_{2}\right), 26.76,26.50,26.31,25.81,23.64$ (s, $\mathrm{CH}-\mathrm{C}_{7} \mathrm{H}_{13}$, ratio $\left.1: 1: 1: 2: 2\right) ;{ }^{29} \mathrm{Si}\left\{{ }^{1} \mathrm{H}\right\}\left(99.3 \mathrm{MHz}, \mathrm{CDCl}_{3}, 0.02 \mathrm{M} \mathrm{Cr}(\mathrm{acac})_{3}\right)$ : due to the low solubility of $1 \mathrm{c}$ it was nog possible to obtain a clear NMR spectrum, although the peaks intensities roughly estimate. Anal. Calcd. for $\mathrm{C}_{106} \mathrm{H}_{198} \mathrm{Cl}_{2} \mathrm{Mg}_{4} \mathrm{O}_{26} \mathrm{Si}_{14}$ : C $51.96 \%, \mathrm{H} 8.15 \%$. Found $\mathrm{C} 47.34 \%, \mathrm{H} 7.98 \%$ (Possibly due to formation of silicon carbides, no satisfying elemental analyses could be obtained)

\section{Synthesis of $\left\{\left(c-\mathrm{C}_{5} \mathrm{H}_{9}\right)_{7} \mathrm{Si}_{7} \mathrm{O}_{9}\left(\mathrm{O}_{2} \mathrm{Mg}\right)(\mathrm{OH})\right\}_{2} \cdot(\mathrm{THF})(2)$.} $\left(\mathrm{CH}_{3}\right)_{2} \mathrm{Mg} \cdot \mathrm{THF}(0.32 \mathrm{~g}, 2.53 \mathrm{mmol})$ in THF $(5 \mathrm{~mL})$ was added to a cooled solution $\left(-60^{\circ} \mathrm{C}\right)$ of the trisilanol silsesquioxane $\left(c-\mathrm{C}_{5} \mathrm{H}_{9}\right)_{7} \mathrm{Si}_{7} \mathrm{O}_{9}(\mathrm{OH})_{3}(2.20 \mathrm{~g}, 2.50 \mathrm{mmol})$ in THF $(40 \mathrm{~mL})$. Immediately after the addition of the dialkyl magnesium reagent, a vigorous gas evolution took place. The resulting clear solution was stirred for overnight. Evaporation to dryness yielded 2 as a white powder $\left(2.3 \mathrm{~g}, 2.37 \mathrm{mmol}, 98 \%\right.$ \%). NMR data: ${ }^{1} \mathrm{H}(400$ $\mathrm{MHz}_{\mathrm{CDCl}}, \mathrm{C}$ ): 3.8 (m, THF- $\left.\alpha-\mathrm{CH}_{2}, 4 \mathrm{H}\right), 2.9$ (s, $\left.\mathrm{SiOH}, 2 \mathrm{H}\right), 1.9$ (m, THF- $\left.\beta-\mathrm{CH}_{2}, 4 \mathrm{H}\right), 1.8-1.2\left(\mathrm{~m}, \mathrm{CH}_{2}-\mathrm{C}_{5} \mathrm{H}_{9}\right.$, 
112H), 1.1-0.7 (m, CH-C $\left.{ }_{5} \mathrm{H}_{9}, 14 \mathrm{H}\right) ;{ }^{13} \mathrm{C}\left\{{ }^{1} \mathrm{H}\right\}\left(100 \mathrm{MHz}, \mathrm{CDCl}_{3}, \delta\right): 27.36-26.85\left(\mathrm{~s}, \mathrm{CH}_{2}-\mathrm{C}_{5} \mathrm{H}_{9}\right), 25.57$ (s, THF-

$\beta-C H 2), 22.81,22.17,22.15,22.01,21.46$ (s, CH-C ${ }_{5} \mathrm{H}_{9}$, ratio. 2:1:1:2:1); ${ }^{29} \mathrm{Si}\left\{{ }^{1} \mathrm{H}\right\}\left(99.3 \mathrm{MHz}, \mathrm{CDCl}_{3}, 0.02 \mathrm{M}^{2}\right.$

$\left.\mathrm{Cr}(\mathrm{acac})_{3}, \delta\right):-53.66,-55.08,-55.41,-64.62,-64.85\left(\mathrm{~s}, \mathrm{C}_{5} \mathrm{H}_{9} \mathrm{SiO}_{3}\right.$, ratio 1:1:2:1:2); IR ( $\left.\mathrm{KBr}, \operatorname{disc}\right): 3661 \mathrm{~m}$

$(v(\mathrm{SiOH}))$; Anal. Calcd. for $\left(\mathrm{C}_{35} \mathrm{H}_{64} \mathrm{MgO}_{12} \mathrm{Si}_{7}\right)_{2} \cdot\left(\mathrm{C}_{4} \mathrm{H}_{8} \mathrm{O}\right)$ : C $47.59 \%$, H 7.34 \%. Found C $47.21 \%$, H $7.23 \%$.

\section{Attempts to substitute the chloride atom on 1a}

All reactions were performed in a standard manner and are outlined in detail for one example. Butyl lithium $\left(0.50 \mathrm{~mL}\right.$ of a $2.5 \mathrm{M}$ solution in hexanes) is added to butanol $(90 \mathrm{mg}, 1.22 \mathrm{mmol})$ in $20 \mathrm{~mL} \mathrm{THF}$ at $-40{ }^{\circ} \mathrm{C}$. The resulting solution is allowed to heat up to room temperature and is subsequently added to a solution of 1 a (1.25 $\mathrm{g}, 0.61 \mathrm{mmol}$ ) in $20 \mathrm{~mL}$ THF. After heating to reflux, the suspension is left stirring for $16 \mathrm{~h}$. The solvent is then removed in vacuo, and the residue is extracted with ether. Comparison of the NMR spectra of the compound after recrystallisation from THF shows that no reaction took place. Similar behavior was observed upon reaction with $\mathrm{MeOH}, \mathrm{LiOMe}, \mathrm{LiN}\left(\mathrm{SiMe}_{3}\right)_{2}, \mathrm{MeMgCl}$ and $\mathrm{HN}^{\mathrm{i}} \mathrm{Pr}_{2}$.

\section{Reaction of 1a with silver triflate}

$1 \mathrm{a}(1.39 \mathrm{~g}, 0.68 \mathrm{mmol})$ was dissolved in $30 \mathrm{~mL}$ toluene and $\mathrm{AgOS}\left(\mathrm{O}_{2}\right) \mathrm{CF}_{3}(\operatorname{AgOTf}, 0.35 \mathrm{~g}, 1.36 \mathrm{mmol})$ in 10 $\mathrm{mL}$ THF was added dropwise to this solution. Immediately upon addition of the silver triflate, a white precipitate was formed. After 30 minutes stirring at room temperature, the mixture was filtered over Celite, and the clear colourless solution was concentrated. After 16 hours, $0.70 \mathrm{~g}$ of a white microcrystalline material was formed. No well-resolved NMR data could be obtained.

\section{NMR tube transmetallation reactions of 1a}

All NMR tube reactions were performed in a similar manner. About $30 \mathrm{mg}$ of complex 1a and an equimolar amount of the other reactant were weighed out in a glovebox and dissolved in $1 \mathrm{~mL} \mathrm{CDCl}_{3}$. This solution was transferred to an NMR tube, which was then sealed to prevent contact with air. Multinuclear NMR $\left({ }^{1} \mathrm{H}\right.$ and $\left.{ }^{13} \mathrm{C}\right)$ was used to follow the reaction. The reaction of $\left(\eta^{5}-\mathrm{C}_{5} \mathrm{H}_{5}\right) \mathrm{TiCl}_{3}$ with $\mathbf{1 a}$ could be followed by the resonance of the cyclopentadienyl ligand. NMR data: ${ }^{1} \mathrm{H}\left(400 \mathrm{MHz}, \mathrm{CDCl}_{3}, \delta\right): \mathrm{t}=0,7.05\left(\mathrm{~s}, \eta^{5}-\mathrm{C}_{5} H_{5} \mathrm{TiCl}_{3}\right) ; \mathrm{t}=20 \mathrm{~min}, 7.05$ (s, $\left.\eta^{5}-\mathrm{C}_{5} H_{5} \mathrm{TiCl}_{3}\right), 6.92,6.73,6.58,6.47,6.44$ (all s, intermediate products); $\mathrm{t}=16 \mathrm{~h}, 7.05\left(\mathrm{~s}, \eta^{5}-\mathrm{C}_{5} H_{5} \mathrm{TiCl}_{3}\right)$, $6.92,6.86,6.77,6.75,6.73,6.66,6.68,6.60,6.55,6.47,6.44$ (all s, intermediate products); $\mathrm{t}=2$ days, 6.48 (s, $\eta^{5}$ $\left.\mathrm{C}_{5} \mathrm{H}_{5} \mathrm{TiO}_{3}\right)$. Products of the reaction of $\mathbf{1 a}$ with $\mathrm{SiCl}_{4}$ or $\mathrm{O}=\mathrm{ReCl}_{3}\left(\mathrm{PPh}_{3}\right)_{2}$ were identical to those prepared in an alternative way, viz. via amine hydrochloride elimination.

\section{X-ray diffraction: Crystal and Molecular Structure of 1a.}

Diffraction data were collected on a Bruker SMART CCD area detector diffractometer. The structure was solved by direct methods using the program SHELXTL. ${ }^{44}$ Hydrogen atoms were included in the final refinement riding on their carrier atoms. The positional and anisotropic displacement parameters for the non-hydrogen atoms and isotropic displacement parameters for hydrogen atoms were refined on $F^{2}$ with full-matrix leastsquares procedures. Crystal data and numerical details on data collection and refinement are given in Table 4. 


\section{X-ray diffraction: Crystal and Molecular Structure of 1c.}

Intensity data for 1c were collected on a Nonius KappaCCD diffractometer with rotating anode (Mo $K \alpha, \lambda=$ $0.71073 \AA$ ) at $150 \mathrm{~K}$. An absorption correction was considered unnecessary in all cases. The structures were solved by direct methods (SIR97) and refined on $F^{2}$ by least-squares procedures using SHELXL97. ${ }^{4}$ All nonhydrogen atoms were refined with anisotropic displacement parameters. Hydrogen atoms were constrained to idealized geometries and allowed to ride on their carrier atoms with an isotropic displacement parameter related to the equivalent displacement parameter of their carrier atoms. Structure validation and molecular graphics preparation were performed with the PLATON package. The asymmetric unit contains half of the centrosymmetric silsesquioxane complex. Five of the seven independent cycloheptyl rings, as well as the one independent coordinated THF molecule, are disordered over two conformations. The crystal structure also contains large voids $\left(543 \AA^{3}\right)$ filled with disordered solvent molecules $\left(\mathrm{CHCl}_{3}\right.$ and THF); their contribution to the structure factors was ascertained by back-Fourier transformation using PLATON/CALC SQUEEZE (196 e/unit cell).

Table 4. Crystal data and details of the structure determination for $\mathbf{1 a}$ and $\mathbf{1 c}$

\begin{tabular}{lll}
\hline & $\mathbf{1 a}$ & $\mathbf{1 c}$ \\
\hline Formula & $\mathrm{C}_{78} \mathrm{H}_{142} \mathrm{Cl}_{2} \mathrm{Mg}_{4} \mathrm{O}_{26} \mathrm{Si}_{14} \cdot 6\left(\mathrm{C}_{4} \mathrm{H}_{8} \mathrm{O}\right)$ & $\mathrm{C}_{106} \mathrm{H}_{198} \mathrm{Cl}_{2} \mathrm{Mg}_{4} \mathrm{O}_{26} \mathrm{Si}_{14}$ \\
Formula Weight, g.mol ${ }^{-1}$ & 2489.93 & 2450.04 \\
Space group & $\mathrm{P} 2_{1} / \mathrm{n},(\mathrm{No} .14)$ & $\mathrm{C} 2 / \mathrm{c}(\mathrm{No} .15)$ \\
$\mathrm{a}, \AA$ & $15.744(1)$ & $25.8555(5)$ \\
$\mathrm{B}, \AA$ & $26.526(2)$ & $16.0707(2)$ \\
$\mathrm{C}, \AA$ & $16.917(1)$ & $32.1226(5)$ \\
$\beta$, deg & $113.229(2)$ & $96.9490(4)$ \\
$\mathrm{V}, \AA^{3}$ & $6492.3(8)$ & $13249.4(3)$ \\
$\mathrm{Z}$ & 2 & 4 \\
$\mathrm{~T},{ }^{\circ} \mathrm{C}$ & -100 & -123 \\
$\rho_{\text {calc }}, \mathrm{g} . \mathrm{cm}{ }^{-3}$ & 1.274 & 1.228 \\
$\lambda(\mathrm{MoK} \alpha)$, & 0.71073 & 0.71073 \\
$\mu, \mathrm{cm}^{-1}$ & 2.7 & 2.58 \\
$\mathrm{R}(\mathrm{F})^{\mathrm{a}}$ & 0.0628 & 0.0775 \\
$\mathrm{R}_{\mathrm{w}}\left(\mathrm{F}^{2}\right)^{\mathrm{b}}$ & 0.1732 & 0.2241 \\
\hline
\end{tabular}

${ }^{a} R(F)=\Sigma\left(|| F_{o}|-| F_{c} \mid\right) / \Sigma\left|F_{o}\right|$ for 6327 reflections obeying $F_{o} \geq 4.0 \sigma\left(F_{o}\right) .{ }^{b} w R\left(F^{2}\right)=\left[\Sigma\left[\mathrm{w}\left(F_{o}{ }^{2}-F_{c}^{2}\right)^{2}\right] /\right.$ $\left.\Sigma\left[w\left(\mathrm{~F}_{\mathrm{o}}{ }^{2}\right)^{2}\right]\right]^{1 / 2}$ for 11045 reflections with $F_{o}{ }^{2} \geq 0$

\section{Computational details}

Density Functional Theory (DFT) forms the basis of our computations as implemented in the Amsterdam density functional $\left(\mathrm{ADF}^{45}\right)$ code. The exchange correlation functionals in the local-density approximation (Vosko, Wilk and Nusair ${ }^{46}$ ) were augmented by generalized gradient approximations to the exchange $\left(\right.$ Becke $\left.^{47}\right)$ and correlation $\left(\right.$ Perdew $^{48}$ ). All the corrections were used in the self-consistent computations. A double $\zeta$ basis set with polarization function for carbon, oxygen, and chlorine was used with a frozen core of the 1s electrons. 
For magnesium and silicon a double $\zeta$ basis set with polarization function and a $2 \mathrm{p}$ frozen core has been chosen. A quasi Newtonian approach ${ }^{49}$ to geometry optimization is combined with the direct inversion in the iterative subspace method ${ }^{50}$ (DIIS). Full geometry optimization has been used in all computations in this work. The convergence criteria used in these computations are $10^{-3}$ Hartree for the energy, $5^{*} 10^{-3}$ Hartree/Ångstrom for the gradients and $5^{*} 10^{-3}$ Angstrom for the Cartesian displacement. ADF code makes use of the natural symmetry properties of the different clusters. The silsesquioxanes were approximated by substitution of the large cyclopentyl groups on the silicon atoms by hydrogen atoms. 


\section{Bibliography}

[1] Abbenhuis,H.C.L. Chem.Eur.J. 2000, 6, 25-32.

[2] Feher,F.J.; Newman,D.A.; Walzer,J.F. J.Am.Chem.Soc. 1989, 111, 1741-1748.

[3] Krijnen,S.; Harmsen,R.J.; Abbenhuis,H.C.L.; Van Hooff,J.H.; Van Santen,R.A. Chem.Commun. 1999, 501-502.

[4] Feher,F.J.; Phillips,S.H. J.Organomet.Chem. 1996, Vol 521, 401-403.

[5] Feher,F.J.; Newman,D.A. J.Am.Chem.Soc. 1990, 112, 1931-1936.

[6] Feher,F.J. J.Am.Chem.Soc. 1986, 108, 3850-3852.

[7] Duchateau,R.; Cremer,U.; Harmsen,R.J.; Mohamud,S.I.; Abbenhuis,H.C.L.; Van Santen,R.A.; Meetsma,A.; Thiele,S.K.; Van Tol,M.F.; Kranenburg,M. Organometallics 1999, 18, 5447-5459.

[8] Buys,I.E.; Hambley,T.W.; Houlton,D.J.; Maschmeyer,T.; Masters,A.F.; Smith,A.K. J.Mol.Catal.A 1994, 86, 309-318.

[9] Maxim,N.; Abbenhuis,H.C.L.; Stobbelaar,P.J.; Mojet,B.L.; Van Santen,R.A. Phys.Chem.Chem.Phys. 1999, 1, 4473-4477.

[10] Abbenhuis,H.C.L.; Van Herwijnen,H.W.; Van Santen,R.A. Chem.Commun. 1996, 1941-1942.

[11] Feher,F.J.; Walzer,J.F. Inorg.Chem. 1991, 30, 1689-1694.

[12] Abbenhuis,H.C.L.; Vorstenbosch,M.L.; Van Santen,R.A.; Smeets,W.J.; Spek,A.L. Inorg.Chem. 1997, 36, 6431-6433.

[13] Liu,J.C. Chem.Commun. 1996, 1109-1110.

[14] Feher,F.J.; Blanski,R.L. J.Am.Chem.Soc. 1992, 114, 5886-5887.

[15] Duchateau,R.; Abbenhuis,H.C.L.; Van Santen,R.A.; Thiele,S.K.; Van Tol,M.F. Organometallics 1998, $17,5222-5224$.

[16] Duchateau,R.; Abbenhuis,H.C.L.; Van Santen,R.A.; Meetsma,A.; Thiele,S.K.; Van Tol,M.F. Organometallics 1998, 17, 5663-5673.

[17] Feher,F.J.; Tajima,T.L. J.Am.Chem.Soc. 1994, 116, 2145-2146.

[18] Abbenhuis,H.C.L.; Krijnen; Van Santen,R.A. Chem.Commun. 1997, 331-332.

[19] Vorstenbosch, M. L. W. Alkene epoxidation with silsesquioxane based chromium and titanium complexes. 2002

[20] Maschmeyer,T.; Klunduk,M.C.; Martin,C.M.; Shephard,D.S.; Thomas,J.M.; Johnson,B.F. Chem.Commun. 1997, 1847-1848.

[21] Klunduk,M.C.; Maschmeyer,T.; Thomas,J.M.; Johnson,B.F. Chem.Eur.J. 1999, 5, 1481-1485.

[22] Feher,F.J.; Budzichowski,T.A.; Rahimian; Ziller,J.W. J.Am.Chem.Soc. 1992, 114, 3859-3866.

[23] Feher,F.J.; Rahimian,K.; Budzichowski,T.A. Organometallics 1995, 14, 3920-3926.

[24] Feher,F.J.; Phillips,S.H.; Ziller,J.W. Chem.Commun. 1997, 829-830.

[25] Annand,J.; Aspinall,H.C.; Steiner,A. Inorg.Chem. 1999, 38, 3941-3943.

[26] Bickelhaupt,F. Chem.Soc.Rev. 1999, 28, 17-23.

[27] Liu,J.C. Appl.Organomet.Chem. 1999, 13, 295-302.

[28] Either the absence of a coordinating Lewis base, such as THF or the difference in steric hindrance between the different silsesquioxane ligands could cause this difference in behavior.

[29] Bocelli,G.; Cantoni,A.; Sartori,G.; Maggi,R.; Bigi,G. Chem.Eur.J. 1997, 3, 1269

[30] Willard,G.; Salvino,J.M. J.Chem.Soc.Chem.Commun. 1986, 153

[31] Holloway,C.E.; Melnik,M. J.Organomet.Chem. 1994, 465, 1-33.

[32] Atwood,D.A.; Cowley,A.H.; Jones,R.A. Organometallics 1993, 12, 236

[33] Chisholm,M.H.; Huffman,J.C.; Phomphrai,K. J.Chem.Soc.Dalton Trans. 2001, 222-224.

[34] Chisholm,M.H.; Eilerts,N.W.; Huffman,J.C.; Iyer,S.S.; Pacold,M.; Phomphrai,K. J.Am.Chem.Soc. 2000, $122,11845-11854$.

[35] Smet,P.; Riondato,J.; Pauwels,T.; Moens,L.; Verdonck,L. Inorg.Chem.Comm. 2000, 3, 557-562.

[36] Feher,F.J.; Weller,K.; Schwab,J.J. Organometallics 1995, 14, 2009-2017.

[37] Handlir,K.; Holecek,J.; Benes,L. Collect.Czech.Chem.Commun. 1985, 50, 2422

[38] Duchateau,R.; Harmsen,R.J.; Abbenhuis,H.C.L.; Van Santen,R.A.; Meetsma,A.; Thiele,S.K.; Kranenburg,M. Chem.Eur.J. 1999, 5, 3130-3135.

[39] Ashby,E.C.; Arnott,R.C. J.Organomet.Chem. 1968, 14, 1-11.

[40] Brown,J.F., Jr.; Vogt,L.H., Jr. J.Am.Chem.Soc. 1965, 87, 4313-4317.

[41] Feher,F.J.; Budzichowski,T.A.; Blanski,R.L.; Weller,K.J.; Ziller,J.W. Organometallics 1991, 10, 25262528.

[42] Winter,C.H.; Zhou,X.-X.; Dobbs,D.A.; Heeg,M.J. Organometallics 1991, 10, 210

[43] Lebuis,A.-M.; Beauchamp,A.L. Can.J.Chem. 1993, 71, 441

[44] Sheldrick, G. M. SHELXL-97. Program for the refinement of crystal structures. 1997.

[45] ADF. (2.3.0). 1997. Theoretical Chemistry, Universty of Amsterdam 
[46] Vosko,S.H.; Wilk,L.; Nusair,M. Can.J.Phys. 1980, 58, 1200

[47] Becke,A.D. Phys.Rev.A. 1988, 38, 3098

[48] Perdew,J.P. Phys.Rev.B. 1986, 22, 8822

[49] Fan,L.; Ziegler,T. J.Chem.Phys. 1991, 95, 7401

[50] Fischer,T.H.; Almhöf,J. J.Chem.Phys. 1992, 13, 295-302. 


\section{Synthesis and reactivity of zinc silsesquioxane complexes}

12 eaction of dialkyl zinc compounds with silsesquioxane trisilanols yield a series of tetrahedrally and trigonally surrounded zinc atoms are present with protolyzable alkyl groups on the outer, trigonal zinc atoms. These complexes have been structurally and spectroscopically investigated. From crystal structure analysis of these complexes and comparison with related magnesium silsesquioxane complexes, we conclude that the unique structural motif of the complexes is common among silsesquioxane complexes with divalent metals. Based on an alternative synthesis method we propose a mechanism of formation for this type of complexes. The reactivity of the zinc alkyl bond was tested by reaction with various alcohols with and without intramolecular coordinating moieties. When using the latter type of alcohols, polymeric gel-like materials were formed in solution by selfaggregation and molecular compounds could no longer be isolated. 


\section{Introduction}

Over the last years, the interest in low coordinated zinc alkyl complexes has gained

substantial interest. ${ }^{1-7}$ The current interest has multiple reasons. On the one hand insight into the fundamental aspects of low-coordinate metal species is sought, where the ligand surrounding can induce some special reactivity effects. On the other hand these species are easily converted into active catalysts for the synthesis of specialty plastics, such as polylactides or polylactones. ${ }^{8-14}$ The most direct way to synthesize these usually threecoordinated planar zinc species is by direct reaction of a ligand with a alkyl zinc precursor in a non-protic and non-coordinating solvent. ${ }^{5 ; 6}$ Ligands should posses some steric bulk to prevent dimerization of the complex by bridging over the alkyl group, although this bridging behavior is not common. Reaction of a lithiated ligand with a zinc halide in a noncoordinating solvent is also a convenient way to produce planar zinc species, although this route facilitates the formation of dimeric structures by bridging of the halide groups and possibly the inclusion of lithium chloride salt in the complex. ${ }^{4 ; 6}$

Initiation of the polymerization of lactide is usually slow, mainly because of the lower nucleophilicity of the alkyl group compared to the more commonly applied zinc alkoxides. For this reason the planar zinc complexes are converted to the zinc alkoxide-complexes by reaction with either alcohols (for the zinc alkyl complexes) or lithium alkoxides (zinc halide complexes). The use of very sterically hindered alcohols, such as 2,6-disubstituted phenols can retain the low coordinated state of the zinc atom. ${ }^{2}$ Zinc alkoxides mostly exist in a dimeric form by bridging through the alkoxides groups, but the action of coordinating solvents such as THF can form monomeric species, although these can only be observed in solution. ${ }^{6}$

In this chapter, we describe the reaction of dialkyl zinc complexes with silsesquioxane trisilanol ligands in toluene. The resulting complexes are shown to have three-coordinate and four-coordinate zinc atoms. The reactivity of these complexes towards protic substances is investigated and the complexes are tested in the polymerization of lactide. The reaction of methyl zinc chloride with a silsesquioxane trisilanol was also investigated and the product was shown to be analogous to the magnesium complexes described in Chapter 2. 


\section{Synthesis of alkyl zinc silsesquioxane complexes}

The protolysis of two equivalents of dimethyl zinc with the silsesquioxane trisilanol ligands $\left(i-\mathrm{C}_{4} \mathrm{H}_{9}\right)_{7} \mathrm{Si}_{7} \mathrm{O}_{9}(\mathrm{OH})_{3},\left(c-\mathrm{C}_{5} \mathrm{H}_{9}\right)_{7} \mathrm{Si}_{7} \mathrm{O}_{9}(\mathrm{OH})_{3},\left(c-\mathrm{C}_{6} \mathrm{H}_{11}\right)_{7} \mathrm{Si}_{7} \mathrm{O}_{9}(\mathrm{OH})_{3}$ and $\left(c-\mathrm{C}_{7} \mathrm{H}_{13}\right)_{7} \mathrm{Si}_{7} \mathrm{O}_{9}(\mathrm{OH})_{3}$ in toluene proceeds vigorously with the rapid release of methane from the solution in only a few minutes (See Scheme 1). After stirring the solution for 30 minutes, large crystals of 1a-d could be obtained almost quantitatively by heating the solution and allowing it to cool down slowly to room temperature. The analogous use of diethyl zinc as source for the metal yields similar complexes with a zinc ethyl group instead of a zinc methyl group, although the speed of the reaction is significantly lower. Compounds 1a-d and 1a' are air and moisture sensitive solids, but they can be handled in air for a short time, due to their preference to form large crystals.

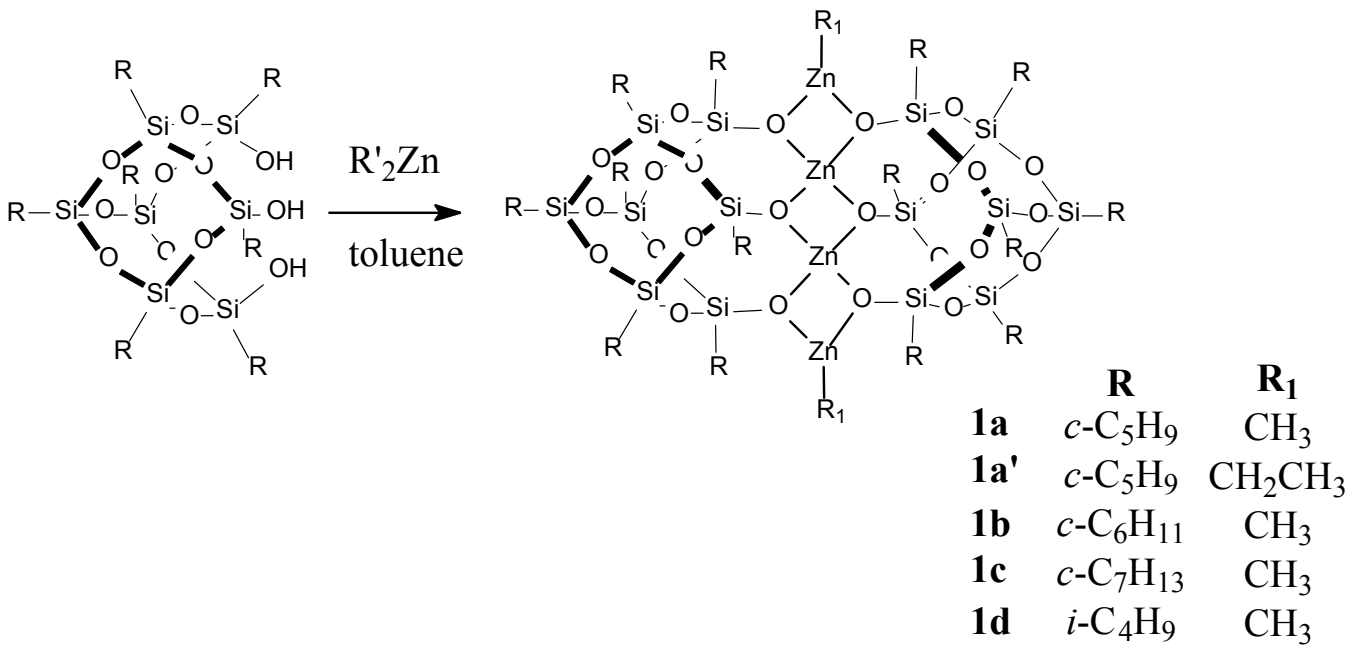

Scheme 1. Synthesis of tetranuclear silsesquioxane zinc complexes by protolysis of dialkyl zinc with trisilanol ligands

Although the addition of water to a solution of 1a-d seems to protolyse the remaining zincmethyl groups as is indicated by the formation of gas, it is not sufficient to completely destroy the inner zinc siloxide core of the complex. The starting trisilanol could be formed back quantitatively by the reaction of 1a-d with diluted hydrochloric acid and subsequent extraction with toluene. This indicates that the inner core of the silsesquioxane zinc complexes is rather unreactive towards protic substances. Complexes 1a-d all have similar solubility properties. They are sparsely soluble in aromatic solvents and chloroform, and tend to crystallize from these solvents in good yields. The solubility of the cycloheptyl substituted silsesquioxane complex is even too low to allow for well-resolved NMR spectra. For this 
reason the zinc-methyl resonance cannot be clearly seen in ${ }^{13} \mathrm{C}-\mathrm{NMR}$, but it is expected to be between -14 and -12 ppm based on the data for this resonance in 1a,b and 1d. An interesting effect of the use of chloroform as NMR solvent instead of benzene- $d_{6}$ is the upfield shift of the zinc methyl resonance in the proton NMR from $0 \mathrm{ppm}$ to $-0.6 \mathrm{ppm}$. The same shift was also observed for related alkyl gallium silsesquioxane compounds. ${ }^{15}$

An alternative route to prepare complexes 1a-d is the two-step addition of the two equivalents of dimethyl zinc. After the addition of the first equivalent of dimethyl zinc, the resulting compound was isolated and analyzed by NMR. For complex $\mathbf{2 a}$, the proton NMR showed a broad resonance at $2.8 \mathrm{ppm}$, while for $\mathbf{2 d}$ the resonance was at $2.7 \mathrm{ppm}$. These values are indicative of a free silanol group with no hydrogen bonding. No high-field zincmethyl resonances could be detected, showing that all these bonds had been protolyzed. Addition of the second equivalent of dimethyl zinc to these complexes led to the formation of the known complexes 1a and 1d, as depicted in Scheme 2.

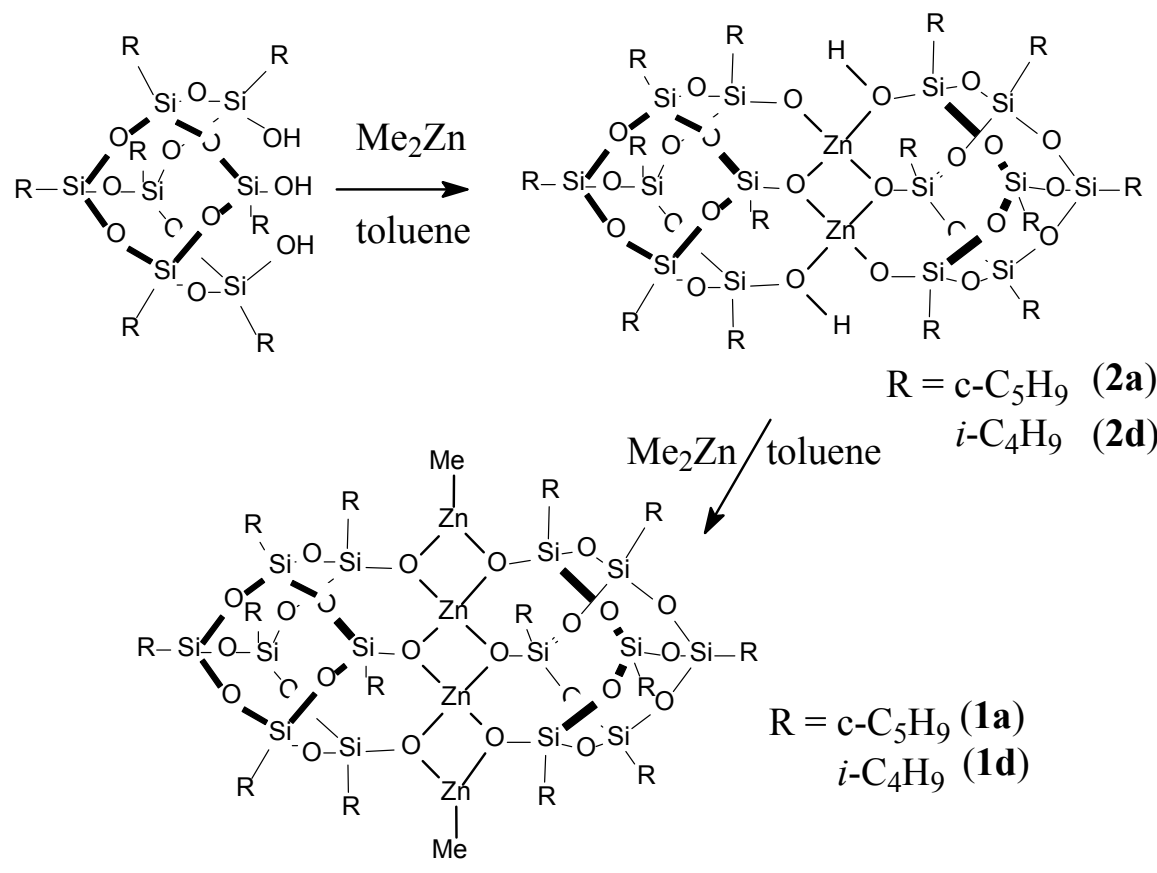

Scheme 2. The proposed formation mechanism of the tetranuclear complexes $1 \mathrm{a}$ and $1 \mathrm{~d}$ via intermediates $2 a$ and $2 b$.

It is probable that both these reactions with $\mathrm{Me}_{2} \mathrm{Zn}$ also take place consecutively in solution where the two equivalents of zinc alkyl are already present. The complexes $2 \mathbf{a}$ and $\mathbf{2 d}$ are highly soluble in toluene and hexane while the resulting complexes 1a and 1d crystallize swiftly from a toluene solution. It is therefore proposed that the first equivalent of dialkyl 
zinc reacts fast with the highly acidic silanol groups of the silsesquioxane ligands, while the second equivalent reacts much slower with the less acidic third silanol group, after which the tetranuclear complex precipitates from solution.

\section{Crystal structures of $1 \mathrm{a}$ and $1 \mathrm{~b}$.}

Because of the tendency of the silsesquioxane zinc cluster complexes to grow big crystals, samples suitable for an X-ray single-crystal study could be grown relatively easily by cooling down a saturated toluene solution. An ORTEP drawing of 1a is shown in Figure 1. Selected bond lengths and bond angles are given in Table 1. The monoclinic unit cell contains four units of the title compound separated by normal van der Waals distances. Each asymmetric unit contains one molecule of 1a. The molecule is almost inversion symmetric with small deviations from perfect symmetry.

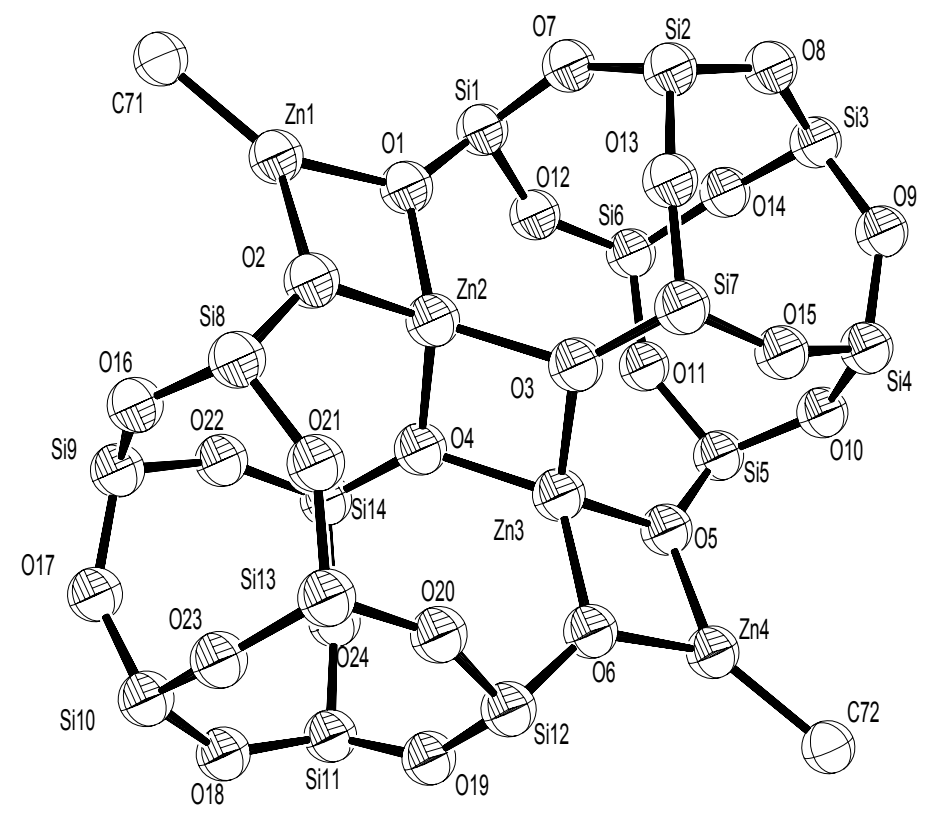

Figure 1. Structure of $\left[\left(\mathrm{C}_{5} \mathrm{H}_{9}\right)_{7} \mathrm{Si}_{7} \mathrm{O}_{12}\right]_{2} \mathrm{Zn}_{4} \mathrm{Me}_{2}$ (1a) in the crystal (ORTEP drawing). The cyclopentyl groups have been omitted for clarity. 
Table 1. Selected bond lengths $(\AA)$ and angles $\left(^{\circ}\right)$ for $1 \mathrm{a}$.

\begin{tabular}{|c|c|c|c|}
\hline \multicolumn{4}{|c|}{ Bond lengths } \\
\hline $\mathrm{Zn} 1-\mathrm{C} 71$ & $1.941(5)$ & $\mathrm{Zn} 4-\mathrm{C} 72$ & $1.942(5)$ \\
\hline $\mathrm{Zn} 1-\mathrm{O} 1$ & $1.950(3)$ & $\mathrm{Zn} 1-\mathrm{O} 2$ & $1.959(3)$ \\
\hline $\mathrm{Zn} 2-\mathrm{O} 1$ & $1.966(3)$ & $\mathrm{Zn} 2-\mathrm{O} 2$ & $1.963(3)$ \\
\hline $\mathrm{Zn} 2-\mathrm{O} 3$ & $1.943(3)$ & $\mathrm{Zn} 2-\mathrm{O} 4$ & $1.971(3)$ \\
\hline $\mathrm{Zn} 3-\mathrm{O} 3$ & $1.964(3)$ & $\mathrm{Zn} 3-\mathrm{O} 4$ & $1.947(3)$ \\
\hline $\mathrm{Zn} 4-\mathrm{O} 5$ & $1.957(3)$ & $\mathrm{Zn} 4-\mathrm{O} 6$ & $1.950(3)$ \\
\hline $\mathrm{Sil}-\mathrm{O} 1$ & $1.621(3)$ & $\mathrm{Si} 8-\mathrm{O} 2$ & $1.627(3)$ \\
\hline $\mathrm{Si} 7-\mathrm{O} 3$ & $1.622(3)$ & $\mathrm{Si14}-\mathrm{O} 4$ & $1.612(3)$ \\
\hline $\mathrm{Si} 12-\mathrm{O} 6$ & $1.620(3)$ & $\mathrm{Si} 5-\mathrm{O} 5$ & $1.622(3)$ \\
\hline \multicolumn{4}{|c|}{ Bond angles } \\
\hline $\mathrm{C} 71-\mathrm{Zn} 1-\mathrm{O} 1$ & $135.70(18)$ & $\mathrm{C} 72-\mathrm{Zn} 4-\mathrm{O} 5$ & $138.43(18)$ \\
\hline $\mathrm{C} 71-\mathrm{Zn} 1-\mathrm{O} 2$ & $139.12(18)$ & $\mathrm{C} 72-\mathrm{Zn} 4-\mathrm{O} 6$ & $136.67(19)$ \\
\hline $\mathrm{O} 1-\mathrm{Zn} 1-\mathrm{O} 2$ & $83.94(12)$ & $\mathrm{O} 5-\mathrm{Zn} 4-\mathrm{O} 6$ & $84.71(13)$ \\
\hline $\mathrm{Zn} 1-\mathrm{O} 1-\mathrm{Zn} 2$ & $94.63(13)$ & $\mathrm{Zn} 4-\mathrm{O} 5-\mathrm{Zn} 3$ & $94.99(13)$ \\
\hline $\mathrm{O} 1-\mathrm{Zn} 2-\mathrm{O} 2$ & $84.40(13)$ & $\mathrm{O} 5-\mathrm{Zn} 3-\mathrm{O} 6$ & $84.34(13)$ \\
\hline $\mathrm{O} 2-\mathrm{Zn} 2-\mathrm{O} 4$ & $117.04(13)$ & $\mathrm{O} 1-\mathrm{Zn} 2-\mathrm{O} 3$ & $1210.89(13)$ \\
\hline $\mathrm{O} 4-\mathrm{Zn} 3-\mathrm{O} 6$ & $122.80(13)$ & $\mathrm{O} 3-\mathrm{Zn} 3-\mathrm{O} 5$ & $117.15(13)$ \\
\hline $\mathrm{Si} 4-\mathrm{O} 4-\mathrm{Zn} 2$ & $131.57(17)$ & $\mathrm{Si} 7-\mathrm{O} 3-\mathrm{Zn} 2$ & $134.49(17)$ \\
\hline $\mathrm{Si} 4-\mathrm{O} 4-\mathrm{Zn} 3$ & $134.24(17)$ & $\mathrm{Si} 7-\mathrm{O} 3-\mathrm{Zn} 3$ & $130.91(17)$ \\
\hline
\end{tabular}

Standard deviations in the last decimal place are given in parentheses.

The structure determination shows 1a to be a tetranuclear, zinc species, with two sets of chemically different zinc atoms. Two of the zinc atoms ( $\mathrm{Zn} 2$ and $\mathrm{Zn} 3)$ are connected to both the silsesquioxane frameworks via four oxygen atoms ( $\mathrm{O} 1$ to $\mathrm{O} 4$ and $\mathrm{O} 3$ to $\mathrm{O} 6)$. $\mathrm{O} 3$ and $\mathrm{O} 4$ are $\mu_{3}$-bonded to the tetrahedrally surrounded zinc atoms, while O1, O2, O5 and O6 are $\mu_{3}$ bonded to both tetrahedral and trigonal zinc atoms. The other two zinc atoms ( $\mathrm{Zn} 1$ and $\mathrm{Zn} 4)$ are bound to only two oxygen atoms of the silsesquioxane ligands. Methyl groups (C71 and C72) complete their trigonal coordination sphere. 
The four zinc atoms are incorporated in an interlayer between two trianionic silsesquioxide ligands. This interlayer consists of three four-membered metallaoxocycles, alternatingly almost perpendicular to each other. The inner metallaoxocycle is rotated $79.8^{\circ}$ degrees with respect to $\mathrm{Zn1-O1-Zn2-O2} \mathrm{and} 86.2^{\circ}$ with respect to Zn3-O5-Zn4-O6. All metallaoxocycles are virtually planar (sums of the angles are between $358.87^{\circ}$ and $359.82^{\circ}$ ). As opposed to the almost identical magnesium compounds described in Chapter 2, the zinc atoms are not positioned in one line. The angle between the vectors $\mathrm{Zn} 1-\mathrm{Zn} 2$ and $\mathrm{Zn} 2-\mathrm{Zn} 3$ is about $7.6^{\circ}$, while the vectors $\mathrm{Zn} 1-\mathrm{Zn} 2$ and $\mathrm{Zn} 3-\mathrm{Zn} 4$ diverge $1.3^{\circ}$ from each other.

The tetrahedral coordination of the inner core zinc atoms is highly distorted with an average $\mathrm{O}-\mathrm{Zn}-\mathrm{O}$ angle of $85.0^{\circ}$ in the four-membered rings and $119.0^{\circ}$ between the rings. This is in line with results found in literature where these angles were found to range from about $76.92^{\circ}$ to $94.58^{\circ}$ for similar complexes. The $\mathrm{Zn}-\mathrm{O}$ bond lengths varied only slightly, having an average distance of $1.96 \AA$, which is consistent with values found in literature. The outer zinc atoms ( $\mathrm{Zn} 1$ and $\mathrm{Zn} 4)$ are rather unusual. They are in a distorted trigonal coordination, a mode that is not common among zinc complexes. The $\mathrm{Zn}-\mathrm{C}$ distance of $1.941 \AA$ is in the normal range for this type of complexes (ranging from 1.933 to $1.962 \AA$ ). The sum of the angles of bonds around the central zinc atoms is $359.8^{\circ}$ indicating a planar coordination. This was also found in literature for all three-coordinate zinc complexes. ${ }^{1 ; 4-6}$

The crystal structure of $\mathbf{1 b}$, the cyclohexyl substituted congener of $\mathbf{1 a}$, shows in essence the same structural elements as 1a. The crystal however shows some differences. The molecule crystallizes in a triclinic unit cell, which contains two independent molecules that are different from each other, and one toluene molecule as solvate. Although a general structural picture of the crystal can be made, refinement of the X-ray data to a structure suitable for publication was not possible, unfortunately. Other means of crystallization (variations in solvents and crystallization circumstances) did not yield crystals suitable for X-ray crystal structure analysis. In spite of the incomplete refinement of the structure, some general comments can be made. From the crystallographic data, it seems that the toluene solvate molecule causes a distortion in the unit cell that hinders the refinement of the data. From the data it can still be seen that the outer zinc atoms have a flat trigonal surrounding of siloxide and methyl ligands, and that the inner zinc atoms are ligated by the siloxide ligands in a distorted tetrahedral fashion (See Figure 2). 


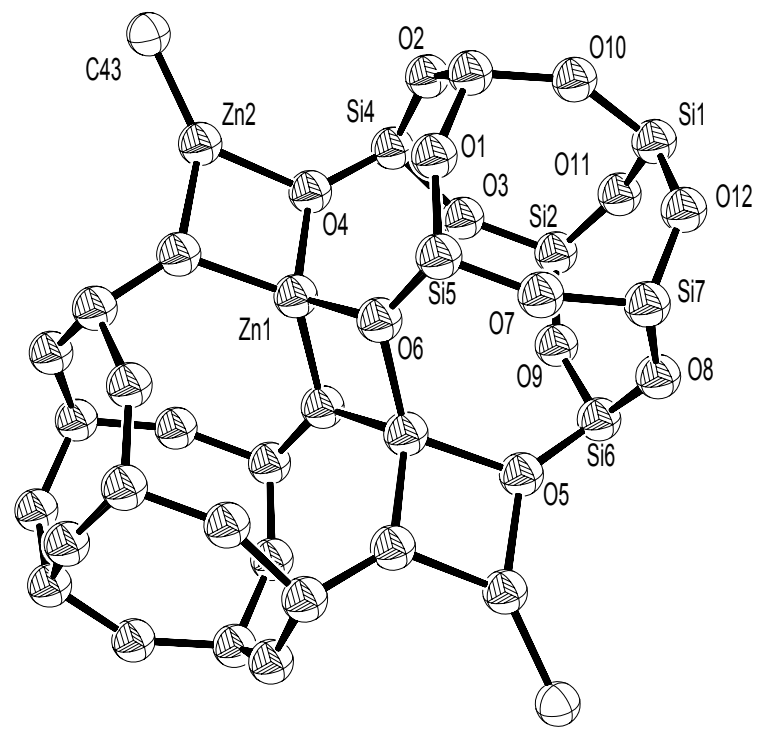

Figure 2. Structure of $\left[\left(\mathrm{C}_{6} \mathrm{H}_{11}\right)_{7} \mathrm{Si}_{7} \mathrm{O}_{12}\right]_{2} \mathrm{Zn}_{4} \mathrm{Me}_{2}$ (1b) in the crystal (ORTEP drawing). The cyclohexyl groups have been omitted for clarity.

\section{Synthesis of a silsesquioxane zinc chloride complex}

In order to make a comparison to the complexes described in the previous chapter, which had essentially the same tetranuclear core as complexes $\mathbf{1 a}$ and $\mathbf{1 b}$, but with a different terminal ligand on the outer atoms, a solution of silsesquioxane trisilanol $\left(c-\mathrm{C}_{5} \mathrm{H}_{9}\right)_{7} \mathrm{Si}_{7} \mathrm{O}_{9}(\mathrm{OH})_{3}$ in THF was treated with a solution of methyl zinc chloride (formed in situ by conproportionation of zinc dichloride in ether and dimethyl zinc in toluene) as shown in Scheme 3. After recrystallization, a single crystalline product could be isolated in high yield. Spectroscopic data $\left({ }^{1} \mathrm{H}\right.$ - and ${ }^{13} \mathrm{C}$-NMR) suggested that a similar complex had been formed. Proton NMR showed the presence of a coordinating THF ligand and the absence of any zinc-methyl group, while ${ }^{13} \mathrm{C}$-NMR spectra showed a 1:2:1:2:1 pattern in the methine region, indicating the expected $\mathrm{C}_{2 \mathrm{v}}$ symmetry. The complex is moderately soluble in most hydrocarbons and can be easily crystallized from a THF solution. 

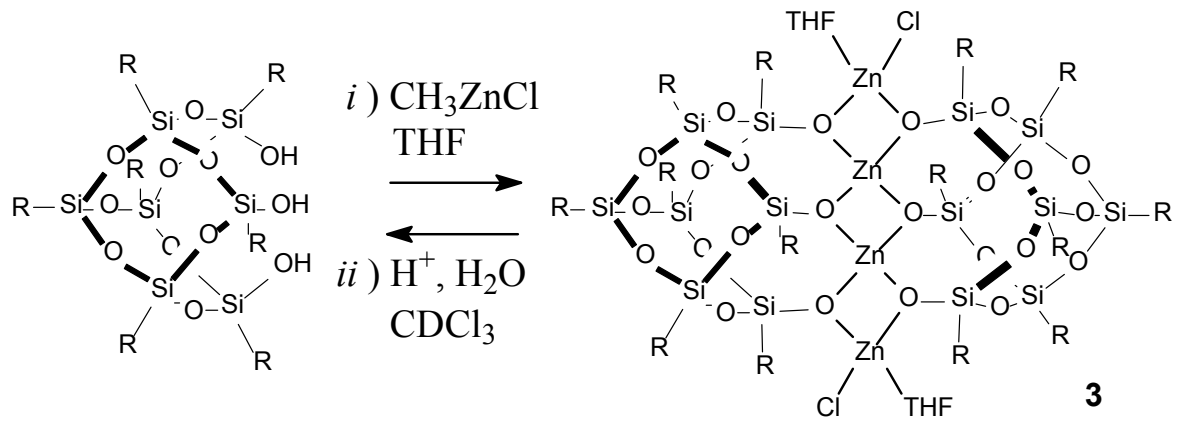

Scheme 3. Reaction of silsesquioxane trisilanol $\left(c-\mathrm{C}_{5} \mathrm{H}_{9}\right)_{7} \mathrm{Si}_{7} \mathrm{O}_{9}(\mathrm{OH})_{3}$ with methylzinc chloride to yield complex 3.

Because an unambiguous assignment of the structure of the zinc complex could not be established on the basis of the spectroscopic data alone, a single-crystal X-ray diffraction study was performed on $\mathbf{3}$. Crystals suitable for X-ray single-crystal studies were obtained by concentration of the reaction medium (diethyl ether/toluene/THF), heating and slow cooling to room temperature. An ORTEP drawing of $\mathbf{3}$ is shown in Figure 3. Selected bond distances and bond angles are given in Table 3 .

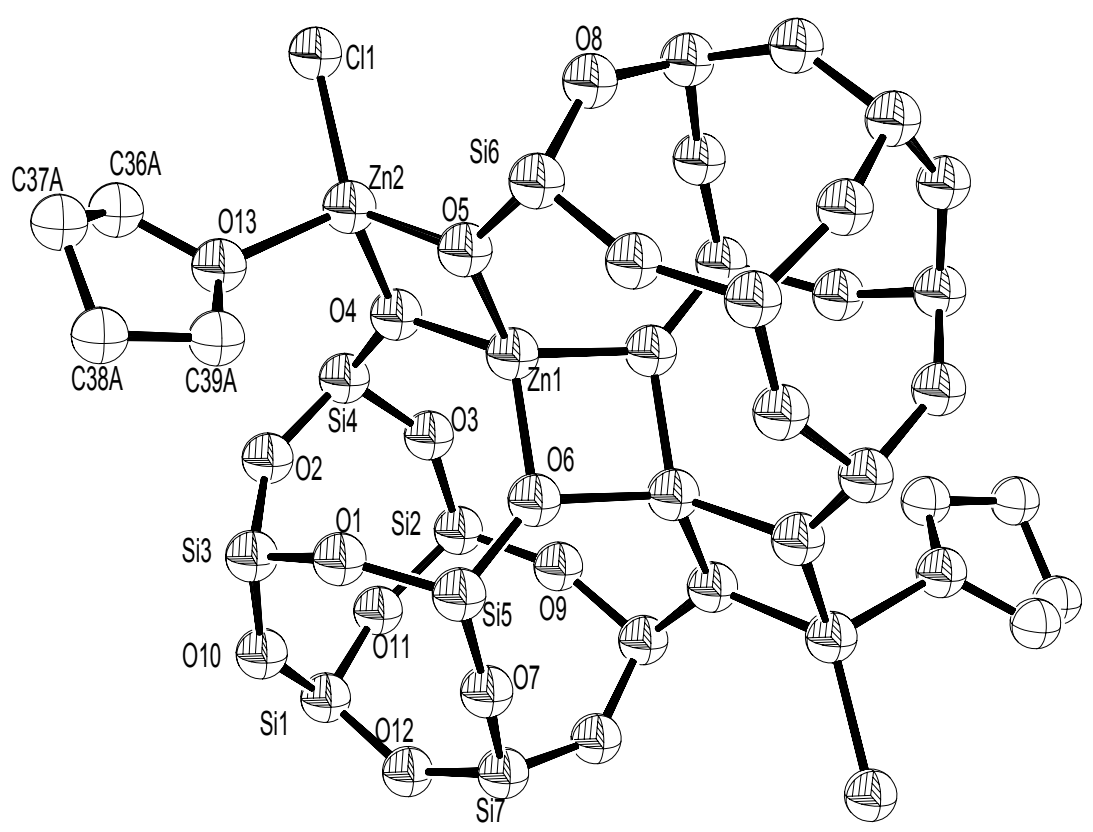

Figure 3. Structure of $\left[\left(\mathrm{C}_{5} \mathrm{H}_{9}\right)_{7} \mathrm{Si}_{7} \mathrm{O}_{12}\right]_{2} \mathrm{Zn}_{4} \mathrm{Cl}_{2}(\mathrm{THF})_{2}(3)$ in the crystal (ORTEP drawing). The cyclopentyl groups have been omitted for clarity. 
Table 2. Selected bond lengths $(\AA)$ and angles $\left(^{\circ}\right)$ for 3 .

\begin{tabular}{|c|c|c|c|}
\hline \multicolumn{4}{|c|}{ Bond lengths } \\
\hline $\mathrm{Zn} 2-\mathrm{Cl}$ & $2.1572(15)$ & $\mathrm{Zn} 1-\mathrm{O} 5$ & $1.965(3)$ \\
\hline $\mathrm{Zn} 2-\mathrm{O} 13$ & $2.055(3)$ & $\mathrm{Zn} 1-\mathrm{O} 6$ & $1.947(3)$ \\
\hline $\mathrm{Zn} 2-\mathrm{O} 4$ & $1.965(3)$ & $\mathrm{Si} 4-\mathrm{O} 4$ & $1.610(4)$ \\
\hline $\mathrm{Zn} 2-\mathrm{O} 5$ & $1.945(3)$ & $\mathrm{Si} 5-\mathrm{O} 6$ & $1.616(4)$ \\
\hline $\mathrm{Zn} 1-\mathrm{O} 4$ & $1.967(4)$ & $\mathrm{Si} 6-\mathrm{O} 5$ & $1.616(4)$ \\
\hline \multicolumn{4}{|c|}{ Bond angles } \\
\hline $\mathrm{Cl}-\mathrm{Zn} 2-\mathrm{O} 13$ & $108.22(11)$ & $\mathrm{Si} 4-\mathrm{O} 4-\mathrm{Zn} 2$ & $134.7(2)$ \\
\hline $\mathrm{Cl}-\mathrm{Zn} 2-\mathrm{O} 4$ & $124.61(12)$ & $\mathrm{Si} 4-\mathrm{O} 4-\mathrm{Zn} 1$ & $127.83(18)$ \\
\hline $\mathrm{Zn} 2-\mathrm{O} 4-\mathrm{Zn} 1$ & $93.08(15)$ & $\mathrm{Si} 5-\mathrm{O} 6-\mathrm{Zn} 1$ & $127.8(2)$ \\
\hline $\mathrm{Zn} 2-\mathrm{O} 5-\mathrm{Zn} 1$ & $92.83(16)$ & $\mathrm{Si} 5-\mathrm{O} 6-\mathrm{Zn} 1 \mathrm{a}$ & $133.2(2)$ \\
\hline $\mathrm{Zn} 1-\mathrm{O} 6-\mathrm{Zn} 1 \mathrm{a}$ & $93.48(15)$ & $\mathrm{Si} 6-\mathrm{O} 5-\mathrm{Zn} 1$ & $127.8(2)$ \\
\hline $\mathrm{O} 4-\mathrm{Zn} 2-\mathrm{O} 5$ & $86.87(14)$ & $\mathrm{Si} 6-\mathrm{O} 5-\mathrm{Zn} 2$ & $130.74(19)$ \\
\hline $\mathrm{O} 4-\mathrm{Zn} 1-\mathrm{O} 5$ & $87.11(14)$ & $\mathrm{O} 4-\mathrm{Zn} 1-\mathrm{O} 6$ & $118.08(14)$ \\
\hline $\mathrm{O} 6-\mathrm{Zn} 1-\mathrm{O} 6 \mathrm{a}$ & $86.52(14)$ & $\mathrm{O} 5-\mathrm{Zn} 1-\mathrm{O} 6$ & $125.65(16)$ \\
\hline
\end{tabular}

Standard deviations in the last decimal place are given in parentheses.

The monoclinic unit cell contains two molecules of $\mathbf{3}$ that are separated by normal Van der Waals distances. The molecule itself is centrosymmetric with an inversion center that is not situated on a specific atom. The difference between the crystals of zinc complex $\mathbf{3}$ and the magnesium complexes described in Chapter 2 is the absence of (or space for) solvent molecules in the crystal of $\mathbf{3}$, which also result in a considerably higher density (1.4 vs. 1.2 g.cm $\left.{ }^{-1}\right)$.

It is clear from Figure 3 that the inner core of the complex shows great similarities to the complexes 1a and $\mathbf{1 b}$, as well as to the related magnesium complexes in Chapter 2. It has the same metal-siloxane connectivity as described before for complexes $\mathbf{1 a}$ and $\mathbf{1 b}$. The silsesquioxane Si-O-Zn skeleton of the complex is in itself static, but all the cyclopentyl groups except the group on $\mathrm{Si} 4$ are highly disordered, with major spatial occupations ranging from $51 \%$ on $\mathrm{Si} 1$ to $88 \%$ for the group on $\mathrm{Si}$. The coordinated THF molecule is also disordered and present in two states, the major having an occupation of $68 \%$. The two different states of the THF molecule are formed by rotation around the $\mathrm{Zn} 2-\mathrm{O} 13$ axis. The 
lengths of the $\mathrm{Zn}-\mathrm{O}$ bonds, on average $1.961 \AA$, are in the normal range for four-coordinate zinc-oxygen bonds. The $\mathrm{Zn} 2-\mathrm{Cl}$ bond however is extremely short (2.1572 $\mathrm{A})$. The Cambridge Crystallographic Database lists six compounds that have a bond length that is either in the same range or a bit shorter. Most of these are coordination compounds of $\mathrm{ZnCl}_{2}$, two are very

sterically crowded pyrazolylborate zinc complexes. ${ }^{16-19}$ Just as described in the previous chapter, these kinds of short distances are usually ascribed to a highly electron-deficient metal center. The metal-O(THF) bond has a normal length.

In conclusion the general motif of four metals in a row connected by $\mu_{3}$-oxygen atoms seems to be common for divalent metal silsesquioxane complexes. The absence of literature data on silsesquioxanes with divalent metals prevents a general conclusion, but the present work on magnesium and zinc silsesquioxane complexes shows a tentative trend towards this type of structure. There is virtually no change in the conformation of the siloxane part of the silsesquioxane ligand, although cycloalkyl side groups, metals and residual ligands on the metal, such as chloride, alkyl, pyridine and THF were varied. The only differences that were found are the occurrences of disorder in the cycloalkyl groups. Differences in the metalsiloxide part of the complexes seem to be caused by the different size of the metal atoms, as there is virtually no difference between the complexes of the same metal with different silsesquioxane ligands.

\section{Reactivity of the outer zinc atoms in $1 \mathrm{a}$}

In order to investigate the reactivity of the zinc complexes, 1a was reacted with various protic and nonprotic reagents. As stated in the previous paragraph, the tri-coordinate outer zinc atoms are in a very electron-deficient state, this would make them susceptible to coordination by coordinating solvents. Although compounds 1a-d are barely soluble in coordinating solvents, they readily accept these as extra ligands to fill up the coordination sphere to form tetrahedral zinc complexes, as indicated in Scheme 4 (step $i$ ). As a result of this coordination, the methyl resonance in the ${ }^{13} \mathrm{C}$-NMR spectrum shifts upfield by 0.5 to $1 \mathrm{ppm}$, due to the increased electron density on the zinc atom. Removal of these coordinating ligands is difficult, but THF can be removed by heating the compound under vacuum to $150{ }^{\circ} \mathrm{C}$ for several hours. The coordinating pyridine is more difficult to remove, leading to deterioration of the whole complex. 


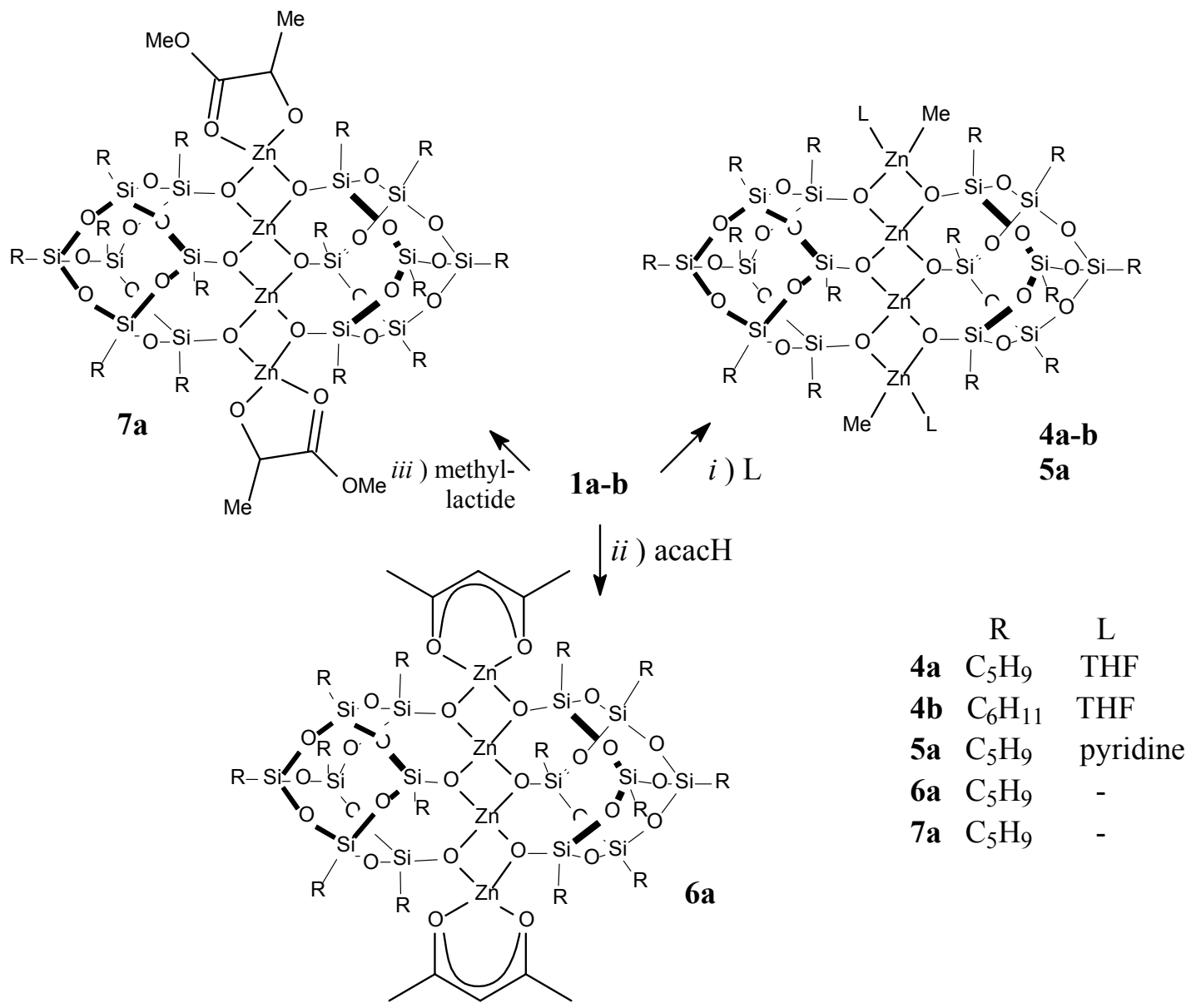

Scheme 4. Reactivity of 1a towards protic and coordinating compounds

Because zinc alkyl bonds are commonly known to be very polarized functionalities, the methyl groups on the outer zinc atoms are expected to react with protic compounds. Reaction of 1a with small amounts of water in a NMR tube lead to the evolution of methane gas, but no clear product could be identified. Products are possibly a mixture of hydrolyzed zinc complexes, with coordinating water species. To ensure the zinc will be in a completely coordinated state after being treated with a protic substance, we reacted 1a with 2,4pentadione (acetylacetone, acacH). Gas evolution took place, and a single product could be isolated by crystallization from toluene (Scheme 4, step ii). From multinuclear NMR $\left({ }^{1} \mathrm{H}\right.$, ${ }^{13} \mathrm{C}$ ) it became clear that two equivalents of acetylacetone had reacted with the zinc methyl groups of $1 \mathbf{a}$ to form complex 6a. The equivalence of the carbonyl carbon atoms in the ${ }^{13} \mathrm{C}$ NMR led us to conclude that the acetylacetonate groups are coordinated in the tetrahedral fashion as depicted in Scheme 4. Compound 6a is a stable monomeric compound, and can be handled in air without degradation. 
The reaction of 1a with methanol in a non-polar solvent such as toluene led to complete gelation of the reaction mixture in a few minutes. A probable cause for this behavior is the formation of a polymer-like structure as depicted in Scheme 5. Addition of a coordinating solvent (THF) broke up the gel, but no crystalline product could be obtained. After dissolution of the powder in benzene- $d_{6}$ or $\mathrm{CDCl}_{3}$ gelation took place again, and no wellresolved NMR spectra could be measured.

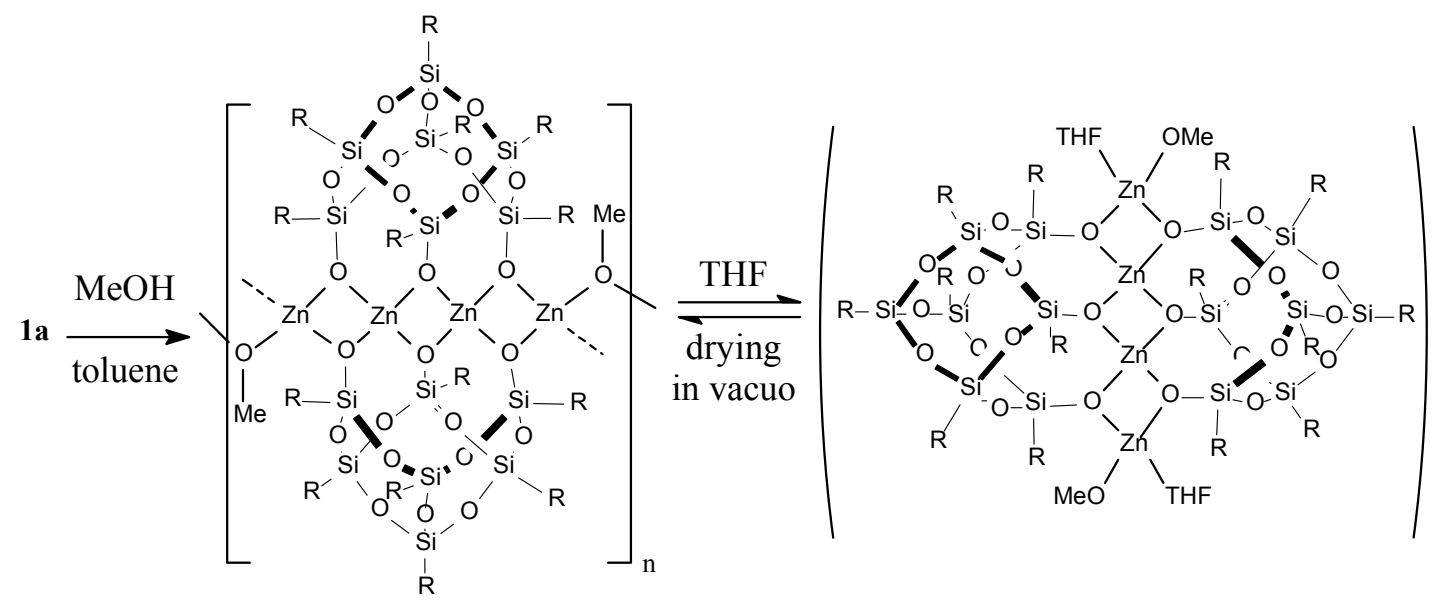

Scheme 5. Possible products of the reaction of 1a with methanol and its behavior in THF solution

Inspired by the reactivity with acetylacetone, which can be also be regarded as an alcohol with a coordinating ketone moiety, 1a was treated with (S)-methyl lactate in order to form a five-membered ring instead of the acac-six-membered ring. ${ }^{4}$ Gas evolution could be clearly seen during the reaction, indicating the release of methane, although NMR data show no conclusive information on the true structure of the product. The resulting gel-like compound that remains after evaporation of the solvent from this reaction mixture could be indicative of the formation of a polymeric structure where the keto-functionality coordinates to one of the zinc atoms of another complex as depicted in Scheme 6.

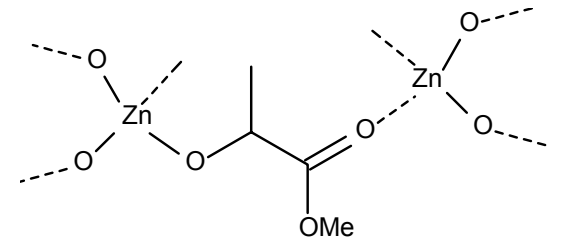

Scheme 6. Coordination of the keto-function of methyl-lactide can probably cause gel-formation 


\section{Polymerization of lactide}

Recent literature has shown a tremendous increase of interest in the synthesis of biocompatible polymers for medicinal and packaging use. ,4;6;8-13;20;21 One of the polymers that attracted a lot of attention was polylactide which is synthesized via ring-opening polymerization of lactide (3,6-dimethyl-1,4-dioxane-2,5-dione). This type of ring-opening polymerization is usually catalyzed or initiated by alkoxides of group 2, 3, 13 or 14 metals. Experiments involving magnesium and zinc precursors with various ligand systems, ranging from ketinimates to tris-pyrazolylborates, showed that these metals where the best choice for initiating polymerization.

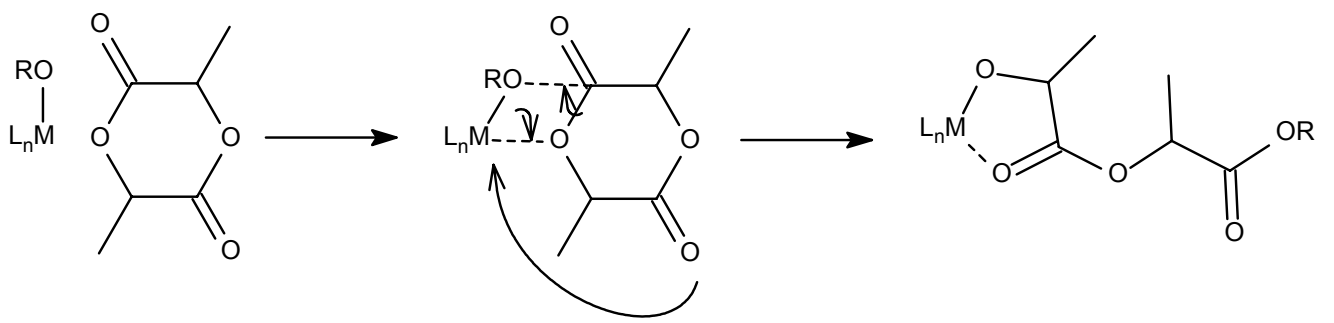

Scheme 7. Proposed initition of lactide polymerization

The mechanism of lactide polymerization is postulated to be an insertion polymerization that is started by activation of a metal alkoxide bond. The activation step is assumed to be the nucleophilic attack of the alkoxide ligand to one of the carbonyl groups of lactide, followed by ring opening (as depicted in Scheme 7). ${ }^{8 ; 10 ; 20 ; 21}$ By coordination of the second carbonyl group to the metal atom, a dormant state is created, until the next lactide molecule is inserted. The rate of the initial activation step is highly dependent on the nature of the nucleophilic group. As found in literature, usually alkoxides have the highest reaction rate. Alkyl groups often show no reactivity at all, or initiate the polymerization very slowly.

Zinc complexes 1a-d were tested in the catalytic polymerization of lactide. Although some polymer was formed, no large quantities could be obtained, even after extensive reaction times. A likely cause for this behavior is the bifunctional reactive center in these complexes. Insertion of monomer can take place at both sides of the complex, which causes the reactive species to precipitate from the solution and renders it inactive for further reaction. Removal of the solvent in vacuo and sublimation of the remaining lactide from the reaction mixture enabled us to isolate small amounts of polymeric material. Mass balance estimated calculations and NMR data indicated the coupling of at most 35 lactide units per molecule of 
zinc complex. However, the error in this number is substantial and it should be interpreted as an indication that the complexes are (at least) able to polymerize lactide. Addition of an alcohol to form a zinc alkoxide as polymerization initiator did not improve the amount of polymer made, but the initiation was faster.

In an attempt to witness the first insertion product, complex 1d was treated with an equimolar amount of (S)-lactide. After stirring for $72 \mathrm{~h}$ in toluene, a gel-like material was formed. No well-resolved NMR data could be obtained from this mixture, because of the low solubility of the gel in common NMR solvents, like $\mathrm{CDCl}_{3}$ or benzene- $d_{6}$. The gel formation is probably caused by either opening of the lactide six-membered ring by the complex (as shown in Scheme 6), or the formation of polymeric coordination complexes, through the ketofunctionality of lactide. Due to the lack of spectroscopic data, no conclusion can be drawn here.

From these data it can be concluded that the silsesquioxane zinc complexes have a limited utility as lactide polymerization catalysts. This is mostly due to their dual-site nature, which causes $(i)$ the formation of coordination polymers with the monomer and the ring-opened monomer, and (ii) the formation of polymer chains on both sides of the complex. The high molecular weight and the relatively low solubility also frustrate the use of zinc silsesquioxane complexes as catalysts in this reaction.

\section{Concluding remarks}

The protolysis of dialkyl zinc compounds with various silsesquioxane trisilanols leads to a series of tetranuclear zinc silsesquioxane complexes with both tetrahedral and trigonal zinc atoms. Besides the silsesquioxide ligands, the trigonal zinc atoms also have an alkyl group attached to it. This series of compounds was characterized by multinuclear NMR and crystal structure analysis for two of the complexes. Protolysis of methyl zinc chloride with the cyclopentyl substituted silsesquioxane trisilanol led to a complex with the same zinc siloxide core and different terminal chloride and THF ligands. A comparison between the zinc complexes in the chapter and related magnesium complexes in a previous chapter showed that variations in ligands have a negligible effect on the structure and geometry of the complexes. The only major difference can be seen by the use of different metals. The reactivity of the silsesquioxane zinc alkyl complexes towards protic and coordinating substances was tested. Coordination of THF and pyridine was facile, and the coordinated 
moieties were difficult to remove. Reaction of the complexes with simple alcohols led to the formation of gels, probably caused by bridging of the alkoxide ligands to the next complex, thereby creating an oligomeric or polymeric material. Some isolated complexes were tested in the polymerization of lactide. These complexes showed a very short lifetime, due to the precipitation of the complexes. 


\section{Experimental Section}

\section{General remarks.}

All operations involving air and moisture sensitive materials were performed in an inert atmosphere using standard Schlenk techniques and an argon filled glovebox. Solvents were dried over Na/K alloy (THF, toluene, hexane, benzene- $\left.d_{6}\right), \mathrm{Na} /$ benzophenone $\left(\mathrm{Et}_{2} \mathrm{O}\right)$ or $4 \AA$ molecular sieves $\left(\mathrm{CDCl}_{3}\right.$, toluene- $\left.d_{8}\right)$ and were degassed before use. Dimethyl zinc (2.0 M solution in toluene, Merck), diethyl zinc (1.0 M solution in $n$-heptane, Merck), zinc dichloride (1.0 M in $\mathrm{Et}_{2} \mathrm{O}$, Aldrich) were used as purchased. The silsesquioxane ligands ${ }^{22-24}$ were prepared according to literature procedures. Methyl zinc chloride was synthesized by equimolar conproportionation of dimethyl zinc and zinc dichloride. ${ }^{14}$ NMR spectra were recorded on VARIAN Mercury 400 and VARIAN Inova 500 spectrometers and referred to residual solvent resonances $\left({ }^{1} \mathrm{H},{ }^{13} \mathrm{C}\right)$ or $\mathrm{SiMe}_{4}\left({ }^{29} \mathrm{Si}\right)$. The Organic Chemistry Department of the Eindhoven University of Technology (The Netherlands) carried out the elemental analyses. In cases where no elemental analysis is mentioned, no suitable analysis could be obtained, even after addition of oxidizing aids, such as $\mathrm{V}_{2} \mathrm{O}_{5}$. The formation of carbides could be responsible for the low carbon content. This was also seen in Chapter 2 for the magnesium compounds. Crystal structures were determined at the Crystal Structure Center (University of Groningen, 1a) and The Laboratory of Crystal and Structural Chemistry (University of Utrecht, 1b, 3)

\section{Synthesis of $\left\{\left(c-\mathrm{C}_{5} \mathrm{H}_{9}\right)_{7} \mathrm{Si}_{7} \mathrm{O}_{9}\right\}_{2}\left[\left(\mu_{3}-\mathrm{O}\right) \mathrm{Zn}\right]_{2}\left[\left(\mu_{3}-\mathrm{O}\right) \mathrm{ZnCH}_{3}\right]_{2}$ (1a)}

Dimethyl zinc $(3.21 \mathrm{~mL}, 6.42 \mathrm{mmol})$ was added to a solution of the silsesquioxane trisilanol (c$\left.\mathrm{C}_{5} \mathrm{H}_{9}\right)_{7} \mathrm{Si}_{7} \mathrm{O}_{9}(\mathrm{OH})_{3}(2.81 \mathrm{~g}, 3.21 \mathrm{mmol})$. During the addition a vigorous gas evolution took place and an exothermal reaction was observed. After 30 min the solution became cloudy. The suspension was heated until it became clear again, and was left to cool down slowly. After one day colorless block-shaped crystals of 1a (2.25 g, $1.10 \mathrm{mmol}, 69 \%)$ suitable for crystal structure analysis were formed. NMR Data: ${ }^{1} \mathrm{H}\left(400 \mathrm{MHz}, \mathrm{C}_{6} \mathrm{D}_{6}, \delta\right)$ 2.3-1.5 (m, $\left.\mathrm{CH}_{2}, \mathrm{C}_{5} \mathrm{H}_{9}, 112 \mathrm{H}\right), 1.5-1.1\left(\mathrm{~m}, \mathrm{CH}, \mathrm{C}_{5} \mathrm{H}_{9}, 14 \mathrm{H}\right),-0.01\left(\mathrm{~s}, \mathrm{ZnCH}_{3}, 6 \mathrm{H}\right) ;{ }^{13} \mathrm{C}\left\{{ }^{1} \mathrm{H}\right\}\left(100 \mathrm{MHz}, \mathrm{C}_{6} \mathrm{D}_{6}, \delta\right)$ : 28.71, 28.50, 28.35, 28.31, 27,92, 27.90, 27.73, 27.64, 27.54, 27.48, 27.42 (s, $\left.\mathrm{CH}_{2}, \mathrm{C}_{5} \mathrm{H}_{9}\right), 24.78,24.38,24.29$, 22.79, 22.69 (s, $\mathrm{CH}, \mathrm{C}_{5} \mathrm{H}_{9}$, relative intensities 1:1:2:2:1), -14.23 (s, $\left.\mathrm{ZnCH}_{3}\right) ;{ }^{29} \mathrm{Si}\left\{{ }^{1} \mathrm{H}\right\}\left(99 \mathrm{MHz}, \mathrm{C}_{6} \mathrm{D}_{6}, \delta\right)$ : $56.82,-61.20,-63.42,-64.02,-69.28$ (relative intensities $2: 1: 1: 2: 1$ ).

\section{Synthesis of $\left\{\left(c-\mathrm{C}_{5} \mathrm{H}_{9}\right)_{7} \mathrm{Si}_{7} \mathrm{O}_{9}\right\}_{2}\left[\left(\mu_{3}-\mathrm{O}\right) \mathrm{Zn}\right]_{2}\left[\left(\mu_{3}-\mathrm{O}\right) \mathrm{ZnCH}_{2} \mathrm{CH}_{3}\right]_{2}\left(\mathbf{1 a}^{\prime}\right)$}

Diethyl zinc $(4.91 \mathrm{~mL}, 4.91 \mathrm{mmol})$ was added to a solution of the silsesquioxane trisilanol $\left(c-\mathrm{C}_{5} \mathrm{H}_{9}\right)_{7} \mathrm{Si}_{7} \mathrm{O}_{9}(\mathrm{OH})_{3}$ $(2.15 \mathrm{~g}, 2.46 \mathrm{mmol})$. During the addition a vigorous gas evolution took place and an exothermal reaction was observed. After $20 \mathrm{~min}$ the solution became cloudy. The suspension was heated until it became clear again, and was left to cool down slowly. After one day colorless block-shaped crystals of 1a' (1.59 g, $0.77 \mathrm{mmol}, 63 \%)$ suitable for crystal structure analysis were formed. NMR Data: ${ }^{1} \mathrm{H}\left(400 \mathrm{MHz}, \mathrm{C}_{6} \mathrm{D}_{6}, \delta\right)$ 2.3-1.5 (m, $\mathrm{CH}_{2}, \mathrm{C}_{5} \mathrm{H}_{9}$, $112 \mathrm{H}), 1.55$ (t, $\left.\mathrm{ZnCH}_{2} \mathrm{CH}_{3}, 6 \mathrm{H}\right), 1.4-1.2\left(\mathrm{~m}, \mathrm{CH}, \mathrm{C}_{5} \mathrm{H}_{9}, 14 \mathrm{H}\right), 0.88$ (q, $\left.\mathrm{ZnCH}_{2} \mathrm{CH}_{3}, 4 \mathrm{H}\right) ;{ }^{13} \mathrm{C}\left\{{ }^{1} \mathrm{H}\right\}(100 \mathrm{MHz}$, $\left.\mathrm{C}_{6} \mathrm{D}_{6}, \delta\right): 28.70,28.49,28.35,27.90,27.78,27.64,27.52,27.49,27.43\left(\mathrm{~s}, C_{2}, \mathrm{C}_{5} \mathrm{H}_{9}\right), 24.76,24.48,22.81$, $22.70\left(\mathrm{~s}, \mathrm{CH}, \mathrm{C}_{5} \mathrm{H}_{9}\right.$, relative intensities 1:3:2:1), $11.92\left(\mathrm{~s}, \mathrm{ZnCH}_{2} \mathrm{CH}_{3}\right), 0.77\left(\mathrm{~s}, \mathrm{ZnCH}_{2} \mathrm{CH}_{3}\right) ;{ }^{29} \mathrm{Si}\{1 \mathrm{H}\}(99.3$ MHz, C6D6, d): -56.41, -60.73, -63.00, -63.62, -68.89 (relative intensities 2:1:1:2:1) . 


\section{Synthesis of $\left\{\left(c-\mathrm{C}_{6} \mathrm{H}_{11}\right)_{7} \mathrm{Si}_{7} \mathrm{O}_{12}\right\}_{2}\left[\left(\mu_{3}-\mathrm{O}\right) \mathrm{Zn}_{2}\left[\left(\mu_{3}-\mathrm{O}\right) \mathrm{ZnCH}_{3}\right]_{2}\right.$ (1b)}

Dimethyl zinc $(1.89 \mathrm{~mL}, 3.80 \mathrm{mmol})$ was added to a solution of the silsesquioxane trisilanol (c$\left.\mathrm{C}_{6} \mathrm{H}_{11}\right)_{7} \mathrm{Si}_{7} \mathrm{O}_{9}(\mathrm{OH})_{3}(1.85 \mathrm{~g}, 1.90 \mathrm{mmol})$. During the addition a vigorous gas evolution took place and an exothermal reaction was observed. After 30 min the solution became cloudy. The suspension was heated until it became clear again, and was left to cool down slowly. After one day colorless block-shaped crystals of $\mathbf{1 b}$ (1.60 g, $0.72 \mathrm{mmol}, 76 \%)$ suitable for crystal structure analysis were formed. NMR Data: ${ }^{1} \mathrm{H}\left(400 \mathrm{MHz}, \mathrm{C}_{6} \mathrm{D}_{6}, \delta\right)$ 2.3-0.9 (m, $\mathrm{CH}_{2}$ and $\left.\mathrm{CH}, \mathrm{C}_{6} \mathrm{H}_{11}, 122 \mathrm{H}\right), 0.04\left(\mathrm{~s}, \mathrm{ZnCH}_{3}, 6 \mathrm{H}\right) ;{ }^{13} \mathrm{C}\left\{{ }^{1} \mathrm{H}\right\}\left(100 \mathrm{MHz}, \mathrm{C}_{6} \mathrm{D}_{6}, \delta\right): 28.37,28.20,28.16$, 27.89, 27.83, 27.71, 27.65, 27.60, 27.46, 27.27, 27.17, $27.12\left(\mathrm{~s}, \mathrm{CH}_{2}, \mathrm{C}_{5} \mathrm{H}_{9}\right)$, 25.73, 25.48. 25.45, 23.87, 23.69 (s, $\mathrm{CH}, \mathrm{C}_{5} \mathrm{H}_{9}$, relative intensities 1:2:1:2:1), -13.45 (s, $\left.\mathrm{ZnCH}_{3}\right) ;{ }^{29} \mathrm{Si}\left\{{ }^{1} \mathrm{H}\right\}(99.3 \mathrm{MHz}, \mathrm{C} 6 \mathrm{D} 6, \delta):-58.63,-63.31,-$ $65.13,-65.54,-71.34$ (relative intensities $2: 1: 1: 2: 1$ )

\section{Synthesis of $\left\{\left(c-\mathrm{C}_{7} \mathrm{H}_{13}\right)_{7} \mathrm{Si}_{7} \mathrm{O}_{12}\right\}_{2}\left[\left(\mu_{3}-\mathrm{O}\right) \mathrm{Zn}_{2}\left[\left(\mu_{3}-\mathrm{O}\right) \mathrm{ZnCH}_{3}\right]_{2}(1 \mathrm{c})\right.$}

Dimethyl zinc $(1.71 \mathrm{~mL}, 3.41 \mathrm{mmol})$ was added to a solution of the silsesquioxane trisilanol (c$\left.\mathrm{C}_{7} \mathrm{H}_{13}\right)_{7} \mathrm{Si}_{7} \mathrm{O}_{9}(\mathrm{OH})_{3}(1.83 \mathrm{~g}, 1.71 \mathrm{mmol})$. During the addition a vigorous gas evolution took place and an exothermal reaction was observed. After $30 \mathrm{~min}$ the solution became cloudy. The suspension was heated until it became clear again, and was left to cool down slowly. After one day of microcrystals of $1 \mathbf{c}(0.85 \mathrm{~g}, 0.35 \mathrm{mmol}$, $41 \%$ ) were formed. NMR Data: ${ }^{1} \mathrm{H}\left(400 \mathrm{MHz}, \mathrm{C}_{6} \mathrm{D}_{6}, \delta\right) 2.4-0.75\left(\mathrm{~m}, \mathrm{CH}_{2}\right.$ and $\left.\mathrm{CH}, \mathrm{C}_{5} \mathrm{H}_{9}, 126 \mathrm{H}\right), 0.05$ (s, $\left.\mathrm{ZnCH}_{3}, 6 \mathrm{H}\right) ;{ }^{13} \mathrm{C}\left\{{ }^{1} \mathrm{H}\right\}\left(100 \mathrm{MHz}, \mathrm{C}_{6} \mathrm{D}_{6}, \delta\right): 30.66,30.26,29.84,26.69,29.57,29.46,29.13,29.02,28.74,28.45$ $\left(\mathrm{s}, \mathrm{CH}_{2}, \mathrm{C}_{5} \mathrm{H}_{9}\right), 27.34,26.58,26.12,25.79,24.49\left(\mathrm{~s}, \mathrm{CH}, \mathrm{C}_{5} \mathrm{H}_{9}\right.$, relative intensities 1:1:2:1:2), the carbon in the zinc methyl group could not be detected due to low solubility of the complex, just as a suitable ${ }^{29} \mathrm{Si}\left\{{ }^{1} \mathrm{H}\right\}-\mathrm{NMR}$ spectrum could not be obtained.

\section{Synthesis of $\left\{\left(i-\mathrm{C}_{4} \mathrm{H}_{9}\right)_{7} \mathrm{Si}_{7} \mathrm{O}_{12}\right\}_{2}\left[\left(\mu_{3}-\mathrm{O}\right) \mathrm{Zn}_{2}\left[\left(\mu_{3}-\mathrm{O}\right) \mathrm{ZnCH}_{3}\right]_{2}(1 \mathrm{~d})\right.$}

Dimethyl zinc $(3.0 \mathrm{~mL}, 6.0 \mathrm{mmol})$ was added to a solution of the silsesquioxane trisilanol $\left(i-\mathrm{C}_{4} \mathrm{H}_{9}\right)_{7} \mathrm{Si}_{7} \mathrm{O}_{9}(\mathrm{OH})_{3}$ $(2.36 \mathrm{~g}, 2.98 \mathrm{mmol})$. During the addition a vigorous gas evolution took place and an exothermal reaction was observed. After 30 minutes the solution was concentrated and after 4 hour spectroscopically pure crystals of $\mathbf{1 d}$ had formed (2.01 g, $1.00 \mathrm{mmol}, 67 \%$ ). NMR Data: ${ }^{1} \mathrm{H}\left(400 \mathrm{MHz}, \mathrm{C}_{6} \mathrm{D}_{5} \mathrm{CD}_{3}, \delta\right)$ 1.32-1.12 (m, $\left.\mathrm{CH}_{3}, \mathrm{C}_{4} \mathrm{H}_{9}, 86 \mathrm{H}\right)$, 1.10-0.86 (m, $\mathrm{CH}$ and $\left.\mathrm{CH}_{2}, \mathrm{C}_{4} \mathrm{H}_{9}, 42 \mathrm{H}\right),-0.08\left(\mathrm{~s}, \mathrm{ZnCH}_{3}, 6 \mathrm{H}\right) ;{ }^{13} \mathrm{C}\left\{{ }^{1} \mathrm{H}\right\}\left(100 \mathrm{MHz}, \mathrm{C}_{6} \mathrm{D}_{5} \mathrm{CD}_{3}, \delta\right): 26.56,26.45$, 26.31, 26.12, 26.06, 26.02, 25.79 (s, $\left.\mathrm{CH}_{3}, \mathrm{CH}\left(\mathrm{CH}_{3}\right)_{2}\right)$ 24.81, 24.74, 24.58, 24.40, 24,29, 23.121, 22.84 (s, $\mathrm{CH}_{2} \mathrm{CH}$ and $\mathrm{CH}_{2} \mathrm{CH}\left(\mathrm{CH}_{3}\right)_{2}$, relative intensities $\left.1: 2: 1: 1: 2: 1: 1: 2: 2: 1\right) ;{ }^{29} \mathrm{Si}\left\{{ }^{1} \mathrm{H}\right\}\left(99.3 \mathrm{MHz}, \mathrm{C}_{6} \mathrm{D}_{6}, \delta\right):-57.55$, $62.57,-64.88,-65.36,-70.26$ (relative intensities $2: 1: 1: 2: 1$ )

\section{Synthesis of $\left\{\left(c-\mathrm{C}_{5} \mathrm{H}_{9}\right)_{7} \mathrm{Si}_{7} \mathrm{O}_{9}\left[\left(\mu_{3}-\mathrm{O}\right)_{2} \mathrm{Zn}\right](\mathrm{OH})\right\}_{2}(2 \mathrm{a})$}

Dimethyl zinc $(1.15 \mathrm{ml}, 2.30 \mathrm{mmol})$ was added to a solution of trisilanol $\left(\left(c-\mathrm{C}_{5} \mathrm{H}_{9}\right)_{7} \mathrm{Si}_{7} \mathrm{O}_{9}(\mathrm{OH})_{3}(2.02 \mathrm{~g}, 2.30\right.$ mmol). After methane evolution had taken place, the solution was stirred for another 30 minutes and subsequently evaporated to dryness. The remaining white waxy solid was stripped with hexanes. The white power (1.95 g, 1.10, mmol, $90 \%$ ) was spectroscopically pure. NMR Data: ${ }^{1} \mathrm{H}\left(400 \mathrm{MHz}, \mathrm{C}_{6} \mathrm{D}_{6}, \delta\right) 2.85$ (s, $\mathrm{SiOH}, 2 \mathrm{H}), 1.9-1.2\left(\mathrm{~m}, \mathrm{CH}_{2}, \mathrm{C}_{5} \mathrm{H}_{9}, 112 \mathrm{H}\right), 1.05-0.80\left(\mathrm{~m}, \mathrm{CH}, \mathrm{C}_{5} \mathrm{H}_{9}, 14 \mathrm{H}\right) ;{ }^{13} \mathrm{C}\left\{{ }^{1} \mathrm{H}\right\}\left(100 \mathrm{MHz}, \mathrm{C}_{6} \mathrm{D}_{6}, \delta\right): 27.36$, 27.26, 27.18, 27.13, 27.11, 26.99, 26.98, 26.94, 26.89, $26.84\left(\mathrm{~s}, \mathrm{CH}_{2}, \mathrm{C}_{5} \mathrm{H}_{9}\right), 22.29,22.17,22.16,22.02,21.48$ 
(s, CH, $\mathrm{C}_{5} \mathrm{H}_{9}$, relative intensities 2:1:1:2:1); ${ }^{29} \mathrm{Si}\left\{{ }^{1} \mathrm{H}\right\}(99.3 \mathrm{MHz}, \mathrm{C} 6 \mathrm{D6}, \delta):-53.97,-55.32,-55.67,-64.93,-$ 65.13 (relative intensities 1:1:2:1:2). Anal. Calcd. for $\left(\mathrm{C}_{35} \mathrm{H}_{64} \mathrm{ZnO}_{12} \mathrm{Si}_{7}\right)_{2}: \mathrm{C} 44.78 \%$, H $6.87 \%$. Found C 44.34 $\%$, H $6.58 \%$

\section{Synthesis of $\left\{\left(i-\mathrm{C}_{4} \mathrm{H}_{9}\right)_{7} \mathrm{Si}_{7} \mathrm{O}_{9}\left[\left(\mu_{3}-\mathrm{O}\right)_{2} \mathrm{Zn}\right](\mathrm{OH})\right\}_{2}(2 \mathrm{~d})$}

Dimethyl zinc $(0.81 \mathrm{ml}, 1.62 \mathrm{mmol})$ was added to a solution of trisilanol $\left(\left(i-\mathrm{C}_{4} \mathrm{H}_{9}\right)_{7} \mathrm{Si}_{7} \mathrm{O}_{9}(\mathrm{OH})_{3}(1.28 \mathrm{~g}, 1.62\right.$ mmol). After methane evolution had taken place, the solution was stirred for another 30 minutes and subsequently evaporated to dryness. The remaining white waxy solid was stripped with hexanes. The white power (1.47 g, $0.73 \mathrm{mmol}, 91 \%$ ) was spectroscopically pure. NMR Data: ${ }^{1} \mathrm{H}\left(400 \mathrm{MHz}, \mathrm{C}_{6} \mathrm{D}_{6}, \delta\right) 2.85$ (s, $\mathrm{SiOH}$, 2H),1.9-1.2 (m, $\left.\mathrm{CH}_{2}, \mathrm{C}_{5} \mathrm{H}_{9}, 112 \mathrm{H}\right), 1.05-0.80\left(\mathrm{~m}, \mathrm{CH}, \mathrm{C}_{5} \mathrm{H}_{9}, 14 \mathrm{H}\right) ;{ }^{13} \mathrm{C}\left\{{ }^{1} \mathrm{H}\right\}\left(100 \mathrm{MHz}, \mathrm{C}_{6} \mathrm{D}_{6}, \delta\right): 27.36,27.26$, 27.18, 27.13, 27.11, 26.99, 26.98, 26.94, 26.89, 26.84 (s, $\left.\mathrm{CH}_{2}, \mathrm{C}_{5} \mathrm{H}_{9}\right)$, 22.29, 22.17, 22.16, 22.02, 21.48 (s, CH, $\mathrm{C}_{5} \mathrm{H}_{9}$, relative intensities 2:1:1:2:1); Anal. Calcd. for $\left(\mathrm{C}_{28} \mathrm{H}_{64} \mathrm{ZnO}_{12} \mathrm{Si}_{7}\right)_{2}$ : C $39.34 \%$, H 7.55 \%. Found C 39.00 $\%$, H $7.39 \%$

\section{Synthesis of $\left\{\left(c-\mathrm{C}_{5} \mathrm{H}_{9}\right)_{7} \mathrm{Si}_{7} \mathrm{O}_{12}\right\}_{2}\left[\left(\mu_{3}-\mathrm{O}\right) \mathrm{Zn}\right]_{2}\left[\left(\mu_{3}-\mathrm{O}\right) \mathrm{ZnCl}(\mathrm{THF})\right]_{2}(3)$}

Methylzinc chloride (7.6 mL of a $1.3 \mathrm{M}$ solution in $\mathrm{Et}_{2} \mathrm{O} /$ toluene, $9.93 \mathrm{mmol}$ ) was added to a solution of the silsesquioxane trisilanol $\left(c-\mathrm{C}_{5} \mathrm{H}_{9}\right)_{7} \mathrm{Si}_{7} \mathrm{O}_{9}(\mathrm{OH})_{3}(2.90 \mathrm{~g}, 3.31 \mathrm{mmol})$ in toluene/THF $(20 \mathrm{~mL} / 10 \mathrm{~mL})$. The solution was stirred for 30 minutes until all the gas had evolved, and was subsequently concentrated until material started to precipitate. The solution was then heated up and slowly cooled down to yield crystals of 3 (2.55 g, 1.15 mmol, 69 \%). NMR Data: ${ }^{1} \mathrm{H}\left(400 \mathrm{MHz}, \mathrm{C}_{6} \mathrm{D}_{6}, \delta\right) 3.90\left(\alpha-\mathrm{CH}_{2}, \mathrm{THF}, 8 \mathrm{H}\right) 1.95\left(\beta-\mathrm{CH}_{2}, \mathrm{THF}, 8 \mathrm{H}\right), 1.8-1.1(\mathrm{~m}$, $\left.\mathrm{CH}_{2}, \mathrm{C}_{5} \mathrm{H}_{9}, 112 \mathrm{H}\right), 1.05-0.90\left(\mathrm{~m}, \mathrm{CH}, \mathrm{C}_{5} \mathrm{H}_{9}, 14 \mathrm{H}\right) ;{ }^{13} \mathrm{C}\left\{{ }^{1} \mathrm{H}\right\}\left(100 \mathrm{MHz}, \mathrm{C}_{6} \mathrm{D}_{6}, \delta\right): 69.12\left(\alpha-\mathrm{CH}_{2}, \mathrm{THF}\right), 28.00$, 27.94, 27.85, 27.66, 27.51, 27.21, 27.15, 27.05 (s, $\left.\mathrm{CH}_{2}, \mathrm{C}_{5} \mathrm{H}_{9}\right), 25.47$ ( $\beta-\mathrm{CH}_{2}$, THF), 24.10, 23.99, 23.79, 22.54, $22.11\left(\mathrm{~s}, \mathrm{CH}, \mathrm{C}_{5} \mathrm{H}_{9}\right.$, relative intensities 1:2:1:2:1); ${ }^{29} \mathrm{Si}\left\{{ }^{1} \mathrm{H}\right\}(99.3 \mathrm{MHz}, \mathrm{C} 6 \mathrm{D} 6, \mathrm{~d}):-57.73,-61.80,-63.96,-69.64$ (relative intensities $3: 1: 2: 1$ ).

\section{Synthesis of $\left.\left\{\left(c-\mathrm{C}_{6} \mathrm{H}_{11}\right)_{7} \mathrm{Si}_{7} \mathrm{O}_{12}\right\}_{2}\left(\mu_{3}-\mathrm{O}\right) \mathrm{Zn}\right]_{2}\left[\left(\mu_{3}-\mathrm{O}\right) \mathrm{ZnCH}_{3}(\mathrm{THF})\right]_{2}(4 \mathrm{~b})$}

THF $(5 \mathrm{~mL})$ was added to a solution of $\mathbf{1 b}(0.56 \mathrm{~g}, 2.74 \mathrm{mmol})$ in toluene $(20 \mathrm{~mL})$. This mixture was heated to reflux for 5 minutes and allowed to cool to room temperature. During concentration of the solution $4 \mathbf{b}$ precipitated as white crystalline material. After evaporation, $\mathbf{1 b}$ was found to be converted quantitatively to $\mathbf{4 b}$. NMR data: ${ }^{1} \mathrm{H}\left(400 \mathrm{MHz}, \mathrm{C}_{6} \mathrm{D}_{6}, \delta\right): 3.72\left(\alpha-\mathrm{CH}_{2}, \mathrm{THF}, 8 \mathrm{H}\right) 1.50\left(\beta-\mathrm{CH}_{2}, \mathrm{THF}, 8 \mathrm{H}\right), 2.4-1.2\left(\mathrm{~m}, \mathrm{CH}_{2}, \mathrm{C}_{6} \mathrm{H}_{11}\right.$, $140 \mathrm{H}), 1.2-1.00\left(\mathrm{~m}, \mathrm{CH}, \mathrm{C}_{5} \mathrm{H}_{9}, 14 \mathrm{H}\right),-0.05\left(\mathrm{~s}, \mathrm{Zn}\left(\mathrm{CH}_{3}\right), 6 \mathrm{H}\right) ;{ }^{13} \mathrm{C}\left\{{ }^{1} \mathrm{H}\right\}\left(100 \mathrm{MHz}, \mathrm{CDCl}_{3}, \delta\right): 68.05\left(\alpha-\mathrm{CH}_{2}\right.$, THF), 28.28, 28.20, 28.07, 27.84, 27.74, 27.70, 27.67, 27.58, 27.46, 27.26, 27.16 (s, $\left.C_{2}, \mathrm{C}_{5} \mathrm{H}_{9}\right), 25.60\left(\beta-C \mathrm{H}_{2}\right.$, THF), 25.71, 25.64, 25.47, 24.15, $23.66\left(\mathrm{~s}, \mathrm{CH}, \mathrm{C}_{6} \mathrm{H}_{11}\right.$, relative intensities 2:1:1:2:1), -14.14 (s, $\left.\mathrm{Zn}\left(\mathrm{CH}_{3}\right)_{2}\right)$

\section{Synthesis of $\left\{\left(c-\mathrm{C}_{5} \mathrm{H}_{9}\right)_{7} \mathrm{Si}_{7} \mathrm{O}_{12}\right\}_{2}\left[\left(\mu_{3}-\mathrm{O}\right) \mathrm{Zn}\right]_{2}\left[\left(\mu_{3}-\mathrm{O}\right) \mathrm{ZnCH}_{3} \text { (pyridine) }\right]_{2}$ (5a)}

THF $(5 \mathrm{~mL})$ was added to a solution of $\mathbf{1 a}$ in toluene $(20 \mathrm{~mL})$. This mixture was heated to reflux for 5 minutes and allowed to cool to room temperature. During concentration of the solution 5a precipitated as white crystalline material. NMR data: ${ }^{1} \mathrm{H}\left(400 \mathrm{MHz} \mathrm{CDCl}_{3}, \delta\right): 8.1-7.1$ (py $\left.5 \mathrm{H}\right), 1.8-1.3\left(\mathrm{~m}, \mathrm{CH}_{2}, \mathrm{C}_{5} \mathrm{H}_{9}, 112 \mathrm{H}\right), 1.0-$ $0.80\left(\mathrm{~m}, \mathrm{CH}, \mathrm{C}_{5} \mathrm{H}_{9}, 14 \mathrm{H}\right),-0.63\left(\mathrm{~s}, \mathrm{Zn}\left(\mathrm{CH}_{3}\right), 6 \mathrm{H}\right) ;{ }^{13} \mathrm{C}\left\{{ }^{1} \mathrm{H}\right\}\left(100 \mathrm{MHz}, \mathrm{CDCl}_{3}, \delta\right): 27.98,27.82,27.68,27.42$, 
27.35, 27.21, 27.13, 27.06, 27.03, $26.99\left(\mathrm{~s}, \mathrm{CH}_{2}, \mathrm{C}_{5} \mathrm{H}_{9}\right), 24.10,23.99,23.79,22.46,22.22\left(\mathrm{~s}, \mathrm{CH}, \mathrm{C}_{5} \mathrm{H}_{9}\right.$, relative intensities $1: 2: 1: 2: 1),-15.46\left(\mathrm{~s}, \mathrm{Zn}\left(\mathrm{CH}_{3}\right)\right)$

\section{Synthesis of $\left.\left\{\left(c-\mathrm{C}_{6} \mathrm{H}_{11}\right)_{7} \mathrm{Si}_{7} \mathrm{O}_{12}\right\}_{2}\left(\mu_{3}-\mathrm{O}\right) \mathrm{Zn}\right]_{2}\left[\left(\mu_{3}-\mathrm{O}\right) \mathrm{Zn}(\mathbf{a c a c})\right]_{2}(6 \mathbf{a})$}

Acetylacetone $(0.95 \mathrm{~g}, 0.95 \mathrm{mmol})$ was added to a solution of $\mathbf{1 a}(1.0 \mathrm{~g}, 0.45 \mathrm{mmol})$ in toluene/THF (20/10 $\mathrm{mL}$ ). Methane gas evolved over the period of 5 minutes. and the solution was stirred for $30 \mathrm{~min}$. Concentration of the solution yielded microcrystalline 6a $(0.60 \mathrm{~g}, 0.25 \mathrm{mmol}, 56 \%)$. NMR Data: ${ }^{1} \mathrm{H}\left(400 \mathrm{MHz}, \mathrm{C}_{6} \mathrm{D}_{6}, \delta\right) 5.38$ (s, $\mathrm{CH}$, acac, 2H), 1.90, (s, $\mathrm{CH}_{3}$, acac, $\left.12 \mathrm{H}\right), 1.9-1.1$ (m, $\left.\mathrm{CH}_{2}, \mathrm{C}_{5} \mathrm{H}_{9}, 112 \mathrm{H}\right), 1.10-0.90$ (m, $\left.\mathrm{CH}, \mathrm{C}_{5} \mathrm{H}_{9}, 14 \mathrm{H}\right)$; ${ }^{13} \mathrm{C}\left\{{ }^{1} \mathrm{H}\right\}(100 \mathrm{MHz}, \mathrm{C} 6 \mathrm{D} 6, \delta): 194.01$ (s, CO, acac), 100.04 (s, CH, acac), 27.94, 27.88, 27.72, 27.58, 27.38, 27.24, 27.21, 27.17, 27.10, 27.02 (s, $\left.\mathrm{CH}_{2}, \mathrm{C}_{5} \mathrm{H}_{9}\right), 26.97$ (s, $\mathrm{CH}_{3}$, acac), 24.16, 2.85, 23.57, 22.58, 22.34 (s, CH, $\mathrm{C}_{5} \mathrm{H}_{9}$, relative intensities 1:2:1:2:1); ${ }^{29} \mathrm{Si}\left\{{ }^{1} \mathrm{H}\right\}\left(99.3 \mathrm{MHz}, \mathrm{CDCl}_{3}, \mathrm{~d}\right)$ : $-57.92,-61.92,-64.19,-64.70,-70.09$ (relative intensities $2: 1: 1: 2: 1$ ).

\section{Reaction of 1a with methanol}

Methanol $(40 \mathrm{mg})$ was added to a solution of $1 \mathrm{a}(1.3 \mathrm{~g}, 0.64 \mathrm{mmol})$ in toluene $(20 \mathrm{~mL})$, this solution was stirred for 40 minutes. After this time, the solution turned into a gel-like polymer. Removal of the toluene was only partially successful, and NMR data could not be obtained.

\section{Crystal structure determinations of 1 a}

A colorless parallelepiped-shaped crystal mounted on a glass fiber was aligned on a Bruker SMART APEX CCD diffractometer with a $4 \mathrm{~K} C C D$ detector set $60.0 \mathrm{~mm}$ from the crystal. Intensity measurements were performed using graphite monochromated Mo-K $\alpha$ radiation. Data integration and global cell refinement were performed with the program $S A I N T$. Intensity data were corrected for Lorentz and polarization effects, scale variation, decay and absorption. The program suite SHELXTL was used for space group determination (XPREP). The structure was solved by Patterson methods and extension of the model was accomplished by direct methods applied to difference structure factors using the program DIRDIF. The positional and anisotropic displacement parameters for the non-hydrogen atoms were refined. The hydrogen atoms were included in the final refinement riding on their carrier atoms. Refinement was complicated by a twin problem. After introduction of the suggested twin-rotation-matrix of PLATON and refining with option HKLF 5 the remainder of the structure refined smoothly. All refinement calculations and graphics were performed with the program packages SHELXL, PLATON and a locally modified version of the program PLUTO. Structure checking and calculations were performed with the PLATON package. The final results were checked for missed symmetry with PLATON/MISSYM option and solvent accessible voids with the PLATON/SOLV option.

\section{Crystal structure determinations of $\mathbf{1 b}$}

Intensity data for $\mathbf{1 b}$ were collected on a Nonius KappaCCD diffractometer with rotating anode $(\mathrm{Mo} K \alpha, \lambda=$ $0.71073 \AA$ ) at $150 \mathrm{~K}$. An absorption correction was considered unnecessary in all cases. The structures were solved by direct methods (SHELXS97 for 1a) and refined on $F^{2}$ by least-squares procedures using SHELXL97. All non-hydrogen atoms were refined with anisotropic displacement parameters. Hydrogen atoms were constrained to idealized geometries and allowed to ride on their carrier atoms with an isotropic displacement 
parameter related to the equivalent displacement parameter of their carrier atoms. Structure validation and molecular graphics preparation were performed with the PLATON package. Due to defects in the crystal that could not be corrected for, the crystal structure is not of publishable quality, although the general connectivity can be considered correct.

\section{Crystal structure determinations of 3}

Intensity data for 3 were collected on a Nonius KappaCCD diffractometer with rotating anode (Mo $K \alpha, \lambda=$ $0.71073 \AA$ ) at $150 \mathrm{~K}$. An absorption correction was considered unnecessary in all cases. The structures were solved by direct methods (SHELXS97 for 1a) and refined on $F^{2}$ by least-squares procedures using SHELXL97 All non-hydrogen atoms were refined with anisotropic displacement parameters. Hydrogen atoms were constrained to idealized geometries and allowed to ride on their carrier atoms with an isotropic displacement parameter related to the equivalent displacement parameter of their carrier atoms. Structure validation and molecular graphics preparation were performed with the PLATON package. The asymmetric unit contains half of the centrosymmetric silsesquioxane complex. Six of the seven independent cyclopentyl rings, as well as the one independent coordinated THF molecule, are disordered over two conformations.

Table 3. crystal structure data for compounds $\mathbf{1 a}, \mathbf{1 b}$ and $\mathbf{3}$

\begin{tabular}{|c|c|c|c|}
\hline Compound & 1a & $1 b$ & 3 \\
\hline Formula & $\mathrm{C}_{72} \mathrm{H}_{132} \mathrm{O}_{24} \mathrm{Si}_{14} \mathrm{Zn}_{4}$ & $\mathrm{C}_{86} \mathrm{H}_{160} \mathrm{O}_{24} \mathrm{Si}_{14} \mathrm{Zn}_{4}\left(\mathrm{C}_{7} \mathrm{H}_{8}\right)$ & $\mathrm{C}_{78} \mathrm{H}_{142} \mathrm{Cl}_{2} \mathrm{O}_{26} \mathrm{Si}_{14} \mathrm{Zn}_{4}$ \\
\hline $\mathrm{M}_{\mathrm{w}}, \mathrm{g} \cdot \mathrm{mol}^{-1}$ & 2036.58 & 2325.01 & 2221.56 \\
\hline Space group & $\mathrm{P} 2{ }_{1} / \mathrm{n}$, No. 14 & $\mathrm{P}_{1}$ (No. 2) & $\mathrm{P} 2{ }_{1} / \mathrm{c}$, No. 14 \\
\hline $\mathrm{a}, \AA$ & $15.3106(7)$ & $17.5335(4)$ & $16.2001(3)$ \\
\hline $\mathrm{b}, \AA$ & $22.908(1)$ & $18.2870(8)$ & $19.1026(3)$ \\
\hline $\mathrm{c}, \AA$ & $26.557(1)$ & $21.2003(5)$ & $20.9868(3)$ \\
\hline$\alpha,{ }^{\circ}$ & 90 & $69.9344(8)$ & 90 \\
\hline$\beta, \circ$ & $92.874(1)$ & $85.3602(8)$ & $128.2930(9)$ \\
\hline$\gamma,{ }^{\circ}$ & 90 & $64.4970(10)$ & 90 \\
\hline $\mathbf{V}, \AA^{3}$ & $9302.8(7)$ & $5744.9(2)$ & $5097.35(16)$ \\
\hline Z & 4 & 2 & 2 \\
\hline $\mathrm{T}, \mathrm{K}$ & 125 & 150 & 150 \\
\hline$\rho_{\text {calc }}$, g.cm ${ }^{-3}$ & 1.454 & 1.344 & 1.447 \\
\hline \multirow[t]{2}{*}{$\lambda, \AA$} & 0.71073 & 0.71073 & 0.71073 \\
\hline & $(\mathrm{MoK} \alpha)$ & $(\mathrm{Mo} \mathrm{K} \alpha)$ & $(\mathrm{MoK} \alpha)$ \\
\hline$\mu, \mathrm{cm}^{-1}$ & 12.57 & 1.035 & 12.15 \\
\hline \multirow[t]{2}{*}{$\mathrm{R}(\mathrm{F})$ (reflections) } & 0.0689 & 0.1152 & 0.054 \\
\hline & $(15423)^{\mathrm{a}}$ & $(20135)$ & $(6477)^{\mathrm{a}}$ \\
\hline \multirow[t]{2}{*}{$\mathrm{R}_{\mathrm{w}}\left(\mathrm{F}^{2}\right)$ (reflections) } & 0.1986 & 0.3274 & 0.1350 \\
\hline & $(22995)^{b}$ & (12780) & $(10016)^{\mathrm{c}}$ \\
\hline
\end{tabular}




\section{Bibliography}

[1] Hannant,M.D.; Schormann,M.; Bochmann,M. J.Chem.Soc.Dalton Trans. 2002, 4071

[2] Chisholm,M.H.; Gallucci,J.C.; Zhen,H. Inorg.Chem. 2001, 40, 5051

[3] Chisholm,M.H.; Gallucci,J.C.; Phomphrai,K. Inorg.Chem. 2001, 2785

[4] O'Keefe,B.J.; HillMyer,M.A.; Tolman,W.B. J.Chem.Soc.Dalton Trans. 2001, 2215

[5] Prust,J.; Stasch,A.; Zheng,W.; Roesky,H.W.; Alexopoulus,E.; Usón,I.; Böhler,D.; Schuchart,T. Organometallics 2001, 38, 3825

[6] Cheng,M.; Moore,D.R.; Reczek,J.J.; Chamberlain,B.M.; Lobkovsky,E.B.; Coates,G.W. J.Am.Chem.Soc. 2001, 123, 8738-8749.

[7] Driess,M.; Merz,K.; Rell,S. Eur.J.Inorg.Chem. 2000, 2517-2522.

[8] Chisholm,M.H.; Eilerts,N.W.; Huffman,J.C.; Iyer,S.S.; Pacold,M.; Phomphrai,K. J.Am.Chem.Soc. 2000, $122,11845-11854$.

[9] Dove,A.P.; Gibson,V.C.; Marshall,E.L.; White,A.J.; Williams,D.J. Chem.Commun. 2001, 283-284.

[10] Dubois,Ph.; Ropson,N.; Jérôme,R.; Teyssié,Ph. Macromol. 1996, 1965-1975.

[11] Giesbrecht,G.R.; Whitener,G.D.; Arnold,J. J.Chem.Soc.Dalton Trans. 2001, 923-9237.

[12] Ovitt,T.M.; Coates,G.W. J.Am.Chem.Soc. 2002,

[13] Chisholm,M.H.; Huffman,J.C.; Phomphrai,K. J.Chem.Soc.Dalton Trans. 2001, 222-224.

[14] Seyferth,D. Organometallics 2001, 20, 2940-2955.

[15] Duchateau,R.; Gerritsen,G.; Van Santen,R.A.; Yap,G.P. Organometallics 2003, 22, 100-110.

[16] Krieger,M.; Gould,R.O.; Neumuller,B.; Harms,K.; Dehnicke,K. Z.anorg.allg.Chem. 1998, 624, 1434

[17] Hartmann,F.; Klaui,W.; Kramer-Aach,A.; Mootz,D.; Strerath,A.; Wunderlich,H. Z.anorg.allg.Chem. 1993, 619, 2071

[18] Wright,C.A.; Shapley,J.R. Inorg.Chem. 2001, 40, 6338

[19] Pang,J.; Marcotte,E.J.P.; Seward,C.; Brown,R.S.; Wang,S. Angew.Chem.Int.Ed. 2001, 40, 4042

[20] Yu,R.-C.; Hung,C.-H.; Huang,J.-H.; Lee,H.-Y.; Chen,J.-T. Inorg.Chem. 2002, 41, 6450-6455.

[21] Cheng,M.; Attygalle,A.B.; Lobkovsky,E.B.; Coates,G.W. J.Am.Chem.Soc. 1999, 121, 11583-11584.

[22] Brown,J.F., Jr.; Vogt,L.H., Jr. J.Am.Chem.Soc. 1965, 87, 4313-4317.

[23] Feher,F.J.; Newman,D.A. J.Am.Chem.Soc. 1990, 112, 1931-1936.

[24] Feher,F.J.; Budzichowski,T.A.; Blanski,R.L.; Weller,K.J.; Ziller,J.W. Organometallics 1991, 10, 2526 


\section{The formation of heterobimetallic silsesquioxane clusters}

2 he reaction of easily protolyzable reagents like dialkyl magnesium or dialkyl zinc silsesquioxanes with residual reactive silanol groups. The groups can be reacted with main group and transition metal species to form new heterobimetallic silsesquioxane complexes. Depending on the secondary reagent, either the expected heterobimetallic compound is formed, or a transmetallation occurs. A heterometallic magnesium-vanadium complex of this type was found to be active in ethene polymerization. 


\section{Introduction}

The controlled synthesis of heterometallic silsesquioxane complexes has not yet been described in literature. Although Feher et al. mentioned the synthesis of mixed trivalent Group IV, V and VI transition metals, these compounds were obtained by concurrent reaction of the respective metal halides with the silsesquioxane trisilanol ligands in the presence of a base (as shown in Figure 1, compound A). ${ }^{1}$ This approach led to the formation of a statistical distribution of heterobimetallic complexes in which the reactivity of the metal precursor is the determining factor for the amount of each metal incorporated in the complex. Control of the amounts of metal is therefore very difficult and can only be achieved by carefully tuning the amount of metal to the relative reactivity.
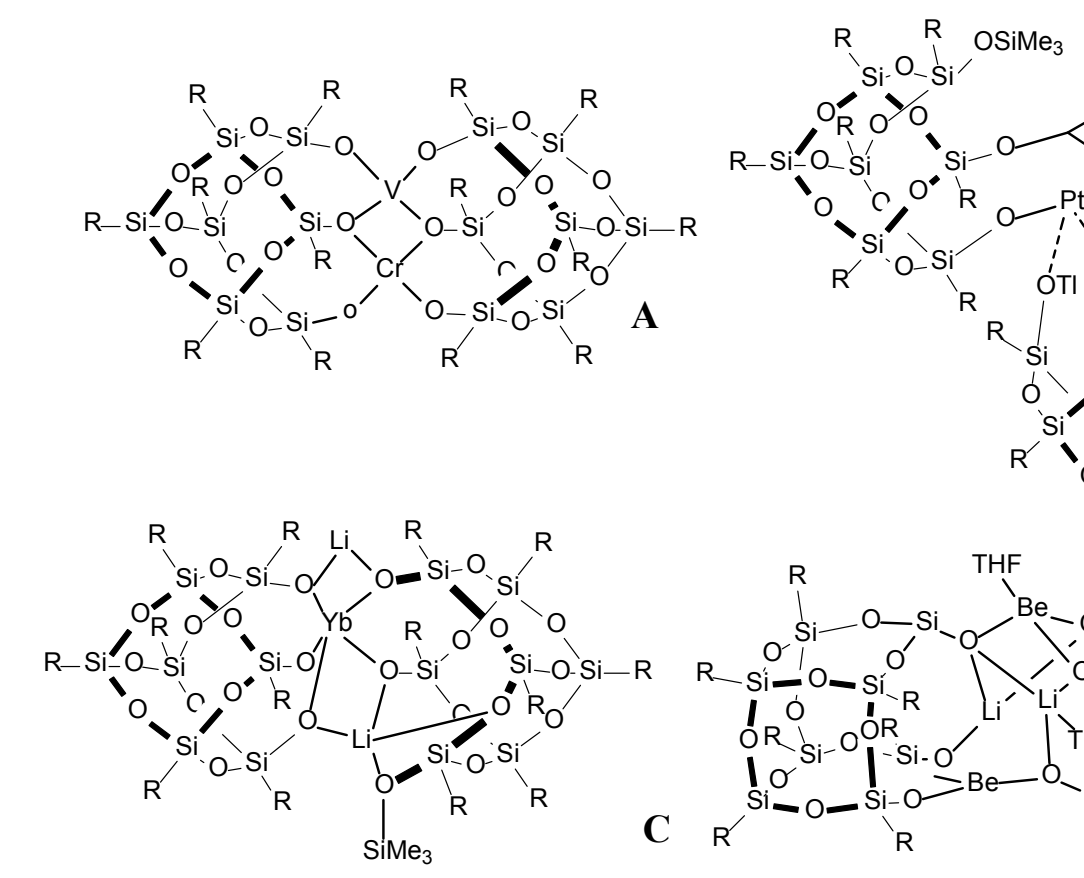

$$
\text { A }
$$

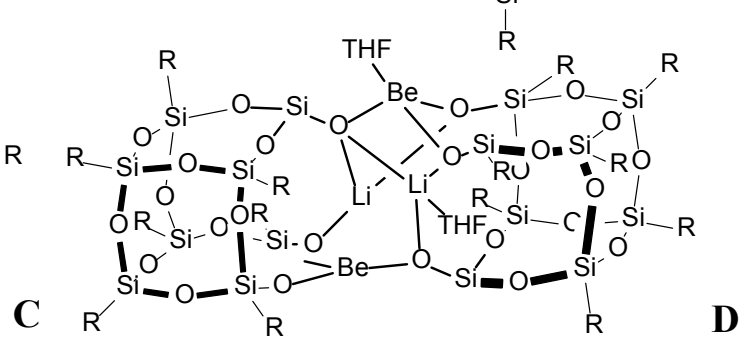

Figure 1. Some occurences of heterobimetallic silsesquioxane complexes in literature

A more common occurrence of heterometallic silsesquioxane complexes is the unanticipated inclusion of residual lithium or thallium ions in the complex. Aspinall et al., ${ }^{2}$ Edelmann et al. ${ }^{3}$ and Johnson et al. ${ }^{4}$ have prepared some examples of this type of complexes through attempts of transmetallation with the respective metal ions. Also this way of synthesizing heterometallic complexes can lead to unexpected results as shown in the examples above (Figure 1, compounds $\mathbf{B}, \mathbf{C}$ and $\mathbf{D})$. The inclusion of the salt can usually be rationalized in terms of filling coordination requirements of either metals or silsesquioxane ligand, but is hard to predict beforehand, because it is usually an unwanted step in the way to an anticipated product. 
It would be better to build bimetallic complexes in a stepwise fashion. Common methods to build complexes in this way are e.g. the compartmentalization of the ligand or the stepwise addition of metal salts to the complex precursor. Mirkin et al. presented a recent example of compartmentalization, where they designed a ligand with two selective coordinating sites, a phosphine-thioether group for rhodium and salicylaldiminato group for zinc. ${ }^{5}$ The order of addition of the metal precursors did not matter because of the preferential coordination of the metal to the different sites. An example of the second method (stepwise addition of the metal salts) is presented by de Blas et al. ${ }^{6}$ in a recent paper with symmetrical macrocyclic Schiff base ligands. A lanthanide complex of these ligands was treated with a solution of zinc nitrate to yield 1:1 lanthanide-zinc heterobinuclear complexes. A second example of this method was presented by Hidai et al. ${ }^{7} \mathrm{Cp}^{*} \mathrm{Rh}\left(\mathrm{PMe}_{3}\right)(\mathrm{SH})_{2}$ was treated with metal halides $\left(\mathrm{TiCl}_{4}, \mathrm{CpTiCl}_{3}\right.$, $\left.\mathrm{VCl}_{3}\right)$ to yield the appropriate heterobimetallic complexes $\mathrm{Cp}{ }^{*} \mathrm{Rh}\left(\mathrm{PMe}_{3}\right)\left(\mu^{2}-\mathrm{S}_{2}\right)\left(\mathrm{TiL}_{\mathrm{n}}\right)$ (with $\mathrm{L}=\mathrm{Cl}$ or $\mathrm{Cp})$ or the cationic heterotrimetallic complex $\left[\mathrm{Cp}^{*} \mathrm{Rh}\left(\mathrm{PMe}_{3}\right)\left(\mu^{2}-\mathrm{S}_{2}\right) \mathrm{V}\left(\mu^{2}-\mathrm{S}_{2}\right)\right.$ $\left.\mathrm{Rh}\left(\mathrm{PMe}_{3}\right) \mathrm{PMe}_{3}\right]^{+}$.

The formations of monometallic, polynuclear silsesquioxane complexes are described in detail in Chapters 2 and 3. In these chapters, a stepwise formation mechanism for this type of complexes is proposed. In this chapter the related synthesis of some heterobimetallic silsesquioxane complexes is described. It is shown that the approach is valid for the synthesis of complexes based on precursors that are highly reactive towards silanol protons, like metal alkyls.

\section{Heterobimetallic main group metal complexes}

Recently, Liu et al. reported the synthesis of silsesquioxane ligated magnesium complexes. ${ }^{8 ; 9}$ The reaction of the cyclohexyl substituted silsesquioxane trisilanol $\left(c-\mathrm{C}_{6} \mathrm{H}_{11}\right)_{7} \mathrm{Si}_{7} \mathrm{O}_{9}(\mathrm{OH})_{3}$ with an dialkyl magnesium compound in boiling heptane yielded a mixture of three distinct magnesium silsesquioxane complexes that could not be separated. Upon repetition of this experiment in our labs in coordinating solvents, we found the same mixture of compounds. However, for the cyclopentyl substituted silsesquioxane ligand, a different chemistry was found. The reaction of the silsesquioxane trisilanol $\left(c-\mathrm{C}_{5} \mathrm{H}_{9}\right)_{7} \mathrm{Si}_{7} \mathrm{O}_{9}(\mathrm{OH})_{3}$ (1) with one equivalent of dimethyl magnesium in THF proceeds rapidly, with the release of methane gas, even when performed at $-40^{\circ} \mathrm{C}$ (Scheme 1). NMR data of 2 are consistent with a silsesquioxane complex in which two of the three silanol groups have reacted with the dialkyl 
magnesium compound and the third silanol is left unreacted, as shown in Scheme 1 (reaction i). No other reaction product could be isolated.

Distinct differences in silanol-mediated reactions are probably caused by the steric properties of the cycloalkyl substituents on the silicon atoms. This contrast in chemical behavior was also observed in the synthesis of aluminum silsesquioxanes, where the cyclopentyl substituted aluminum complexes led to polymers, whereas the cyclohexyl silsesquioxane formed molecularly defined complexes. ${ }^{10}$ A similar result was obtained in the reaction of Grignard reagents with silsesquioxane trisilanol. In this case the reaction of the cyclopentyl and cycloheptyl substituted trisilanol lead to a dimeric tetra-magnesium complex while the cyclohexyl silsesquioxane led to a polymeric substance. ${ }^{11}$ The synthesis of a heterobimetallic complex based on $\mathbf{2}$ and containing zinc is relatively easy and can be accomplished by the addition of methyl zinc chloride to a solution of 2 in THF (as shown in Scheme 1, reaction ii). Properties of this bimetallic compound 4 will be discussed in the next section.

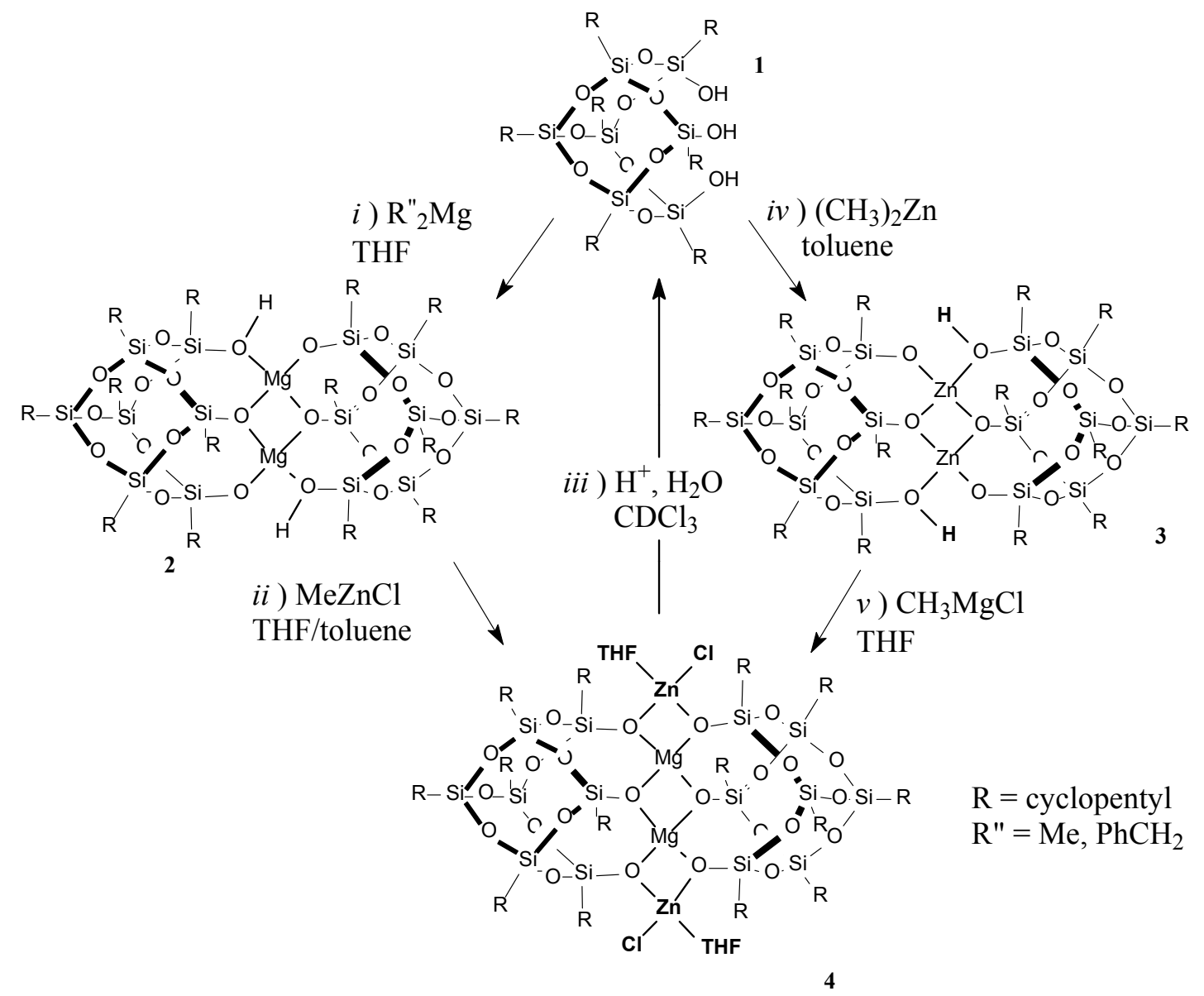

Scheme 1. Synthesis of compounds 2,3 and 4 by stepwise addition of magnesium and zinc reagents 
The introduction of zinc in a silsesquioxane silanolate framework is readily achieved as shown in Chapter 3 by the clean reaction with one equivalent of dimethyl zinc. After the evolution of gas was completed, the product 3 was isolated and shown to have silanol groups available for further reaction. The addition of two equivalents of methyl magnesium chloride to a solution of $\mathbf{3}$ caused the dismissal of methane gas and subsequent precipitation of the heterometallic complex 4 from toluene. ${ }^{1} \mathrm{H}$ - and ${ }^{13} \mathrm{C}$-NMR spectra are indicative of a similar $\mathrm{C}_{2 \mathrm{v}}$-symmetry as found in the complexes described in Chapters 2 and 3. Compound 4 is a white solid crystalline material that is moderately soluble in chloroform, THF and aromatic solvents. Its water stability is comparable to the metal chloride complexes described in Chapters 2 and 3, and the addition of acidified water causes quantitative hydrolysis of the complex to the pure starting material. Compound $\mathbf{4}$ could be crystallized from toluene/THF to yield single crystals suitable for X-ray crystal structure analysis. The ORTEP drawing of the crystal structure of $\mathbf{4}$ is shown in Figure 2. Selected bond lengths and bond angles are given in Table 1.

Table 1. Selected bond lengths $(\AA)$ and angles $\left(^{\circ}\right)$ for 4.

\begin{tabular}{llcl}
\hline & \multicolumn{3}{c}{ Bond lengths } \\
\hline $\mathrm{Zn}-\mathrm{Cl}$ & $\mathrm{Mg}-\mathrm{O} 5 \mathrm{a}$ & $1.963(2)$ \\
$\mathrm{Zn}-\mathrm{O} 13$ & $2.014(2)$ & $\mathrm{Mg}-\mathrm{O} 6$ & $1.9512(18)$ \\
$\mathrm{Zn}-\mathrm{O} 4$ & $1.9663(18)$ & $\mathrm{Si} 4-\mathrm{O} 4$ & $1.6101(17)$ \\
$\mathrm{Zn}-\mathrm{O} 5 \mathrm{a}$ & $1.9790(18)$ & $\mathrm{Si} 5-\mathrm{O} 6$ & $1.6113(15)$ \\
$\mathrm{Mg}-\mathrm{O} 4$ & $1.9574(18)$ & $\mathrm{Si}-\mathrm{O} 5$ & $1.6172(17)$ \\
& & Bond angles & $136.85(11)$ \\
$\mathrm{Cl}-\mathrm{Zn}-\mathrm{O} 13$ & $105.69(7)$ & $\mathrm{Si} 4-\mathrm{O} 4-\mathrm{Zn}$ & $127.56(11)$ \\
$\mathrm{Cl}-\mathrm{Zn}-\mathrm{O} 4$ & $124.58(5)$ & $\mathrm{Si} 5-\mathrm{O} 4-\mathrm{Mg}$ & $130.60(11)$ \\
$\mathrm{Zn}-\mathrm{O} 4-\mathrm{Mg}$ & 93.53 & $\mathrm{Si} 5-\mathrm{O} 6-\mathrm{Mg}(\mathrm{a})$ & $135.68(11)$ \\
$\mathrm{Zn}-\mathrm{O} 5 \mathrm{a}-\mathrm{Mg}$ & $93.96(13)$ & $\mathrm{Si} 6-\mathrm{O} 5-\mathrm{Mg}(\mathrm{a})$ & $129.65(11)$ \\
$\mathrm{Mg}-\mathrm{O} 6-\mathrm{Mg}(\mathrm{a})$ & $92.95(13)$ & $\mathrm{Si}-\mathrm{O}-\mathrm{Zn}$ & $129.85(19)$ \\
$\mathrm{O} 4-\mathrm{Zn}-\mathrm{O} 5 \mathrm{a}$ & $86.16(13)$ & $\mathrm{O} 4-\mathrm{Mg}-\mathrm{O} 6$ & $117.71(7)$ \\
$\mathrm{O} 4-\mathrm{Mg}-\mathrm{O} 5 \mathrm{a}$ & $85.37(13)$ & $\mathrm{O} 5 \mathrm{a}-\mathrm{Mg}-\mathrm{O} 6 \mathrm{a}$ & $130.63(7)$ \\
$\mathrm{O} 6-\mathrm{Mg}-\mathrm{O} 6 \mathrm{a}$ & $87.05(13)$ &
\end{tabular}

Standard deviations in the last decimal place are given in parentheses. 


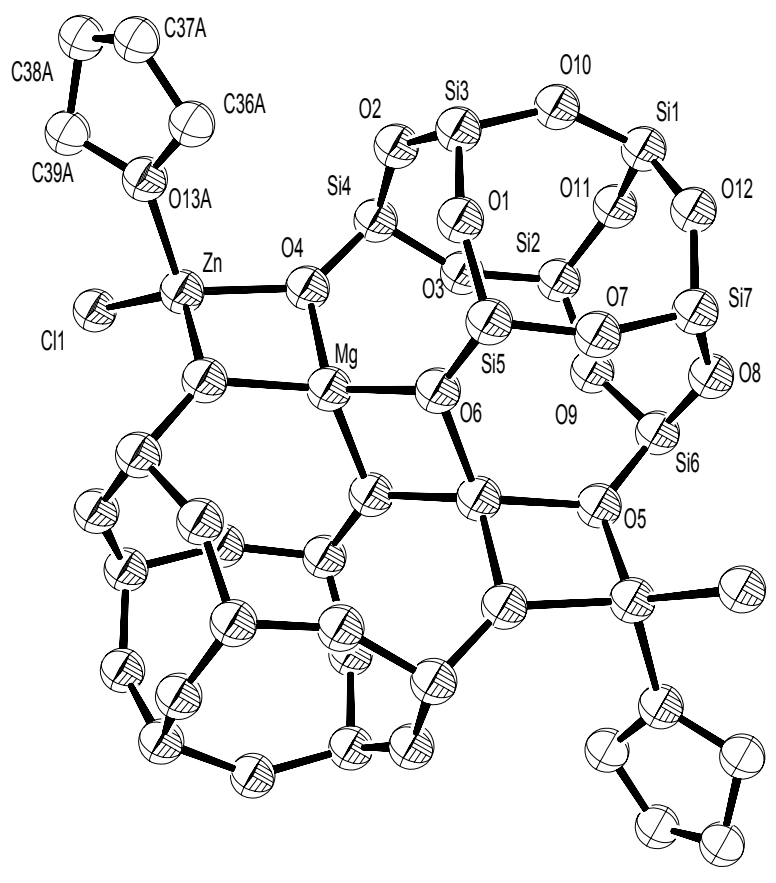

Figure 2. Crystal structure of the heterobimetallic zinc-magnesium silsesquioxane complex 4

The monoclinic unit cell contains two units of the title compound and twelve THF solvent molecules separated by normal van der Waals distances. Each asymmetric unit contains half a molecule of 4, and three lattice THF solvent molecules, of which two are disordered and one did not refine well in PLATON.

The structure determination shows 4 to be an inversion symmetric, tetranuclear and heterobimetallic magnesium zinc species. The magnesium atoms are connected to two silsesquioxane ligands via three crystallographically different oxygen atoms, of which one oxygen atom (O6) is $\mu_{3}$-bonded to the magnesium atoms and two oxygen atoms $(\mathrm{O} 4, \mathrm{O} 5)$ are $\mu_{3}$-bonded to both magnesium and zinc atoms. The zinc atom is connected to one chloride and to two silsesquioxane ligands via two oxygen atoms. To complete the tetrahedral coordination sphere of $\mathrm{Zn}$, this zinc atom also has one coordinated THF molecule.

The four metal atoms are incorporated in an interlayer between the two trianionic silsesquioxide ligands. This interlayer consists of three almost planar four-membered metallaoxocycles, alternatingly perpendicular to each other, in which the four metal atoms are 
in a linear structure (the dihedral angle of $\mathrm{Zn}(\mathrm{a})-\mathrm{Mg}(\mathrm{a})-\mathrm{Mg}-\mathrm{Zn}$ is $180^{\circ}$ ). The two outer metallaoxocycles are virtually planar (the sum of all angles is $358.4^{\circ}$ ) and the oxygen atoms are bent slightly out of plane toward the coordinated THF molecule. The inner metallaoxocycle is perfectly planar (sum of all angles is $360.0^{\circ}$ ).

The crystallographic positions of the metal atoms are not completely occupied by the designated metal. The initial state of the complex (i.e. the zinc atoms situated in the inner sphere) is relatively stable and the exchange process was not completed in the samples that were measured. The relative occupation of site 1 (designated as the site of magnesium) is $91 \%$ magnesium and $9 \%$ zinc. The relative occupation of site 2 (designated as the site of zinc) is $6 \%$ magnesium and $94 \%$ zinc.

The metal atoms are in a pseudo-tetrahedral surrounding with angles between the directly connected atoms ranging from $85^{\circ}$ to $124^{\circ}$. The average $\mathrm{M}-\mathrm{O}-\mathrm{M}(\mathrm{M}=\mathrm{Mg}, \mathrm{Zn})$ is $89.73^{\circ}$, which is in line with results found in the Cambridge Crystallographic Database (CCD) where angles ranged from $79.1^{\circ}$ to $95.1^{\circ}$. The magnesium-oxygen bonds are consistent with those compiled by Holloway and Melnik ${ }^{12}$ for tetracoordinated magnesium compounds (1.819$2.219 \AA$ ). The zinc-oxygen bond lengths are also comparable to their congeners in Chapter 3 and for complexes found in the CCD. The $\mathrm{Zn}-\mathrm{Cl}$ bond length is also very short, again indicative of the electron-withdrawing effect of the silsesquioxane ligand and/or the innercore metallaligand.

Although the zinc atoms were initially in the inner positions of the complex, they were exchanged with magnesium upon addition of the Grignard reagent. The exchange is slow as reflected by the crystal structure, where the two metals were only partially exchanged. This could also be noticed in the methine region of the ${ }^{13} \mathrm{C}-\mathrm{NMR}$. After stirring for a short time (less than 30 minutes) after the addition of the Grignard reagent, small signals of an impurity could still be observed. Stirring overnight (and heating to keep the compound in solution) completely removed these signals yielding spectroscopically pure material. The exchange of zinc and magnesium atoms in siliceous materials such as silsesquioxanes and silica-like materials is uncommon and was only previously described by Erxleben et al. for salicylaldiminato ligands. ${ }^{13}$ Usually the exchange is reverse as stated in the order of the Irving-Williams series. ${ }^{14}$ Although the order of the Irving-Williams series is said to be rather 
independent of the ligand, the substitution can be rationalized by the differences in hardness of the metal. Zinc can be considered a soft metal, while magnesium is hard. The difference in hardness (and therefore also the difference in oxophilicity) causes magnesium to preferentially be in the oxygen-rich surrounding, while the zinc atom will be preferentially in the softer surrounding of the chlorine atom and the coordinated THF molecule.

The mechanism of this exchange is yet unknown, but it is reasonable to assume that that the first step is the reaction of the remaining silanol groups with the Grignard species, just as stated in Chapters 2 and 3 (Scheme 2). Following the exchange reaction by NMR spectroscopy is frustrated by the fact that methane gas is released in the reaction. The occurrence of small residual resonances in the NMR spectrum of the not completely converted compound $(\mathbf{E})$ with the same symmetry as the end product $\left(\mathrm{C}_{2 \mathrm{v}}\right.$, indicated by the ratio of 2:2:1:1:1 in the resonances in ${ }^{13} \mathrm{C}$ - and ${ }^{29} \mathrm{Si}-\mathrm{NMR}$ ) and the spectroscopic absence of other intermediates indicate that the exchange reaction is very fast after an initial activation barrier is overcome.

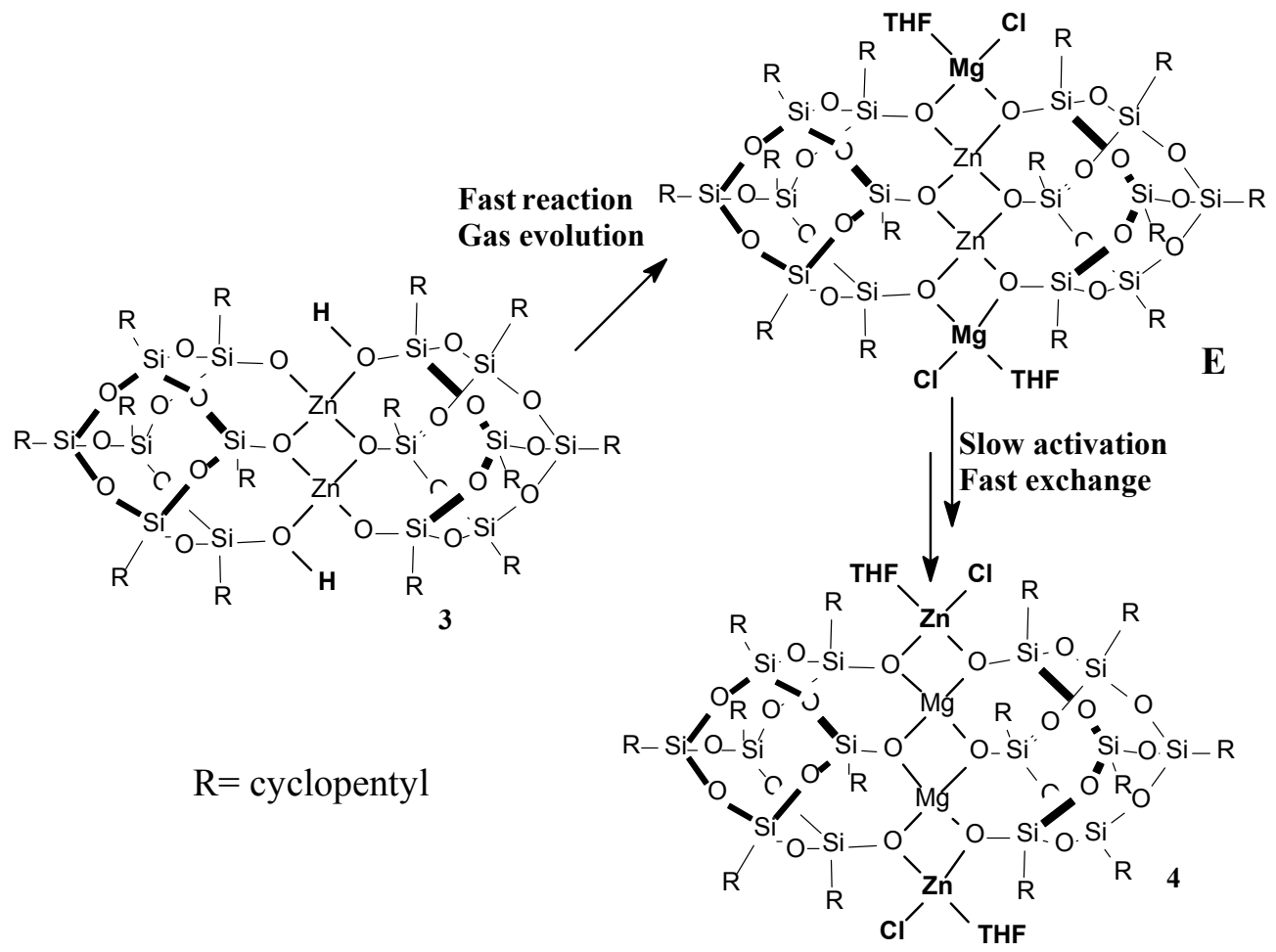

Scheme 2. Reaction mechanism for the formation of the mixed magnesium-zinc silsesquioxane complex 4 from zinc silsesquioxane 3 
In order to see if the synthesis of heterobimetallic complexes in this way is more generally applicable to silsesquioxane trisilanol ligands, 3 was reacted with trimethyl aluminum to possibly yield a bimetallic compound as shown in Scheme 3. After the reaction, during which gas was released, a colorless precipitate was formed. Recrystallization of this compound in toluene yielded crystals suitable for crystal structure determination. The precipitate proved to be the monometallic tetra-zinc complex that was similar to the one already described in Chapter 3, although the zinc sites were exchanged with approximately $6 \%$ aluminum, an indication that the transmetallation process was not yet completed. Repeated concentration of the mother liquor and subsequent recrystallization yielded more of the zinc complex, which became more and more polluted with several unknown compounds, most probably monometallic aluminum silsesquioxane complexes. Separation of these species proved to be very difficult.

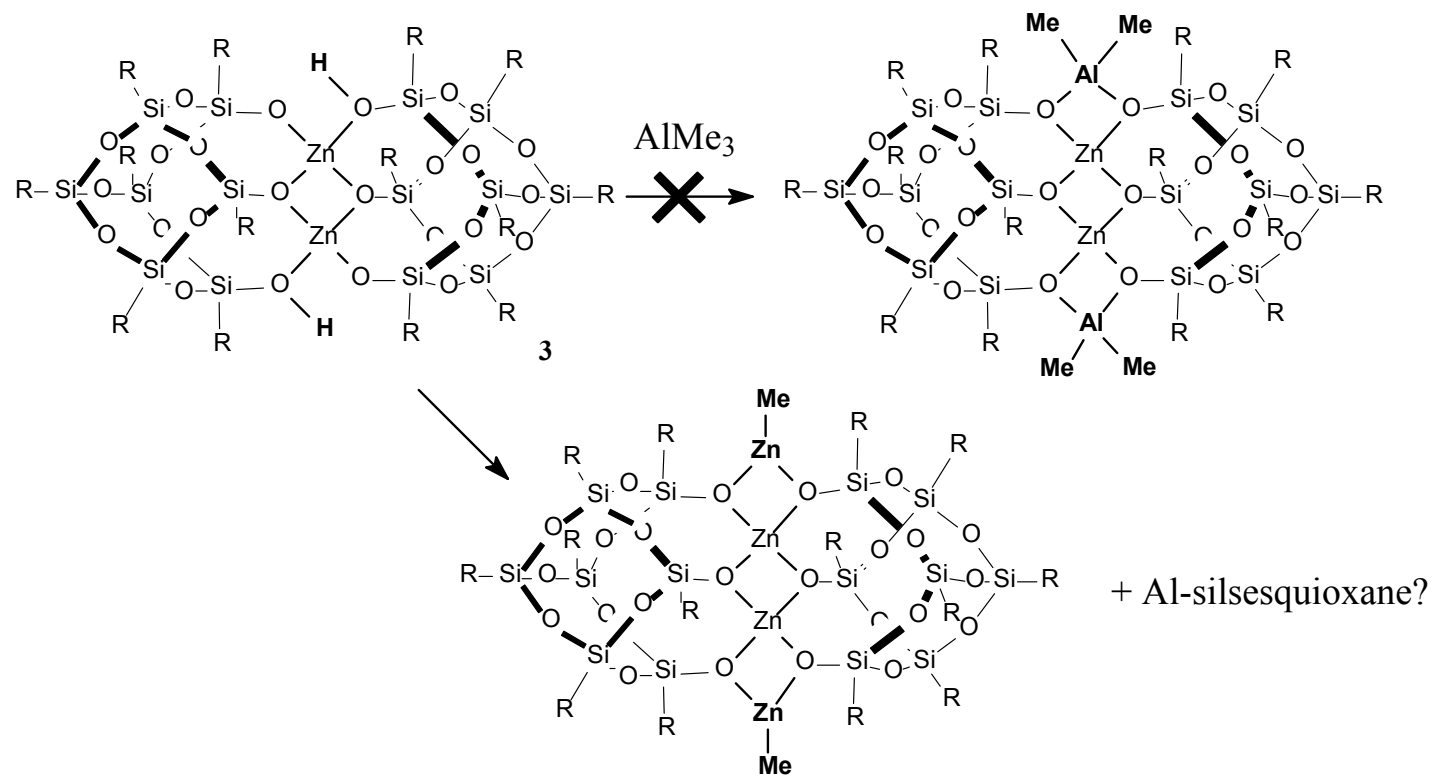

Scheme 3. Reaction of zinc silsesquioxane 3 with trimethyl aluminum to possibly form the heterobimetallic aluminum-zinc silsesquioxane complex led to the formation of a homometallic zinc complex

It is probable that the highly reactive and highly oxophilic aluminum precursor expels the softer zinc atoms out of the complex, forming $\mathrm{Me}_{2} \mathrm{Zn}$, where these react with remaining 3 to form the tetranuclear zinc complex. The low solubility of $\mathbf{3}$ in toluene enforces the crystallization of $\mathbf{3}$, while the unknown aluminum silsesquioxane species might be more soluble. ${ }^{10 ; 15-17}$ 


\section{Heterobimetallic transition metal complexes}

Liu et al. ${ }^{8 ; 9}$ described the synthesis and polymerization behavior of a cyclohexyl substituted bimetallic magnesium/titanium complex based on the aforementioned magnesium complexes. They found two titanium containing complexes in a 3:1 ratio, respectively a monomer and a dimer. These experiments were also repeated and confirmed in our labs. However, again we found a difference caused by the sterics of the cycloalkyl group on the silsesquioxane ligand. In the case of the cyclopentyl silsesquioxane, a compound was formed that can only be formulated (based on NMR data and elemental analysis) as 6 depicted in Scheme 4. The magnesium atoms in the compound were used as a transmetallating agent for the titanium atoms and the corner-capped chloro titanium silsesquioxane complex 6 was formed (see Scheme 4). Elemental analyses of 6 showed a carbon content that was too low to be consistent with solely the titanium silsesquioxane complex. It is likely that $\mathrm{MgCl}_{2}$ is part of the complex via bridging chloride species as proposed in Scheme 4. Numerous examples of this type of complexes are known in literature. ${ }^{18-22}$

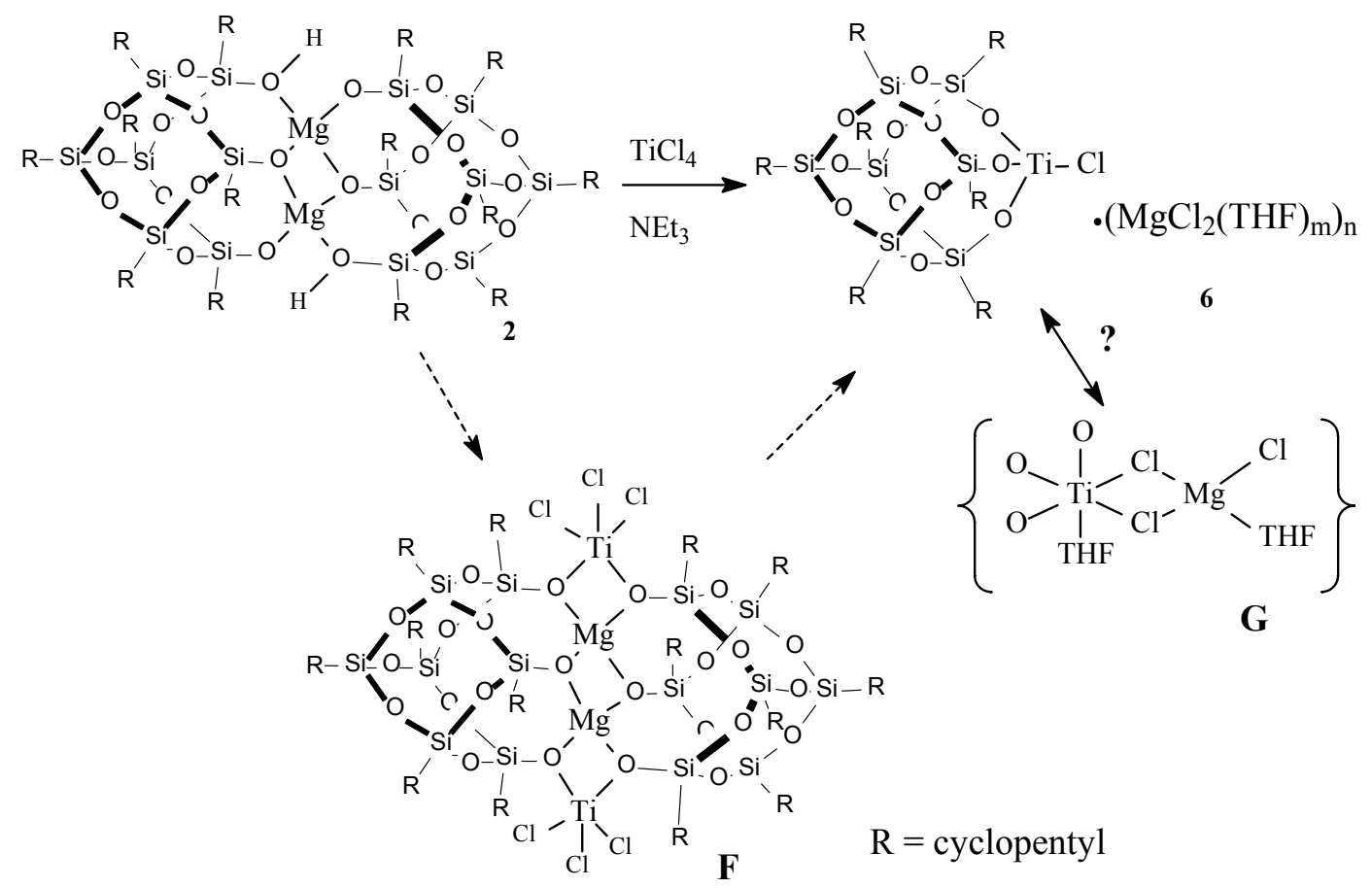

Scheme 4. The reaction of magnesium silsesquioxane complex 2 with titanium tetrachloride does not form the expected compound $F$ but transmetallates magnesium and titanium

A survey on the potential for catalytic polymerization of ethene using various alkyl aluminum cocatalysts showed that $\mathbf{6}$ had no activity at all. This can be easily explained due to the lack 
of free coordination sites and the impossibility of the formation of a cationic metal-alkyl species without breaking metal-siloxy bonds. When 6 was activated with MAO, a polymer was formed from ethene. This indicates that MAO is able to break the metal siloxy bonds in metal silsesquioxane complexes, leading to indeterminate metal species, which was also confirmed by the work of Duchateau et $a .^{23}$ These metal species are likely to be nonsilsesquioxane titanium species, and are more or less related to titanium based Ziegler-Natta catalysts. The role of the ligand in this matter can be considered negligible.

Compound 6 was also active in the catalytic epoxidation of cyclooctene with tertbutylhydroperoxide and showed good activity and selectivity comparable to the complexes as described by Abbenhuis, ${ }^{24}$ Klunduk et al., ${ }^{25 ; 26}$ and Crocker et al. ${ }^{27,28}$ This is due to the fact that the metal center is converted to the active $(\equiv \mathrm{SiO})_{3}$ TiOR-species $\left(\mathrm{R}={ }^{t} \mathrm{Bu}, \mathrm{H}\right)$ during the reaction with the hydroperoxide. ${ }^{29}$

To investigate the application of a mixed vanadium/magnesium complex in the catalytic polymerization of ethene conform the one reported by Sobota et al., ${ }^{30}$ magnesium complex 2 was treated with a THF solution of vanadium trichloride in the presence of a base. After filtration of the hydrochloric ammonium salt, a brick red, extremely air and moisture sensitive powder was isolated. Because of the high magnetic moment, NMR analysis of the material was impossible. The high reactivity with non-solvents like acetonitrile and acetone and the high solubility in common non-reactive solvents prevented X-ray crystal structure analysis. To preclude the possibility of magnesium-vanadium exchange as reported for the titanium-magnesium complex (vide supra), cyclopentyl substituted silsesquioxane trisilanol was treated with vanadium trichloride in $\mathrm{THF} / \mathrm{Et}_{3} \mathrm{~N}$ to form the proposed exchange product. The isolated material, comparable to the vanadium (III) dimer of Feher et al. ${ }^{1}$ was blue, even in the presence of THF and the magnetic susceptibility was different from 7. A test with ethene polymerization indicated that the Feher vanadium (III) dimer showed no activity when activated with diethyl aluminum chloride. Concluding from this, we can state that a complex like the one reported by Feher was not formed. Based on the results obtained in this and the previous Chapters, the structure as shown in Scheme 5 is proposed for 7. 


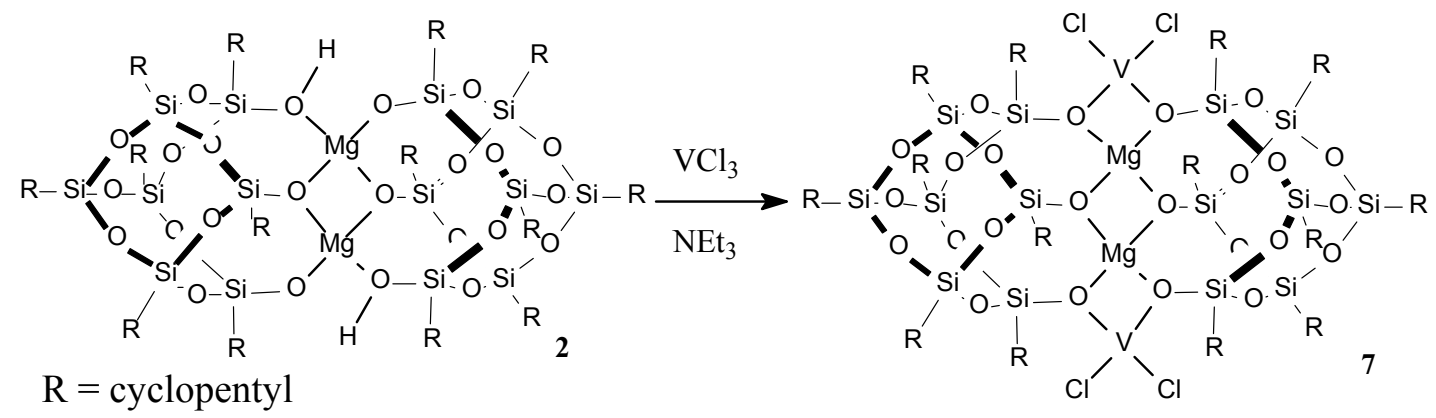

Scheme 5. Reaction of magnesium silsesquioxane 2 with vanadium trichloride to form the heterobimetallic magnesium-vanadium silsesquioxane complex 7

The bimetallic magnesium vanadium silsesquioxane complex was tested in the catalytic polymerization of ethene in toluene or hexane and with various co-catalysts, viz. methyl alumoxane (MAO), diethyl aluminum chloride (DEAC) and triethyl aluminum (TEA). Results of these polymerization experiments are listed in Table 2. It is clear from Table 2 that the vanadium complex is able to polymerize ethene to high molecular weight polyethene. However, the temperature and activator are of great importance. Low temperature (room temperature or lower) is necessary to retain a high activity and stability of the catalyst. At higher reaction temperatures the activity drops considerably, most likely due to deactivation of the catalyst. The notorious instability of vanadium alkyl complexes is known in literature, ${ }^{31}$ although exceptions are known. ${ }^{32}$ Thus, at higher reaction temperatures, the active complex degrades faster to an inactive state, most probably a low-valent (I or II state) vanadium complex. ${ }^{33 ; 34}$ On application of DEAC as activator, there is another temperature effect. Apparently a second species if formed that produces a higher molecular weight polymer.

Table 2. Results of ethene polymerization runs with complex 7 and various co-catalysts.

\begin{tabular}{|c|c|c|c|c|c|}
\hline Activator & $T\left({ }^{\circ} \mathrm{C}\right)$ & $P E(g)$ & $\begin{array}{l}\text { Actvity } \\
\left(10^{3} \text { g.mol } \text { mo }^{-1} \cdot r^{-1} \cdot h^{-1}\right)\end{array}$ & $\begin{array}{c}M_{w} \\
\left(k g . \mathrm{mol}^{-1}\right)\end{array}$ & $M_{w} / M_{r}$ \\
\hline $\mathrm{AlEt}_{2} \mathrm{Cl}$ & 25 & 9.2 & 280 & 416 & 2.2 \\
\hline $\mathrm{AlEt}_{2} \mathrm{Cl}$ & 50 & 7.8 & 230 & 1190 & 11.8 \\
\hline $\mathrm{AlEt}_{3}$ & 25 & 1.1 & 40 & 978 & 139.6 \\
\hline MAO & 25 & 4.7 & 160 & 2446 & 2.5 \\
\hline MAO & 50 & 3.8 & 130 & 1875 & 3.3 \\
\hline MAO & 70 & 0.9 & 30 & 1676 & 2.0 \\
\hline
\end{tabular}


The activator is thus also very important. DEAC is the best activator for this precursor to achieve high polymerization rates; this was found for most vanadium complexes in literature. TMA has an effect on the molecular weight distribution comparable to DEAC, but it is noticeable even at room temperature. A bimodal distribution of high molecular weight and low molecular weight was formed. The use of MAO as activator for the vanadium silsesquioxane precursor seems to activate the complex to a different state, as the molecular weights of the polymers produced are significantly higher, while keeping the polydispersity almost equal. Most probably, a new non-silsesquioxane vanadium species is formed due to metal-siloxy bond splitting by the MAO, just as seen by the aforementioned titanium complex 6.

\section{Concluding remarks}

The reaction of easily protolyzable reagents like dialkyl magnesium or dialkyl zinc with silsesquioxane trisilanol ligands in equimolar amount leads to metal silsesquioxanes with residual reactive silanol groups. The groups can be reacted with main group and transition metal species to form new heterobimetallic silsesquioxane complexes. Although this is a good example of synthesizing heterobimetallic complexes in a step-wise way, still unwanted reactions can occur. Addition of the highly reactive titanium tetrachloride can induce transmetallation of magnesium in the complex and the addition of Grignard to a zinc silsesquioxane complex has a metal exchange effect. The introduction of highly reactive species in the complex, like trimethyl aluminum lead to the unexpected formation of a monometallic tetra-zinc system, which is likely to be the product of an intermolecular exchange of metals. Transition metal containing heterometallic complexes were tested in catalytic epoxidation of alkenes (Mg-Ti) and polymerization of ethene ( $\mathrm{Mg}$ - Ti and $\mathrm{Mg}-\mathrm{V})$. In the catalytic epoxidation of cyclooctene, results were obtained that were comparable to earlier systems with comparable geometry. For the polymerization of ethene, the $\mathrm{Mg}$ - $\mathrm{Ti}$ system was not active, as suspected, unless MAO was used as activator. This indicates that MAO can split the siloxy-titanium bond. The Mg-V system was also active in ethene polymerization when activated with aluminum alkyl (halides), although both activator and temperature played an important role in the formation of the active species. It is suspected that in some cases non-silsesquioxane, thus leached, species are responsible for catalytic activity. In conclusion, we present a method for synthesizing heterobimetallic complexes that is, however, not generally applicable. Caution should be taken with respect to the 'hardness' and oxophilicity of the various metals compared to each other. The more oxophilic metal 
will more likely move to the central position in the complex, either by forcing the other metal to the outer positions, or completely expelling it from the complex. 


\section{Experimental Section}

\section{General remarks.}

All operations involving air and moisture sensitive materials were performed in an inert atmosphere using standard Schlenk techniques and an argon filled glovebox. Solvents were dried over Na (THF, toluene) or $4 \AA$ molecular sieves $\left(\mathrm{CDCl}_{3}\right)$ and were degassed before use. Trimethyl aluminum $(1.0 \mathrm{M}$ solution in toluene), methyl magnesium chloride (3.0 $\mathrm{M}$ solution in THF, Merck), $\mathrm{TiCl}_{4}$ (99.9 \%, Acros), $\mathrm{VCl}_{3}(99 \%$, Acros) and $\mathrm{Cr}(\mathrm{acac})_{3}(97 \%$, Jansen-Chimica) were used as purchased. The THF adduct of dimethyl magnesium was prepared by 1,4-dioxane precipitation of magnesium dichloride from methyl magnesium chloride ${ }^{35}$ in THF and subsequent evaporation of the solvent. The silsesquioxane ligands, ${ }^{36,37} \mathrm{TiCl}_{4}(\mathrm{THF})_{2}{ }^{38}$ and $\mathrm{VCl}_{3}(\mathrm{THF})_{3}{ }^{38}$ were prepared according to literature procedures. NMR spectra were recorded on VARIAN Mercury 400 and VARIAN Inova 500 spectrometers and referred to residual solvent resonances $\left({ }^{1} \mathrm{H},{ }^{13} \mathrm{C}\right)$ or $\mathrm{SiMe}_{4}\left({ }^{29} \mathrm{Si}\right)$. The Organic Chemistry Department of the Eindhoven University of Technology carried out the elemental analyses. In cases where no elemental analysis is mentioned, no suitable analysis could be obtained, even after addition of oxidizing aids, such as $\mathrm{V}_{2} \mathrm{O}_{5}$. The formation of carbides could be responsible for the low carbon content. Magnetic moments were determined by the Evans method ${ }^{39 ; 40}$. The molecular weights and molecular-weight distributions were measured at $135^{\circ} \mathrm{C}$ using 1,2,4-trichlorobenzene by gel-permeation chromatography (GPC apparatus) at Solvay Polyolefins Europe. The crystal structure of $\mathbf{4}$ was determined The Laboratory of Crystal and Structural Chemistry (University of Utrecht)

Synthesis of $\left\{\left(c-\mathrm{C}_{5} \mathrm{H}_{9}\right)_{7} \mathrm{Si}_{7} \mathrm{O}_{12}\right\}_{2}\left[\left(\mu_{3}-\mathrm{O}\right) \mathrm{Mg}\right]_{2}\left[\left(\mu_{3}-\mathrm{O}\right) \mathrm{H}_{2}(2)\right.$

$\left(\mathrm{CH}_{3}\right)_{2} \mathrm{Mg} \cdot \mathrm{THF}(0.32 \mathrm{~g}, 2.53 \mathrm{mmol})$ in THF $(5 \mathrm{~mL})$ was added to a cooled solution $\left(-60^{\circ} \mathrm{C}\right)$ of the trisilanol silsesquioxane $\left(c-\mathrm{C}_{5} \mathrm{H}_{9}\right)_{7} \mathrm{Si}_{7} \mathrm{O}_{9}(\mathrm{OH})_{3}(2.20 \mathrm{~g}, 2.50 \mathrm{mmol})$ in THF $(40 \mathrm{~mL})$. Immediately after the addition of the dialkyl magnesium reagent, a vigorous gas evolution took place. The resulting clear solution was stirred for 16 h. Evaporation to dryness yielded 2 as a white powder $\left(2.3 \mathrm{~g}, 2.37 \mathrm{mmol}, 98 \%\right.$ \%). NMR data: ${ }^{1} \mathrm{H}(400 \mathrm{MHz}$, $\mathrm{CDCl}_{3}, \delta$ ): 3.8 (m, $\alpha-\mathrm{CH}_{2}$-THF, 2H), 2.9 (s, $\left.\mathrm{SiOH}, 1 \mathrm{H}\right), 1.9\left(\mathrm{~m}, \beta-\mathrm{CH}_{2}-\mathrm{THF}, 2 \mathrm{H}\right), 1.8-1.2\left(\mathrm{~m}, \mathrm{CH}_{2}-\mathrm{C}_{5} \mathrm{H}_{9}, 56 \mathrm{H}\right)$, 1.1-0.7 (m, methyn-CH-C $\left.\mathrm{H}_{9}, 7 \mathrm{H}\right) ;{ }^{13} \mathrm{C}\left\{{ }^{1} \mathrm{H}\right\}\left(100 \mathrm{MHz}, \mathrm{CDCl}_{3}, \delta\right): 68.90$ (s, $\left.\alpha-\mathrm{CH}_{2}-\mathrm{THF}\right), 27.36-26.85\left(\mathrm{~s}, \mathrm{CH}_{2}-\right.$ $\mathrm{C}_{5} \mathrm{H}_{9}$ ), 25.57 (s, $\beta-\mathrm{CH}_{2}$-THF), 22.81, 22.17, 22.15, 22.01, 21.46 (s, methyn- $C H-\mathrm{C}_{5} \mathrm{H}_{9}$, ratio. 2:1:1:2:1); ${ }^{29} \mathrm{Si}\left\{{ }^{1} \mathrm{H}\right\}$ (99.3 MHz, $\left.\mathrm{CDCl}_{3}, 0.02 \mathrm{M} \mathrm{Cr}(\mathrm{acac})_{3}, \delta\right):-53.66,-55.08,-55.41,-64.62$, -64.85 $\left(\mathrm{s}, \mathrm{C}_{5} \mathrm{H}_{9} \mathrm{SiO}_{3}\right.$, ratio 1:1:2:1:2); IR $\left(\mathrm{KBr}\right.$, disc): $3661 \mathrm{~m}(\mathrm{v}(\mathrm{SiOH}))$; Anal. Calcd. for $\left[\mathrm{C}_{35} \mathrm{H}_{64} \mathrm{MgO}_{12} \mathrm{Si}_{7}\right]_{2} \cdot\left(\mathrm{C}_{4} \mathrm{H}_{8} \mathrm{O}\right): \mathrm{C} 47.59 \%$, H $7.34 \%$. Found $\mathrm{C}$ $47.21 \%$, H $7.23 \%$.

\section{Synthesis of $\left\{\left(c-\mathrm{C}_{5} \mathrm{H}_{9}\right)_{7} \mathrm{Si}_{7} \mathrm{O}_{12}\right\}_{2}\left[\left(\mu_{3}-\mathrm{O}\right) \mathrm{Zn}\right]_{2}\left[\left(\mu_{3}-\mathrm{O}\right) \mathrm{H}\right]_{2}(3)$}

Dimethyl zinc $(0.81 \mathrm{ml}, 1.62 \mathrm{mmol})$ was added to a solution of trisilanol $\left(\left(i-\mathrm{C}_{4} \mathrm{H}_{9}\right)_{7} \mathrm{Si}_{7} \mathrm{O}_{9}(\mathrm{OH})_{3}(1.28 \mathrm{~g}, 1.62\right.$ $\mathrm{mmol})$. After methane evolution had taken place, the solution was stirred for another 30 minutes and subsequently evaporated to dryness. The remaining white waxy solid was stripped with hexanes. The white power (1.20 g, 0.74 mmol, $91 \%$ ) was spectroscopically pure. NMR Data: ${ }^{1} \mathrm{H}\left(400 \mathrm{MHz}, \mathrm{C}_{6} \mathrm{D}_{6}, \delta\right) 2.85(\mathrm{~s}, \mathrm{SiOH}, 2 \mathrm{H}), 1.9-1.2(\mathrm{~m}, \mathrm{CH}$, $\left.\mathrm{C}_{5} \mathrm{H}_{9}, 112 \mathrm{H}\right), 1.05-0.80\left(\mathrm{~m}, \mathrm{CH}, \mathrm{C}_{5} \mathrm{H}_{9}, 14 \mathrm{H}\right) ;{ }^{13} \mathrm{C}\left\{{ }^{1} \mathrm{H}\right\}\left(100 \mathrm{MHz}, \mathrm{C}_{6} \mathrm{D}_{6}, \delta\right): 27.36,27.26,27.18,27.13,27.11$, 26.99, 26.98, 26.94, 26.89, $26.84\left(\mathrm{~s}, \mathrm{CH}_{2}, \mathrm{C}_{5} \mathrm{H}_{9}\right), 22.29,22.17,22.16,22.02,21.48\left(\mathrm{~s}, \mathrm{CH}, \mathrm{C}_{5} \mathrm{H}_{9}\right.$, relative 
intensities 2:1:1:2:1); ${ }^{29} \mathrm{Si}\left\{{ }^{1} \mathrm{H}\right\}\left(99.3 \mathrm{MHz}, \mathrm{CDCl}_{3}, 0.02 \mathrm{M} \mathrm{Cr}(\mathrm{acac})_{3}, \delta\right):-53.97,-55.32,-55.67,-64.93,-65.13$ (s, $\mathrm{C}_{5} \mathrm{H}_{9} \mathrm{SiO}_{3}$, relative ratio: 1:1:2:1:2) Anal. Calcd. for $\left(\mathrm{C}_{35} \mathrm{H}_{64} \mathrm{ZnO}_{12} \mathrm{Si}_{7}\right)_{2}: \mathrm{C} 44.78 \%$, H $6.87 \%$. Found $\mathrm{C} 44.21 \%$, H $7.01 \%$

\section{Synthesis of $\left\{\left(c-\mathrm{C}_{5} \mathrm{H}_{9}\right)_{7} \mathrm{Si}_{7} \mathrm{O}_{12}\right\}_{2}\left[\left(\mu_{3}-\mathrm{O}\right) \mathrm{Mg}_{2}\left[\left(\mu_{3}-\mathrm{O}\right) \mathrm{ZnCl}(\mathrm{THF})\right]_{2}(4)\right.$}

Dimethyl zinc $(0.95 \mathrm{ml}, 1.90 \mathrm{~mol})$ was added to a solution of $\left(\mathrm{C}_{5} \mathrm{H}_{9}\right)_{7} \mathrm{Si}_{7} \mathrm{O}_{9}(\mathrm{OH})_{3}(1.6 \mathrm{~g}, 1.89 \mathrm{mmol})$ in $30 \mathrm{~mL}$ of toluene and a vigorous gas evolution could be observed. After the gas evolution had ended the clear colourless solution was stirred for another 30 minutes after which methyl magnesium chloride $(0.6 \mathrm{ml}$ of a $3.0 \mathrm{M}$ solution in THF, $1.8 \mathrm{~mol}$ ) was added. After stirring for 1 additional hour, some material had precipitated. After concentration of the solution and recrystallization $1.2 \mathrm{~g}(0.56 \mathrm{mmol}, 62 \%)$ of spectroscopically pure 4 could be obtained. The colorless block-shaped crystals from this batch were also suitable for a crystal structure determination. ${ }^{1} \mathrm{H}\left(400 \mathrm{MHz}, \mathrm{C}_{6} \mathrm{D}_{6}, \delta\right) 4.0$ (s, THF, 8H), 1.95 (s, THF, 8H), 2.0-1.2 (m, $\left.\mathrm{CH}_{2}, \mathrm{C}_{5} \mathrm{H}_{9}, 112 \mathrm{H}\right), 1.10$ $0.90\left(\mathrm{~m}, \mathrm{CH}, \mathrm{C}_{5} \mathrm{H}_{9}, 14 \mathrm{H}\right) ;{ }^{13} \mathrm{C}\left\{{ }^{1} \mathrm{H}\right\}\left(100 \mathrm{MHz}, \mathrm{C}_{6} \mathrm{D}_{6}, \delta\right): 28.06,27.98,27.80,27.64,27.13,27.04\left(\mathrm{~s}, \mathrm{CH}_{2}, \mathrm{C}_{5} \mathrm{H}_{9}\right)$, $24.5024 .14,23.84,22.55,22.09\left(\mathrm{~s}, \mathrm{CH}, \mathrm{C}_{5} \mathrm{H}_{9}\right.$, relative intensities 1:2:1:2:1); Anal. Calcd. for $\mathrm{C}_{78} \mathrm{H}_{142} \mathrm{Zn}_{2} \mathrm{Mg}_{2} \mathrm{O}_{26} \mathrm{Si}_{14} \mathrm{Cl}_{2}$ : C $43.79 \%$, H $6.69 \%$. Found C $42.2 \%$, H $6.1 \%$

\section{Reaction of 2 with $\mathrm{TiCl}_{4}(\mathrm{THF})_{2}$ (6)}

$2(1.25 \mathrm{~g}, 0.67 \mathrm{mmol})$ was dissolved in $40 \mathrm{~mL} \mathrm{THF} / \mathrm{Et}_{3} \mathrm{~N}(38: 2)$ and a solution of $\mathrm{TiCl}_{4}(\mathrm{THF})_{2}(0.45 \mathrm{~g}, 1.34$ mmol) in $10 \mathrm{~mL}$ THF was slowly added to this. After the addition of the yellow $\mathrm{TiCl}_{4}$ solution, the solution decolorized fast and a white precipitate was formed. After the addition was completed, the suspension was stirred overnight and the solvent was evaporated. The remaining powder was extracted with hexanes and the filtrate was concentrated. A white crystalline material was isolated and NMR data indicated it to be 6. NMR data: ${ }^{1} \mathrm{H}\left(400 \mathrm{MHz}, \mathrm{CDCl}_{3}, \delta\right): 3.95$ (s, $\left.\alpha-\mathrm{CH}_{2}-\mathrm{THF}, 6 \mathrm{H}\right), 1.92$ (s, $\left.\beta-\mathrm{CH}_{2}-\mathrm{THF}\right), 1.8-1.4\left(\mathrm{~m}, \mathrm{CH}_{2}-\mathrm{C}_{5} \mathrm{H}_{9}, 56 \mathrm{H}\right)$, 1.1-0.9 (m, CH-C $\left.{ }_{5} \mathrm{H}_{9}, 7 \mathrm{H}\right) ;{ }^{13} \mathrm{C}\left\{{ }^{1} \mathrm{H}\right\}\left(100 \mathrm{MHz}, \mathrm{CDCl}_{3}, \delta\right): 69.44$ (s (broad), $\left.\alpha-\mathrm{CH}_{2}-\mathrm{THF}\right) 27.35,27.28,27.23$, 26.97, 26.90 (s, $\mathrm{CH}_{2}-\mathrm{C}_{5} \mathrm{H}_{9}$ ), 25.62 (s (broad), $\beta-\mathrm{CH}_{2}-\mathrm{THF}$ ), 22.12, 22.06, 21.67 (s, methyn- $C \mathrm{H}-\mathrm{C}_{5} \mathrm{H}_{9}$, ratio. 1:3:3); ${ }^{29} \mathrm{Si}\left\{{ }^{1} \mathrm{H}\right\}$ (99.3 MHz, $\left.\mathrm{CDCl}_{3}, 0.02 \mathrm{M} \mathrm{Cr}(\mathrm{acac})_{3}, \delta\right):-64.70,-66.58,-67.16\left(\mathrm{~s}, \mathrm{C}_{5} \mathrm{H}_{9} \mathrm{SiO}_{3}\right.$, ratio 3:1:3). Anal. Calcd. for $\mathrm{C}_{35} \mathrm{H}_{64} \mathrm{O}_{12} \mathrm{Si}_{7} \mathrm{Ti} \cdot\left(\mathrm{MgCl}_{2}\right)_{3} \cdot\left(\mathrm{C}_{4} \mathrm{H}_{8} \mathrm{O}\right)_{\cdot 1.5}$ : C $39.61 \%$, H $6.08 \%$. Found C $39.38 \%$, H $6.41 \%$

\section{Synthesis of $\left\{\left(c-\mathrm{C}_{5} \mathrm{H}_{9}\right)_{7} \mathrm{Si}_{7} \mathrm{O}_{12}\right\}_{2}\left[\left(\mu_{3}-\mathrm{O}\right) \mathbf{M g}\right]_{2}\left[\left(\mu_{3}-\mathrm{O}\right) \mathrm{VCl}_{2}\right]_{2}(7)$.}

$\left(c-\mathrm{C}_{5} \mathrm{H}_{9}\right) \mathrm{Si}_{7} \mathrm{O}_{9}\left(\mathrm{O}_{2} \mathrm{Mg} . \mathrm{THF}_{0.5}\right)(\mathrm{OH})(1,0.86 \mathrm{~g})$ was dissolved in $40 \mathrm{~mL}$ THF and a solution of $0.32 \mathrm{~g} \mathrm{VCl}_{3}\left(\mathrm{THF}_{3}\right.$ in $10 \mathrm{~mL}$ THF was slowly added to this. Upon addition of the red $\mathrm{VCl}_{3}$ solution, the initially colourless silsesquioxane solution turned purple. After the addition was completed, the solution was stirred overnight and the solvent was evaporated. The remaining grayish powder was extracted with hexanes. The filtrate was dried in vacuo, which left a pale red paramagnetic solid $\left(\mu_{\text {eff }}=4.51 \mathrm{BM}\right)$. Anal. Calcd. for $\left(\mathrm{C}_{35} \mathrm{H}_{63} \mathrm{O}_{12} \mathrm{Si}_{7} \mathrm{MgVCl}_{2}\right)_{2} \mathrm{C}$ $41.27 \%$, H $6.23 \%$. Found C $40.85 \%$, H $6.47 \%$.

\section{Ethene polymerization}

Ethene polymerization experiments were carried out in an $800 \mathrm{~mL}$ autoclave using compound $\mathbf{6}$ and 7. In a typical experiment about $20 \mu \mathrm{mol}$ of complex (6 or 7) was dissolved in toluene and the reactor was filled with either hexane or toluene and degassed. The cocatalyst (various alkyl aluminum species) was added to the reactor 
and after 10 minutes the catalyst solution was injected. Then ethene was introduced at 5 bar. After 40 minutes, stopping the ethene supply and subsequent addition of acidic methanol quenched the polymerization. The white precipitate was filtered and washed with an aqueous solution of $\mathrm{HCl}$, copious methanol and acetone. The resulting polymer was finally dried in an oven for $12 \mathrm{~h}$.

\section{Crystal Structure Determination for 4}

Intensity data for 4 were collected on a Nonius KappaCCD diffractometer with rotating anode (Mo $K \alpha, \lambda=$ $0.71073 \AA$ ) at $150 \mathrm{~K}$. An absorption correction was considered unnecessary in all cases. The structures were solved by direct methods (SHELXS97 $7^{41}$ for 4) and refined on $F^{2}$ by least-squares procedures using SHELXL97. All non-hydrogen atoms were refined with anisotropic displacement parameters. Hydrogen atoms were constrained to idealized geometries and allowed to ride on their carrier atoms with an isotropic displacement parameter related to the equivalent displacement parameter of their carrier atoms. Structure validation and molecular graphics preparation were performed with the PLATON package. ${ }^{42}$ The asymmetric unit contains half of the centrosymmetric silsesquioxane complex. In the two metal sites, $\mathrm{Mg}(1)$ and $\mathrm{Zn}(2)$ are partially substituted (6.2(2) \%) by the other metal. Four of the seven independent cyclopentyl rings, as well as the one independent coordinated THF molecule, are disordered over two conformations. The crystal structure also contains large voids $\left(1534 \AA^{3}\right.$ ) filled with disordered solvent molecules (THF); their contribution to the structure factors was ascertained by back-Fourier transformation using PLATON/CALC SQUEEZE (496 e/unit cell). ${ }^{42}$

Table 3. Crystal data and details of the structure determination for 4 .

\begin{tabular}{ll}
\hline & 4 \\
\hline Formula & $\mathrm{C}_{78} \mathrm{H}_{142} \mathrm{Cl}_{2} \mathrm{Mg}_{2} \mathrm{Zn}_{2} \mathrm{O}_{26} \mathrm{Si}_{14}$ \\
Formula Weight, g.mol ${ }^{-1}$ & 2139.47 \\
Space group & $\mathrm{P} 2_{1} / \mathrm{n},(\mathrm{No} .14)$ \\
$\mathrm{a}, \AA$ & $15.6915(1)$ \\
$\mathrm{B}, \AA$ & $26.4998(2)$ \\
$\mathrm{C}, \AA$ & $17.9733(1)$ \\
$\beta, \mathrm{deg}$ & $119.9340(4)$ \\
$\mathrm{V}, \AA^{3}$ & $6476.70(8)$ \\
$\mathrm{Z}$ & 2 \\
$\mathrm{~T}, \mathrm{~K}$ & 150 \\
$\rho_{\mathrm{calc}}, \mathrm{g} . \mathrm{cm}^{-3}$ & $1.0971(1)$ \\
$\lambda(\mathrm{MoK} \alpha)$, & 0.71072 \\
$\mu, \mathrm{cm}^{-1}$ & 6.05 \\
$\mathrm{R}(\mathrm{F})$ & 0.0433 \\
$\mathrm{R}$ & 0.1364 \\
\hline
\end{tabular}




\section{Bibliography}

[1] Feher,F.J.; Walzer,J.F. Inorg.Chem. 1990, 29, 1604-1611.

[2] Annand,J.; Aspinall,H.C.; Steiner,A. Inorg.Chem. 1999, 38, 3941-3943.

[3] Lorenz,V.; Fischer,A.; Edelmann,F.T. Inorg.Chem.Comm. 2000, 3, 292-295.

[4] Johnson,B.F.; Quadrelli,E.A.; Davies,J.E.; Feeder,N. Chem.Commun. 2000, 1031-1032.

[5] Gianneschi,N.C.; Mirkin,C.A. Inorg.Chem. 2002, 41, 5326-5328.

[6] Rodríguez-Cortiñas,R.; Avecilla,F.; Platas-Iglesias,C.; Imbert,D.; Bunzli,J.-C.G.; de Blas,A.; RodríguezBlas, T. Inorg. Chem. 2002, 41, 5336-5349.

[7] Kuwata,S.; Nagano,T.; Matsubayasha,A.; Ishii,Y.; Hidai,M. Inorg.Chem. 2002, 41, 4324-4330.

[8] Liu,J.C. Chem.Commun. 1996, 1109-1110.

[9] Liu,J.C. Appl.Organomet.Chem. 1999, 13, 295-302.

[10] Duchateau,R.; Harmsen,R.J.; Abbenhuis,H.C.L.; Van Santen,R.A.; Meetsma,A.; Thiele,S.K.; Kranenburg,M. Chem.Eur.J. 1999, 5, 3130-3135.

[11] Hanssen,R.W.J.M.; Meetsma,A.; Van Santen,R.A.; Abbenhuis,H.C.L. Inorg.Chem. 2000, 40, 4049-4052.

[12] Holloway,C.E.; Melnik,M. J.Organomet.Chem. 1994, 465, 1-33.

[13] Hermann,J.; Schumacher,D.; Erxleben,A. Eur.J.Inorg.Chem. 2002, 2276-2280.

[14] Irving,H.M.N.H.; Williams,R.J.P. J.Chem.Soc. 1953, 3192-3210.

[15] Feher,F.J.; Budzichowski,T.A.; Weller,K. J.Am.Chem.Soc. 1989, 111, 153-163.

[16] Feher,F.J.; Weller,K. Organometallics 1990, 9, 2638-2640.

[17] Feher,F.J.; Weller,K.; Ziller,J.W. J.Am.Chem.Soc. 1992, 114, 9686-9688.

[18] Bart,J.C.J.; Bassi,I.W.; Calcaterra,M.; Giannini,U.; Parodi,S. Z.Anorg.Allg.Chem. 1981, 482, $121-132$.

[19] Bart,J.C.J.; Bassi,I.W.; Calcaterra,M.; Albizzati,E.; Giannini,U.; Parodi,S. Z.Anorg.Allg.Chem. 1983, 496, 205-216.

[20] Giunchi,G.; Albizzati,E.; Malpezzi,L.; Gianetti,E. Inorganica Chimica Acta 1988, 147, 159

[21] Stephan,D.W. Organometallics 2002, 11, 996-999.

[22] Sobota,P.; Wroblenska,M.; Szafert,S.; Giowak,T. J.Organomet.Chem. 1994, 481, 57

[23] Duchateau,R.; Abbenhuis,H.C.L.; Van Santen,R.A.; Thiele,S.K.; Van Tol,M.F. Organometallics 1998, $17,5222-5224$.

[24] Abbenhuis,H.C.L. Chem.Eur.J. 2000, 6, 25-32.

[25] Klunduk,M.C.; Maschmeyer,T.; Thomas,J.M.; Johnson,B.F. Chem.Eur.J. 1999, 5, 1481-1485.

[26] Maschmeyer,T.; Klunduk,M.C.; Martin,C.M.; Shephard,D.S.; Thomas,J.M.; Johnson,B.F. Chem.Commun. 1997, 1847-1848.

[27] Crocker,M.; Herold,R.H.; Orpen,A.G. Chem.Commun. 1997, 2411-2412.

[28] Crocker,M.; Herold,R.H.; Orpen,A.G.; Overgaag,M. J.Chem.Soc.Dalton Trans. 1999, 3791-3804.

[29] Vorstenbosch, M. L. W. Alkene epoxidation with silsesquioxane based chromium and titanium complexes. 2002

[30] Janas,Z.; Sobota,P.; Kasprzak,M.; Glowiak,T. Chem.Commun. 1996, 2727-2728.

[31] Brussee,E.A.; Meetsma,A.; Hessen,B.; Teuben,J.H. Organometallics 1998, 17, 4090-4095.

[32] Budzelaar,P.H.M.; Van Oort,A.B.; Orpen,A.G. Eur.J.Inorg.Chem. 1998, 1485-1494.

[33] Natta,G.; Zambelli,A.; Lanzi,G.; Pasquon,I.; Mognaschi,E.R.; Segre,A.L.; Centola,P. Makromol.Chem. $\mathbf{1 9 6 5}, 81,161$

[34] Reardon,D.; Conan,F.; Gambarotta,S.; Yap,G.P.; Wang,Q. J.Am.Chem.Soc. 2000, 121, 9318-9325.

[35] Ashby,E.C.; Arnott,R.C. J.Organomet.Chem. 1968, 14, 1-11.

[36] Brown,J.F., Jr.; Vogt,L.H., Jr. J.Am.Chem.Soc. 1965, 87, 4313-4317.

[37] Feher,F.J.; Budzichowski,T.A.; Blanski,R.L.; Weller,K.J.; Ziller,J.W. Organometallics 1991, 10, 25262528.

[38] Manzer,L.E.; Fackler,J.P., Jr.In Inorganic Syntheses XXI; Fackler,J.P., Jr., Ed.; Wiley-Interscience: 1982; pp 135-140.

[39] Evans,D.F. J.Chem.Soc. 1959, 2003-2005.

[40] Sur,S.K. J.Magn.Res. 1989, 82, 169-173.

[41] Sheldrick, G. M. SHELXL-97. Program for the refinement of crystal structures. 1997. University of Göttingen

[42] Spek, A. L. PLATON, A multipurpose crystallographic tool. 2002. University of Utrecht 
Vanadium(III) and Titanium(III) silsesquioxanes in alkene polymerization catalysis

2 rivalent vanadium and titanium silsesquioxane complexes were synthesized by the complexes obtained were analyzed with paramagnetic NMR and UV-Vis, and their reactivity with coordinating solvents, alkylating agents and oxygen was investigated. The effect of the coordination of solvents on the spectral properties and complex stability was rationalized with DFT computations. The complexes were tested in the catalytic polymerization of ethene and the vanadium catalysts were found to be moderately active, while producing highmolecular weight polyethene. An approach to self-immobilization was proposed and was found to be not suitable for these systems. The energetics of the catalytic cycle were rationalized with DFT methods and compared to literature data. 


\section{Introduction}

Vanadium catalysts, be it supported or not, are not widely used in alkene polymerization chemistry. This may be due to their inherent lower activity and stability at polymerization conditions compared to Group IV metal catalysts, as well as the difficulties of characterizing the paramagnetic complexes by standard techniques such as NMR. However, these catalysts have some clear advantages over the ubiquitous group IV (Ti, Zr) catalysts, such as the preparation of high molecular weight polyolefins with a narrow molecular weight distribution, the preparation of ethene/1-alkene copolymers with a high 1-alkene co-monomer content (e.g. EPDM) and the preparation of syndiotactic polypropylene. ${ }^{1}$ Generally of the main deactivation mechanisms is the reduction of the vanadium center to a low-valent state, most probably $\mathrm{V}$ (II) or $\mathrm{V}$ (I), although some V(II) complexes active in ethene polymerization have been synthesized. ${ }^{2-4}$ Most probably the oxidation state of the vanadium center could be retained in its active condition by the use of ancillary ligands. ${ }^{5}$ Especially the use of hard donor ligands such as alkoxides, amides and silylamides has been successfully applied with trivalent vanadium complexes. Figure 1 shows some examples from recent literature where vanadium complexes were applied in ethene polymerization catalysis. ${ }^{6-12}$
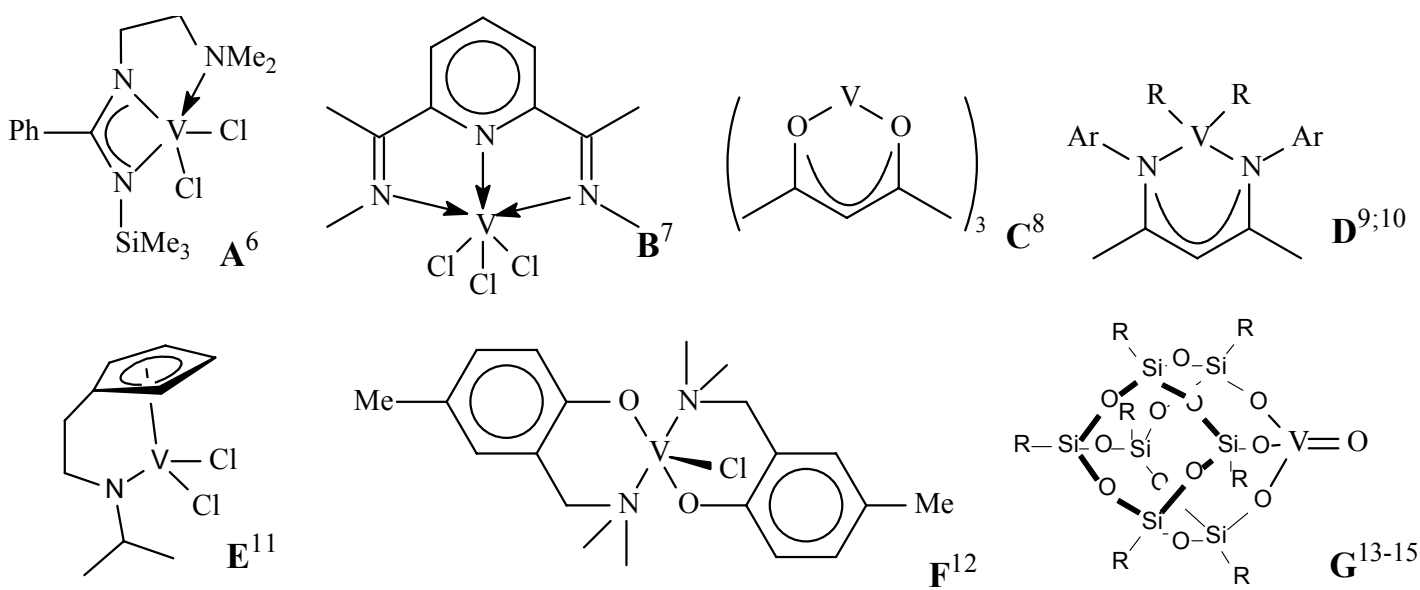

Figure 1. Examples of active vanadium-based alkene polymerization catalysts from recent literature

Silsesquioxanes are a family of ligands that are similar to alkoxides, although they have relatively strong electron-withdrawing properties. The combination of both factors could make them suitable as ligands for vanadium as catalysts in alkene polymerization chemistry. The hard donor capacity could stabilize the tervalent oxidation state, while the electronwithdrawing properties assure the required electron deficiency of the metal center. 
Unfunctionalized silsesquioxane ligands have previously been applied to synthesize V(III) ${ }^{13}$ en $\mathrm{V}(\mathrm{V})$ complexes. ${ }^{14 ; 15}$ Feher et al. tested the $\mathrm{V}(\mathrm{V})$ complexes in ethene polymerization at 1 atmosphere and found that these produced rather low molecular weight polyethene. The activation step was reported to be the splitting of a metal-siloxy bond by the aluminum activator. For vanadium complexes this is not an uncommon event, ${ }^{8}$ but in order to involve the ligand in the control of activity and selectivity during the polymerization process, this should be avoided. The catalytic activity of the dimeric V(III) complexes was not tested, although any catalytic activity should also involve the (partial) removal of the silsesquioxane ligands, thus reducing the potential for ligand control.

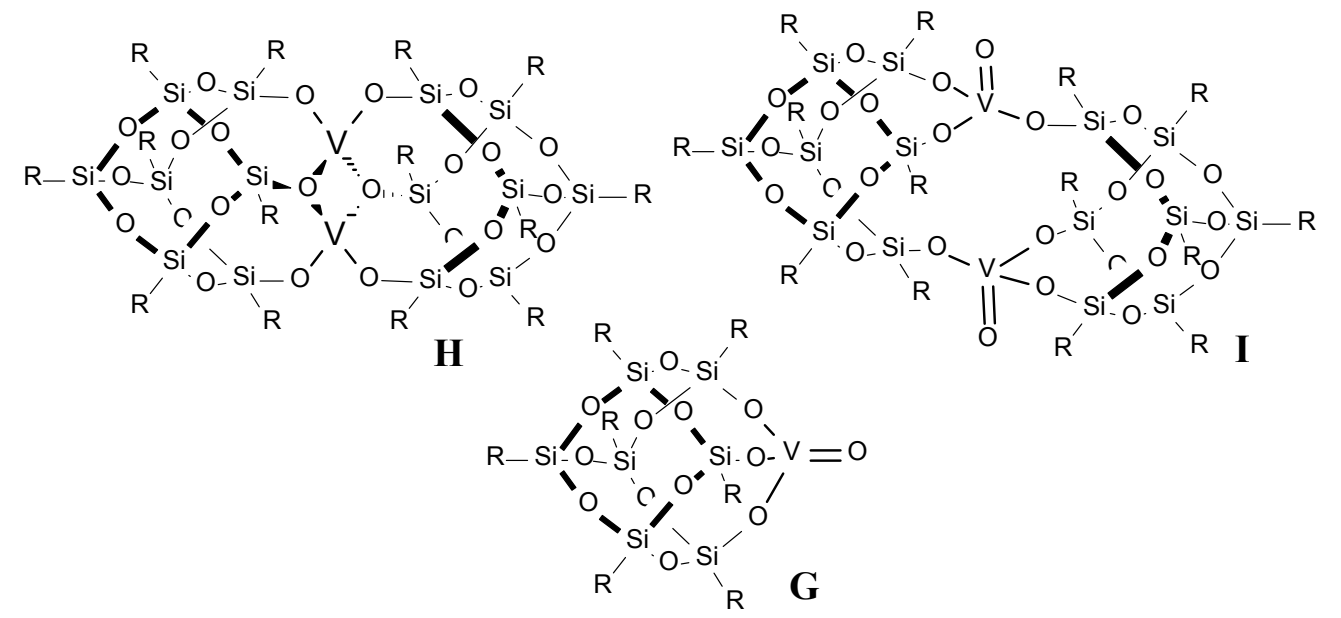

Figure 2. Vanadium silsesquioxanes reported in literature

The use of trivalent titanium species in alkene polymerizations is more widespread. There are examples of trivalent titanium complexes that are very active in the catalytic synthesis of syndiotactic polystyrene. The research towards trivalent titanium species is stimulated by examples of highly active titanium(IV) based catalysts, that were found to be actually titanium(III) after activation by reducing aluminum alkyls. The most significant aspect of trivalent titanium catalysts is their ability to withstand high polymerization temperatures, without any form of performance degradation, possibly due to their resistance to further reduction of the metal center, which is much easier in the case of vanadium catalysts, where all oxidation states between 0 en +5 are easily available.

In this chapter, we report the synthesis of new trivalent vanadium complexes of various silyl substituted silsesquioxane ligands that are able to polymerize ethene without having to split the metal-siloxy bonds. Comparable complexes with trivalent titanium were synthesized and 
tested in the polymerization of ethene. Catalytic cycle and coordination behavior were rationalized by computational methods.

\section{Synthesis and reactivity of vanadium (III) silsesquioxane complexes}

In order to make use of the electron-withdrawing properties of chelating silsesquioxanes to metal in general and vanadium in particular, and to still have one reactive moiety (halide, aryl, alkyl) available for catalytic purposes and reactivity studies, vanadium trichloride or trismesitylvanadium was reacted with mono-silylated silsesquioxanes (Scheme 1).

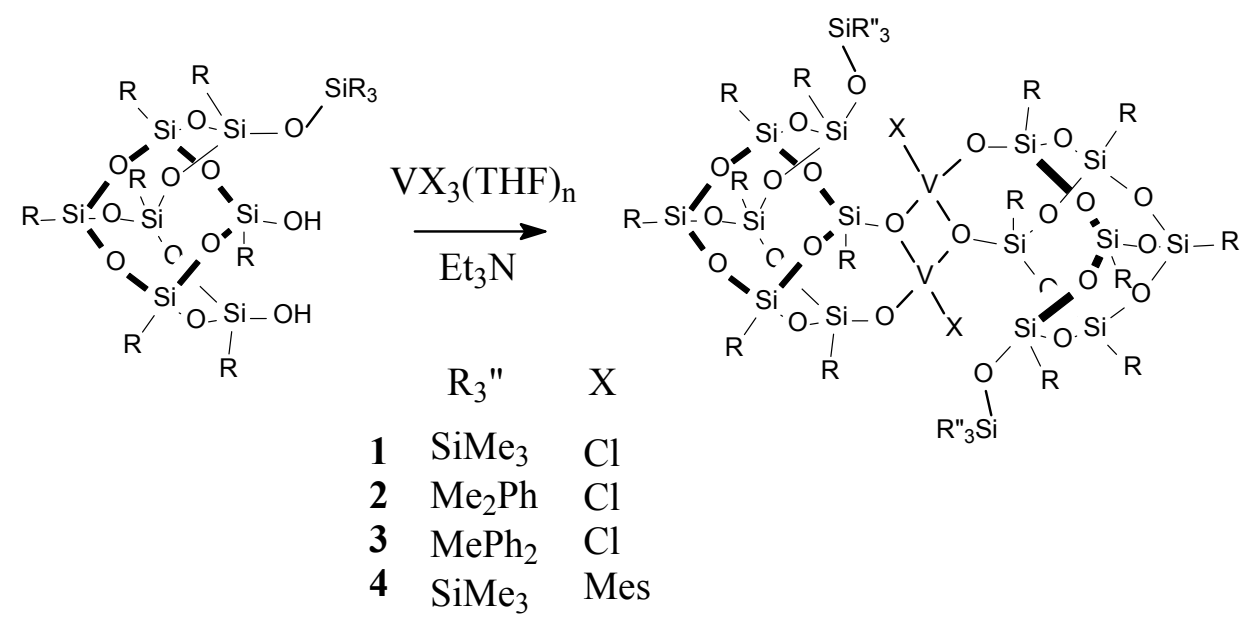

Scheme 1. Reaction of silyl-substituted silsesquioxane disilanol ligands with vanadium (III) trichloride

Upon addition of the solid silsesquioxane ligand to a solution of the vanadium precursor in THF, a swift color change occurred. For the vanadium chloride systems, this was a change from a dark-red solution of the metal salt in $\mathrm{THF} / \mathrm{Et}_{3} \mathrm{~N}$ to purple-red and a precipitation of the triethyl ammonium hydrochloride salt was observed. The rate of color change was clearly dependent on the steric size of the silyl substituent on the silsesquioxane ligand: while the trimethylsilyl substituted ligand reacted almost instantaneous, the bulkier phenylsilyl substituted silsesquioxanes reacted over the course of minutes to evenly colored purple-red solutions. Filtration, drying and subsequent extraction with apolar solvents such as hexanes or methylcyclohexane yielded highly air and moisture sensitive blue greenish solids 1-4. NMR analyses of these materials showed them to be paramagnetic with a paramagnetic susceptibility of about 3.2 BM (dimer), a value under the theoretical value of $2.8 \mathrm{BM}$ per vanadium atom, indicating a strong anti-ferromagnetic exchange interaction between the two metal centers. These results are comparable to results found by the group of Feher for nonsubstituted trisiloxy-vanadium dimer complexes. They found $\chi_{\mathrm{m}}=0.0046 \mathrm{cgms} / \mathrm{mol} \mathrm{dimer}$, 
compared to average $0.0043 \mathrm{cgms} / \mathrm{mol}$ dimer for complexes $1-4 .^{13}$ The NMR analyses of the vanadium compounds were complicated by their paramagnetism and no resonances other than the solvent could be observed, even at high concentrations. Crystals suitable for X-ray crystal structure analysis could not be grown due to the high solubility of the vanadium silsesquioxanes in solvents like hexane, methylcyclohexane or toluene. Addition of acetone or acetonitril, solvents that are often used for precipitation of silsesquioxane compounds, resulted in a change of color of the solution (indicating coordination, vide infra) but no precipitation was observed. Based on the obtained results and literature data of vanadium alkoxides, the structures of vanadium compounds 1-4 are proposed in Scheme 1.

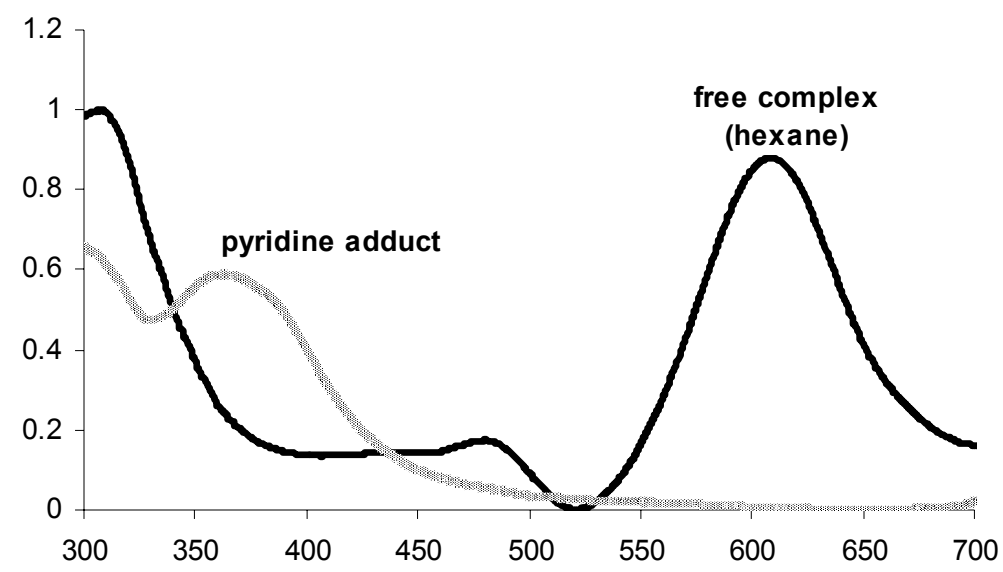

Figure 3. UV-Vis spectra of complex 1 in hexane (solid line) and hexane/pyridine (grey line)

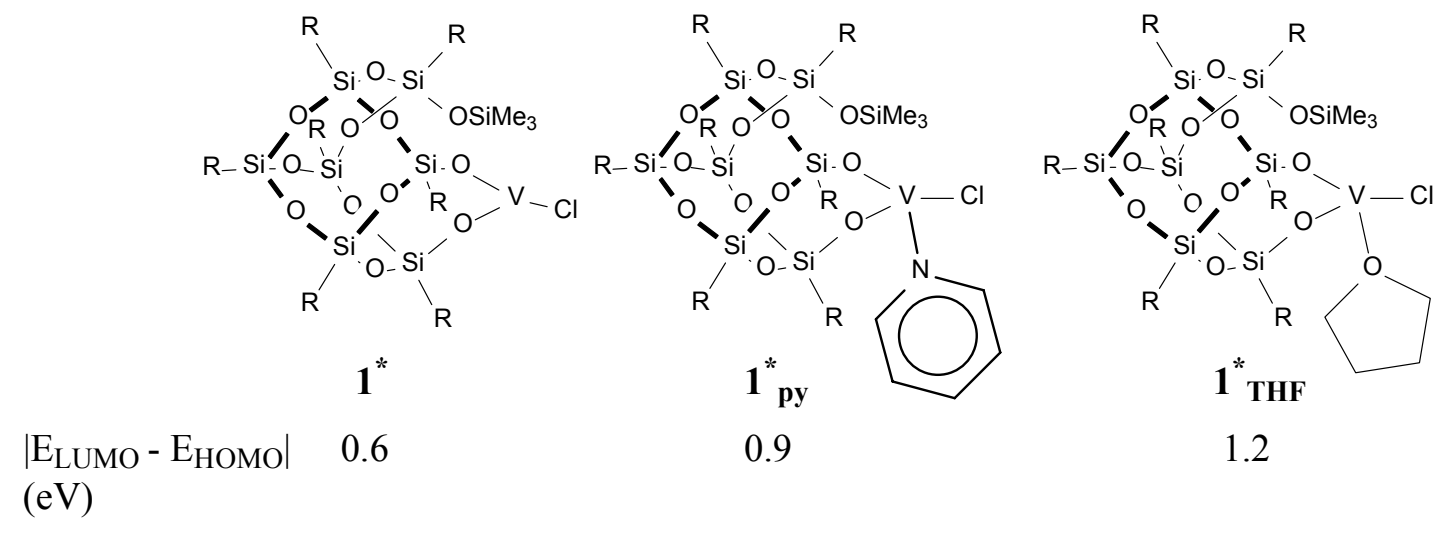

Scheme 2. Models for the vanadium silsesquioxanes complexes used in DFT computations 
When complexes 1-3 are dissolved in coordinating solvent (THF or pyridine), a distinct color change is observed. The original blue color changes to red (THF) or dark green (pyridine). UV-Vis spectra of the free complex 1 and its pyridine adduct are shown in Figure 3. DFT computations performed on simplified model structures, as shown in Scheme 2, corroborate the spectral change qualitatively. The computed differences between the energy levels of the LUMO (lowest unoccupied molecular orbital) and the HOMO (highest occupied molecular orbital) are shown in Scheme 2. The trend on going from $1^{*}$ to $1^{*}$ THF is to increasing energy differences between HOMO and LUMO, indicating UV-Vis absorption going from the red to blue range. This will cause the color shift for the compounds in solution from blue for $1^{*}$ to red for $1^{*}$ THF, as observed. Note that the numbers themselves are not useful for calculating a UV-Vis spectrum, because of the simplified models used in the computations and the assumptions made during the DFT computations in order to reduce computational costs. The observed trends, however, can be considered valid.

The enthalpy of the coordination reactions also explains the relative stability of the solvent adducts. Coordination of THF is only slightly exothermal by $-27 \mathrm{~kJ} / \mathrm{mol}$, while the addition of pyridine to the complexes is much more exothermal $(-81 \mathrm{~kJ} / \mathrm{mol})$. This explains why the coordination of THF is a reversible process (THF can be removed by simply drying the compound in vacuo), while the removal of pyridine is more cumbersome and may lead to thermal decomposition of the complexes.

The addition of air or pure oxygen to a solution of the vanadium compounds in apolar solvents, like hexane or methylcyclohexane, induced a fast color change from blue to brownish red. This indicates oxidation of the vanadium center to a vanadyl species. Subsequent addition of coordinating solvents changed nothing to their UV-Vis properties, indicating that the coordination sphere of the metal is filled. Addition of various epoxides to perform the oxidation of the metal also resulted in the same color change. ${ }^{16}$ While styrene oxide was found to be the fastest oxidant, propylene oxide and cyclohexene oxide were less effective in oxidizing the vanadium center. Attempts to isolate the oxidized compound in each case failed, unfortunately.

Addition of alkylating agents such as methyl magnesium chloride or benzyl magnesium bromide at low temperatures $\left(-80^{\circ} \mathrm{C}\right)$ showed signs of alkylation (the formation of a green solution and white precipitates $\left.\left(\mathrm{MgBr}_{2}\right)\right)$, but the low thermal stability and high solubility of 
the resulting products did not allow the isolation of any species without changing to a mixture of paramagnetic black/brownish sticky residues, probably reduced products. ${ }^{7 ; 17}$

\section{Synthesis and reactivity of titanium (III) silsesquioxane complexes}

A number of titanium (III) silsesquioxane complexes (Scheme 3) were synthesized in analogy to the route employed for vanadium(III). Addition of a silylated silsesquioxane disilanol and triethylamine to a THF solution of titanium trichloride caused a sudden color change from light blue to brown-red and the concommitant precipitation of a grey-white powder. Extraction with apolar solvents, such as methylcyclohexane or n-hexane yielded brown-red compounds that were highly soluble in solvents with which they did not react. These complexes are paramagnetic (average $\mu_{\mathrm{B}}=1.9 \mathrm{BM}$ ). This is comparable to the titanium (III) silsesquioxane complexes, Feher reported. ${ }^{13 ; 18}$ Traces of water or air are detrimental to the oxidation state and ligand connectivity of these complexes. After addition of either agent, no well-resolved NMR spectra can be taken, although these longer reflect paramagnetic species. This indicates (partial) leaching of the metal out of the complexes under the influence of moisture or air.

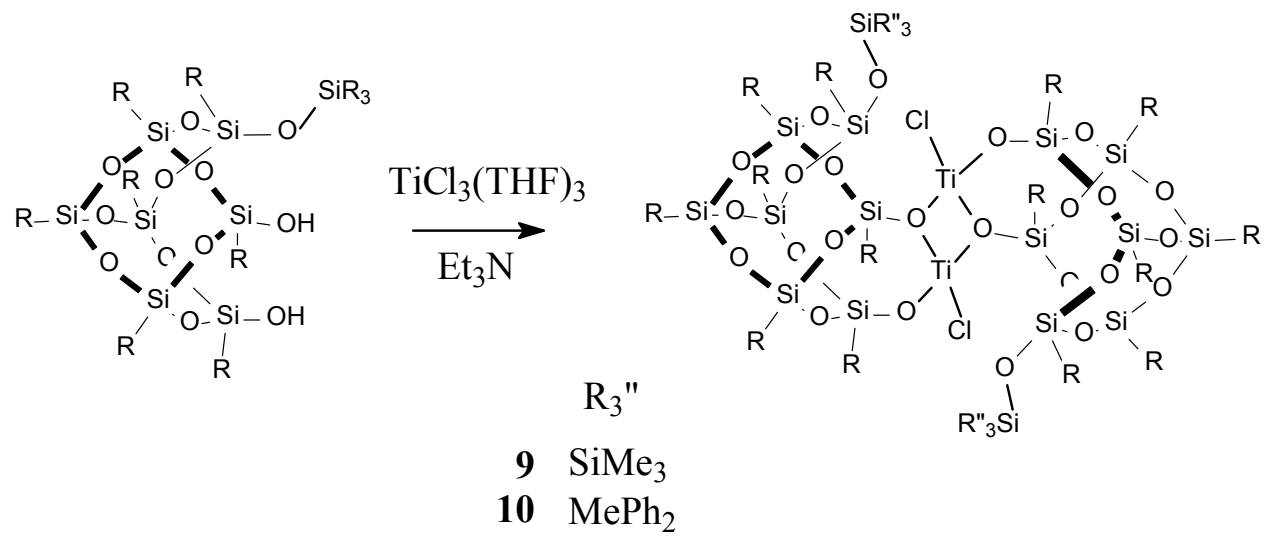

Scheme 3. Reaction of silyl-substituted silsesquioxane disilanol ligands with titanium(III) trichloride

\section{Catalytic polymerization of ethene}

Vanadium and titanium silsesquioxane complexes were tested in the catalytic polymerization of ethene. The results of the polymerization runs are shown in Table 1. As can be seen from Table 1, the vanadium silsesquioxane complexes 1-4 have a much higher activity than the titanium complexes $\mathbf{9}$ and $\mathbf{1 0}$ when activated with activated with diethyl aluminum chloride. After activation of the vanadium compounds the temperature in the reactor increased quickly from room temperature to about $50^{\circ} \mathrm{C}$ and polymer precipitated. 
Table 1. Results of catalytic polymerization of ethene with vanadium and titanium silsesquioxane complexes, activated by aluminum alkyl compounds.

\begin{tabular}{lllll}
\hline & Activator & $\begin{array}{l}\text { Activity }^{a} \\
\left(\times 10^{3}\right.\end{array}$ & $\begin{array}{l}M w \\
\left(\mathrm{~kg}^{3} \mathrm{~mol}^{-1}\right)\end{array}$ & \\
& & $M_{w} / M_{n}$ \\
\hline $\left.\mathbf{1} \cdot \mathrm{mol}^{-1} \cdot \mathrm{h}^{-1} \cdot \mathrm{bar}^{-1}\right)$ & & \\
$\mathbf{1}$ & 240 & 779 & 3.7 \\
$\mathbf{1}^{\mathrm{c}}$ & DEAC & $20^{\mathrm{b}}$ & 802 & 3.6 \\
$\mathbf{1}^{\mathrm{c}}$ & DEAC & $<10$ & - & - \\
$\mathbf{1}^{\mathbf{d}}$ & DEAC & $<10$ & - & - \\
$\mathbf{3}$ & MAO & 0 & - & - \\
$\mathbf{4}$ & DEAC & 230 & 813 & 3.4 \\
$\mathbf{4}$ & DEAC & 0 & - & - \\
$\mathbf{9}$ & - & 730 & 4.5 \\
$\mathbf{1 0}$ & DEAC & 170 & 374 & 59 \\
\hline
\end{tabular}

Conditions: $\sim 10$ mmol complex, 5 bar ethene pressure, 5 minute run, solvent: toluene

a activity per mol vanadium; ${ }^{b} 40$ minute polymerization run (vide infra); ${ }^{c}$ polymerization of propylene; ${ }^{d}$ polymerization of 1-hexene

Compared to literature values, the activity for the vanadium systems is moderately high. In recent overviews by Gibson et al., activities for vanadium based systems were reported ranging from 27 to $1190 \mathrm{~kg} \cdot \mathrm{mol}^{-1} \cdot \mathrm{bar}^{-1} \cdot \mathrm{h}^{-1},{ }^{19 ; 20}$ although a majority of the complexes had an activity in the range of $200-400 \mathrm{~kg} \cdot \mathrm{mol}^{-1} \cdot \mathrm{bar}^{-1} \cdot \mathrm{h}^{-1}$. The vanadium silsesquioxane catalysts produced most of the polymer in the initial stages of the experiment. After 40 minutes, almost the same amount of polymer was produced than after 5 minutes. This shows that the catalyst deactivated fast. The protecting silyl group on the silsesquioxane ligand has virtually no effect on the activity of the complex and on the properties of the produced polymer. This can be explained by its relatively large spatial distance from the metal center, avoiding all forms of steric hindrance, and the non-conducting silicon-oxide nature of the ligands, ensuring that its electronic influence is virtually absent. The silsesquioxane titanium complexes were only slightly active, giving no exothermal polymerization. The amount of polymer produced was very low and the polymer itself was of poor quality. The broad molecular weight distribution and the bimodal character of the GPC data indicate the formation of multiple species. 
Although complex 4 contains a metal-carbon bond present in the compound, it cannot be activated to insert ethene in this bond. The unreactivity of the vanadium mesityl bond with ethene is consistent with the literature where $\mathrm{V}(\mathrm{Mes})_{3}(\mathrm{THF})$ could only insert more reactive nitriles or isonitriles into the metal-carbon bond. ${ }^{16 ; 21 ; 22}$ The addition of an aluminum alkyl does however activate the complex to produce polyethene. This means that either an ethyl group replaces the mesityl group or that the metal is leached out of the complex after activation with aluminum precursors.

\section{Ethene polymerization studied by Density Functional computations}

In order to learn more about the energetics of ethene polymerization mechanism by vanadium silsesquioxane complexes, part of the catalytic cycle was studied by Density Function computations. The organic side groups $(\mathrm{R})$ were replaced by hydrogen atoms and only half of the symmetric molecule was included in the computations to speed up the calculation time. Due to these approximations, the accuracy is limited to about $10-20 \mathrm{~kJ} / \mathrm{mol}$.

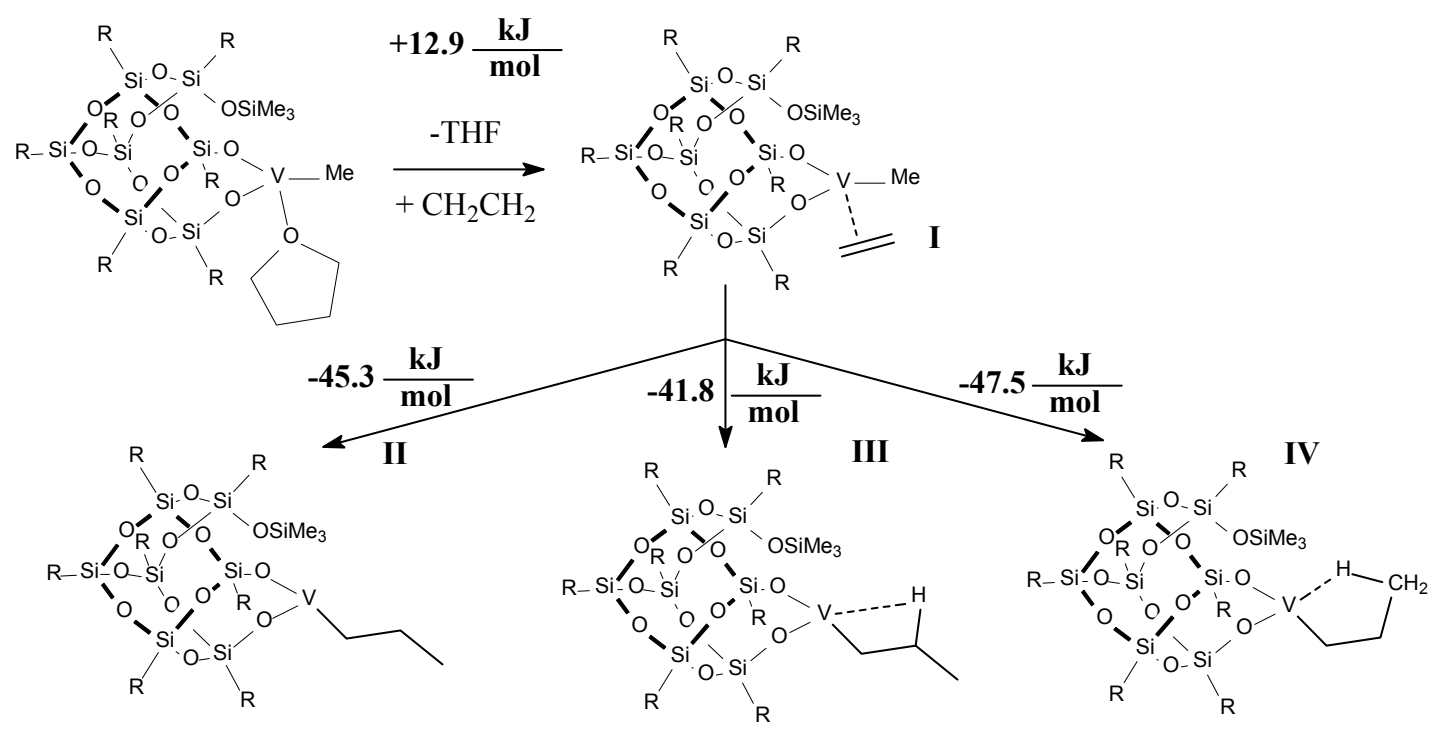

Scheme 4. Density Functional computational study of the coordination and insertion of ethene at a model vanadium silsesquioxane complex

As can be seen in Scheme 4, the coordination of ethene to replace the coordinated THF molecule is a slightly endothermal reaction $(\mathbf{I},+12.9 \mathrm{~kJ} / \mathrm{mol})$ that can easily take place at moderate temperatures. As seen in a previous section, the energy of coordination of THF is about $-27 \mathrm{~kJ} / \mathrm{mol}$. Therefore, the energy of coordination of ethene to the $\mathrm{V}$-methyl species can be estimated at about $-14 \mathrm{~kJ} / \mathrm{mol}$. This is significantly smaller than values reported in 
literature, where Ziegler et al. and Hessen et al. found values of -50 and $-120 \mathrm{~kJ} / \mathrm{mol}$ for nitrogen-based cationic $\mathrm{V}(\mathrm{III})$ and $\mathrm{V}(\mathrm{V})$ complexes. ${ }^{23 ; 24}$ For a nitrogen-based cationic $\mathrm{V}(\mathrm{V})$ complex, Ziegler et al. found an ethene coordination energy between -14 and $-30 \mathrm{~kJ} / \mathrm{mol}$ depending on the mode of coordination. ${ }^{25}$ The main difference is caused by the increased electron-deficiency and low coordination number of the cationic systems.

Overall, the ethene uptake energy of the computed vanadium silsesquioxane complexes seems to be significantly lower than that of several other computed vanadium systems. Although no computations were made for the termination step of the silsesquioxane systems, termination reactions like $\beta$-hydrogen transfer (and possible subsequent reduction to inactive low-valent species) might compete with the almost energy-neutral ethene uptake, shortening the active lifetime of the catalyst.

The first insertion reaction of ethene into the vanadium-carbon bond after its coordination is energetically favorable at about $-45 \mathrm{~kJ} / \mathrm{mol}$ and only slightly depending on the end-situation. It can be seen in Scheme 4 that there is virtually no difference between the end states with no hydrogen-metal interaction (II) and the one with such interactions (III and IV). As there are not much literature values known for vanadium (III) systems, comparison is difficult. Ziegler reported a somewhat higher reaction energy $(-60 \mathrm{~kJ} / \mathrm{mol})$ for the insertion of ethene into the metal carbon in a diamido ligand system. ${ }^{23}$ Other papers reported only the transition state energy barrier. Calculating the barrier for the silsesquioxane systems would require an impractical computational effort. Ziegler reported an insertion barrier of about $40-50 \mathrm{~kJ} / \mathrm{mol}$ for diamido and diiminato systems.

\section{Self-immobilizing polymerization catalysts?}

Alt et al. suggested the incorporation of a polymerizable group covalently attached to metallocene complexes in order to obtain self-immobilizing polymerization catalysts. ${ }^{26-29}$ The immobilization of homogeneous polymerization catalysts offers substantial benefits over classical homogeneous and heterogeneous catalysts. Just as their homogeneous counterparts, the active site is well defined and tunable via the ligand. Moreover, the application of heterogeneous catalysts prevents reactor fouling (a common phenomenon with homogeneous polymerization catalysts), and offers the opportunity of morphology control that leads to better processability of the polymer particles. The approach of Alt was the incorporation of 
copolymerizable alkenyl groups on the backbone on ansa-zirconocene dichloride complexes (Figure 4). When activated with MAO or other alkyl aluminum precursors in the presence of low ethene pressure, a solid red material was formed that was very active in olefin polymerization. Figure 4 shows a silsesquioxane analog of the Alt systems, which is comparable to the ligands used in this Chapter.

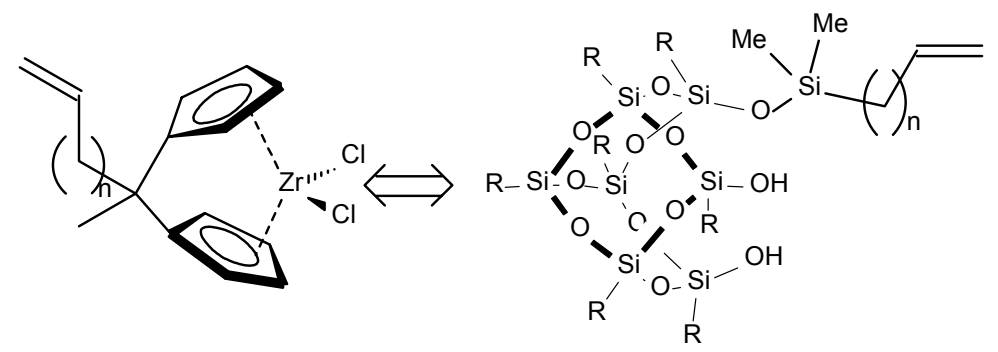

Figure 4. Comparison between Alt and proposed self-immobilizing ligands based on silsesquioxanes

The alkenylgroup-containing ligands were synthesized by reaction of the appropriate chlorosilane with a trisilanol silsesquioxane in the presence of triethylamine. Extraction and recrystallization yielded pure silsesquioxane ligands with pending alkenylgroups. These ligands were treated with $\mathrm{VCl}_{3}(\mathrm{THF})_{3}$ or $\mathrm{TiCl}_{3}(\mathrm{THF})_{3}$ as described in the previous section to yield the very air-sensitive complexes 5, 6, 7 and $\mathbf{1 1}$.

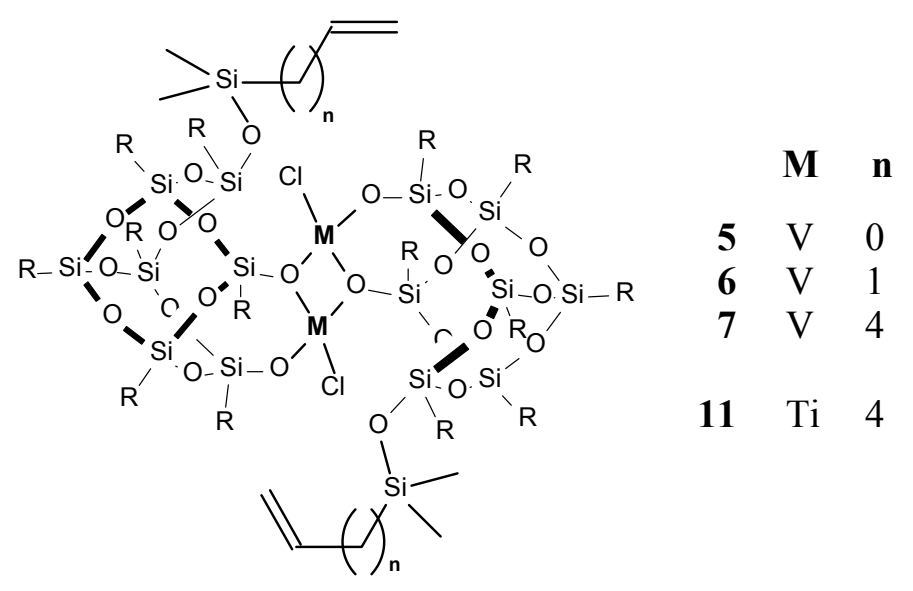

Figure 5. Trivalent metal silsesquioxane complexes with a copolymerizable alkenyl group

These complexes were tested in the catalytic polymerization of ethene as described in the previous section, but in this case the activated complexes were kept in an ethene-saturated toluene solution at 1 bar for 20 minutes in order to enable the formation of polymerimmobilized catalyst. Results of the experiments are listed in Table 2. However, during the preformation phase no polymer had been formed in solution. The polymer properties did 
change compared to the values reported in Table 1. From these data, however, it cannot be concluded that the incorporation of the silsesquioxane complexes in the polymer chain was successful. This can be corroborated by the fact that the vanadium and titanium silsesquioxane complexes also do not polymerize propene and 1-hexene (see Table 1). Thus, the activation of higher alkenes than ethene seems to be unfeasible at the applied conditions, making complexes 1-11 unsuitable for the production of EPDM materials.

Table 2. Results of the catalytic polymerization of ethene with vanadium and titanium silsesquioxane complexes with pending alkenyl groups.

\begin{tabular}{lllll}
\hline & Activator & $\begin{array}{l}\text { Activity } \\
\left(\times 10^{3} \mathrm{~g}_{\mathrm{mol}} \mathrm{mo}^{-1} \cdot \mathrm{h}^{-1} \cdot \mathrm{bar}^{-1}\right)\end{array}$ & $\mathrm{Mw}\left(\mathrm{g} \cdot \mathrm{mol}^{-1}\right)$ & $M_{w} / M_{n}$ \\
\hline $\mathbf{5}$ & DEAC & 200 & 400 & 12 \\
$\mathbf{7}$ & DEAC & 210 & 328 & 5.7 \\
$\mathbf{1 1}$ & DEAC & 20 & 21 & 11
\end{tabular}

Conditions: $\sim 10$ mmol complex; 20 minutes preformation in ethene-saturated toluene; 5 bar ethene pressure, 5 minute run

Unfornately, the concept of self-immobilization of these systems seems to be problematic and should be applied to metals and ligands systems that have a higher activity with longer alkenes, such as propene and 1-hexene.

\section{Concluding remarks}

The reaction of vanadium trichloride and titanium trichloride with silyl-protected silsesquioxane disilanol ligands led to the formation of paramagnetic highly air-sensitive metal silsesquioxane complexes. The effect of subsequent coordination by solvent like THF and pyridine is studied with UV-Vis and qualitatively confirmed by DFT computations. The position of the UV-Vis absorption bands and the relative stability of adducts match well with the computational results. The titanium (III) and vanadium (III) complexes were active in the catalytic polymerization of ethene, although the titanium complexes had very low activity compared to literature values for other complexes. Vanadium silsesquioxane complexes had a moderate activity compared to literature values and produced high molecular weight polyethene, although the catalysts had a short lifetime, possible due to reduction of the active species. An attempt to apply a concept of self-immobilization by means of introducing copolymerizable alkenyl ancillaries was unsuccessful. The initiation and first insertion step of ethene into a vanadium carbon bond was investigated with DFT computation. It was found 
that the energetics of these reactions for vanadium silsesquioxane systems were lower than those reported in literature. 


\section{Experimental Section}

\section{General remarks.}

All operations involving air and moisture sensitive materials were performed in an inert atmosphere using standard Schlenk techniques and an argon filled glovebox. Solvents were dried over Na (THF, toluene, benzene$\left.d_{6}\right)$ or $4 \AA$ molecular sieves $\left(\mathrm{CDCl}_{3}\right)$ and were degassed before use. $\mathrm{VCl}_{3}$ (99\%, Acros), $\mathrm{TiCl}_{3}(99 \%, \mathrm{Acros})$ and $\mathrm{Cr}(\mathrm{acac})_{3}\left(97 \%\right.$, Jansen-Chimica) were used as purchased. The silsesquioxane ligands, ${ }^{30^{-3} 3} \mathrm{TiCl}_{3}(\mathrm{THF})_{3}{ }^{34}$ $\mathrm{VMes}_{3}(\mathrm{THF})^{35}$ and $\mathrm{VCl}_{3}(\mathrm{THF})_{3}{ }^{34}$ were prepared according to literature procedures. NMR spectra were recorded on VARIAN Mercury 400 and VARIAN Inova 500 spectrometers and referred to residual solvent resonances $\left({ }^{1} \mathrm{H},{ }^{13} \mathrm{C}\right)$. Transmission IR spectra were measured on a Nicolet AVATAR 360 FT-IR. SELACT (Groningen, The Netherlands) carried out the elemental analyses. Magnetic moments were determined by the Evans method. $^{36^{-3} 38}$

\section{Synthesis of $\left\{\left(c-\mathrm{C}_{5} \mathrm{H}_{9}\right)_{7} \mathrm{Si}_{7} \mathrm{O}_{9}\left(\mathrm{OSiMe}_{3}\right)\right\}_{2}\left[\left(\mu_{3}-\mathrm{O}\right) \mathrm{VCl}\right]_{2}(1)$}

A THF solution $(20 \mathrm{~mL})$ of silsesquioxane disilanol $\left(c-\mathrm{C}_{5} \mathrm{H}_{9}\right)_{7} \mathrm{Si}_{7} \mathrm{O}_{9}\left(\mathrm{OSiMe}_{3}\right)(\mathrm{OH})_{2}(1.40 \mathrm{~g}, 1.47 \mathrm{mmol})$ and triethylamine $(1 \mathrm{~mL})$ was added slowly to a red-colored solution of $\mathrm{VCl}_{3}(\mathrm{THF})_{3}(0.55 \mathrm{~g}, 1.47 \mathrm{mmol})$ in $\mathrm{THF}(20$ $\mathrm{mL}$ ). Almost immediately after addition of the silsesquioxane/amine solute, the color changed from red to purplish red and a grey precipitate formed. After stirring for $24 \mathrm{~h}$, the solvent and residual $\mathrm{Et}_{3} \mathrm{~N}$ was removed in vacuo. At dryness, the powder changed color from purple-red to blue. The blue powder was extracted with hexane or methylcyclohexane $(40 \mathrm{~mL})$ and the solvent was removed in vacuo. Stripping with hexane yielded 1.1 g of blue-colored $1(0.53 \mathrm{mmol}, 72 \%)$. Magnetic susceptibility $\mu_{\mathrm{B}}=3.21 \mathrm{BM}$. Elemental analysis: calc. C 44.22 $\%, \mathrm{H} 7.03 \%, \mathrm{Cl} 3.44 \%$; found. C $42.90 \%, \mathrm{H} 7.37 \%, \mathrm{Cl} 3.21 \%$

\section{Synthesis of $\left\{\left(c-\mathrm{C}_{5} \mathrm{H}_{9}\right)_{7} \mathrm{Si}_{7} \mathrm{O}_{9}\left(\mathrm{OSiMe}_{2} \mathrm{Ph}\right)\right\}_{2}\left[\left(\mu_{3}-\mathrm{O}\right) \mathrm{VCl}\right]_{2}(2)$}

As 1, instead, silsesquioxane disilanol $\left(c-\mathrm{C}_{5} \mathrm{H}_{9}\right)_{7} \mathrm{Si}_{7} \mathrm{O}_{9}\left(\mathrm{OSiMe}_{2} \mathrm{Ph}\right)(\mathrm{OH})_{2}(2.50 \mathrm{~g}, 2.48 \mathrm{mmol})$; triethylamine $(2$ $\mathrm{mL}) ; \mathrm{VCl}_{3}(\mathrm{THF})_{3}(0.96 \mathrm{~g}, 2.57 \mathrm{mmol})$. Stripping with hexane yielded $1.7 \mathrm{~g}$ of blue-colored $2(0.78 \mathrm{mmol}, 63 \%)$ $\mu_{\mathrm{B}}=3.30$ BM. Elemental analysis: calc. C $47.20 \%, \mathrm{H} 6.82 \%, \mathrm{Cl} 3.24 \%$; found. C $47.01 \%, \mathrm{H} 6.84 \%, \mathrm{Cl}$ $3.21 \%$

\section{Synthesis of $\left\{\left(c-\mathrm{C}_{5} \mathrm{H}_{9}\right)_{7} \mathrm{Si}_{7} \mathrm{O}_{9}\left(\mathrm{OSiMePh}_{2}\right)\right\}_{2}\left[\left(\mu_{3}-\mathrm{O}\right) \mathrm{VCl}\right]_{2}(3)$}

As 1, instead silsesquioxane disilanol $\left(c-\mathrm{C}_{5} \mathrm{H}_{9}\right)_{7} \mathrm{Si}_{7} \mathrm{O}_{9}\left(\mathrm{OsiMePh}_{2}\right)(\mathrm{OH})_{2}(1.69 \mathrm{~g}, 1.58 \mathrm{mmol})$; triethylamine $(2$ $\mathrm{mL}) ; \mathrm{VCl}_{3}(\mathrm{THF})_{3}(0.58 \mathrm{~g}, 1.59 \mathrm{mmol})$. Stripping with hexane yielded $1.2 \mathrm{~g}$ of blue-colored $3(0.52 \mathrm{mmol}, 73 \%)$ $\mu_{\mathrm{B}}=3.21$ BM. Elemental analysis: calc. C $49.26 \%$, H $6.63 \%, \mathrm{Cl} 3.07 \%$; found. C $49.13 \%$, H $6.39 \%, \mathrm{Cl} 2.75$ $\%$

\section{Synthesis of $\left\{\left(c-\mathrm{C}_{5} \mathrm{H}_{9}\right)_{7} \mathrm{Si}_{7} \mathrm{O}_{9}\left(\mathrm{OSiMe}_{3}\right)\right\}_{2}\left[\left(\mu_{3}-\mathrm{O}\right) \mathrm{VMes}\right]_{2}(4)$}

As 1, instead silsesquioxane disilanol $\left(c-\mathrm{C}_{5} \mathrm{H}_{9}\right)_{7} \mathrm{Si}_{7} \mathrm{O}_{9}\left(\mathrm{OSiMe}_{3}\right)(\mathrm{OH})_{2}(1.53 \mathrm{~g}, 1.60 \mathrm{mmol})$; no triethylamine; $\mathrm{V}(\mathrm{Mes})_{3}(\mathrm{THF})(0.77 \mathrm{~g}, 1.60 \mathrm{mmol})$. Stripping with hexane yielded $1.1 \mathrm{~g}$ of blue-colored 4. $\mu_{\mathrm{B}}=3.19 \mathrm{BM}$. Elemental analysis: calc. C $50.29 \%$, H $7.50 \%$; found. C $51.04 \%$, H $7.31 \%$ 


\section{Synthesis of $\left\{\left(c-\mathrm{C}_{5} \mathrm{H}_{9}\right)_{7} \mathrm{Si}_{7} \mathrm{O}_{9}\left(\mathrm{OSi}\left(\mathrm{Me}_{2}\right) \mathrm{CHCH}_{2}\right)\right\}_{2}\left[\left(\mu_{3}-\mathrm{O}\right) \mathrm{VCl}\right]_{2}(5)$}

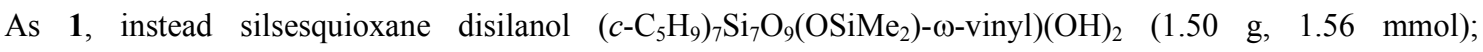
triethylamine $(2 \mathrm{~mL}) ; \mathrm{VCl}_{3}(\mathrm{THF})_{3}(0.58 \mathrm{~g}, 1.56 \mathrm{mmol})$. Stripping with hexane yielded $0.81 \mathrm{~g}$ of blue-colored 5 (3.88 mmol, 48\%) $\mu_{\mathrm{B}}=3.25$ BM. Elemental analysis: calc. C $44.87 \%$, H $6.95 \%$, Cl 3.40 \%; found. C $44.88 \%$, H $6.80 \%, \mathrm{Cl} 3.17 \%$

\section{Synthesis of $\left\{\left(c-\mathrm{C}_{5} \mathrm{H}_{9}\right)_{7} \mathrm{Si}_{7} \mathrm{O}_{9}\left(\mathrm{OSi}\left(\mathrm{Me}_{2}\right) \mathrm{CH}_{2} \mathrm{CHCH}_{2}\right)\right\}_{2}\left[\left(\mu_{3}-\mathrm{O}\right) \mathrm{VCl}\right]_{2}(6)$}

As 1, instead silsesquioxane disilanol $\left(c-\mathrm{C}_{5} \mathrm{H}_{9}\right)_{7} \mathrm{Si}_{7} \mathrm{O}_{9}\left(\mathrm{OSiMe}_{2}\right)-\omega$-allyl $)(\mathrm{OH})_{2}(1.15 \mathrm{~g}, 1.18 \mathrm{mmol})$; triethylamine $(2 \mathrm{~mL}) ; \mathrm{VCl}_{3}(\mathrm{THF})_{3}(0.44 \mathrm{~g}, 1.18 \mathrm{mmol})$. Stripping with hexane yielded $0.76 \mathrm{~g}$ of blue-colored $6(0.35 \mathrm{mmol}$, $61 \%) \mu_{\mathrm{B}}=3.19$ BM. Elemental analysis: calc. C $45.41 \%, \mathrm{H} 7.05 \%$, Cl $3.35 \%$; found. C $45.16 \%$, H $6.93 \%$, Cl $3.54 \%$

\section{Synthesis of $\left\{\left(c-\mathrm{C}_{5} \mathrm{H}_{9}\right)_{7} \mathrm{Si}_{7} \mathrm{O}_{9}\left(\mathrm{OSi}\left(\mathrm{Me}_{2}\right)\left(\mathrm{CH}_{2}\right)_{4} \mathrm{CHCH}_{2}\right)\right\}_{2}\left[\left(\mu_{3}-\mathrm{O}\right) \mathrm{VCl}\right]_{2}(7)$}

As 1, instead silsesquioxane disilanol $\left(c-\mathrm{C}_{5} \mathrm{H}_{9}\right)_{7} \mathrm{Si}_{7} \mathrm{O}_{9}\left(\mathrm{OSi}\left(\mathrm{Me}_{2}\right)-\omega\right.$-hexenyl $)(\mathrm{OH})_{2}(\mathbf{8}, 2.07 \mathrm{~g}, 2.03 \mathrm{mmol})$; triethylamine $(2 \mathrm{~mL}) ; \mathrm{VCl}_{3}(\mathrm{THF})_{3}(0.76 \mathrm{~g}, 2.03 \mathrm{mmol})$. Stripping with hexane yielded $1.3 \mathrm{~g}$ of blue-colored 7 $(0.59 \mathrm{mmol}, 58 \%) . \mu_{\mathrm{B}}=3.26 \mathrm{BM}$. Elemental analysis: calc. C $46.94 \%$, H $7.33 \%$, Cl $3.22 \%$; found. C 47.50 $\%, \mathrm{H} 7.65 \%, \mathrm{Cl} 3.02 \%$

\section{Synthesis of $\left(c-\mathrm{C}_{5} \mathrm{H}_{9}\right)_{7} \mathrm{Si}_{7} \mathrm{O}_{9}\left(\mathrm{OSi}\left(\mathrm{Me}_{2}\right)\left(\mathrm{CH}_{2}\right)_{4} \mathrm{CHCH}_{2}\right)(\mathrm{OH})_{2}(8)$}

Chlorodimethyl-5-hexenylsilane $(2.13 \mathrm{~g}, 12.0 \mathrm{mmol})$ was slowly added to a solution of $\left(c-\mathrm{C}_{5} \mathrm{H}_{9}\right)_{7} \mathrm{Si}_{7} \mathrm{O}_{9}(\mathrm{OH})_{3}$ $(10.2 \mathrm{~g}, 12.0 \mathrm{mmol})$ in THF $(100 \mathrm{~mL}) / \mathrm{Et}_{3} \mathrm{~N}(5 \mathrm{~mL})$. After the addition of the silane, the solution was heated to reflux and left to stir for $16 \mathrm{~h}$, while a precipitate appeared. The solvent and residual triethyl amine were removed in vacuo and the white mass was extracted with hexane $(40 \mathrm{~mL}$ and $20 \mathrm{~mL})$. Concentration of the solution yielded 8 as a pure compound (8.50 g, 69 \%). NMR Data: ${ }^{1} \mathrm{H}\left(400 \mathrm{MHz}, \mathrm{CDCl}_{3}, \delta\right): 5.8$ (m, $1 \mathrm{H}$, $\left.\mathrm{CH}=\mathrm{CH}_{2}\right), 4.9\left(\mathrm{dd}, 2 \mathrm{H}, \mathrm{CH}=\mathrm{CH}_{2}\right), 4.2(\mathrm{~s}, 2 \mathrm{H}, \mathrm{SiOH}), 2.1$ (q, $2 \mathrm{H}, \mathrm{CH}$ ) $, 1.8-1.3\left(\mathrm{~m}, 56 \mathrm{H}, \mathrm{SiC}_{5} H_{9}\right), 1.4^{*}(\mathrm{~m}, 2$ $\left.\mathrm{H}, \mathrm{CH}_{2}\right), 1.3^{*}\left(\mathrm{~m}, 2 \mathrm{H}, \mathrm{CH}_{2}\right)$ 1.1-0.9 (m, $7 \mathrm{H}, \mathrm{SiC} 5 \mathrm{H} 9$, ipso). $0.6\left(\mathrm{~m}, 2 \mathrm{H}, \mathrm{CH}_{2}\right), 0.1(\mathrm{~s}, 6 \mathrm{H}, \mathrm{SiMe})_{2} ;{ }^{13} \mathrm{C}\left\{{ }^{1} \mathrm{H}\right\}(100$ $\left.\mathrm{MHz}, \mathrm{CDCl}_{3}, \delta\right): 139.11\left(\mathrm{~s}, \mathrm{CH}=\mathrm{CH}_{2}\right), 114.08\left(\mathrm{~s}, \mathrm{CH}=\mathrm{CH}_{2}\right), 33.50\left(\mathrm{~s}, \mathrm{CH}_{2}\right), 32.62\left(\mathrm{~s}, \mathrm{CH}_{2}\right), 27.58,27.44,27.40$, 27.27, 27.24, 27.11,27.05, 27.03, 27.00 (s, $\mathrm{Si}_{5} \mathrm{H}_{9}$ non-ipso), 23.69, 22.77, 22.41, 22.26, 22.20 (s, $\mathrm{Si}_{5} \mathrm{H}_{9}$, ipso, rel. ratio 1:2:2:1:1), $22.65\left(\mathrm{~s}, \mathrm{CH}_{2}\right), 17.83\left(\mathrm{~s}, \mathrm{CH}_{2}\right),-0.02$ (s, SiMe2).

*: As determined by HETCOR.

\section{Synthesis of $\left\{\left(c-\mathrm{C}_{5} \mathrm{H}_{9}\right)_{7} \mathrm{Si}_{7} \mathrm{O}_{9}\left(\mathrm{OSiMe}_{3}\right)\right\}_{2}\left[\left(\mu_{3}-\mathrm{O}\right) \mathrm{TiCl}\right]_{2}(9)$}

A THF solution $(20 \mathrm{~mL})$ of silsesquioxane disilanol $\left(c-\mathrm{C}_{5} \mathrm{H}_{9}\right)_{7} \mathrm{Si}_{7} \mathrm{O}_{9}\left(\mathrm{OSiMe}_{3}\right)(\mathrm{OH})_{2}(1.58 \mathrm{~g}, 1.60 \mathrm{mmol})$ and triethylamine $(2 \mathrm{~mL})$ was added slowly to a light blue-colored solution of $\mathrm{TiCl}_{3}(\mathrm{THF})_{3}(0.31 \mathrm{~g}, 0.84 \mathrm{mmol})$ in THF $(20 \mathrm{~mL})$. Almost immediately after addition of the silsesquioxane/amine solute, the color changed from light blue to brown red and a grey precipitate formed. After stirring for $24 \mathrm{~h}$, the solvent and residual $\mathrm{Et}_{3} \mathrm{~N}$ was removed in vacuo. The brown-red powder was extracted with hexane or methylcyclohexane $(40 \mathrm{~mL})$ and the solvent was removed in vacuo. Stripping with hexane yielded $1.1 \mathrm{~g}$ of brown-red colored 9. Magnetic 
suscitibility $\mu_{\mathrm{B}}=1.79$ BM. Elemental analysis: calc. C $44.35 \%$, H $7.05 \%$, Cl $3.45 \%$; found. C $43.92 \%$, H 7.15

$\%, \mathrm{Cl} 3.48 \%$

\section{Synthesis of $\left\{\left(c-\mathrm{C}_{5} \mathrm{H}_{9}\right)_{7} \mathrm{Si}_{7} \mathrm{O}_{9}\left(\mathrm{OSiMePh}_{2}\right)\right\}_{2}\left[\left(\mu_{3}-\mathrm{O}\right) \mathrm{TiCl}\right]_{2}(9)$}

As 9, instead silsesquioxane disilanol $\left(c-\mathrm{C}_{5} \mathrm{H}_{9}\right)_{7} \mathrm{Si}_{7} \mathrm{O}_{9}\left(\mathrm{OSi}\left(\mathrm{MePh}_{2}\right)(\mathrm{OH})_{2}(1.03 \mathrm{~g}, 0.96 \mathrm{mmol})\right.$; triethylamine $(2$ $\mathrm{mL}) ; \mathrm{TiCl}_{3}(\mathrm{THF})_{3}(0.36 \mathrm{~g}, 0.96 \mathrm{mmol})$. Stripping with hexane yielded $0.8 \mathrm{~g}$ of redbrown-colored 10. $\mu_{\mathrm{B}}=1.84$ BM. Elemental analysis: calc. C $50.00 \%$, H $6.64 \%$, Cl $3.07 \%$; found. C $49.73 \%$, H $6.83 \%$, Cl $3.70 \%$

\section{Synthesis of $\left\{\left(c-\mathrm{C}_{5} \mathrm{H}_{9}\right)_{7} \mathrm{Si}_{7} \mathrm{O}_{9}\left(\mathrm{OSi}\left(\mathrm{Me}_{2}\right)\left(\mathrm{CH}_{2}\right)_{4} \mathrm{CHCH}_{2}\right)\right\}_{2}\left[\left(\mu_{3}-\mathrm{O}\right) \mathrm{TiCl}\right]_{2}(11)$}

As 9, instead silsesquioxane disilanol $\left(c-\mathrm{C}_{5} \mathrm{H}_{9}\right)_{7} \mathrm{Si}_{7} \mathrm{O}_{9}\left(\mathrm{OSi}\left(\mathrm{Me}_{2}\right)-\omega\right.$-hexenyl $)(\mathrm{OH})_{2} \quad(8,1.53 \mathrm{~g}, 1.60 \mathrm{mmol})$; triethylamine $(2 \mathrm{~mL}) ; \mathrm{TiCl}_{3}(\mathrm{THF})_{3}(0.59 \mathrm{~g}, 1.59 \mathrm{mmol})$. Stripping with hexane yielded $1.0 \mathrm{~g}$ of redbrowncolored 11. $\mu_{\mathrm{B}}=1.74 \mathrm{BM}$. Elemental analysis: calc. C $47.07 \%$, H $7.35 \%$, Cl $3.23 \%$; found. C $46.67 \%$, H 7.05 $\%, \mathrm{Cl} 3.09 \%$

\section{Ethene polymerization and analysis}

Ethene polymerization experiments were carried out in an glass Buchi autoclave, using vanadium and titanium compounds. In a typical experiment about $20 \mathrm{mg}(\sim 10 \mu \mathrm{mol}$ complex $)$ of the complex was dissolved in toluene. The reactor was filled $60 \mathrm{~mL}$ of toluene, degassed and the solvent was saturated with toluene. The cocatalyst (diethyl aluminum chloride, $1 \mathrm{~mL}, 1.8 \mathrm{mmol}$ ) was added to the reactor to remove the last traces of weater and after 10 minutes the catalyst solution was injected. Then ethene was introduced at 5 bar. After 5 minutes, stopping the ethene supply and subsequent addition of acidic methanol quenched the polymerization. The white precipitate was filtered and washed with an aqueous solution of $\mathrm{HCl}$, copious methanol and acetone. The resulting polymer was finally dried in an oven for $16 \mathrm{~h}$. The molecular weight of the polyethene samples was determined byHT-GPC at $135^{\circ} \mathrm{C}$ using 1,2,4-trichlorobenzene (TCB) as solvent and narrow MWD polystyrene standard samples as references. The measurements were performed on a PL-GPC210 (Polymer Laboratories) equiped with 4 PL-Gel mixed A columns, 210 differential viscometer (Viscotek), refractive index meter and DM400 datamanager (Viscotek).

\section{Computational details}

Density Functional Theory (DFT) forms the basis of our computations as implemented in the Amsterdam density functional $\left(\mathrm{ADF}^{39}\right)$ code. The exchange correlation functionals in the local-density approximation $\left(\right.$ Vosko, Wilk and Nusair ${ }^{40}$ ) were augmented by generalized gradient approximations to the exchange $\left(\right.$ Becke $\left.^{41}\right)$ and correlation $\left(\right.$ Perdew $^{42}$ ). All the corrections were used in the self-consistent computations. A double $\zeta$ basis set with polarization function for carbon, oxygen, nitrogen and chlorine was used with a frozen core of the $1 \mathrm{~s}$ electrons. For vanadium and silicon a double $\zeta$ basis set with polarization function and a $2 \mathrm{p}$ frozen core has been chosen. A quasi Newtonian approach ${ }^{43}$ to geometry optimization is combined with the direct inversion in the iterative subspace method ${ }^{44}$ (DIIS). Full geometry optimization has been used in all computations in this work. The convergence criteria used in these computations are $10^{-3}$ Hartree for the energy, $5^{*} 10^{-3}$ Hartree/Ångstrom for the gradients and $5^{*} 10^{-3}$ Angstrom for the Cartesian displacement. ADF code makes use of the natural 
symmetry properties of the different clusters. The silsesquioxanes were approximated by substitution of the large cyclopentyl groups on the silicon atoms by hydrogen atoms. 


\section{Bibliography}

[1] Murphy,V.J.; Turner,H. Organometallics 1997, 16, 2495-2497.

[2] Hagen,H.; Boersma,J.; Van Koten,G. Chem.Soc.Rev. 2002, 31, 357-364.

[3] Natta,G.; Zambelli,A.; Lanzi,G.; Pasquon,I.; Mognaschi,E.R.; Segre,A.L.; Centola,P. Makromol.Chem. 1965, 81,161

[4] Jiao,S.; Yu,D. Polymer.J. 1985, 899

[5] Henderson,R.A.; Hughes,D.L.; Janas,Z.; Richards,R.L.; Sobota,P.; Szafert,S. J.Organomet.Chem. 1998, Vol 554, 195-201.

[6] Brandsma,M.J.; Brussee,E.A.; Meetsma,A.; Hessen,B.; Teuben,J.H. Eur.J.Inorg.Chem. 1998, 1867-1870.

[7] Reardon,D.; Conan,F.; Gambarotta,S.; Yap,G.P.; Wang,Q. J.Am.Chem.Soc. 2000, 121, 9318-9325.

[8] Ma,Y.; Gambarotta,S.; Yap,G.P. Organometallics 1999, 18, 2773-2781.

[9] Budzelaar,P.H.M.; Van Oort,A.B.; Orpen,A.G. Eur.J.Inorg.Chem. 1998, 1485-1494.

[10] Kim,W.-K.; Fevola,M.J.; Liable-Sands,L.; Rheingold,A.L.; Theopold,K.H. Organometallics 1998, 17, 4541-4543.

[11] Witte,P.T.; Meetsma,A.; Hessen,B. Organometallics 1999, 18 , 2944-2946.

[12] Hagen,H.; Boersma,J.; Lutz,M.; Spek,A.L.; Van Koten,G. Eur.J.Inorg.Chem. 2001, 117-123.

[13] Feher,F.J.; Walzer,J.F. Inorg.Chem. 1990, 29, 1604-1611.

[14] Feher,F.J.; Walzer,J.F.; Blanski,R.L. J.Am.Chem.Soc. 1991, 113, 3618-3619.

[15] Feher,F.J.; Blanski,R.L. J.Am.Chem.Soc. 1992, 114, 5886-5887.

[16] Vivanco,M.; Ruiz,J.; Floriani,C.; Chiesi-Villa,A.; Rizzoli,C. Organometallics 1993, 12, 1802-1810.

[17] Desmangles,N.; Gambarotta,S.; Bensimon,C.; Davis,S.; Zahalka,H. J.Organomet.Chem. 1998, 562, 5360.

[18] Feher,F.J.; Gonzales,S.L.; Ziller,J.W. Inorg.Chem. 1988, 27, 3440-3442.

[19] Gibson,V.C.; Spitzmesser,S.K. Chem.Rev. 2003, 103, 283-315.

[20] Britovsek,G.J.P.; Gibson,V.C.; Wass,D.F. Angew.Chem. 1999, 111, 448-468.

[21] Ruiz,J.; Vivanco,M.; Floriani,C.; Chiesi-Villa,A.; Rizzoli,C. Organometallics 1993, 12, 1822

[22] Vivanco,M.; Ruiz,J.; Floriani,C.; Chiesi-Villa,A.; Rizzoli,C. Organometallics 1993, 12, 1794-1801.

[23] Deng,L.; Schmid,R.; Ziegler,T. Organometallics 2000, 19, 3069-3076.

[24] Witte,P.T.; Meetsma,A.; Hessen,B.; Budzelaar,P.H.M. J.Am.Chem.Soc. 1997, 119, 10561-10562.

[25] Margl,P.; Deng,L.; Ziegler,T. Organometallics 1998, 17, 933-946.

[26] Peifer,B.; Milius,W.; Alt,H.G. J.Organomet.Chem. 1998, 553 , 205-220.

[27] Alt,H.G. J.Chem.Soc.Dalton Trans. 1999, 1703-1709.

[28] Alt,H.G.; Jung,M. J.Organomet.Chem. 1999, 562, 229-253.

[29] Alt,H.G. J.Mol.Catal.A 2001, 165, 23-32.

[30] Brown,J.F., Jr.; Vogt,L.H., Jr. J.Am.Chem.Soc. 1965, 87, 4313-4317.

[31] Feher,F.J.; Budzichowski,T.A.; Blanski,R.L.; Weller,K.J.; Ziller,J.W. Organometallics 1991, 10, 25262528.

[32] Feher,F.J.; Newman,D.A. J.Am.Chem.Soc. 1990, 112, 1931-1936.

[33] Skowronska-Ptaskinska,M.D.; Duchateau,R.; Van Santen,R.A.; Yap,G.P. Eur.J.Inorg.Chem. 2001, 133137.

[34] Manzer,L.E.; Fackler,J.P., Jr.In Inorganic Syntheses XXI; Fackler,J.P., Jr., Ed.; Wiley-Interscience: 1982; pp 135-140.

[35] Gambarotta,S.; Floriani,C.; Chiesi-Villa,A.; Guastini,C. J.Chem.Soc.Chem.Commun. 1984, 886-887.

[36] Evans,D.F. J.Chem.Soc. 1959, 2003-2005.

[37] Schubert,E.M. J.Chem.Ed. 2000, 62

[38] Sur,S.K. J.Magn.Res. 1989, 82, 169-173.

[39] ADF. (2.3.0). 1997. Theoretical Chemistry, Universty of Amsterdam

[40] Vosko,S.H.; Wilk,L.; Nusair,M. Can.J.Phys. 1980, 58, 1200

[41] Becke,A.D. Phys.Rev.A. 1988, 38, 3098

[42] Perdew,J.P. Phys.Rev.B. 1986, 22, 8822

[43] Fan,L.; Ziegler,T. J.Chem.Phys. 1991, 95, 7401

[44] Fischer,T.H.; Almhöf,J. J.Chem.Phys. 1992, 13, 295-302. 


\section{Summary and conclusions}

Silsesquioxane chemistry has taken a tremendous flight over the past decade. New synthetic approaches were developed; new complexes based on elements throughout the periodic table were synthesized, and were applied in catalytic processes such as alkene epoxidation, Oppenauer oxidation, alkene polymerization, Diels-Alders reactions and alkene metathesis. The use of silsesquioxane ligands as models for silica surface disclosed intimate knowledge of the reactions on the surface of this much-used support. New methods were developed to incorporate silsesquioxanes into new materials. Encapsulation in siloxane polymers provided precision supports for catalysts and controlled calcination produced materials with welldefined metal oxide particles.

A detailed knowledge of the synthetic part towards catalytically active complexes is needed in order to make the appropriate complexes. This thesis is concerned with the interaction of main group and transition metal precursors with silsesquioxane trisilanol ligands in order to study the coordination chemistry and to synthesize new catalysts based on silsesquioxane ligands. In the first chapter, concepts and literature of silsesquioxane ligands and their metal complexes are reviewed. The main conclusions from the literature to date (February 2003) are (i) that silsesquioxane are the best available models for silica surfaces, (ii) that the ligands can be used to bind to a large variety of metals, be it main group, early or late transition metals, and (iii) that the application of silsesquioxane metal complexes in catalysis is not yet widespread, but promising in some areas.

The second chapter describes the reactivity of silsesquioxane trisilanol ligands with Grignard and dialkyl magnesium reagents. Reaction of Grignard reagents with trisilanol ligands leads to the formation of a new tetranuclear di-silsesquioxane structure. The formation of this new material is investigated by the use of model reactions that represent phases in the synthesis steps of the complex. It was found that these model reactions fit well to the proposed three-step model. The apparent electron-withdrawing character of the silsesquioxide ligand was noticed in the very short length of the magnesium-chloride bond, and was confirmed by DFT computations. The strength of the magnesium chloride bond was also of influence in the study of the reactivity of the complexes towards protic and metallated substances like alcohols, alkoxides and amides. No reaction could be determined. Only the 
use of silver triflate resulted in the formation of silver chloride and a degradated silsesquioxane framework. Activation of the silicon-oxygen-magnesium bond proved to be easier, and could be used to prepare silsesquioxane complexes with other metals than magnesium.

Chapter three deals with the investigation of the interaction of silsesquioxane trisilanol ligands with alkyl zinc precursors. Reaction of these ligands with dialkyl zinc reagents in non-coordinating solvents yielded planar three-coordinate silsesquioxide zinc alkyl complexes with the same tetranuclear motif as found in the second chapter. The formation of this type of complexes was independent of the silsesquioxane side group, contrary to the magnesium type compounds. The polar character of the carbon-zinc moiety and the low coordination of zinc atoms made the complexes very reactive towards coordinating and polar substances. Addition of methyl zinc chloride, a zinc congener of a Grignard reagent, to a solution of trisilanol in THF formed the zinc alternative to the magnesium complexes in the second chapter. The zinc complexes were tested in the polymerization of lactide and were found to be active for a very short time before they precipitated from solution.

In the fourth chapter, the knowledge of formation mechanisms gained in the previous two chapters was applied to the synthesis of heterobimetallic compounds. The formation of heterobimetallic silsesquioxane complexes proved to be dependent on the oxophilicity of both metal compounds. Oxophilic ('hard') metals could easily replace softer metals to gain a more oxygen-rich environment. In case of zinc/magnesium, this led to exchange of the metal sites; in the case of aluminum and titanium, it led to complete expulsion of the softer metal. A mixed-metal magnesium-vanadium complex was tested in the catalytic polymerization of ethene and found to be reasonably active in producing high-molecular weight polyethene. However, it was found to be sensitive toward metal leaching depending on the temperature and aluminum activor.

Based on the successful application of vanadium silsesquioxane chemistry polymerization of ethene in the previous chapter, chapter five is involved with trivalent vanadium and titanium complexes of silyl-substituted silsesquioxane disilanol ligands. The coordination behavior of solvents like THF and pyridine is studied with UV-Vis and qualitatively confirmed by DFT computations. The position of the UV-Vis absorption bands and the relative stability of adducts match well with the computational results. Polymerization of ethene to high 
molecular weight polyethene was possible with both vanadium and titanium complexes, although the activity of the titanium catalyst was very low. Under the conditions studied, the vanadium catalysts were very active, but only for a few minutes A possible way of selfimmobilizing catalysts by incorporating polymerizable groups in the ligand was proposed and tested, but the current systems could not be used with this approach. A tentative catalytic cycle was described and supported by DFT computations. The energetics of the reactions were found to be significantly lower than literature values, possibly explaining the low stability of the catalyst at reaction conditions.

\section{General conclusions}

A new family of complexes, based on a general motif of four metal atoms in a $\mu_{3}$-oxygen surrounding has been synthesized and the reactivity was tested. Depending on the ligands on the outer (reactive) metal atoms, the reactivity ranges from very reactive towards protic and coordinating substances to completely unreactive. Based on the reaction mechanism, new heterobimetallic complexes could be synthesized, although caution should be taken regarding the 'hardness' of the metals. Selected complexes were tested in various catalytic reactions and were found to be inactive (Diels-Alder), active but unsuitable (lactide polymerization), or very active (ethene polymerization). Integrating the synthetic knowledge from this thesis into the relevant new developments in silsesquioxane chemistry could lead to the introduction of new and active catalysts for Lewis-acid based catalysis. 


\section{Samenvatting en conclusies}

De silsesquioxaanchemie heeft in de afgelopen jaren een enorme ontwikkeling doorgemaakt. Nieuwe synthetische technieken zijn ontwikkeld; nieuwe complexen met elementen uit alle delen van het periodiek systeem werden gesynthetiseerd, en deze werden toegepast in een variëteit van katalytische processen, zoals alkeen epoxidatie, Oppenauer oxidaties, alkeen polymerisatie, Diels-Alder reacties en alkeen metathese. Het gebruik van silsesquioxaan liganden als model voor silica-oppervlakken bracht diepgaande kennis over de reacties van dit vaak toegepaste dragermateriaal. Nieuwe methoden zijn ontwikkeld om silsesquioxanen in te bouwen in nieuwe materialen. Het inkapselen in siloxaan polymeren biedt de mogelijkheid tot het maken van dragermaterialen met een zeer uniforme ligandomgeving, en door gecontroleerde calcinatie kan men materialen verkrijgen met goed gedefiniëerde metaaloxide deeltjes.

Er is behoefte aan gedetailleerde kennis van de synthetische chemie voor het maken van katalytisch actieve complexen. Dit proefschrift gaat over de interactie van hoofdgroep- en overgangsmetaalprecursors met silsesquioxaan trisilanol liganden met het oogmerk de coordinatiechemie te bestuderen en nieuwe op silsesquioxaan gebaseerde katalysatoren te bereiden. In het eerste hoofdstuk worden zowel de concepten als de literatuur van de silsesquioxaanliganden en hun gerelateerde metaalcomplexen besproken. De algemene conclusies uit de literatuur tot op heden (Februari 2003) waren dat (i) silsesquioxanen tot nu toe de beste modelverbindingen zijn voor silica-oppervlakken, (ii) dat ze als ligand gebruikt kunnen worden voor een grote diversiteit van metalen, zowel hoofdgroepmetalen als vroege en late overgangsmetalen, en (iii) dat de toepassing van silsesquioxaan metaal complexen in katalytische processsen nog in de kinderschoenen staat, maar op sommige gebieden wel veelbelovend is.

Het tweede hoofdstuk beschrijft de reactiviteit van silsesquioxaan trisilanol liganden met Grignard en dialkyl magnesium reagentia. Reactie van Grignard verbindingen met trisilanol liganden leidt tot de vorming van een nieuwe vierkernige di-silsesquioxaan structuur. De vorming van dit nieuwe materiaal is onderzocht met behulp van modelreacties die fases weergeven tijdens de synthese van dit complex. Deze modelreacties bleken goed te passen bij het voorgestelde driestapsmodel. Het waargenomen electronzuigende karakter van het silsesquioxide ligand werd geuit in de zeer korte lengte van de magnesium-chloride binding, 
en werd bevestigd door DFT berekeningen. De sterkte van de genoemde binding was ook van invloed op de reactiviteit van de complexen met protische en gemetalleerde reagentia zoals alkoholen, alkoxides en amides. Met deze verbindingen werd geen reactie waargenomen. Alleen het gebruik van zilver triflaat resulteerde in de vorming van zilverchloride en een ontleed silsesquioxaan raamwerk. De activering van silicium-zuurstof-magnesium bindingen bleek gemakkelijker, en was van nut om silsesquioxaan complexen met andere metalen dan magnesium te bereiden.

Hoofdstuk drie gaat over het onderzoek naar de interactie van silsesquioxaan trisilanol liganden met alkylzinc precursors. Reactie van deze liganden met dialkylzinc reagentia in niet-coördinerende oplosmiddelen gaf vlakke drievoudig gecoördineerde zinkalkyl silsesquioxide complexen met een vergelijkbaar vierkernig motief als dat werd besproken in het voorgaande hoofdstuk. De vorming van dit type van complexen met zink was onafhankelijk van de silsesquioxaan-zijgroep, in tegenstelling tot de besproken magnesiumcomplexen. Het polaire karakter van het koolstof-zink element en het lage coördinatiegetal van de zinkatomen maakte dat de complexen zeer snel reageerden met coördinerende en polaire verbindingen. Door het toevoegen van methylzinkchloride, de zinkvariant van een Grignard reagens, aan een oplossing van trisilanol in THF werd het zinkanaloog van de magnesiumcomplexen uit hoofdstuk twee gevormd. De zinkcomplexen werden getest in de polymerisatie van lactide en ze bleken een korte tijd katalytisch actief, voordat ze uit de oplossing precipiteerden.

In het vierde hoofdstuk wordt de kennis uit de vorige twee hoofstukken toegepast op de bereiding van heterobimetallische verbindingen. De vorming van heterobimetallische silsesquioxaan complexen bleek sterk afhankelijk te zijn van de oxofiliciteit van de beide metalen. Oxofiele ('harde') metalen konden gemakkelijk 'zachtere' metalen substitueren om in een zuurstofrijkere omgeving te komen. In het geval magnesium/zink leidde dit tot verwisseling van de plaats van het metaal in het complex; in geval van aluminium en titanium leidde dit zelfs tot de volledige verwijdering van het zachtere metaal. Een gemengde magnesium-vanadium verbinding werd getest in de katalytische polymerisatie van etheen en werd redelijk actief bevonden in het maken van polyetheen met hoog moleculair gewicht. Wel werd ontdekt dat de katalysator gevoelig was voor metaalverlies, afhankelijk van temperatuur en de gebruikte aluminium activator. 
Vanwege de succesvolle toepassing van de vanadium silsesquioxaan chemie in de polymerisatie van etheen in het vorige hoofdstuk gaat hoofdstuk vijf over driewaardige vanadium- en titaancomplexen van silylgesubstitueerde silsesquioxaan disilanolliganden. Het coördinatiegedrag van oplosmiddelen als tetrahydrofuraan en pyridine werd bestudeerd met UV-Vis en werd kwalitatief bevestigd door middel van DFT berekeningen. De positie van de UV-Vis-absorptiebanden en de relatieve stabiliteit van de adducten kwamen goed overeen met de resultaten van de berekeningen. De polymerisatie van etheen tot polyetheen met een hoog molecuulgewicht was mogelijk met zowel vanadium- als titaancomplexen, hoewel de activiteit van de titaankatalysatoren zeer laag was. De vanadiumkatalysatoren daarentegen waren voor een korte tijd zeer actief. Een mogelijke manier van zelfimmobilisatie van katalysatoren door het inbouwen van polymeriseerbare groepen in het ligand werd voorgesteld, maar de huidige systemen konden niet gebruikt worden met deze aanpak. Een mogelijke katalytische cyclus werd beschreven en geïllustreerd met DFT berekeningen. De energieën van deze reacties bleken significant lager dan waarden uit de literatuur, hetgeen de lage stabiliteit van de katalysatoren onder reactie-omstandigheden kan verklaren.

\section{Algemene conclusies}

Een nieuwe familie van complexen, gebaseerd op een algemeen motief van vier metaalatomen in een $\mu_{3}$-zuurstofomgeving werd bereid en de reactiviteit ervan werd getest. Afhankelijk van de liganden op de buitenste (reactieve) metaalatomen, bleek de reactiviteit te variëren tussen zeer reactief (protische en coordinerende reagentia) tot volledig niet-reactief. Nieuwe heterobimetallische complexes konden worden bereid, gebaseerd op de principes van het gevonden vormingsmechanisme, hoewel wel rekening moest worden gehouden met de 'hardheid' van de metalen. Sommige complexen werden toegepast in verscheidene katalytische reacties en bleken niet actief (Diels-Alder), actief maar niet toepasbaar (lactide polymerisatie) of zeer actief (etheen polymerisatie). Het integreren van de synthetische kennis uit dit proefschrift in de relevante nieuwe ontwikkelingen in de silsesquioxaanchemie zou kunnen leiden tot de introductie van nieuwe, actieve katalysatoren voor Lewiszuurgekatalyseerde reacties. 


\section{Graphical Abstract}

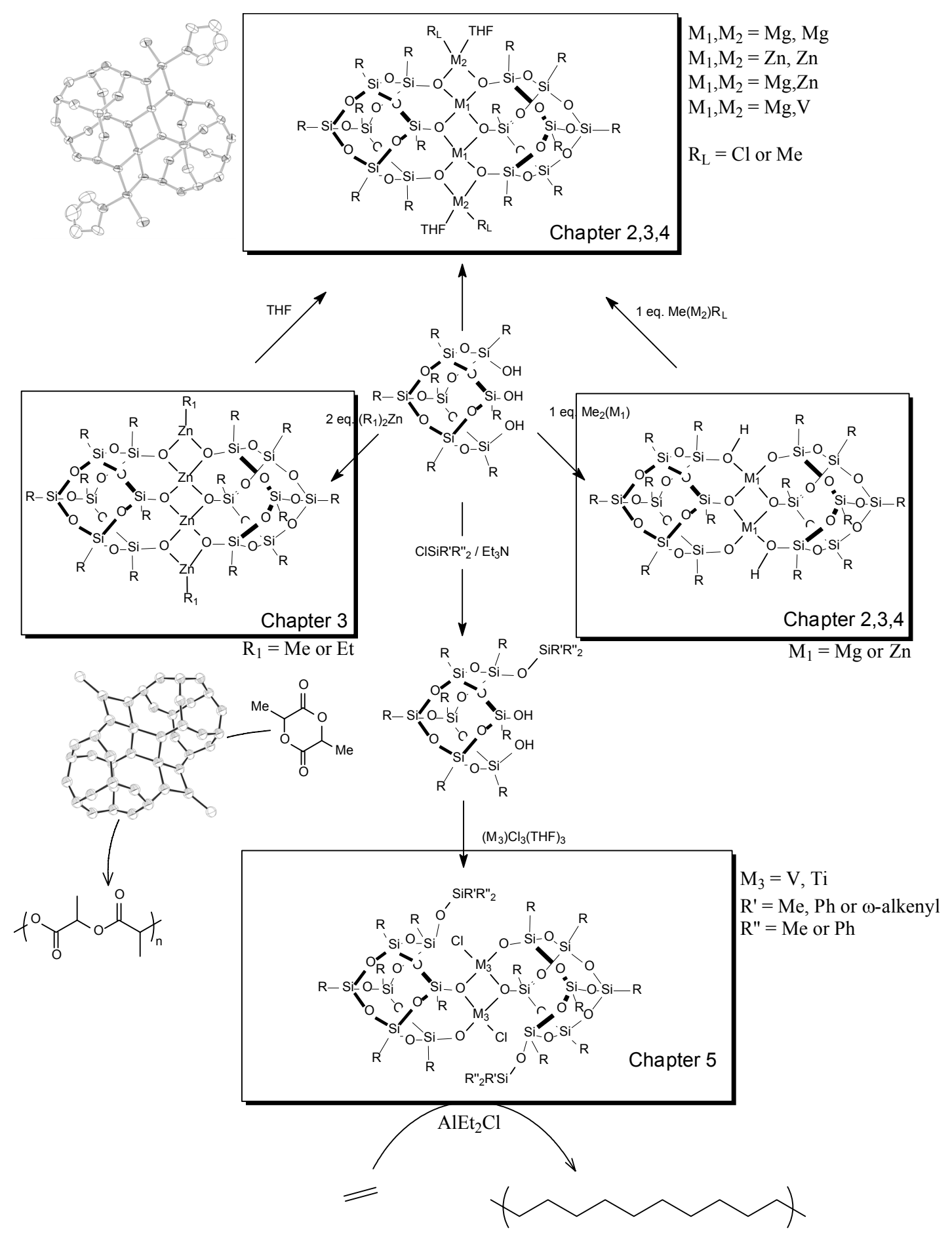




\section{Dankwoord}

Een promotieonderzoek wordt nooit alleen verricht. De intellectuele capaciteiten, het vereiste verregaande specialisme in meerdere sub- en vakgebieden en tegelijkertijd een brede kijk op de implicaties van onderzoek en zijn toepassingen zijn nooit zodanig in één persoon vertegenwoordigd, dat deze alleen een onderzoek compleet kan krijgen. In zoverre ben ik dan een heleboel mensen dank verschuldigd omdat ze mij geholpen hebben dit manuscript voor elkaar te krijgen. Allereerst wil ik mijn promotor Rutger van Santen bedanken voor zijn tomeloze energie voor het verzinnen van nieuwe plannen, waaruit ik de krenten kon pikken. Ook de grote mate van vrijheid die mij in de afgelopen periode werd gegeven waardeer ik zeer. Erik Abbenhuis bedank ik voor zijn input, hulp, goede (en/of wilde) ideeën, vrijheid en vermanende, maar toch richtinggevende toespraken. Ook mijn tweede promotor, Dieter Vogt, en de leescommissieleden, Kees Elsevier en Piet van Leeuwen, wil ik bedanken voor de tijd en moeite die zij gestoken hebben in het doorwrochten van de manuscriptversie van dit boekje. Rob Duchateau, bedankt voor de praktische tips, vele discussies en terechtwijzingen als ik het weer eens fout zag. In dit proefschrift staat ook een aantal kristalstructuren beschreven. Deze waren nooit mogelijk geweest zonder de hulp van Auke Meetsma (Rijksuniversiteit Groningen), Dianne Ellis en Allison Mills (Universiteit Utrecht). Henk Eding (SMO) en Hans van der Velde (SELACT) worden bedankt voor de elementanalyses van die vervelende clusterverbindingen die nooit schenen te kloppen. Ze verbrandden nogal moeilijk, wat werd uitgevonden door Nicolae Maxim. Nicu, our work on the iron silsesquioxane calcination was very inspiring to me. Good luck with your job at ASML. Verder dank aan Philippe François (Solvay Polyolefins Europe) en Andries Jekel (Rijkuniversiteit Groningen) voor de polymeeranalyses uit hoofdstukken 4 en 5. Roelant, uiteindelijk zijn dan niet alle DFT berekeningen in dit boekje terechtgekomen, maar ze waren wel verhelderend.

Natuurlijk zijn er ook een heleboel mensen die niet in zodanig hebben meegewerkt aan dit boekje, maar wel een belangrijke bijdrage hebben geleverd om de afgelopen jaren met plezier door te komen. Iedereen binnen SKA (of 'vroeger' TAK) die wel eens deel heeft genomen aan sociale activiteiten zoals koffie/thee-drinken, laserquesten, paintballen, biljarten, karten, filmpje pikken, Onderwerelten, eten, drinken, kletsen, zwammen en dergelijke, bedankt! Een paar mensen wil ik in het bijzonder bedanken. Ten eerste, Simon Krijnen die me de fijne kneepjes van de oxidatiekatalyse bijbracht en mij bij TAK binnenloodste. Het is nog altijd 
een goede keuze gebleken. Mark Vorstenbosch, goede vriend, eeuwige collega, medecomputergek, co-herriemuziekliefhebber, spellenmaniak, en (korte tijd) STW4.41medeholbewoner, bedankt voor al je grote bijdrages aan mijn promotietijd. Tessa Dijkstra, eeuwige kamergenoot, SKActiviteitencommissielid, Drent, Groninger, Brabander en sinds kort Hollander, succes met het schrijven van je eigen proefschrift, en bedankt voor de leuke tijden in STW4.41 en daarbuiten. Jarl Ivar van der Vlugt, Knut, 'waar gaan we eten'-deel 1, basketballer in STW4.40, filosoof en part-time misantroop (maar dan wel een aardige), bedankt voor alle discussies (wetenschappelijk en niet-wetenschappelijk), het grotendeels corrigeren van dit proefschrift en onze culinaire strooptochten door Eindhoven. De Gelegenheid was misschien wel een beetje duur, maar heeft grote gevolgen gehad. Eric Zijp, 'waar gaan we eten'-deel 2, kommaneuker-eerste klas (en dat is positief bedoeld), bedankt voor de gezelligheid en tripjes richting Mensa en AOR, en voor het corrigeren van dit proefschrift. Bouke, Chretien, Joost, Sander, ook wel het cultuurgezelschap. Bedankt voor de tripjes naar allerlei plaatsen (Londen was gedenkwaardig), films (Tears of the Black Tiger!), muziek, boeken, sinterkerst, eten en drinken (bitterballen en cider?) en alle gesprekken over alles en niks.

Verder nog dank aan de $(A) D \& D$ 'ers (Roelant, Ronald, Luis, Arnoud, Mark, Wouter, Dave, Peter, Chretien en Sander), het War- en StarCraft Guild (teveel om op te noemen), het whisk(e)y-gezelschap, Tiny Verhoeven, Beavis \& Butthead (a.k.a. Marco \& Leon), de SKActiviteitencommissie, de Homo's en Silico's, en diegenen die nog bedankt hadden moeten worden, maar het niet zijn.

Pap, mam, Moniek en de rest van de familie, ondanks dat jullie eigenlijk niet wisten wat ik eigenlijk aan het doen was, hebben jullie toch altijd achter me gestaan, gedurende al die jaren dat ik op de universiteit rondliep. Bedankt voor alles.

Joyce, naast het boekje en de titel is onze relatie toch wel het beste dat uit de afgelopen jaren is voortgekomen. Je nimmer aflatende steun en aanmoediging hebben me door veel moeilijke periodes heengetrokken. Dank je voor al je liefde. Dat het nog lang zo mag blijven. 


\section{Curriculum Vitae}

Rob Hanssen werd in 1974 geboren te Meijel en ging daar naar de lagere school Aen den Mortel. Na het beëindigen van het Atheneum aan het Bouwens van der Boye College te Panningen, begon hij in 1992 aan de studie Scheikundige Technologie aan de Technische Universiteit Eindhoven. In 1997 studeerde hij daar cum laude af op het onderwerp "Heterogenisatie van silsesquioxaan titaan complexen" binnen het Laboratorium voor Anorganische Chemie en Katalyse. Vervolgens werd hij Assistant in Opleiding, begeleid door dr. Erik Abbenhuis en prof.dr. Rutger van Santen, in dezelfde capaciteitsgroep. Een deel van het daar verrichte onderzoek staat beschreven in dit proefschrift.

Rob Hanssen was born in 1974 in Meijel and received his primary school education there. After finishing the Atheneum at the Bouwens van der Boye College in Panningen, he started studying Chemical Engineering at the Eindhoven University of Technology in 1992. He graduated with honors on the subject "Heterogenization of silsesquioxane titanium complexes" at the Laboratory of Inorganic Chemistry and Catalysis in 1997 after which he started his Ph.D. research in the same group, guided by dr. Erik Abbenhuis and prof.dr. Rutger van Santen. Part of his research is described in this thesis.

\section{List of publications}

N. Maxim, A.R. Overweg, P.J. Kooyman, R.W.J.M. Hanssen, R.A. van Santen, H.C.L. Abbenhuis, Synthesis and Characterisation of Microporous Fe-Si-O Materials with Tailored Iron Content from Silsesquioxane Precursors, J. Phys. Chem. B (2002) 106(9), 2203-2209

R.W.J.M. Hanssen, A. Meetsma, R.A. van Santen, H.C.L. Abbenhuis, Synthesis, Structural Characterization and Transmetallation Reactions of a Tetranuclear Magnesium Silsesquioxane Complex, Inorg. Chem. (2001) 40, 4049-4052

H.T. Hintzen, R.W.J.M. Hanssen, S.R. Jansen, R. Metselaar, On the Existence of Europium Aluminum Oxynitrides with a Magnetoplumbite or Beta-Alumina Type-Structure, Journal of Solid State Chemistry (1999) 142(1), 48-50

S. Krijnen, H.C.L. Abbenhuis, R.W.J.M. Hanssen, J.H.C. van Hooff, R.A. van Santen, Heterogenization of a novel Epoxidation Catalyst: Phase Immobilization of a Titanium Silsesquioxane in an MCM-41 Molecular Sieve, Materials Research Society (1999) , 645

S. Krijnen, H.C.L. Abbenhuis, R.W.J.M. Hanssen, J.H.C. van Hooff, R.A. van Santen, Solid Phase Immobilization of a New Epoxidation Catalyst, Angew. Chem. Int. Ed. Engl. (1998) 37(3), 356-358 
S.R. Jansen, J.W. de Haan, L.J.M. van de Ven, R.W.J.M. Hanssen, H.T. Hintzen, R. Metselaar, Incorporation of Nitrogen in Alkaline-Earth Hexaaluminates with a BetaAlumina-Type or a Magnetoplumbite-Type Structure, Chemistry of Materials (1997) 9(7), 1516-1523

H.C.L. Abbenhuis, R.W.J.M. Hanssen, S. Krijnen, R.A. van Santen, Verfahren zur Herstellung eines Tragerkatalysators, DE19730376, AU8731198, WO09903581, 1998

R.W.J.M. Hanssen, AuthClassed, Authentification at your fingertips, 2002, (http://authclassed.sourceforge.net)

\section{In progress}

R.W.J.M. Hanssen, H.C.L. Abbenhuis, R.A. van Santen, The dynamic status quo of silsesquioxane coordination chemistry, Eur. J. Inorg. Chem. (Chapter 1)

R.W.J.M. Hanssen, A. Mills, A.L.H Spek, A. Meetsma, R.A. van Santen, H.C.L. Abbenhuis, Synthesis and reactivity of silsesquioxane zinc complexes, Organometallics (Chapter 3)

A. Mills, D.E. Ellis, R.W.J.M. Hanssen, H.C.L. Abbenhuis, R.A. van Santen, A.L.H. Spek, The structure of $\mathrm{Ph}_{3} \mathrm{SiOSiMe}_{2} \mathrm{OSiPh}_{3}$, Acta Cryst C.

J.I. Van der Vlugt, M.M.P. Grutters, R.W.J.M. Hanssen, H.C.L. Abbenhuis, D. Vogt, Silsphite 